\title{
Cerium dioxide nanoparticle exposure and microvascular dysfunction: Potential mechanistic links
}

\author{
Valerie C. Minarchick
}

Follow this and additional works at: https://researchrepository.wvu.edu/etd

\section{Recommended Citation}

Minarchick, Valerie C., "Cerium dioxide nanoparticle exposure and microvascular dysfunction: Potential mechanistic links" (2015). Graduate Theses, Dissertations, and Problem Reports. 6236.

https://researchrepository.wvu.edu/etd/6236

This Dissertation is protected by copyright and/or related rights. It has been brought to you by the The Research Repository @ WVU with permission from the rights-holder(s). You are free to use this Dissertation in any way that is permitted by the copyright and related rights legislation that applies to your use. For other uses you must obtain permission from the rights-holder(s) directly, unless additional rights are indicated by a Creative Commons license in the record and/ or on the work itself. This Dissertation has been accepted for inclusion in WVU Graduate Theses, Dissertations, and Problem Reports collection by an authorized administrator of The Research Repository @ WVU.

For more information, please contact researchrepository@mail.wvu.edu. 


\title{
CERIUM DIOXIDE NANOPARTICLE EXPOSURE AND MICROVASCULAR DYSFUNCTION: POTENTIAL MECHANISTIC LINKS
}

\author{
VALERIE C. MINARCHICK
}

Dissertation submitted to the

School of Medicine at West Virginia University

In partial fulfillment of the requirements for the degree of

\section{Doctor of Philosophy}

in

Cellular and Integrative Physiology

Jefferson C. Frisbee, Ph.D., Chair

Timothy R. Nurkiewicz, Ph.D., Mentor

Matthew A. Boegehold, Ph.D.

Dale W. Porter, Ph.D.

Edward M. Sabolsky, Ph.D.

Aaron Barchowsky, Ph.D., External Examiner

Department of Physiology and Pharmacology

Center for Cardiovascular and Respiratory Sciences

Morgantown, West Virginia

2015

Keywords: Microcirculation, Cerium Dioxide, Nanoparticles, Exposure Routes, Reactive Oxygen Species, Endothelium Dependent Dilation Copyright 2015 Valerie Minarchick 


\section{Abstract \\ Cerium Dioxide Nanoparticle Exposure and Microvascular Dysfunction: \\ Potential Mechanistic Links}

\section{Valerie C. Minarchick}

Cerium dioxide nanoparticles $\left(\mathrm{CeO}_{2} \mathrm{NP}\right)$, an engineered nanomaterial, have great potential from a consumer and therapeutic perspective. Currently, $\mathrm{CeO}_{2} \mathrm{NP}$ are added to diesel fuel to decrease the soot emissions commonly associated with diesel engines. $\mathrm{CeO}_{2} \mathrm{NP}$ also have therapeutic applications (e.g. improve outcomes following stroke and radiation treatments) due to their anti-oxidant capabilities. These applications increase $\mathrm{CeO}_{2} \mathrm{NP}$ exposure risk not only for manufacturers, but also for the general community; however, there are currently limited studies that investigated the effects of $\mathrm{CeO}_{2} \mathrm{NP}$ exposure via multiple exposure routes. Furthermore, there are no studies that investigate the microvascular consequences of $\mathrm{CeO}_{2} \mathrm{NP}$ exposure despite its importance in blood pressure and flow regulation.

Therefore, the aim of the first study was to determine the microvascular impacts of pulmonary $\mathrm{CeO}_{2} \mathrm{NP}$ exposure. Based on previous studies with other nanoparticles, we predicted that $\mathrm{CeO}_{2} \mathrm{NP}$ exposure would cause microvascular dysfunction that was dose and microvascular bed dependent. Microvascular function was assessed in mesenteric and coronary arterioles via isolated microvessels. Following exposure, endotheliumdependent and -independent arteriolar dilation was significantly impaired. $\mathrm{CeO}_{2} \mathrm{NP}$ exposure also resulted in pulmonary inflammation (assessed via bronchoalveolar lavage). Finally, these impairments and inflammatory changes were dose dependent and microvascular bed dependent.

The aims of the second study were 1) determine the microvascular impacts of $\mathrm{CeO}_{2} \mathrm{NP}$ exposure via non-pulmonary exposure routes (e.g. injection and ingestion) and 2) investigate the underlying mechanisms of microvascular dysfunction. Isolated mesenteric arterioles were analyzed $24 \mathrm{~h}$ post-exposure. Endothelium-dependent and independent dilation was significantly impaired following the injection and ingestion of $\mathrm{CeO}_{2} \mathrm{NP}$ and the severity of dysfunction was dose and exposure route dependent. Finally, this study determined that these impairments might be mechanistically linked to decreased soluble guanylyl cyclase activation, cyclic guanosine monophosphate responsiveness, and nitric oxide (NO) bioavailability. Finally, this study, along with the first study, established the dose, which caused a $50 \%$ impairment in arteriolar reactivity $\left(E_{50}\right)$ for each exposure route.

The final study in this dissertation aimed to determine the in vivo anti-oxidant activity of $\mathrm{CeO}_{2} \mathrm{NP}$ in the presence of a pre-existing pathology. Based on $\mathrm{CeO}_{2} \mathrm{NP}$ catalytic activity, we predicted that exposure would decrease the microvascular dysfunction and oxidative stress associated with hypertension. Endothelium-dependent dilation was assessed via intravital microscopy and was significantly improved in spontaneously hypertensive $(\mathrm{SH})$ rats following $\mathrm{CeO}_{2} \mathrm{NP}$ exposure. Vascular oxidative stress was also significant reduced in the $\mathrm{SH}$ rats post- $\mathrm{CeO}_{2} \mathrm{NP}$ exposure. Finally, $\mathrm{CeO}_{2}$ NP altered the expression of pro-inflammatory cytokines in the Wistar-Kyoto and $\mathrm{SH}$ groups. 
In conclusion, these studies indicated that $\mathrm{CeO}_{2} \mathrm{NP}$ exposure results in microvascular alterations, which are microvascular bed, exposure route, dose, and pathology dependent. Furthermore, these alterations may be due to changes in inflammation, oxidative stress, NO bioavailability, and/or intracellular signaling. These studies improve our understanding of the microvascular effects of $\mathrm{CeO}_{2} \mathrm{NP}$, which is essential for the development of these nanoparticles in commercial and therapeutic applications. 


\section{Acknowledgements}

Years ago at the young age of thirteen, I declared I was going to grow-up and be a research scientist in a creative writing assignment. In case this is difficult to believe the beginning of this paper is pictured below:

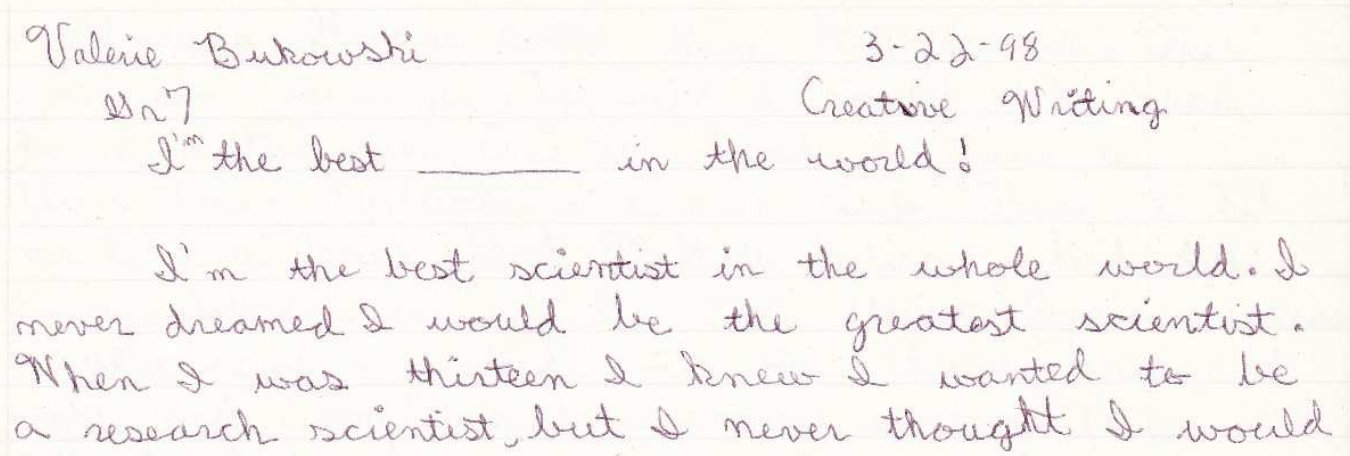

Now as I am adding the final touches to this dissertation, I find it amazing that I was able to actually achieve my childhood dream. Of course, I could not have completed this dream on my own and I encountered many people who told me to consider a different career path. So before I thank the people that matter I would like to say to those that doubted me... "Haha!" I did do it and I used your negativity as one source of motivation to never give up.

Now, l'd like to move on for the imporatant part of these acknowledgements. First, I need to thank my parents, Steve \& Colleen. They fostered my love of science from age 5 and beyond. They support me in everything I do and even if they don't understand most of the work I do now, they are always willing to listen. You instilled a work ethic in me that let me know I could achieve anything through hard work and determination. I also need to thank my parents-in-law, Greg \& Denise. You have opened your home and your hearts to me and treat me like a daughter. Your words of encouragement drove my perservence over the years. I know you will listen to me talk about my work (even if you don't understand it all and need Siri to help come up with questions). I love you all.

I also need to thank my husband, Nate. He has seen me at my worst and my best. I thank him for everything he has done to help me earn my PhD. The list could go on and on, but these are some of my favorites... pushing me when I wanted to do anything except write, making popcorn in the evening, purchasing an in-home massage table, proofreading my papers at $3 \mathrm{AM}$, learning to love Disney as much as I do, taking trips to Smitty's Kountry Kreme, forcing me to find personal motivation to continue, taking me on random car rides to unknown destinations, being my personal chef, and everything you conjured up to help me succeed. Looking back, I would like to think that you would marry me again a week before I begin grad school and "suffer" through the following six years with me again. I can't wait to turn the page in our "Adventure Book" because "Adventure is out there." I love you! Also, I would like to thank Mr. Bojangles and Bobby Magee for keeping me company while I write and letting me know when I need a break by laying on my laptop.

To the rest of my family (sisters, brothers, cousins, aunts, uncles, grandparents, and in-laws) and friends. You are all awesome. You have helped me relax when I was 
most stressed, whether it was a campfire in the the evening, making a homemade pie over the weekend, reunions, vacations, playing board games, or watching long distance TV or Pittsburgh sports with me in the evenings. I needed all those stress relievers and you were always available. Also, one of my greatest stress relievers was spending time with my nieces (Hannah \& Bella) and nephews (Alex \& Peyton). You all make me smile and I love you all dearly.

Now that I thanked my family, it is important to thank my mentors. First, Dr. Vince Castrnova and Dr. Steve Leonard, it is because of you two and your mentoring that I decided to go back to school and pursue my PhD. You saw I had what it took and believed I could succeed before I did. Next, Dr. Jefferson Frisbee, Dr. Adam Goodwill, and Dr. Phoebe Stapleton, thank you for your guidance. After many converstations, it was because of your guidance and persistence that I decided to rotate and eventually go in to Tim's lab. My disseration would be vastly different and I believe a lot less enjoyable without your advice.

To my dissertation committee, thank your for you direction as my dissertation project developed. You all know I can add too much to my plate and be overambitious and you helped me keep that all in check. I also need to specifically recognize Dr. Edward Sabolsky and his laboratory members for making the cerium dioxide that was vital to my experiments and for training me on the characterization techniques. Also, a special thank you to Katarzyna Sabolsky for obtaining the TEM images of the cerium dioxide nanoparticles.

Before, I thank Tim I need to thank the lab. Phoebe- Thank you for your support over the last 6 years. Our extensive conversations about science and life helped carry me through to the next day. Carroll-You make the lab work and were always available to help when I needed it. I don't know what I will do without my weekly spring and summer harvests from your garden! Alaeddin-Enjoy your time in the lab and have fun socializing at the conferences!

Finally, last but not least, Dr. Tim Nurkiewicz, thanks for letting me work in your lab. I have grown into the scientist of my childhood dream through my time in your lab. You have helped me become the scientist I am and I hope I can live up to any expectations you have. I shall return one day to avenge the disgraceful display of Mortal Kombat fatalities. I have learned not only many tangables during my time but also many intangables. Thank you for everything, both in lab and out. I will certainly miss being fired on a weekly (sometimes daily) basis. Also, I'm grateful for the entire Nurkiewicz family (Janet, Gwen, Maegyn, Izzy, and extended family) for graciously hosting lab family gatherings and making us all feel right at home. 


\section{Table of Contents}

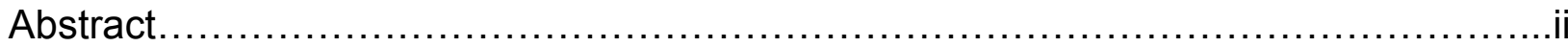

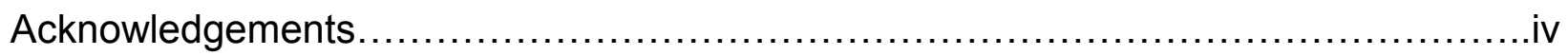

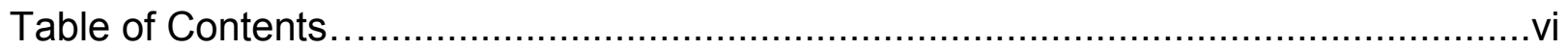

Glossary of Abbreviations..............................................................

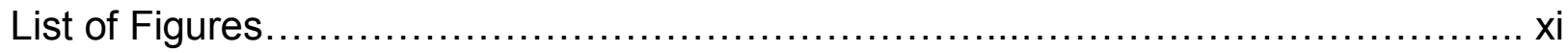

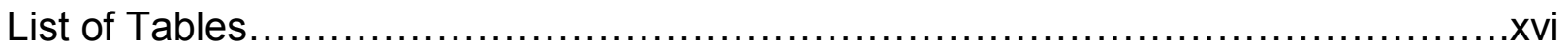

I. Literature Review

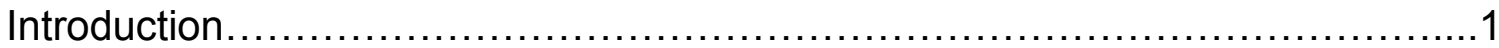

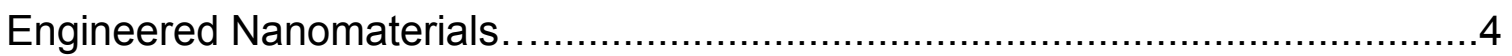

Cardiovascular Function......................................................

Potential Mechanisms of Dysfunction ............................................

ENM Exposure Routes and Specific Outcomes................................25

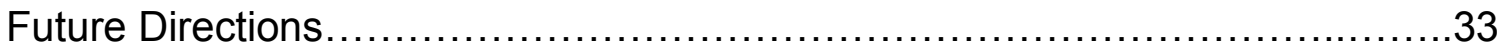

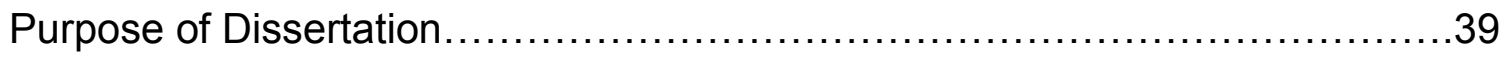



II. Chapter 2: Pulmonary Cerium Dioxide Nanoparticles Exposure Differentially Impairs Coronary and Mesenteric Arteriolar Reactivity .....................................60

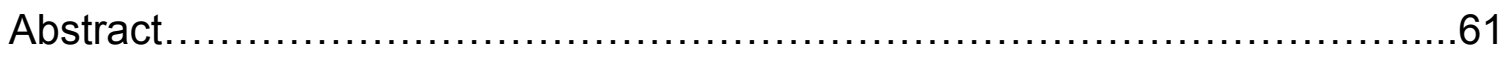

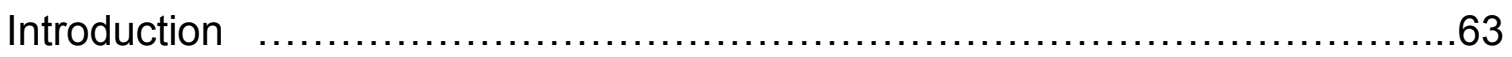

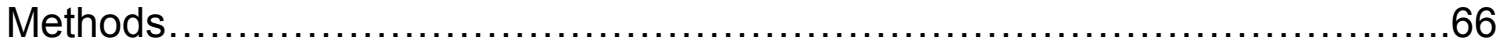

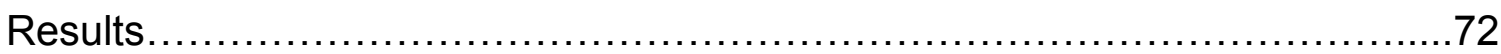

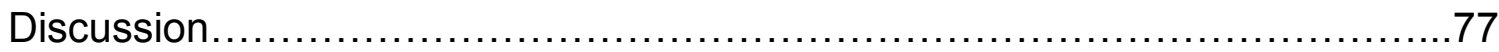


References.

III. Chapter 3: Intravenous and Gastric Cerium Dioxide Nanoparticle Exposure Disrupts Microvascular Smooth Muscle Signaling …......................................... 107

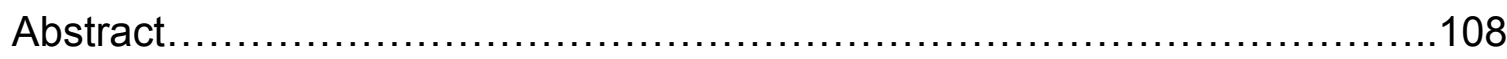

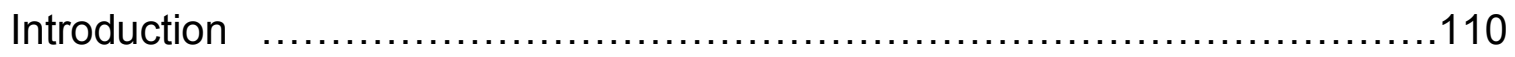

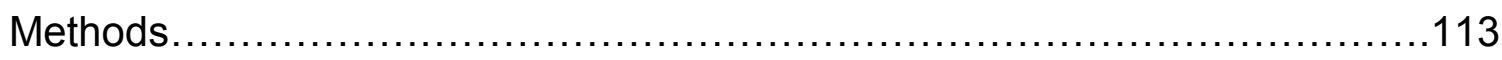

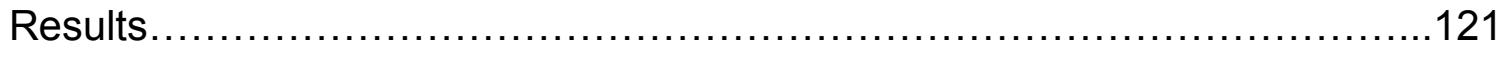

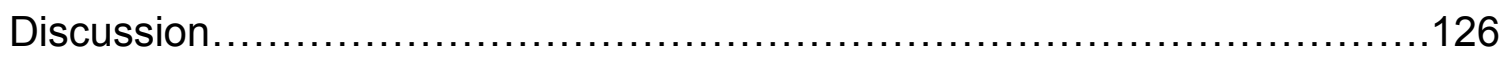

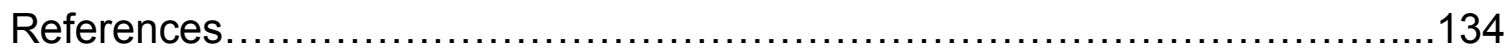

IV. Chapter 4: Cerium Dioxide Nanoparticles Improve Microvascular Dysfunction and Reduce Oxidative Stress in Spontaneously Hypertensive Rats.......................153

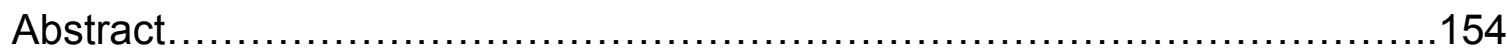

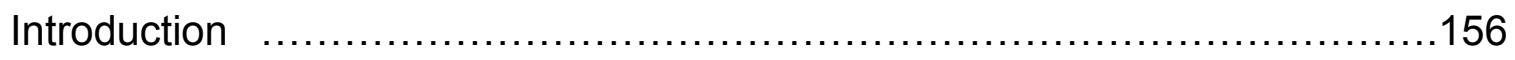

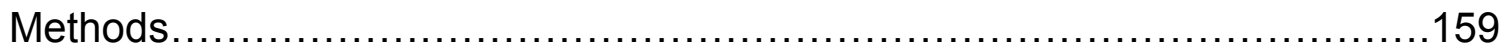

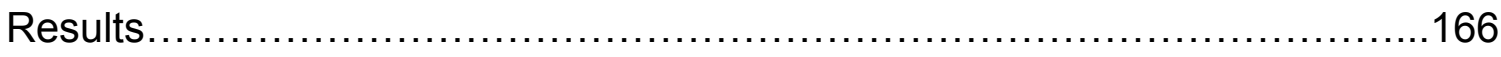

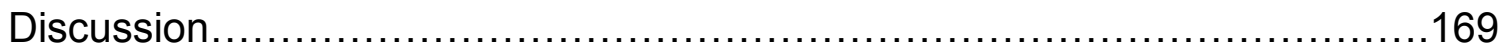

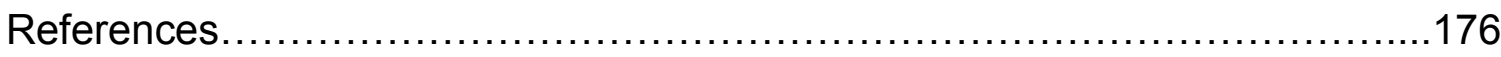

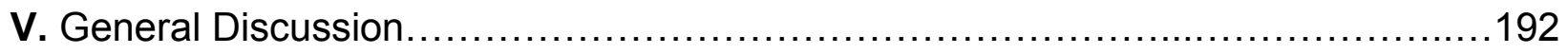

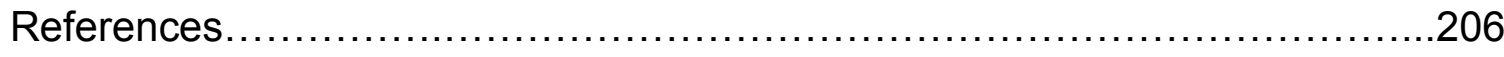

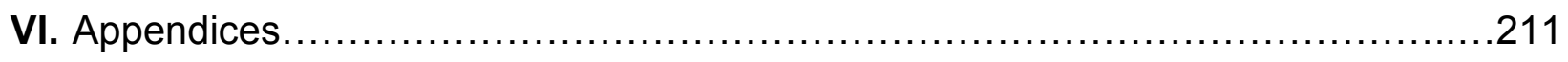

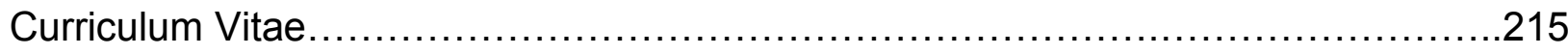




\section{Glossary of Abbreviations}

$1 \mathrm{H}-[1,2,4]$ oxadiazolo[4,3-a]quinoxalin-1-one

2,2,6,6-tetramethylpiperidine-N-oxyl

3-(5'-hydroxymethyl-2'-furyl)-1-benzylindazole

5,5-dimethyl-1-pyrroline- $\mathrm{N}$-oxide

ODQ

TEMPOL

YC-1

DMPO

Acetylcholine

ACh

Adenosine

ADO

Alveolar macrophages

AM

Analysis of variance

ANOVA

Bronchoalveolar lavage

BAL

Carbon nanotubes

CNT

Cerium dioxide nanoparticles

$\mathrm{CeO}_{2} \mathrm{NP}$

cGMP-protein kinase

PKG

Control diameter

$D_{\text {con }}$

Cyclic guanosine monophosphate

cGMP

Cyclooxygenase

COX

Dihydroethidium

DHE

Concentration that causes a $50 \%$ impairment in function

$\mathrm{EC}_{50}$

Dynamic light scattering

DLS

Electron spin resonance

ESR

Endothelium-derived hyperpolarizing factor

EDHF

Engineered nanomaterials

ENM

Environmental Protection Agency

EPA

Federal Drug Administration

FDA

Fetal Bovine serum

FBS

Heart rate

$\mathrm{HR}$

Heart rate variability

HRV

Hour

$\mathrm{h}$

Indomethacin

Initial steady-state diameter

INDO

Inner diameter

D।

ID

Intraperitoneal

ip

Interferon gamma

IFN-Y

Interleukin-1 beta

$\mathrm{IL}-1 \beta$

Interleukin-4

IL-4

Interleukin-5

IL-5

Interleukin-6

IL-6 
$\begin{array}{ll}\text { Interleukin-10 IL-10 } & \end{array}$

Interleukin-13 IL-13

Keratinocyte chemoattractant/human growth-regulated oncogene KC/GRO

Lactate dehydrogenase $\quad$ LDH

Left anterior descending LAD

Mass median aerodynamic diameter MMA

Maximal diameter

Mean Arterial Pressure MAP

Minute Min

Myeloperoxidase MPO

Nicotinamide adenine dinucleotide phosphate NADPH

National Institute for Occupational Safety and Health $\quad \mathrm{NIOSH}$

National Nanotechnology Initiative

$N^{G}$-monomethyl-L-arginine

Nitric oxide

Nitric oxide synthase

$\mathrm{NNI}$

L-NMMA

NO

NOS

Occupational Safety and Health Administration

OSHA

Outer diameter

OD

Particulate matter

Particulates not otherwise regulated

PM

Permissible exposure limit

Phenylephrine

PNOR

PEL

PE

Phosphate-buffered saline

PBS

Physiological salt solution

PSS

Plasminogen activator inhibitor-1

PAI-1

Polymorphonuclear leukocytes

PMN

Potassium tetraperoxochromate

$\mathrm{K}_{3} \mathrm{CrO}_{3}$

Reactive oxygen species

ROS

Recommended exposure limit

REL

Reduction-oxidation

Redox

Region of interest

ROI

Residual oil fly ash

ROFA

Second

$\mathrm{Sec}$

Serotonin

5-HT

Shear Stress

$\mathrm{T}$

S-nitroso-N-acetyl-D,L-penicillamine SNAP

Sodium nitroprusside

SNP

Soluble guanylyl cyclase

sGC 
Spermine NONOate

SPR

Spontaneously hypertensive

$\mathrm{SH}$

Steady-state diameter

DSS

Standard error

SE

Titanium dioxide nanoparticles

Tetrahydrobiopterin

$\mathrm{TiO}_{2} \mathrm{NP}$

Tetramethylammonium hydroxide pentahydrate

$\mathrm{BH}_{4}$

Transmission electron microscope

Tumor necrosis factor alpha

TMAOH

TEM

TNF- $\alpha$

Vascular endothelial growth factor

VEGF

Vascular smooth muscle

Volumetric flow

VSM

Q

Wall thickness

Wall-to-lumen ratio

WT

Wistar-Kyoto

WLR

WKY

X-ray photoelectron spectroscopy

XPS

Zinc oxide nanoparticles

ZnO NP 


\section{Literature Review}

\section{List of Figures}

Figure 1 Potential Cellular Interactions and Outcomes of ENM Exposure Routes: A:

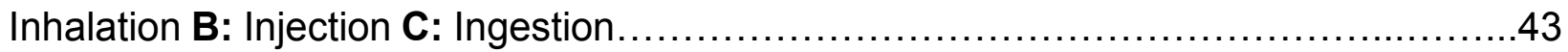

\section{Chapter 2}

Figure 1: TEM Images of $\mathrm{CeO}_{2}$ nanoparticles at A) low magnification $B$ ) high magnification. Red dashes indicate individual particles that were estimated to be 4-6 $\mathrm{nm}$. C) DLS distribution curve of the suspended $\mathrm{CeO}_{2} \mathrm{NPs}$ with an average agglomerate size for peak 1: $191 \pm 77 \mathrm{~nm}$; peak 1: $901 \pm 391 \mathrm{~nm}$; peak 3: $5081 \pm 566 \mathrm{~nm} \ldots \ldots \ldots \ldots \ldots \ldots . . .97$

Figure 2: XPS Spectra of the hydrothermally synthesized and dried $\mathrm{CeO}_{2}$ nanoparticles with deconvoluted peaks using a Gaussian fit A) C 1s B) O 1s.........................98

Figure 3: Pulmonary inflammation was altered after exposure to $\mathrm{CeO}_{2} \mathrm{NPs}$. There was a significant increase in LDH (A), AM activation (C), and PNM infiltration (D). However, there was no change in albumin (B) levels after exposure. Values are means $\pm S E . \dagger p \leq$ 0.05 vs. control; ${ }^{\wedge} p \leq 0.05$ vs. $100 \mu \mathrm{g} \mathrm{CeO} 2$ NPs.

Figure 4: ACh-induced vasodilation was impaired in mesenteric $(A ; n=8-13)$ and coronary (B; $n=7-9)$ arterioles from groups $24 \mathrm{~h}$ post-exposure to $\mathrm{CeO}_{2} \mathrm{NPs}$. Values are means \pm SE. $\dagger p \leq 0.05$ vs. control; * $p \leq 0.05$ vs. $10 \mu \mathrm{geO}_{2}$ NPs. The right panel represents the responses of the various doses of $\mathrm{CeO}_{2} \mathrm{NPs}$ and was analyzed by nonlinear regression. The left panel highlights the point-to-point differences between the control and $\mathrm{CeO}_{2} \mathrm{NP}$ exposed group. 100

Figure 5: The $\mathrm{Ca}^{2+}$ ionophore (A23187)-induced vasodilation was impaired in mesenteric $(A ; n=6-11)$ and coronary $(B ; n=6-8)$ arterioles from groups $24 \mathrm{~h}$ post-exposure to $\mathrm{CeO}_{2}$ NPs. Values are means $\pm S E$. $\dagger p \leq 0.05$ vs. control. The right panel represents the responses of the various doses of $\mathrm{CeO}_{2} \mathrm{NPs}$ and was analyzed by nonlinear regression. The left panel highlights the point-to-point differences between the control and $\mathrm{CeO}_{2} \mathrm{NP}$

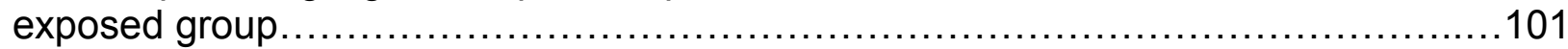

Figure 6: SNP-induced vasodilation was impaired in mesenteric $(A ; n=9-11)$ and coronary $(B ; n=6-13)$ arterioles from groups $24 \mathrm{~h}$ post-exposure to $\mathrm{CeO}_{2} \mathrm{NPs}$. Values are means \pm SE. $\dagger p \leq 0.05$ vs. control. 102

Figure 7: SPR-induced vasodilation was impaired in mesenteric $(A ; n=6-12)$ and coronary $(B ; n=6-8)$ arterioles from groups $24 \mathrm{~h}$ post-exposure to $\mathrm{CeO}_{2} \mathrm{NPs}$. Values are means \pm SE. $\dagger p \leq 0.05$ vs. control; ${ }^{*} p \leq 0.05$ vs. $10 \mu \mathrm{g} \mathrm{CeO} 2$ NPs; $\ddagger p \leq 0.05$ vs. $50 \mu \mathrm{g}$ $\mathrm{CeO}_{2} \mathrm{NPs} ;{ }^{\wedge} p \leq 0.05$ vs. $100 \mu \mathrm{g} \mathrm{CeO} 2$ NPs. The right panel represents the responses of the various doses of $\mathrm{CeO}_{2} \mathrm{NPs}$ and was analyzed by nonlinear regression. The left panel highlights the point-to-point differences between the control and $\mathrm{CeO}_{2} \mathrm{NP}$ exposed group. 103 
Figure 8: $P E$-induced vasoconstriction was not significantly impaired in mesenteric $(A$; $n=5-13$ ) and coronary (B; $n=6-9)$ arterioles from groups 24 h post-exposure to $\mathrm{CeO}_{2} \mathrm{NPs}$. Values are means $\pm \mathrm{SE}$. The right panel represents the responses of the various doses of $\mathrm{CeO}_{2} \mathrm{NPs}$ and was analyzed by nonlinear regression. The left panel highlights the point-to-point differences between the control and $\mathrm{CeO}_{2}$ NP exposed

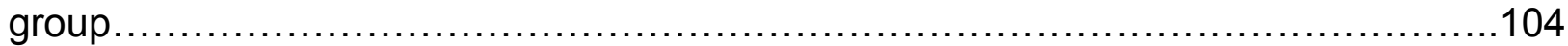

Figure 9: 5-HT-induced vasoconstriction was not significantly impaired in mesenteric $(A$; $n=6-10)$ arterioles. An attenuated response was observed only in coronary ( $B ; n=6-8)$ arterioles from groups $24 \mathrm{~h}$ post-exposure to $400 \mu \mathrm{g} \mathrm{CeO} 2 \mathrm{NPs}$. Values are means SE. $\ddagger$ $p \leq 0.05$ vs. $50 \mu \mathrm{g} \mathrm{CeO}_{2} \mathrm{NPs}^{\wedge}{ }^{\wedge} p \leq 0.05$ vs. $100 \mu \mathrm{g} \mathrm{CeO} 2$ NPs. The right panel represents the responses of the various doses of $\mathrm{CeO}_{2} \mathrm{NPs}$ and was analyzed by nonlinear regression. The left panel highlights the point-to-point differences between the control

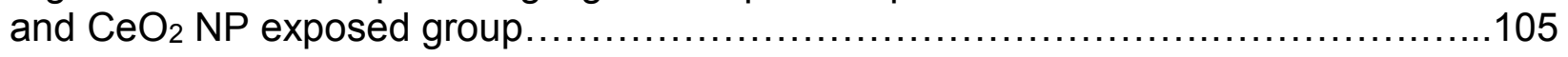

Figure 10: Myogenic responsiveness was not impaired in mesenteric $(A ; n=10-15)$ and coronary $(B ; n=6-9)$ arterioles from groups $24 \mathrm{~h}$ post-exposure to $\mathrm{CeO}_{2} \mathrm{NPs}$. Values are means $\pm \mathrm{SE}$. The right panel represents the responses of the various doses of $\mathrm{CeO}_{2} \mathrm{NPs}$ and was analyzed by nonlinear regression. The left panel highlights the point-to-point differences between the control and $\mathrm{CeO}_{2} \mathrm{NP}$ exposed group.........................106

\section{Chapter 3}

Figure 1: $A C h$-induced vasodilation was impaired in arterioles following intravenous injection (A: $n=8-15)$ and gastric gavage $(B: n=9-13)$ of $\mathrm{CeO}_{2} N P$. ${ }^{*} p \leq 0.05$ vs. control, $\uparrow p \leq 0.05$ vs. low dose $\mathrm{CeO}_{2} \mathrm{NP}(50 \mu \mathrm{g}$ for intravenous injection and $100 \mu \mathrm{g}$ for gastric gavage), $\ddagger \mathrm{p} \leq 0.05$ vs. middle dose $\mathrm{CeO}_{2} \mathrm{NP}(100 \mu \mathrm{g}$ for intravenous injection and $300 \mu \mathrm{g}$ for gastric gavage). The brackets indicate differences in the overall slope of the determination 143

Figure 2: NO-induced vasodilation (via SPR) was impaired in mesenteric arterioles following intravenous injection ( $A: n=8-12)$ and gastric gavage $(B: n=8-10)$ of $\mathrm{CeO}_{2}$ NP. ${ }^{*} p \leq 0.05$ vs. control, $\uparrow p \leq 0.05$ vs. low dose $\mathrm{CeO}_{2} \mathrm{NP}(50 \mu \mathrm{g}$ for intravenous injection and $100 \mu \mathrm{g}$ for gastric gavage), $\ddagger \mathrm{p} \leq 0.05$ vs. middle dose $\mathrm{CeO}_{2} \mathrm{NP}(100 \mu \mathrm{g}$ for intravenous injection and $300 \mu \mathrm{g}$ for gastric gavage), $\wedge p \leq 0.05$ vs. high dose $\mathrm{CeO}_{2} \mathrm{NP}$ (900 $\mu \mathrm{g}$ for intravenous injection and $600 \mu \mathrm{g}$ for gastric gavage). The brackets indicate differences in the overall slope of the determination..................................... 144

Figure 3: Vasodilation in response increasing intraluminal pressure following intravenous injection ( $A: n=8-13)$ and gastric gavage $(B: n=9-10)$ of $\mathrm{CeO}_{2} N P$ was not significantly different. ${ }^{*} p \leq 0.05$ vs. control. 145

Figure 4: The left panels are vasodilation in response to increases in intraluminal flow following intravenous injection ( $\mathrm{A}: \mathrm{n}=5-10)$ and gastric gavage $(\mathrm{B}: \mathrm{n}=6-8)$ of $\mathrm{CeO}_{2}$ NP. The right panels are vasodilation in response to increasing shear stress following 
intravenous injection (C: $n=6-10)$ and gastric gavage (D: $n=6-8$ ) of $\mathrm{CeO}_{2} N P$. ${ }^{*} p \leq$ 0.05 vs. control.

Figure 5: Vasoconstriction stimulated by $P E$ following intravenous injection ( $A: n=7-12)$ and gastric gavage (B: $n=9-11$ ) of $\mathrm{CeO}_{2} \mathrm{NP}$ was not significantly different. ${ }^{*} p \leq 0.05$ vs. control.

Figure 6: Calculated of $\mathrm{EC}_{50}$ for $\mathrm{ACh}(\mathrm{A})$ and $\mathrm{SPR}(\mathrm{B})$ for intratracheal instillation, intravenous injection, and gastric gavage. The scatter plot $(C)$ shows dilation response to ACh $\left(10^{-4} M\right)$ for all exposure routes. The following linear equations $(y=m x+b)$ and $r^{2}$ values were obtained for each exposure route: intratracheal instillation: $y=-0.07 x+$ 41.26, $r^{2}=0.2513$, intravenous injection: $y=-0.03 x+49.39, r^{2}=0.1994$, and gastric gavage: $y=-0.05 x+54.71, r^{2}=0.2465$ 148

Figure 7: Vasodilation in response to ACh following incubation with either L-NMMA $\left(10^{-4}\right.$ $\mathrm{M})$, INDO $\left(10^{-5} \mathrm{M}\right)$ or both inhibitors. There was a significant impairment in dilation of control arterioles following incubation with L-NMMA and INDO $(A: n=14-34)$. There was a partial restoration in function following incubation with L-NMMA after intratracheal instillation of $65 \mu \mathrm{CeO}_{2} \mathrm{NP}(\mathrm{B}: \mathrm{n}=5-14)$. Intravenous injection of $100 \mu \mathrm{g} \mathrm{CeO} 2 \mathrm{NP}$ caused an attenuated response to ACh after incubation with INDO that was significantly different from the $\mathrm{CeO}_{2} \mathrm{NP}$ exposure alone (C: $n=5$ - 9). Gastric gavage of $400 \mu \mathrm{g} \mathrm{CeO}_{2}$ NP) caused a significant impairment in arteriolar dilation following L-NMMA incubation compared to the $\mathrm{CeO}_{2} \mathrm{NP}$ exposure alone (D: $\left.\mathrm{n}=8-15\right)$. ${ }^{*} p \leq 0.05$ vs. L-NMMA $\left(10^{-4}\right.$ $\mathrm{M}), \uparrow p \leq 0.05$ vs. INDO $\left(10^{-5} \mathrm{M}\right), \ddagger p \leq 0.05$ vs. both inhibitors, ${ }^{\wedge} p \leq 0.05$ vs. $\mathrm{CeO}_{2} \mathrm{NP}$ exposure. The brackets indicate differences in the overall slope of the determination. 149

Figure 8: $\mathrm{CeO}_{2} \mathrm{NP}$ reacted with $\mathrm{NO}$ in an acellular environment (A). There was a significant decrease in the amount of $\mathrm{NO}$ detected following intravenous injection (B: $n=$ 14 - 21). NO was released with SNAP $\left(1.6 \times 10^{-4} \mathrm{M}\right)$ for the acellular assessments and with A23187 $\left(10^{-5} \mathrm{M}\right)$ for the cellular assessments. ${ }^{*} p \leq 0.05$ vs. control, $\dagger p \leq 0.05$ vs. intratracheal instillation 150

Figure 9: $\mathrm{CeO}_{2} \mathrm{NP}$ ability to scavenge and/or generate free radicals was assessed in an acellular environment $(A: n=3)$, with control $A M(B: n=4-7)$, and with $A M$ from $\mathrm{CeO}_{2}$ exposed animals via different exposure routes (C: $n=7-9)$. Images of representative superoxide and hydroxyl free radical spectra are inset in panel A. ${ }^{*} p \leq 0.05$ vs. control, $\dagger$ $p \leq 0.05$ vs. $\mathrm{Cr}^{6+}$ alone, $\neq p \leq 0.05$ vs. control $\mathrm{AM}+\mathrm{CeO}_{2} \mathrm{NP}, \wedge p \leq 0.05$ vs. gastric gavage $\mathrm{AM}+\mathrm{CeO}_{2} \mathrm{NP} . \mathrm{NoP}=$ No detectable ESR peaks. 151

Figure 10: VSM function was impaired following $\mathrm{CeO}_{2} \mathrm{NP}$ exposure and was not exposure route-dependent. Soluble GC activation was assessed with YC-1 (A: $n=8-11)$. Cyclic GMP responsiveness was assessed with 8-bromo-cGMP (B: $n=10)$. ${ }^{*} p \leq 0.05$ vs. control, $\uparrow p \leq 0.05$ vs. intratracheal instillation. The brackets indicate differences in the overall slope of the determination. 152

\section{Chapter 4}


Figure 1 Endothelium-Dependent Dilation: ACh-induced vasodilation was impaired in arterioles from $\mathrm{SH}-\mathrm{Sham}$ animals but was significantly improved in the $\mathrm{SH}-\mathrm{CeO}_{2} \mathrm{NP}$ group comparted to the SH-Sham $(n=12-29)$. ${ }^{*} p \leq 0.05$ vs. WKY-Sham, $\dagger p \leq 0.05$ vs.

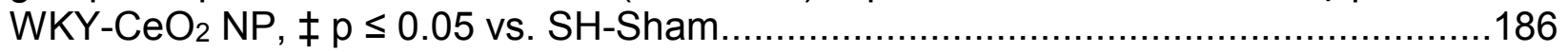

Figure 2 Endothelium-Independent Dilation: Vascular smooth muscle responsiveness to $\mathrm{NO}$ was not impaired in the Sham groups or following $\mathrm{CeO}_{2} \mathrm{NP}$ exposure $\left(\mathrm{WKY}-\mathrm{CeO}_{2}\right.$ $\mathrm{NP}$ and $\mathrm{SH}-\mathrm{CeO}_{2} \mathrm{NP}$ groups; $\mathrm{n}=$ 9-19). 187

Figure 3 Overall Influences of NO, COX products, and ROS: The line graphs are the arterioles overall response to the various chemical interventions. A: The role of NO was assessed during incubation with L-NMMA $(n=14-18)$. This incubation resulted in a significant difference in the overall slopes of the dose-response determination within the WKY groups only. B: The role of COX products was assessed during incubation with INDO $(n=9-14)$. This incubation resulted in a significant difference in the overall slopes of the dose-response determination within the WKY groups only. C: Local ROS was scavenged during incubation with TEMPOL and catalase $(n=6-18)$. This incubation resulted in no changes in the overall slopes of the dose-response determination in any of the four treatment groups. D: ACh-induced vasodilation was assessed during coincubation with the four chemical interventions $(n=10-15)$. This incubation resulted in a significant difference in the overall slopes of the dose-response determination within the WKY groups only. ${ }^{*} p \leq 0.05$ vs. WKY-Sham, $\uparrow p \leq 0.05$ vs. WKY-CeO 2 NP..............188

Figure 4 Influences of NO, COX products, and ROS at $150 \mathrm{nAmp}$ : The bar graph is the dilation that was observed at $150 \mathrm{nAmp}$ for each animal group in the presence of the selected chemical intervention. A: The role of $\mathrm{NO}$ was assessed during incubation with L-NMMA ( $n=14-18)$. This incubation resulted in a significant decrease in arteriolar vasodilation in the WKY groups. There was a significant increase in vasodilation during incubation in the SH-Sham group but there was no change in ACh-induced dilation in the $\mathrm{SH}-\mathrm{CeO}_{2} \mathrm{NP}$ group. B: The role of $\mathrm{COX}$ products was assessed during incubation with INDO ( $\mathrm{n}=9-14)$. This incubation resulted in a significant decrease in arteriolar vasodilation in the WKY groups. There was no change in vasodilation in the $\mathrm{SH}$-Sham group, but there was a significant increase in vasodilation following $\mathrm{CeO}_{2} \mathrm{NP}\left(\mathrm{SH}-\mathrm{CeO}_{2}\right.$ NP). C: Local ROS was scavenged during incubation with TEMPOL and catalase $(n=6$ 18). This incubation resulted in no change in arteriolar vasodilation in the WKY groups and the $\mathrm{SH}-\mathrm{CeO}_{2} \mathrm{NP}$ group. There was increase in vasodilation in the $\mathrm{SH}$-Sham group during incubation. D: ACh-induced vasodilation was assessed during co-incubation with the four chemical interventions $(n=10-15)$. This incubation resulted in a significant decrease in arteriolar vasodilation in the WKY groups. There was no change in vasodilation in the $\mathrm{SH}$-Sham group but there was a significant increase in vasodilation following $\mathrm{CeO}_{2} \mathrm{NP}\left(\mathrm{SH}-\mathrm{CeO}_{2} \mathrm{NP}\right)$. The open bars represent responses to $\mathrm{ACh}$ in the presence of a chemical mediator. ${ }^{*} p \leq 0.05$ vs. WKY-Sham, $\uparrow p \leq 0.05$ vs. WKY-CeO 2 $\mathrm{NP}, \ddagger \mathrm{p} \leq 0.05$ vs. SH-Sham, ${ }^{\wedge} \mathrm{p} \leq 0.05$ vs. $\mathrm{SH}-\mathrm{CeO}_{2} \mathrm{NP}$ 189

Figure 5 Vascular Oxidative Stress: A: Representative ethidium bromide images indicating an increase in oxidative stress in the SH-Sham group. B: Quantitative analysis 
of the ethidium bromide images revealed a significant increase in vascular oxidative stress in the $\mathrm{SH}-\mathrm{Sham}$ group that was reduced in the $\mathrm{SH}-\mathrm{CeO}_{2}$ group $(n=6-10)$. These levels were similar to the WKY-Sham and WKY-CeO 2 NP groups. * $p \leq 0.05$ vs. WKYSham, $\ddagger p \leq 0.05$ vs. SH-Sham. 190

Figure 6 Systemic Inflammation: A: Leukocyte flux was assessed in venules during intravital microscopy. There was a significant increase in leukocyte flux in the SH-Sham group, which was decreased following $\mathrm{CeO}_{2} \mathrm{NP}$ exposure $(n=12-15)$. B: Plasma IL-10 levels were significantly increased in the $\mathrm{WKY}-\mathrm{CeO}_{2} \mathrm{NP}$, but not in the other three groups $(\mathrm{N}=7)$. C: Plasma TNF- $\alpha$ levels were significantly increased in the $\mathrm{WKY}-\mathrm{CeO}_{2} \mathrm{NP}$, but not in the other three groups $(\mathrm{N}=6-7)$. D: Plasma IL-1 $\beta$ levels were significantly decreased in the $\mathrm{SH}-\mathrm{Sham}$ and $\mathrm{SH}-\mathrm{CeO}_{2} \mathrm{NP}$ groups, but were unaltered in the WKY$\mathrm{CeO}_{2} \mathrm{NP}$ group $(\mathrm{N}=6-7)$. ${ }^{*} \mathrm{p} \leq 0.05$ vs. WKY-Sham, $\dagger \mathrm{p} \leq 0.05$ vs. WKY-CeO $2 \mathrm{NP}, \ddagger p$ $\leq 0.05$ vs. $\mathrm{SH}-\mathrm{Sham},{ }^{\wedge} \mathrm{p} \leq 0.05$ vs. $\mathrm{SH}-\mathrm{CeO}_{2} \mathrm{NP}$. 191

\section{Appendix A}

Figure 1 Pulmonary inflammation: Pulmonary inflamamtion was not altered after exposure to $\mathrm{CeO}_{2} \mathrm{NP}$ in $\mathrm{SH}$ or WK rats. There was no significant increase in $\mathbf{A}$ : AM or $\mathbf{B}$ : $\mathrm{PMN}$ infiltration. 212

\section{Appendix B}

Figure 1 Systemic Inflammation: A: Plasma IFN- $y$ levels were significantly decreased in all three exposure groups compared to saline controls $(\mathrm{N}=3)$. B: Plasma IL-13 levels were significantly decreased in all three exposure groups compared to saline controls ( $\mathrm{N}$ $=3$ ). There were no significant differences in plasma levels (data not shown). ${ }^{*} p \leq 0.05$ vs. Control. .214 


\section{Chapter 2}

\section{List of Tables}

Table I: Animal Characteristics........................................................93

Table IIA: Mesentery Arteriole Characteristics ..........................................99

Table IIB: Coronary Arteriole Characteristics ........................................ 95



Chapter 3

Table I: Animal Characteristics........................................................

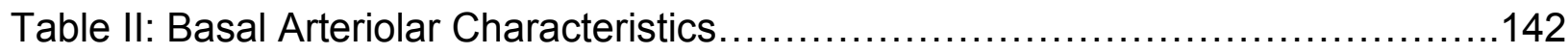

\section{Chapter 4}

Table I: Animal Characteristics. 184

Table II: Basal Arteriolar Characteristics. 185 


\section{Introduction}

\section{Literature Review}

Exposure to foreign materials has been associated with increased morbidity and mortality due to cardiovascular events since the 1930s (Helfand et al. 2001; Nemery et al. 2001). Historically, ambient particulate matter (PM) or air pollution contributed the majority of these inhaled xenobiotic particles. Recently, the emergence of nanotechnology has led to the development of new foreign materials that may also be associated with adverse cardiovascular effects. Engineered nanomaterials (ENM) are compounds manufactured from various elements (e.g. carbon, cerium, titanium, and iron) with specific size dimensions $(<100 \mathrm{~nm})$ that take advantage of unique characteristics (e.g. surface area, and charge) (Borm and Muller-Schulte 2006).

The emergence of these novel xenobiotic materials is evident in the tremendous surge of consumer products that contain ENM. In 2005, 212 products contained ENM compared to the 1,868 products currently commercially available worldwide (Consumer Products Inventory 2014). ENM are being utilized as anti-bacterial agents (e.g. silver, and zinc), to create stronger and lighter equipment (e.g. carbon), to increase computer memory storage while decreasing mass and size (e.g. carbon, silica), and to filter the air or water (e.g. titanium and cerium). However, despite these many commercial applications, perhaps the greatest potential of ENM is their ability to enhance medical diagnostics and therapeutics (Hartmann et al. 2013; Janz et al. 2010). For example, Celegene Abraxane is an ENM based cancer treatment approved by the Federal Drug Administration (FDA). Celegene Abraxane directs chemotherapeutic drugs to breast cancer cells. This drug targeting helps protect healthy cells from exposure to the toxic drugs (Roco et al. 2010). This ability for ENM to have both therapeutic and diagnostic 
properties is termed theranostics (Kelkar and Reineke 2011). Other potential theranostic applications for ENM include improving magnetic resonance imaging, stroke outcomes, and decreasing the side effects associated with radiation treatment (Celardo et al. 2011; Degnan et al. 2012; Kaittanis et al. 2012; Richards et al. 2011). The multitude of applications and uses has expanded ENM exposure risk from (the traditional) inhalation exposures to include other non-pulmonary exposure routes (e.g. intravenous and oral) Furthermore, many of these products and ENM have not been extensively examined to determine the health effects associated with their use, specifically the cardiovascular effects (Roco et al. 2010).

The need for investigations into the unintentional effects of ENM is evident by the formation of the National Nanotechnology Initiative (NNI) in the United States. This committee is dedicated to supporting and funding nanotechnology research and development (Subcommittee on Nanoscale Science et al. 2014). Currently, the NNI intends to dedicate approximately $7 \%$ of their 2015 budget to evaluate the toxicological outcomes of ENM, which is only fraction of the $\$ 4.2$ billion that will be invested in the development of new ENM (Subcommittee on Nanoscale Science et al. 2014).

The cardiovascular consequences of ENM exposure is an area in need of additional research because disruptions in cardiovascular function can have significant impacts on overall health (e.g. nutrient exchange, fluid balance, cardiac output, blood flow regulation, and blood pressure). Optimal cardiovascular function is essential for whole body homeostasis. Homeostasis is the ongoing maintenance of an internal physiological environment for a given tissue or organ despite various external physiochemical changes (e.g. metabolic demand, osmolality, temperature) (Woods and Ramsay 2007). 
Functionally, the cardiovascular system is responsible for providing nutrients (e.g. oxygen) and removing wastes (e.g. carbon dioxide) from the body's organs and is involved in temperature regulation, fluid balance, and immune responses (Renkin 1984). Many of these functions are finely controlled by the microcirculation (see Cardiovascular Function). Microvascular responses (e.g. dilation and constriction) ensure an organ receives the appropriate blood flow despite minute-to-minute changes in blood pressure and/or metabolic demand (Zweifach 1984). Microvascular dysfunction may result in homeostatic disruptions that, if unresolved, may contribute to the development of systemic adaptations and/or pathological conditions (e.g. hypertension, cardiomyopathy, and obesity) (Prewitt et al. 2002; Schwartzkopff et al. 1998). Therefore, it is pivotal to understand if and how ENM affect microvascular function, especially if the full range of ENM applications are to be realized.

This literature review will highlight the current outcomes that are associated with different ENM exposures and draw attention to areas of ENM research that are presently lacking. These aims will be achieved via three avenues. First, potential mechanisms and current hypotheses for ENM will be presented. Due to the complexity and wide range of effects, the proposed mechanisms will primarily focus on proposed sources of microvascular dysfunction. Second, the major effects currently associated with ENM exposure routes will be discussed. Finally, this review will highlight the areas within the literature that are currently lacking for ENM evaluations. 


\section{Engineered Nanomaterials}

ENM possess physical and chemical characteristics that are distinctly different from their larger counterparts. These properties allow them to be developed for a myriad of applications ranging from medical theranostics to consumer electronics. The following section will explain some of the physical and chemical properties associated with ENM and the key applications that utilize these properties. Additionally, these ENM features may also influence the observed effects that follow exposure, and will be discussed in detail later (see sections Potential Mechanisms of Dysfunction and ENM Exposure Routes and Specific Outcomes).

Shape

ENM can be created with many different shapes depending on the targeted outcome and these shapes can influence their activity in vivo (Albanese et al. 2012). In addition, many ENM have the capacity to exist in two or more shapes (e.g. carbon, cerium and titanium) (Baker et al. 2008; Ji et al. 2012; Stapleton et al. 2012). The multitude of shapes that ENM can exist in makes it near impossible to discuss them individually; therefore, one potential characterization method that can be used is the aspect ratio of the ENM. ENM that have a high aspect ratio are $<100 \mathrm{~nm}$ in one dimension but are typically several microns in another dimension. One general group of ENM with a high aspect ratio are fibrous ENM. These ENM have a spear-like or rod-shaped appearance (e.g. nanorods, nanotubes, nanowires) and commonly have a high tensile strength (Demczyk et al. 2002). These factors make carbon nanotubes (CNT), an example of a fibrous ENM, an ideal material for developing more durable fitness equipment while still maintaining a light weight (Demczyk et al. 2002). Despite this commercial application, the 
high aspect ratio of some ENM has been associated with in vivo cellular damage. These ENM are able to penetrate and damage cells indicating these ENM are less than ideal for therapeutic applications (Mercer et al. 2010). Furthermore, these ENM have also been compared to asbestos, due to their similar shape and inability to be cleared from the lungs; therefore, it is reasonable to speculate that fibrous ENM may also be associated with an increased risk of developing cancer (Pacurari et al. 2010).

ENM sheets also have high aspect ratios but may have different toxicities compared to the fibrous ENM due to their difference in shape and surface area (Stankovich et al. 2006). These ENM have high thermal conductivity and tensile strength which makes them ideal to be used for the improvement of electronic devices (Stankovich et al. 2006). Unfortunately, studies investigating the toxicity, both in vitro and in vivo, of ENM sheets are extremely limited. Although there does appear to be some cellular toxicity associated with these ENM, the extent and long-term damage is currently unclear (Mao et al. 2013).

ENM that have low aspect ratios are similar in size in all dimensions and include a variety of different shapes (e.g. spherical, triangular, and cuboidal). Research indicates that low aspect ratio ENM may be easier for immune and non-immune cells to engulf compared to fibrous ENM and therefore may result in less damage and cell death (Johnston et al. 2012a; Limbach et al. 2005; Niu et al. 2011; Singh et al. 2010). This potential for decreased cellular toxicity makes low aspect ratio ENM ideal candidates for theranostic applications. The spherical shape of iron oxide nanomaterials allows them to be encapsulated by red blood cells with limited toxicity to the red blood cells (Jung et al. 2012; Rahmer et al. 2013). This encapsulation, along with the improved imaging 
resolution and magnetic properties of these ENM, presents the potential of directing them to particular locations and tracing blood flow distribution, which could help detect areas of ischemia and tumors earlier (Jung et al. 2012; Rahmer et al. 2013). It appears that the shape of ENM helps dictate their potential applications and toxicity; however, other factors (e.g. size and valence state) are also vital for ENM development.

Size

The primary size of an ENM may also greatly influence its effects within the body. The primary size is the average size of single ENM with at least one dimension being $<100 \mathrm{~nm}$ and changes in the primary size can greatly impact the toxicity of an ENM (Borm et al. 2006; Suttiponparnit et al. 2011; Zhang et al. 2011). For example, silver nanomaterials with a primary diameter less than $40 \mathrm{~nm}$ increased cellular permeability to a greater extent than the particles over $40 \mathrm{~nm}$ (Sheikpranbabu et al. 2010; Trickler et al. 2010). The primary size of the ENM also affects the surface area. The immense increase in surface area compared to larger particles is particularly important for the development of ENM as an antibiotic. Silver and zinc nanomaterials are used in food packaging, adhesive bandages, and medical devices because their high surface area creates a barrier that decreases bacterial growth (de Mel et al. 2012; Ragaseema et al. 2012).

The ENM size can also affect interactions with itself and local environment. ENM are typically suspended in solution preceding in vitro and in vivo exposures. Once in solution, the ENM interacts with other nanomaterials to form larger masses. These agglomerations form based on several parameters (e.g. primary ENM size, surface charge, Van der Waals interactions, and hydrophobicity) and can be up to several microns in diameter. Therefore, considerations for agglomerate size should be accounted for 
when assessing ENM effects, since large agglomerates may not be able to penetrate deep into tissue or be remove by filtration and/or phagocytosis (Banerjee 2013; Gobre and Tkatchenko 2013; Mercer et al. 2010).

\section{Functional Groups}

ENM are modified or functionalized by adding reactive chemical groups (e.g. lipids, methyl groups, citrate, and drugs) during the engineering process. These compounds are intentionally bound to the ENM to alter its purpose and/or function; thus adding another complication to determining the effects of ENM. The addition these functional groups has many purposes. First, coating the ENM with a biological compatible coating (e.g. aluminum oxide and citrate) has been shown to decrease the toxicity associated with some ENM (Shannahan et al. 2015; Taylor et al. 2014). The ability to control and alter the toxicity of ENM is especially important as these nanomaterials are developed for theranostic applications; because ultimately researchers want to eliminate the unintentional effects associated with the pharmaceutical agents and the ENM. Furthermore, if an ENM can be coated with another compound while still maintaining its original function (e.g. electrochemical properties), then the hazard risks associated with unintentional exposures would be greatly reduced.

From a therapeutic perspective, the addition of functional groups along with the increased surface area could decrease the amount of a pharmaceutical agent needed to treat a certain condition. Decreasing the dosage may also decrease the side effects associated with the drug. In addition to the FDA approved ENM based drug Celegene Abraxane, other ENM (e.g. gold, silver, and iron oxide) are being investigated for their drug delivery potential due to the ability to add a variety of functional groups (Bae et al. 
2012; Johnston et al. 2012b; Prades et al. 2012; Roco et al. 2010; Zhang et al. 2013). Iron oxide ENM can be functionalized with drugs, and a temperature specific coating (Yu et al. 2010). Once injected, these ENM can be directed to a specific location (e.g. heart) and then triggered to release pharmaceutical agents by increasing the local temperature (e.g. heart) (Yu et al. 2010). It should be noted that although many of these ENM have great therapeutic promise and may reduce side effects associated with known pharmaceuticals, it is also important to analyze the potential off target effects that may be associated with the ENM.

The addition of functional groups can also alter the charge associated with a particular ENM, and can impact the in vivo effects due to alterations in the development of a protein corona (Lundqvist et al. 2008). The protein corona is a "shell" that develops on the ENM after it is exposed to serum or cell culture media. This ability to develop a protein corona may be limited based on the charge of the ENM. Many circulating proteins have a negative charge and therefore, would be attracted and potentially bind ENM with the same charge. The formation of a protein corona may have divergent effects on ENM toxicity and biological compatibility (Mao et al. 2013; Shannahan et al. 2015). On one hand, the protein corona may increase the ENM toxicity thus hindering its use as a therapeutic or antibacterial agent. On the other hand, the protein corona may hide or mask an ENM from the body thus increasing its ability to interact with target organs and its therapeutic potential. The unknown influences of the protein corona and functional groups on ENM toxicity highlight need for additional research. Furthermore, it is imperative that the in vivo interactions associated with the addition of functional groups be understood to realize fully the potential of ENM. 


\section{Valence State}

The valance states of an ENM impact its use in various applications. The valance state of an ENM helps determine its influence in oxidation-reduction (redox) chemistry. Redox chemistry is the transfer of electrons from one chemical to another; therefore, ENM that can undergo redox chemistry have an increased propensity to scavenge reactive oxygen species (ROS) due to the unpaired electrons in these compounds. This potential redox chemistry makes ENM with multiple valence states prime candidates for the development of catalysts and anti-oxidants. Regardless of these promising applications, ENM with multiple valence states also have the potential to generate ROS particuarlly if the ENM cannot adiquitely quench ROS or transfer the elelctrons to other compounds. Further research is needed to determine when and how these ENM either scavenge or produce ROS in various environments (i.e. mechanical and biological).

When activated by ultraviolet radiation, titanium dioxide nanoparticles $\left(\mathrm{TiO}_{2} \mathrm{NP}\right)$ act as a catalyst and are thus being added to paints and building materials in an attempt to decrease air pollution by reacting with ambient free radicals (Lv and Zhu 2013). Additionally, cerium dioxide nanoparticles $\left(\mathrm{CeO}_{2} \mathrm{NP}\right)$ are added to diesel fuel where it acts as a catalyst to increase the combustion efficiency, thus, decreasing the large soot emissions associated with diesel engines and ultimately contributing to decreased air pollution (Cassee et al. 2011). Finally, from a therapeutic standpoint, $\mathrm{CeO}_{2}$ NP have antioxidant capabilities and may protect patients from some of the deleterious effects of strokes and radiation treatments (Celardo et al. 2011; Kaittanis et al. 2012). Despite these promising uses that are possible due to ENM redox chemistry, it is still largely unknown how the valence state of an ENM affects its toxicity, especially in an in vivo model. Overall, 
a full understanding of the physical and chemical characteristics and their potential alterations is essential as ENM continue to be developed and modified. 


\section{Cardiovascular Function}

The cardiovascular system significantly contributes to homeostasis and disruptions in this system can have major implications in function and overall health (Prewitt et al. 2002; Schwartzkopff et al. 1998; Woods and Ramsay 2007). Historically, studies with PM have shown cardiovascular effects, which include cardiac and vascular dysfunction (Brook 2008; Brook et al. 2010). The cardiovascular influences of ENM are an area of active investigation, and due to their similar size, it is reasonable to speculate the ENM may affect cardiovascular function in a matter similar to PM. The following section will highlight basic cardiovascular physiology and some potential ENM effects.

\section{Cardiac and Macrovascular Function}

The cardiac cycle is a complex process that can be disrupted in a myriad of ways. The known effects of ENM exposure on the cardiac cycle are extremely limited but some studies have investigated the influences on stroke volume, electrical signaling, and heat rate. In the simplest terms, the heart functions as a pump that forces blood out of the ventricles and into the circulation (pulmonary and systemic) and the amount a blood that is ejected from the heart during one cardiac cycle is the stroke volume. Silver nanomaterial exposure has resulted in decreased stroke volume, which if unresolved could have significant impacts on heart rate $(\mathrm{HR})$, and cardiac output (Raieszadeh et al. 2013). Alterations in either of these parameters can lead to decrease organ perfusion, structural remodeling in the heart and heart failure (Raieszadeh et al. 2013). Stroke volume (and cardiac output) may also be altered due an increased afterload, which makes it harder for the heart to ejection blood. One source of altered afterload is from decreased compliance in the aorta and conduit arteries. This decreased compliance can be the result 
of arterial stiffening due to macrovascular dysfunction. Although ENM have not been directly linked to arterial stiffening, ENM have been show to impair macrovascular function, which if unresolved over time may contribute to decreased compliance in the aorta and conduit arteries (Akbar et al. 2011; Wingard et al. 2011).

In addition to stroke volume, cardiac output can also be affected by changes in HR. ENM exposure has resulted in decreases and increases in HR depending on the ENM utilized in the study (Asharani et al. 2011; Park et al. 2013; Stampfl et al. 2011). These alterations can be attributed to a variety of mechanisms and the exact mechanism is currently unknown. One proposed mechanism for altered HR following ENM exposure is changes in neural signaling (e.g. sympathetic and parasympathetic). Sympathetic stimulation results in the secretion of norepinephrine which binds to adrenergic receptors ( $\alpha$ and $\beta$ ) within the heart (Gordan et al. 2015). This results in an increase in HR, contractility, and electrical conduction velocity, all of which lead to an increased cardiac output. Parasympathetic stimulation results in the secretion of acetylcholine which binds to muscarinic receptors in the heart (Gordan et al. 2015). In the heart, acetylcholine slows the depolarization rate of cells within the sinoatrial node and decreases contractility in cardiomyocytes, which results in a decreased HR. Given the small size and various charges of ENM, it is reasonable to speculate that they may bind to various receptors. Furthermore, ENM are capable of depositing in the heart (Stapleton et al. 2012; Yokel et al. 2012). Based on this observation, these ENM may interact with neurotransmitter receptors within the heart that could impair autonomic signaling and alter HR and cardiac output. 
The influence of sympathetic and parasympathetic control within the heart is partially regulated through baroreceptor and chemoreceptor activation. Baroreceptors are located in the aortic arch, carotid arteries, atria and venae cavae (Gordan et al. 2015). These mechanoreceptors respond to changes in pressure within these structures and trigger autonomic signaling within the heart that results in increases or decrease in HR and cardiac output. For example, if venous return was increased the mechanoreceptors in the atria would be activated due to the increased blood volume. This would cause an increase in HR due to increased sympathetic stimulation and sinoatrial node firing rate. It has been speculated that ENM may altered blood pressure and venous return due to alterations in cellular permeability and/or microvascular function (Nurkiewicz et al. 2009; Trickler et al. 2010). These changes could affect baroreceptor activation and thus lead to changes in autonomic control, HR and cardiac output.

The activation of peripheral chemoreceptors can also have a significant impact of autonomic signaling. These receptors respond to changes in the level of oxygen, carbon dioxide, and $\mathrm{pH}$ of the blood (Gordan et al. 2015). These factors can be influenced by changes in respiration rate. ENM have been linked to the development of fibrosis and may interfere with the signaling of C-fibers in the lung, which over time can lead to changes in respiration rate (Hubbs et al. 2011; Lee 2009). Increases and decreases in respiration rate can alter the oxygen and carbon dioxide levels of the blood, which would lead to the activation of chemoreceptors in the aorta, carotid arteries, and brain and would result in altered HR and cardiac output.

Disruptions in electrical signaling and autonomic regulation within the heart have been speculated following ENM exposure, due to their similarity in size to PM. Heart rate 
variability (HRV) is the change in time between cardiac cycles and is typically used to predict the risk of developing and/or detecting alterations in cardiac electrical signaling (Shaffer et al. 2014). Both increases and decreases in HRV can indicate physiological alterations in cardiac electrical signaling. Increases in HRV by indicate impaired cardiac function (e.g. decreased cardiac out, and/or stroke volume); whereas decreases in HRV are associated with the development of pathologies (e.g. cardiovascular disease) (Shaffer et al. 2014). Changes in this parameter are largely unknown following ENM exposure; despite this lack of research, there is evidence that xenobiotic particles can alter electrical signaling both positively and negatively. Therapeutically, ENM have been used to treat atrial fibrillation (Pok et al. 2014; Yu et al. 2010). Whereas PM has been linked to an increase incidence of arrhythmic events and therefore it is reasonable to speculate the ENM may also induce cardiac arrhythmias (Carll et al. 2015; Yu et al. 2010). Furthermore, ENM have been shown to translocate from the lungs to the heart and brain (Mercer et al. 2011; Oberdorster et al. 2004; Stapleton et al. 2012). Due to this translocation and the electrical conductance properties of some ENM, it is reasonable to speculate that ENM could alter autonomic signaling within the heart through any one of the described mechanisms. Despite these basic observations, the full extent of ENM exposure on cardiac function is largely unknown, even though this understanding is essential for the therapeutic development of ENM.

\section{Microvascular Function}

The microcirculation has important roles in contributing to blood pressure and flow regulation within an organ (Renkin 1984; Zweifach 1984). This control helps to ensure ample nutrient exchange and maintains proper waste removal, which contributes to 
overall homeostasis within an organ (Woods and Ramsay 2007). Briefly, the microcirculation can be defined as the arterioles, capillaries and venules that are contained within a specific tissue and each of these vessels have unique properties that contribute to overall microvascular function. Due to the small size and homeostatic importance of these vessels, and the even smaller size of ENM, there is a clear potential for the microcirculation to be impacted by ENM exposure.

\section{Resistance Arteries and Arterioles}

The resistance vasculature significantly contributes to autoregulation within the microcirculation by responding to various factors (e.g. chemical, neural, and physical). Chemical mediators [e.g. carbon dioxide, nitric oxide (NO), and adenosine] interact with both endothelial and vascular smooth muscle cells by binding to receptors and/or by diffusing directly into the cell and initiating various signaling processes. In addition to chemical stimuli, arterioles respond to autonomic signaling, both parasympathetic and sympathetic (Khaisman 1975). Overall, sympathetic influences are greater that parasympathetic innervations and therefore have a greater impact on microvascular function by promoting vascular smooth muscle signaling cascades via norepinephrine (Ohyanagi et al. 1991). Finally, physical forces (e.g. shear stress and pressure changes) also contribute to maintaining microvascular function (Henrion 2005). These physical forces can activate receptors on the endothelial cells that trigger signaling cascades within the endothelial and vascular smooth muscle cells (Bevan and Laher 1991).

Regardless of the initial stimuli, the end physiological response is either vasodilation or vasoconstriction of the arteriole that influences the overall homeostasis of an organ. Furthermore, these factors do not work independently of one another but in 
concert to help regulate pressure, flow, and microvascular tone (Henrion 2005). ENM have the propensity to alter any of the factors that contribute to proper arteriolar function. Research has repeatedly shown the ENM exposure alters NO signaling; however, their influences on other chemical mediators, sympathetic stimulation, physical forces, and vascular tone are largely unknown (Du et al. 2013; LeBlanc et al. 2010; Nurkiewicz et al. 2009).

\section{Capillaries}

Capillaries are a single endothelial cell layer and are the primary sites of nutrient exchange and waste removal. This function is primarily completed by filtration and reabsorption, and can be summarized by Starling's Law:

$$
J_{v}=K_{f}\left[\left(P_{c}-P_{i}\right)-\delta\left(\pi_{c}-\pi_{i}\right)\right] .
$$

This equation summarizes the net movement $\left(\mathrm{J}_{\mathrm{v}}\right)$ of fluid out of the capillaries, and establishes that this movement is dependent on hydrostatic $\left[\mathrm{K}_{f}\left(\mathrm{P}_{\mathrm{c}}-\mathrm{P}_{\mathrm{i}}\right)\right]$ and oncotic $\left[\delta\left(\pi_{c}\right.\right.$ $\left.-\pi_{i}\right)$ ] pressures within and outside of the capillaries. It is important to note that this net movement of fluid varies based on vascular bed and cellular permeability within the vascular ben (e.g. brain, kidneys, and skeletal muscle) (CRONE 1963). Due to their size, ENM are capable of interacting with capillaries (Longmire et al. 2008). This interaction could potentially disrupt permeability within the capillaries, and depending on the vascular bed could have serious consequences on organ function (e.g. increased fluid in the brain, or decrease filtration in the kidney).

Furthermore, filtration and reabsorption rates in the capillaries are influenced by changes in hydrostatic and oncotic pressures, respectively (Spitzer and Windhager 1970). The net result of these pressure changes is the movement of fluid into and out of 
the extracellular space. Hypothetically, if circulating ENM form large agglomerates or development an extensive protein corona it could alter the oncotic pressure within a capillary, which would lead to changes in reabsorption. This altered reabsorption, particularly in the kidney, may lead to alterations in fluid and solute balance (Imai and Kokko 1972; Spitzer and Windhager 1970).

\section{Venules}

Venules are the primary site of inflammation in the microcirculation (Ley et al. 2007). This is the primary sight of inflammation due to the low endothelial to smooth muscle ratio and the low flow environment. As leukocyte extravasation increases there are changes in cellular permeability within the venules (Ley et al. 2007). This change in permeability can lead to edema and may result in tissue damage if unresolved. Additionally, this increased permeability may allow ENM to enter the interstitial space. Here the ENM have the possibility of being trapped in the tissue or entering the lymphatic system. Furthermore, due the low flow in the venules there is the potential that ENM may agglomerate, and depending on the size of the agglomeration may impair blood flow and increase tissue damage. The effects of ENM exposure on the lymphatic system and venules are unknown and require additional investigation.

To date, very few studies examine disruptions in microvascular function despite its central role in blood pressure and flow regulation. Additionally, disruptions in microvascular function can lead to the development of long-term pathologies (e.g. hypertension, diabetes, and cardiovascular disease) further emphasizing the need for more ENM studies that have a primary emphasis on microvascular consequences. 


\section{Potential Mechanisms of Dysfunction}

There are three prominent hypotheses that attempt to explain the mechanism(s) of action for ENM. These hypotheses were initially developed following PM exposure but the basic mechanistic principles of these hypotheses are easily applicable to ENM. Additionally, it should be noted that, due to the complexity of ENM and the physiological outcomes and potential exposure routes, a single hypothesis would likely not adequately explain the complex effects for a specific ENM. Therefore, it is reasonable to speculate that a combination of these or other mechanism(s) are responsible for the microvascular effects that follow ENM exposure.

Inflammation

This hypothesis states the ENM exposure triggers an innate immune response that can have effects on multiple systems, including the microcirculation. This increase in inflammation has been well documented for several ENM (e.g. $\mathrm{TiO}_{2} \mathrm{NP}, \mathrm{CeO}_{2} \mathrm{NP}$, and CNT) and exposure routes (Nurkiewicz et al. 2008; Porter et al. 2010; Wingard et al. 2011). Specifically, $\mathrm{CeO}_{2}$ NP have been associated with increased mast cell activation, and increased circulating leukocytes and neutrophils (Cho et al. 2010; Hirst et al. 2013; Wingard et al. 2011). This change in inflammatory status is also associated with an increase in circulating pro-inflammatory markers [e.g. vascular cell adhesion molecule-1, intracellular adhesion molecule-1, interleukin-6 (IL-6), and tumor necrosis factor- $\alpha$ (TNFa)] (Duan et al. 2013; Kasper et al. 2011; Liu and Sun 2010; Napierska et al. 2013; Srinivas et al. 2011). These cytokines and adhesion proteins initiate the translocation of leukocytes into the interstitial space, which can disrupt endothelial and arteriolar function. 
Increased inflammation is also associated with an increase in ROS generation. In addition to inflammation, ROS generation can by increased in a variety of ways including the ENM themselves, mitochondrial dysfunction, increased nicotinamide adenine dinucleotide phosphate (NADPH) oxidase activity, increased myeloperoxidase (MPO) and NOS uncoupling (Celardo et al. 2011; Ide et al. 2000; Nurkiewicz et al. 2009; Nurkiewicz et al. 2011). ROS is capable of reacting directly with NO, which impairs its ability to diffuse the smooth muscle. This reaction also results in the production of nitrosative reactive species (e.g. peroxynitrate) that are associated with cellular damage (Corbalan et al. 2012; Du et al. 2013). Regardless of the source of ROS, the outcome is the same; the free radicals react with chemical messengers such as NO, resulting in decreased NO bioavailability (LeBlanc et al. 2009; LeBlanc et al. 2010; Nurkiewicz et al. 2008; Nurkiewicz et al. 2009; Stampfl et al. 2011).

NO bioavailability can be altered by other mechanisms (i.e. increased MPO and NOS uncoupling) in addition to changes in ROS. The level of available NO can be decreased due to NO production via NOS uncoupling. It has been documented that exposure to nano-sized particles can cause NO synthase (NOS) uncoupling, which leads to an increase in superoxide and a decrease in NO production (Campen et al. 2003). Secondly, increases in MPO can also result decreases NO bioavailability, by reacting with NO (Nurkiewicz et al. 2009; Nurkiewicz et al. 2011). The decrease in the NO that is able to react the VSM results in impaired arteriolar dilation. Furthermore, microvascular dysfunction may also results due to changes in VSM intracellular signaling cascade (Courtois et al. 2008). Under normal conditions, NO diffuses to the VSM where it activates soluble guanylyl cyclase (sGC). The activation of sGC increases cyclic guanosine 
monophosphate (cGMP) and cGMP-protein kinase (PKG), which results in a decrease in intracellular calcium and VSM relaxation. Disruptions anywhere within this signaling cascade could result in an impaired VSM response to NO, which would contribute to impaired vasodilation and microvascular dysfunction.

Microvascular reactivity can also be altered by the vascular influences of arachidonic acid (AA) signaling mediated by cyclooxygenase (COX). This pathway can result in the stimulation of several vasoactive agonists, including thromboxane and prostacyclin. AA is unsaturated fatty acid that is stored within the cell membrane and is release is regulated by phospholipase $A_{2}$, which is influence by several factors including inflammation, hormones, and chemical irritants [e.g. ENM (speculation)] (Miller 2006). COX then mediates the metabolism of AA into endoperoxide $\left(\mathrm{PGH}_{2}\right)$, which can be further biotransformed into thromboxane $A_{2}$ (via thromboxane synthase) and prostacyclin (via prostacyclin synthase) (Wong and Vanhoutte 2010). It should be noted that $\mathrm{PGH}_{2}$ may also increase vasoconstriction through the activation of thromboxane-prostanoid receptors (Wong and Vanhoutte 2010). Thromboxane $A_{2}\left(T X A_{2}\right)$ also causes vasoconstriction through these same receptors. The observed vasoconstriction is the result of Rho kinase signaling within the VSM (Wong and Vanhoutte 2010). Prostacyclin normally has the opposite effects of TXA 2 and initiates VSM signaling via prostacyclin receptors (Miller 2006). The binding of prostacyclin results in the activation of a G-protein signaling cascade that increases cyclic adenosine monophosphate (cAMP) (Miller 2006). This activation causes VSM dilation, through a NO-independent mechanism. The production of $\mathrm{TXA}_{2}$ and prostacyclin can be modulated by changes in inflammation, pathology and potentially ENM (Knuckles et al. 2011; Miller 2006; Zareba et al. 2009). 
Overall, the inflammation hypothesis is the most researched to date and many factors associated with inflammation may contribute to observed microvascular alterations.

Direct Interaction/ Translocation

It has been well documented that ENM are capable of translocating from a target organ (e.g. lungs) to other organs (e.g. spleen, liver, kidneys, brain, and blood) (Geraets et al. 2012; Oberdorster et al. 2004; Reddy et al. 2010). It has been suggested that this direct contact may cause alterations in cellular signaling and impact microvascular function. In vitro studies have shown that ENM are capable of being internalized by endothelial cells, cardiomyocytes, and epithelial cells (Shannahan et al. 2015; Singh et al. 2010). This internalization can alter the function of the cell and could result in the release of cytokines, increase ROS generation, and/or trigger apoptosis (Bauer et al. 2011; Hussain et al. 2012; Pacurari et al. 2012; Shannahan et al. 2015; Singh et al. 2010). However, other studies have shown the direct particle contact does not alter vascular inflammation or ROS generation (Colon et al. 2010; Gojova et al. 2009; Hussain et al. 2012). Furthermore, some studies have shown the certain ENM (e.g. $\mathrm{CeO}_{2} \mathrm{NP}$ ) are actually capable of mimicking biological enzymes, specifically superoxide dismutase (Heckert et al. 2008; Pagliari et al. 2012). These conflicting studies, sometimes utilizing the same ENM, highlight the challenges in determining ENM toxicity and their mechanism(s) of action. It also emphasizes the sensitivity and complexity of the ENM, implying that a small change in the particle (e.g. size, charge, and/or valence state) may have a significant impact on its toxicity.

Neural Alterations 
The third hypothesis suggested that microvascular dysfunction is a consequence of altered autonomic regulation (Brook et al. 2011). Of the three hypotheses, neural alterations are the least researched, potentially due to the complexity of assessing these changes. Studies with PM, both human and animal, have documented reduced HRV and increased HR after exposure (Magari et al. 2001; Rhoden et al. 2005; Tankersley et al. 2007). It reasonable to speculate that ENM may have similar responses and a few studies have documented changes in HR following ENM exposure (Asharani et al. 2011; Legramante et al. 2009). These overt cardiovascular changes may due to disruptions in sympathetic and parasympathetic signaling; however, limited ENM studies have documented changes in sympathetic alterations after exposure (Asharani et al. 2011; Kan et al. 2013; Knuckles et al. 2011; Legramante et al. 2009). Autonomic alterations could not only affect microvascular reactivity but also baroreflex function and HR. Furthermore, ENM have been shown to deposit in the brain following exposure where they may interfere with neuron signaling indicating that they make affect autonomic regulation independent of specific cardiovascular effects, (Boyes et al. 2012; Chorley et al. 2014; Kan et al. 2013; Oberdorster et al. 2004; Yokel et al. 2012). Additional studies are needed to fully examine the neural influences of ENM.

\section{Exposure Route Influences}

The previous sections provided a general description of the three prominent hypotheses for the effects of ENM; however, it is important to note that ENM exposure route may have a significant impact on the prevalence of these mechanisms. Inhalation, injection, and ingestion may result in differential exposure to specific cell types, which could impact the dominance of various mechanisms (Figures 1A-C). Inhalation of ENM 
results in primary exposure to pulmonary cells (e.g. macrophages, epithelial cells, and cfibers), which trigger responses that are specific to the exposure route (see ENM Exposure Routes and Specific Outcomes). Briefly, xenobiotic nanoparticle inhalation is typically associated with pulmonary inflammation; however, not all ENM exposure results in this type of inflammatory response (Nurkiewicz et al. 2004; Nurkiewicz et al. 2009; Toya et al. 2010). Pulmonary inflammation is driven by innate inflammatory responses in the lungs (e.g. macrophage activation), which help to ensure foreign substances are removed from the lungs. In theory, this inflammatory response results in systemic inflammation due to cytokine signaling and/or spillover. Therefore, it is reasonable to speculate that systemic inflammation may be a more prominent driving force behind the toxicities associated with inhalation versus the other hypotheses, particularly if initial pulmonary inflammation is present.

Ingestion exposure may result in the ENM passing through several organs (e.g. stomach, intestine, and liver) prior to translocation to other distal organs (e.g. heart, kidney, and brain). This multiple organ exposure may greatly influence the ENM physical and chemical properties and may also significantly affect the exposure dose for specific organs (Stapleton and Nurkiewicz 2014). Furthermore, this multiple organ exposure may alter the influences of neural alterations (specifically within the enteric nervous system), direct organ interaction, and systemic inflammation on the observed physiological effects.

Finally, intravenous injection exposures result in the ENM being directly exposed to the vasculature. In theory, this would result in the highest level of direct endothelium exposure especially since inhalation and ingestion require translocation for the vasculature to be exposed to ENM (Stapleton and Nurkiewicz 2014). Furthermore, this 
presumably high level of direct ENM exposure may significantly impact the resulting toxicities, specifically the cardiovascular effects. Overall, the exact influence on specific exposure routes and the roles of the previously described mechanisms are unknown, but this understanding is essential as these ENM are developed for various applications. 


\section{ENM Exposure Routes and Specific Outcomes}

Due to their diverse applications and fates, ENM have several potential exposure routes. These exposures can be unintentional due to environmental bioaccumulation and manufacturing or intentional due to specific uses. Once an exposure occurs, there is the possibility for both positive and negative outcomes that may be local and/or widespread. The following section will describe the most likely exposure routes and provide an overview of the significant cardiovascular effects associated with each route. Inhalation

The high occupational exposure risk and well document pulmonary effects of PM have resulted in ENM (initially as a PM surrogate) being extensively studied in the literature. ENM have an increased propensity to become airborne during manufacturing, processing, disposal, destruction and/or recycling (Maynard and Kuempel 2005; Yu et al. 2013). There is also a growing potential for undesired community exposures as some ENM have commercial uses such as fuel additives. The addition of $\mathrm{CeO}_{2}$ NP to diesel fuel has been shown to significantly decrease the PM, carbon monoxide, and nitrogen oxide emissions of diesel engine exhaust (Erdakos et al. 2014). These compounds have been historically associated with the development of cardiovascular disease and their decline may result in lower mortality and morbidity due to air pollution. This application also results in a 25 -fold increase in inhalable $\mathrm{CeO}_{2} \mathrm{NP}$ but the biopersistence and health effects of inhaled $\mathrm{CeO}_{2}$ NP are relatively unknown (Erdakos et al. 2014). Despite the limited research on pulmonary $\mathrm{CeO}_{2} \mathrm{NP}$ exposure it is reasonable to speculate, based on the results from other ENM, that once inhaled $\mathrm{CeO}_{2}$ will remain in the lungs inducing 
an inflammatory response and will likely be linked to systemic cardiovascular dysfunction (LeBlanc et al. 2010; Ma et al. 2011; Pairon et al. 1995).

The airway distribution that results following ENM inhalation is size dependent. The airway distribution for PM has been well established and can be applied to ENM distribution as well (Driscoll et al. 2000; Stapleton et al. 2011). Course PM (>10 $\mu \mathrm{m})$ deposit in the tracheobronchial region of the lung and have a higher chance of being cleared from the lungs. Fine PM $(<2.5 \mu \mathrm{m})$ is capable to reaching the alveolar space and deposits in both this region and the tracheobronchial region. Finally, ultrafine PM $(<0.1$ $\mu \mathrm{m})$ and ENM, although capable to interacting with the entire airway, tend to be largely distributed in the alveolar spaces of the lungs. This deposition has been associated with not only increased inflammation but also the development of granulomatous lesions and ultimately fibrosis (Ma et al. 2011; Mercer et al. 2011). However, the unwanted effects of pulmonary ENM exposure are not limited to the lungs. In fact, current research reflects that almost every physiological system may be affected by pulmonary exposure (depending on the specific ENM being analyzed). $\mathrm{CeO}_{2}$ NP have been associated with liver toxicity, whereas CNT are linked to an increased incidence of kidney disease (Nalabotu et al. 2011; Reddy et al. 2010).

Experimentally, the effects associated with pulmonary ENM exposures can be examined using two common methods: inhalation and instillation. Inhalation requires the generation of an artificial environment, which aims to emulate an occupational setting. A benefit of this technique is the animals are able to breathe normally while inhaling the ENM, but the equipment and time needed for this technique can make it cost prohibitive (Wong 2007). On the other hand, intratracheal instillation requires exposing the lungs of 
an anesthetized animal with ENM suspended in a solution (e.g. saline) via a ball tipped needle (Wong 2007). This technique is also cost effective and is often referred to as the "poor man's inhalation" (Driscoll et al. 2000). Regardless, both these techniques result in similar ENM distribution in the lung when equivalent concentrations are used (Henderson et al. 1995).

In regards to the cardiovascular system, coronary damage from ischemia and reperfusion injury can be aggravated in animals previously exposed to carbon nanotubes (Katwa et al. 2012; Urankar et al. 2012). Pulmonary exposure also resulted in cardiac inflammation and fibrosis that ultimately lead to the development of impaired myocardial cells at 30 days post-exposure (Baky et al. 2013; Chuang et al. 2013). This exposure route is also associated with extra-pulmonary arteriolar and aortic endotheliumdependent dysfunction (LeBlanc et al. 2009; LeBlanc et al. 2010; Nurkiewicz et al. 2008; Nurkiewicz et al. 2009; Reddy et al. 2010; Stampfl et al. 2011; Stapleton et al. 2012; Wingard et al. 2011). Finally, pulmonary exposure also resulted in impaired microvascular function in pregnant and fetal rats (Stapleton et al. 2013). Overall, these effects highlight the widespread influences of pulmonary ENM exposure. Furthermore, the majority of pulmonary studies have indicated this exposure route is likely associated with enhanced ENM toxicity, as few studies have indicated any positive benefits for this type of exposure. Injection

Injection exposures are a growing concern particularly as ENM are being developed for theranostic purposes. These applications would likely result in direct administration of the ENM by various injection methods (e.g. intraperitoneal, intramuscular, intravenous and subcutaneous), and each method may influence the ENM 
responses in unique ways. For example, intravenous injections result in the ENM being directly exposed to the blood stream and vascular endothelial cells; whereas, intramuscular injection would result in the muscle receiving the bulk of the ENM concentration.

From a therapeutic perspective, injected ENM are associated with many positive effects such as a treatment for cancer, stroke, and arrhythmias (Kim et al. 2012; Roco et al. 2010; Yu et al. 2010). The injection of functionalized iron oxide nanomaterials have had positive results when targeting them to a specific location in the heart to treat atrial fibrillation (Yu et al. 2010). $\mathrm{CeO}_{2}$ NP have also displayed beneficial results when injected into animals that have had a stroke or received radiation treatments (Kim et al. 2012; Madero-Visbal et al. 2012).

Despite these positive results, there are still studies that highlight the negative effects associated with injection exposures. ENM injection has resulted in decreased mean arterial pressure, HR changes, and decreased tension in mesenteric arteries, which may indicate potential microvascular dysfunction and sympathetic alterations (Akbar et al. 2011; Asharani et al. 2011; Borak et al. 2007; Chen et al. 2013; Iversen et al. 2013; Stampfl et al. 2011). Systemically, injection exposures have resulted in granuloma development in the spleen and liver (Yokel et al. 2012). These organ effects indicate that there may be complications when filtering and removing these ENM from the circulation.

Finally, ENM injection has produced alterations in vascular growth, which may or may not contribute to potential microvascular disruptions. ENM that have vascular endothelial growth factor (VEGF), a critical molecule needed for new vessel growth, attached to them can be directed to the specific organs (e.g. heart) with the intention of 
promoting new vessel growth or angiogenesis (Zhang et al. 2012). Silver and gold ENM have also been to shown to promote angiogenesis, both in vivo and in vitro, despite the lack of VEGF attachment to the ENM (Kang et al. 2011). During periods of growth or after severe organ damage (e.g. myocardial infarction), angiogenesis is a restorative process that helps ensure the survival of a tissue; however, uncontrolled angiogenesis has been associated with tumor growth. Therefore, the ability of injected ENM to modify angiogenesis needs to be monitored and assessed to prevent any unwanted vascular damage. Furthermore, the implications of ENM affecting angiogenesis during growth and development are also unexplored.

Overall, the effects associated with injection exposures appear more promising than pulmonary exposures. There are numerous studies that highlight the short-term beneficial effects; however, the long-term consequences of injected ENM are largely unknown (e.g. cancer development, cardiac failure, hypertension). Additionally, many of the positive studies focus on one specific system or organ so the injected ENM influence on other organs (outside the target organ) is also largely unknown. Finally, these results add to the complexity of determining ENM toxicity and highlight the need to examine ENM using multiple exposure routes.

Ingestion

A common route of drug administration is by oral exposure thus ENM used for theranostics applications could be ingested. Intentional ingestion is not the singular way that ENM can access the gastrointestinal tract. Unintentional or accidental exposure risks are more prevalent due to food and water contamination. One source of this contamination is ENM transferring from food packaging to the food and then being 
consumed. Additionally, the environmental biopersistence of ENM may also increase the prevalence of accidental gastric exposures (Utembe et al. 2015). ENM are manufactured under extreme conditions (e.g. temperature, pressure, and $\mathrm{pH}$ ) that are not common in the environment; therefore, the ENM do not typically degrade naturally. They can enter the water and food supplies and thus create the potential for orally consuming ENM (Yokel et al. 2012). Finally, inhalation exposures present an unexpected risk for unintentional gastric exposure because some inhaled ENM are removed from the lungs by the mucociliary escalator and then swallowed thus entering the gastrointestinal tract (Kreyling et al. 2002).

One of the major complications with gastric exposure is determining the influence of the various $\mathrm{pH}$ environments within the digestive tract. As ENM pass through the gastrointestinal tract, they encounter multiple pHs for variable amounts of time. Initially, the ENM are exposed to a highly acidic environment in the stomach, followed by a basic environment in the intestines. It has been established that different $\mathrm{pHs}$ are capable of biotransforming an ENM (Tok AIY et al. 2013). These potential alterations may impact the ENM size and/or charge, and may modify how it interacts with various tissues. Another experimental consideration is determining if the ENM is absorbed by the intestines or excreted in the feces because this will impact the actual exposure dose for the ENM. Following oral exposure, if large amount of the ENM are excreted in the feces the concentration that was absorbed would be significantly lower, thus the effective concentration would also be lower than initially estimated.

The intestines are specially designed to absorb nutrients and given ENM small size it is possible they can also be absorbed (Brun et al. 2014; Jani et al. 1990). The 
mechanisms of potential absorption are unknown. Hypothetically, ENM may be absorbed directly through various channels and/or between intestinal cells similar to many nutrients (Stevens et al. 1984). Theoretically, ENM may also be encapsulated in phospholipids to form a micelle (Yao et al. 2014). This micelle can then easily cross cellular membranes (Yao et al. 2014). If the ENM are absorbed by either of these methods, they will first interact with the liver increasing the potential for liver toxicity Therefore, liver toxicity should be monitored following ingestion exposures. Current literature indicates that liver toxicity following oral exposures is ENM dependent. Oral administration of $\mathrm{CeO}_{2} \mathrm{NP}$ and zinc oxide nanoparticles ( $\mathrm{ZnO} \mathrm{NP}$ ) both result in liver deposition; however, $\mathrm{CeO}_{2} \mathrm{NP}$ had no observable toxic effects whereas, ZnO NP had an increased toxicity (Hirst et al. 2013; Pasupuleti et al. 2012).

Finally, the known cardiovascular effects following ENM ingestion are extremely limited. One study has associated the development of microscopic lesions on the heart with $\mathrm{ZnO} \mathrm{NP}$, but the results with other ENM are unknown and requires further investigation (Pasupuleti et al. 2012). Despite the limited studies, it appears that gastric exposure results in the lowest toxicity of the exposure routes discussed herein. These differences may be due to an increased clearance rate and volume in the digestive system compared to the lungs (Stapleton and Nurkiewicz 2014; Yokel et al. 2014). Furthermore, ENM may also be excreted with the feces, trapped in the liver, or chemically altered to make them more biocompatible, all of which could significantly influence toxicity. Finally, the toxicity associated with oral exposure may be delayed or limited to specific organs (e.g. intestine and liver). These changes in toxicity may also be due to ENM being trapped or reacting with bile acid, thus permitting them to be recycled and pass through the 
intestines and liver several times (Zwicker and Agellon 2013). Future studies will need to address these potential influences on ENM toxicity to determine why the overall effects are less severe for orally consumed ENM. 


\section{Future Directions}

The previous sections have attempted to address what is currently known about ENM toxicity and the potential mechanisms for the observed effects. Despite this research, there are still extensive knowledge gaps in the field of nanotoxicology (aside from fully understanding the mechanism(s) of action). Specifically, federal regulations and toxicological assessments are currently lacking and need to be established to realize the full potential of ENM. Finally, many of the previously mentioned outcomes were assessed either in vitro or in vivo in young, healthy models and the effects of ENM in models with secondary confounding factors (e.g. disease) are largely known. Currently, \$291 million dollars are invested in ENM research which is mere fraction of the $\$ 4.2$ billion invested into the development of novel ENM (Subcommittee on Nanoscale Science et al. 2014). For these future directions to be realized there must be an increased financial investment in exploring the health effects of ENM particularly as the number of unique ENM continue to grow.

\section{Federal Regulations}

Currently, there are few federal regulations that restrict the manufacturing and use of ENM in consumer products. The Occupational Safety and Health Administration (OSHA) require all workers to wear proper respiratory protection when handling ENM. Additionally, OSHA recommends manufacturers restrict employee exposure to ENM concentrations to no greater than $5 \mathrm{mg} / \mathrm{m}^{3}$ within an 8-hour workday. This is the standard permissible exposure limit (PEL) used for all ENM; however, depending on the ENM toxicity this exposure limit may be too low or too high. Recently, results from pulmonary exposures to $\mathrm{CNT}$ and $\mathrm{TiO}_{2} \mathrm{NP}$ have led to revised recommendations from the National Institute for Occupational Safety and Health (NIOSH), which suggest the recommended 
exposure limit (REL) should be decreased to $1-300 \mu \mathrm{g} / \mathrm{m}^{3}$ (Centers for Disease Control and Prevention 13 A.D.). To date, these are the only ENM with defined REL for occupational workers and these limits have not been accepted as a federal regulation by OSHA. Additional toxicity studies are needed to determine if more or stricter federal regulations are needed. These assessments need to not only include toxicity evaluations but also examine potential off-target effects, delayed on-set effects (e.g. cancer risk), and utilize multiple exposure routes.

Toxicity Assessments

In order for the safety and toxicity of ENM to be determined, toxicological studies need to be completed. This includes establishing proper dose metrics, a dose-response curve, temporal assessments, and clearance rates for specific ENM. Prior to any toxicological assessments, it is essential to characterize properly the ENM (e.g. size, shape, charge, valance state). Not only is ENM characterization good science but it is pivotal for experimental reproducibility.

\section{Dose Metrics}

Prior to toxicological assessments, it is important to establish a proper dose metric. The doses used for ENM studies can be calculated based on a variety of parameters including surface area, mass, and particle number. The proper dose metric for a study should be determined based on the aims of the individual study. It has been suggested that for pulmonary exposures determining the surface are of the ENM may be the best dose metric when establishing a dose-response relationship for the observed effects; however, it has also been presented that particle number may be the best dose metric for this exposure route (Oberdorster et al. 2005; Wittmaack 2007). Furthermore, 
these dose metrics may not be the most relevant when investigating the effects of nonpulmonary exposure routes. In this case, ENM mass may the proper dose metric, since it is likely the more therapeutically relevant metric. Overall, it is currently unclear which dose metric is correct, especially since the proper dose metric may be influenced by a variety of factors (e.g. exposure route, and ENM physiochemical properties). This ambiguity in the establishment of the most relevant dose metric highlights the need to understand the in vivo alterations of ENM via multiple exposure routes.

Dose-Response Curve

The establishment of a dose-response curve provides important information about the overall toxicity or safety of an ENM. One of the main goals is to establish the ENM concentration where negative or toxic health effects are first observed. Additionally, this dose also implies that any amount below that concentration would be considered a safe exposure level with no off-target effects. Another important dose to establish is the amount that causes the greatest amount of toxicity or damage known as the maximal effect level. From a therapeutic standpoint, this can be considered the highest dose before negative effects or deaths from the drug are observed. These parameters also help to determine realistic exposure doses for experimental evaluations.

To date, very few dose-response curves have been established for ENM. The dose dependent studies that exist focus primarily on pulmonary exposure and the outcomes in the lung (Porter et al. 2010). Additionally, dose-response curves following the injection of ENM are also limited and primarily focus on the therapeutic window for the ENM of interest (Kim et al. 2012; Madero-Visbal et al. 2012). Although a dose- 
response curve was established, these limited studies did not investigate the off-target toxicity of the ENM, an angle that warrants consideration in the future.

\section{Temporal Assessments}

Time course studies evaluate the health effects over a given period of time and can range from seconds to several months or even years after initial exposure (Dorato and Engelhardt 2005). The ability to determine the short (acute) and long-term (chronic) effects of ENM exposure is critical because initial negative effects may resolve over time and other new effects may emerge.

Like the establishment of a dose-response curve, few temporal studies have been completed with ENM. Typically, only one time point is used to assess ENM toxicity. There have been a few time course studies, which have examined microvascular dysfunction, but the majority has focused on pulmonary toxicity (Porter et al. 2010; Stapleton et al. 2012). CNT exposure resulted in not only long-term pulmonary damage but also resulted in microvascular dysfunction that was not resolved one week post-exposure (Porter et al. 2010; Stapleton et al. 2012). A simple time course study has also been completed with instilled $\mathrm{CeO}_{2} \mathrm{NP}$ that resulted in liver and spleen damage 90 days after initial exposure indicating long-term damage (Yokel et al. 2012). Together, these results indicate that many ENM may have long-term, off-target effects that need to be considered when developing ENM for various applications, and the mechanisms of these effects are currently unknown. Additionally, these limited studies also highlight the need for more temporal studies that not only focus on off-target damage but also focus on the microvascular impact. Furthermore, these temporal studies are critical especially because the development of some diseases (e.g. cancer, hypertension, and diabetes) 
are significantly delayed from time of initial exposure. This risk for ENM is currently unknown, but due to some ENM having similarities to asbestosis and silica, both known to increase cancer risks, it is reasonable to speculate that ENM may have similar risks (Pacurari et al. 2010). Furthermore, the influences of the proposed mechanisms (see Potential Mechanisms of Dysfunction) may also change overtime. Acute exposure may result in an initial increase in inflammation, which over time can decrease or increase; however, chronic exposure may result in more pronounced effects from neural or direct ENM interactions due to potentially increased translocation of the ENM. Similar to other time course influences, the impact of these mechanisms and time are unknown and warrant further investigation.

\section{Clearance Rates}

Finally, toxicity assessments need to take into account ENM clearance from the body. ENM accumulation within a tissue may affect the organ's function (e.g. lung, liver, and kidney) and ENM clearance can usually be assessed by monitoring removal from the body or translocation to specific organs (Geraets et al. 2012; Hirst et al. 2013; Zhu et al. 2009). Urine and fecal collections typically are used to evaluate ENM clearance from the body (Hirst et al. 2013). If tissue accumulation is occurring, it is essential to identify the organs where the ENM are located using various microscopy techniques and monitoring differences in tissue weight (Stapleton et al. 2012; Yokel et al. 2012). ENM clearance also varies based on exposure route and dose; ENM given by pulmonary instillation are not cleared as rapidly as ENM given by oral or injection exposure routes (Hirst et al. 2013; Mercer et al. 2010; Porter et al. 2010). 
Overall, monitoring ENM clearance is needed because if the ENM is trapped in an organ for a long period of time, then the toxicity to that organ can change versus a more transient exposure of the same organ (Yokel et al. 2012). Furthermore, the clearance of an ENM can influence the effective dose. Regardless of the existence of several studies that assessed the clearance of ENM, these assessments are largely absent in the literature despite the importance of this toxicological evaluation (Mercer et al. 2010; Yokel et al. 2012).

Confounding Influences

Another area where more ENM research is needed, is determining the outcomes associated with exposure in the presence of various pathologies. There is the potential for both positive and negative outcomes when exposure is combined with a pre-existing condition. ENM exposure during stroke has been shown to be beneficial by decreasing the ischemic area (Kim et al. 2012). $\mathrm{CeO}_{2}$ NP have also been shown to reverse some of the negative effects (decreased oxidative stress) associated with cigarette smoke and diesel exhaust exposure (Cassee et al. 2012; Niu et al. 2011). From the perspective of a negative influence, $\mathrm{TiO}_{2} \mathrm{NP}$ increased plaque progression in animals with atherosclerosis indicating these ENM may enhance the progression of this disease (Mikkelsen et al. 2011). These conflicting results highlight the need to test various ENM in the presence of various conditions, specifically diabetes, hypertension, and obesity. These conditions are increasing in the general population but the influence they have on ENM toxicity is largely unknown and warrants additional investigations. 


\section{Purpose of Dissertation}

An ENM that holds great consumer and theranostic potential is $\mathrm{CeO}_{2} \mathrm{NP}$. These ENM are currently being used in commercial applications as a glass polish and a fuel additive. As a fuel additive, $\mathrm{CeO}_{2}$ NP increases the combustion efficiency of diesel fuel, which decreasing the large soot emissions commonly associated with these engines. To date, there are no federal regulations that limit the use of cerium and it has been predicted that ambient $\mathrm{CeO}_{2} \mathrm{NP}$ could increase by 25 -fold in the next few years. This increase would result in an increased inhalation risk, both occupationally and communally. Pulmonary exposure to $\mathrm{CeO}_{2} \mathrm{NP}$ has resulted in inflammation and granuloma formation. Other studies have shown that pulmonary exposure to ENM may result in extra-pulmonary microvascular dysfunction; however, the microvascular effects of this ENM are largely unknown. Therefore, it is reasonable to speculate that pulmonary $\mathrm{CeO}_{2} \mathrm{NP}$ exposure will also result in microvascular alterations.

From a therapeutic perspective, $\mathrm{CeO}_{2} \mathrm{NP}$ have the ability to act as an anti-oxidant and may be able to decrease elevated levels of ROS that are associated with various pathologies. Currently, the treatments for stroke are extremely limited and there is a pressing need to develop additional therapeutics for this disease. In regards to radiation treatment, there are also limited drugs available to combat the tissue damage associated with this often live-saving treatment. Therefore, the development of ENM that improve the outcomes of these two conditions is pivotal. $\mathrm{CeO}_{2} \mathrm{NP}$ are being investigated to treat stroke and protect against radiation damage by decreasing the level ROS and thus decreasing the tissue damage associated with these conditions. In addition to stroke and radiation, $\mathrm{CeO}_{2} \mathrm{NP}$ have been shown to decrease the detrimental effects associated with diesel exhaust and cigarette exposure; however, it is currently unclear if $\mathrm{CeO}_{2} \mathrm{NP}$ can 
improve the outcomes of other pathologies (e.g. hypertension). These applications also introduced the need to assess the health effects via alternate exposure routes.

Therefore, the present studies were designed to evaluate 1) the microvascular effects of $\mathrm{CeO}_{2} \mathrm{NP}$ given by different exposure routes, 2) establish a dose-response curve for each exposure route, 3 ) begin to provide mechanistic explanations for the observed microvascular effects and 4) examine $\mathrm{CeO}_{2} \mathrm{NP}$ anti-oxidant potential in a hypertensive model. The findings of these studies will help improve our understanding of the toxicity of $\mathrm{CeO}_{2} \mathrm{NP}$ and will provide valuable information that is needed for its continued theranostic development.

The specific aims of the studies are listed below.

\section{Study 1}

Sprague-Dawley rats were intratracheally instilled with a range of $\mathrm{CeO}_{2} \mathrm{NP}$ doses (10 - $400 \mu \mathrm{g}) .24$ hours post-exposure mesenteric and coronary arterioles were assessed using the isolated microvessel technique. This preparation provided an understanding of the arteriolar alterations (e.g. endothelium-dependent and endothelium -independent) that follow $\mathrm{CeO}_{2} \mathrm{NP}$ exposure. Furthermore, this study established a dose-response curve for pulmonary exposure. Finally, the potential functional differences between vascular beds were analyzed.

\section{Study 2}

Sprague-Dawley rats were intratracheally instilled, intravenously injected, or gastrically gavaged, with a range of $\mathrm{CeO}_{2}$ NP doses $(50-900 \mu \mathrm{g}) .24$ hours postexposure mesenteric arterioles were assessed using the isolated microvessel technique. This preparation provided an understanding of the arteriolar alterations (e.g. endotheliumdependent and endothelium-independent) that follow $\mathrm{CeO}_{2} \mathrm{NP}$ via alternate exposure 
routes. Furthermore, this study established a dose-response curve for intravenous and gastric exposures. Finally, potential mechanism(s) of action for all three exposure routes were analyzed.

\section{Study 3}

Spontaneously hypertensive $(\mathrm{SH})$ and Wistar-Kyoto rats were intravenously injected with $100 \mu \mathrm{g} \mathrm{CeO} 2 \mathrm{NP} .24$ hours post-exposure mesenteric arteriolar reactivity was assessed using intravital microscopy. This study examined the in vivo anti-oxidant potential of this ENM by determining if microvascular function is improved in the $\mathrm{SH}$ rat after exposure. Additionally, vascular levels of oxidative stress were analyzed in both animal lines using isolated arterioles intraluminally infused with dihydroethidium. Overall, this study provided information, which helped to determine $\mathrm{CeO}_{2} \mathrm{NP}$ influences in the presence of a previously existing pathology, and helped to further establish its potential as a therapeutic. 
Figure Legends:

Figure 1 Potential Cellular Interactions and Outcomes of ENM Exposure Routes: A:

Inhalation B: Injection C: Ingestion 


\section{Figures:}

Figure 1A:
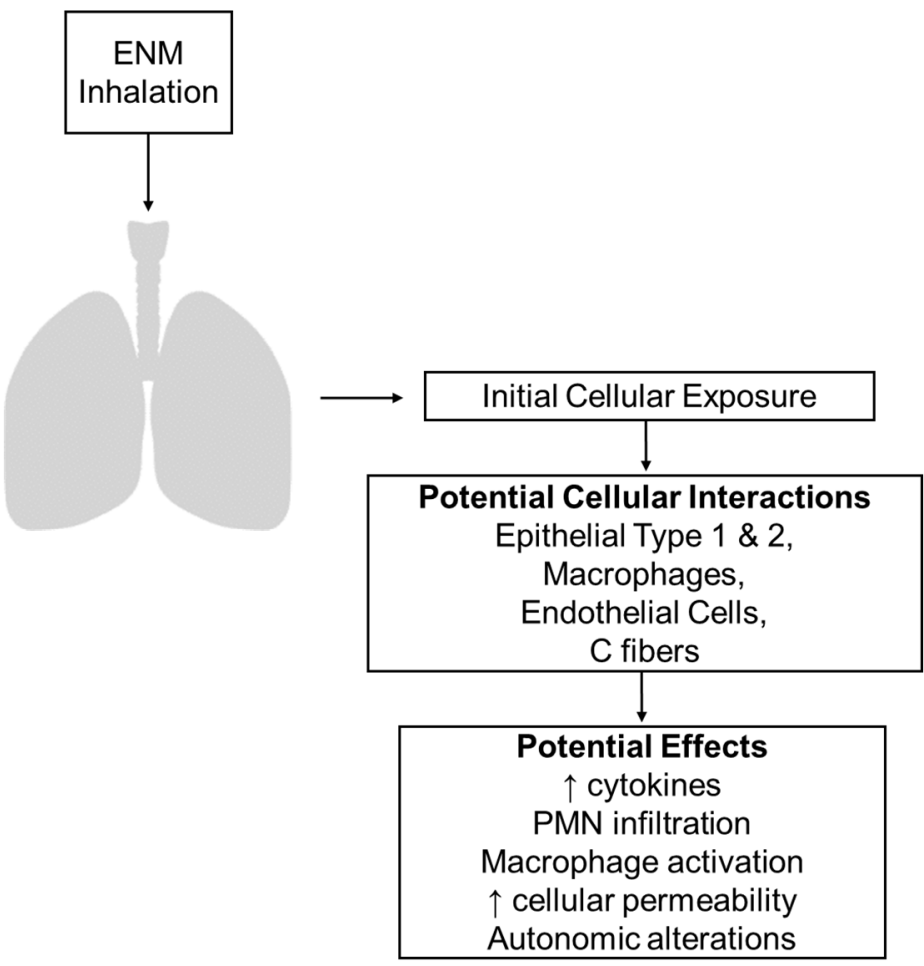
Figure 1B:
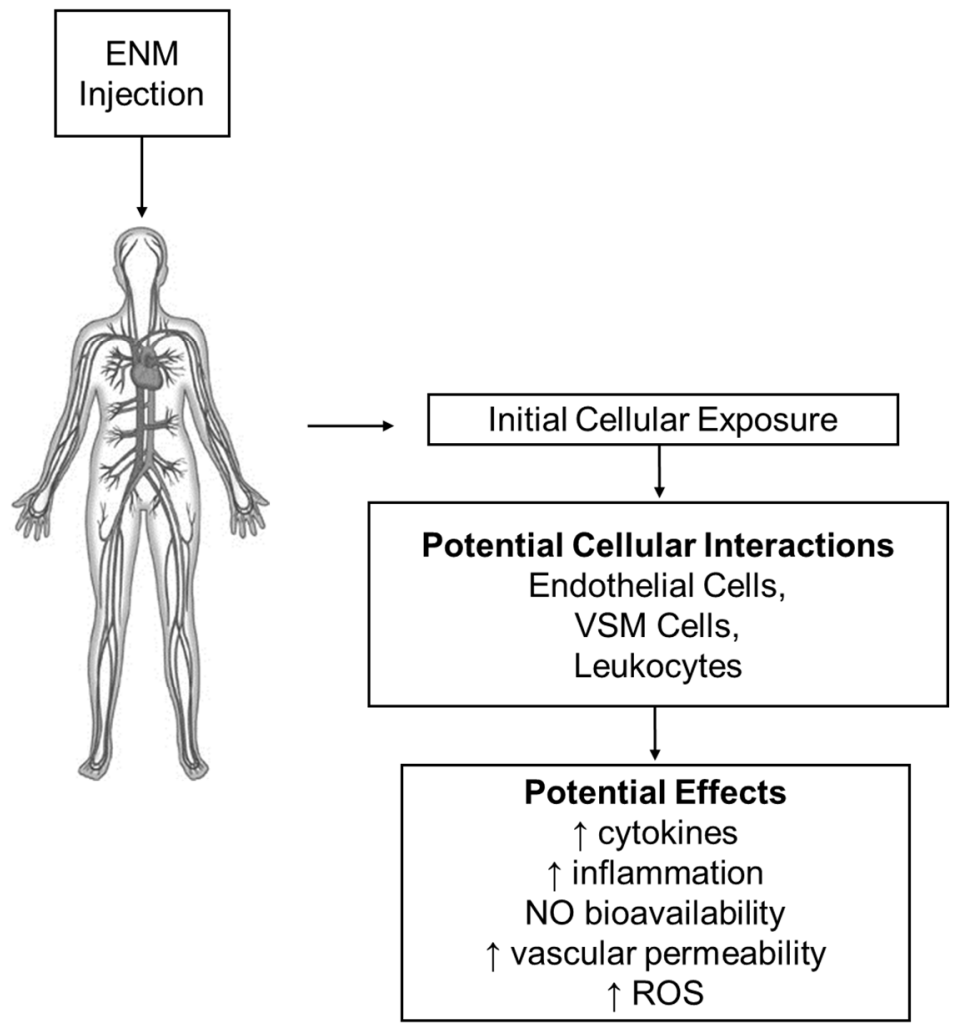

\section{Figure 1C:}
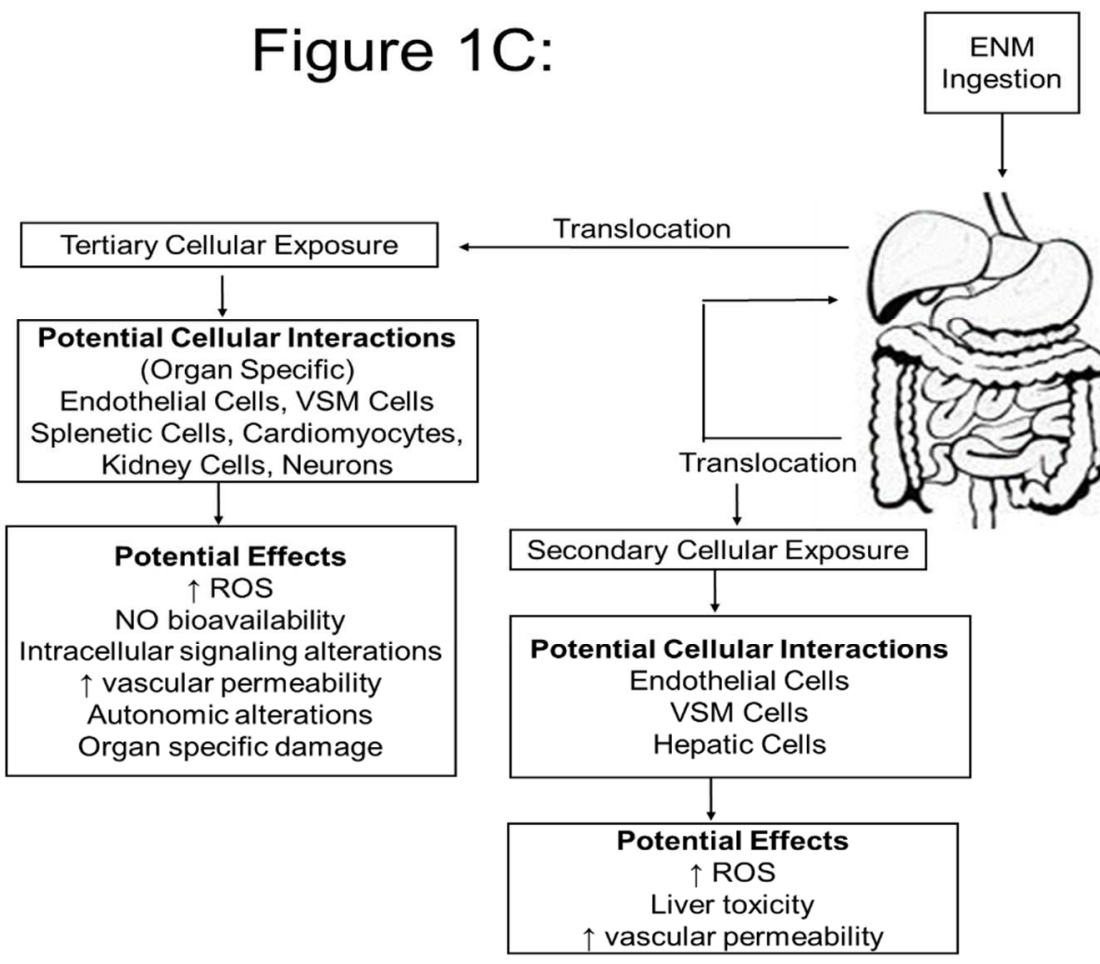


\section{Reference List:}

1. Akbar, N., Mohamed, T., Whitehead, D., and Azzawi, M. (2011). Biocompatibility of amorphous silica nanoparticles: Size and charge effect on vascular function, in vitro. Biotechnol. Appl. Biochem. 58(5), 353-362.

2. Albanese, A., Tang, P. S., and Chan, W. C. (2012). The effect of nanoparticle size, shape, and surface chemistry on biological systems. Annu. Rev. Biomed. Eng 14, $1-16$.

3. Asharani, P. V., Lianwu, Y., Gong, Z., and Valiyaveettil, S. (2011). Comparison of the toxicity of silver, gold and platinum nanoparticles in developing zebrafish embryos. Nanotoxicology. 5(1), 43-54.

4. Bae, S. W., Tan, W., and Hong, J. I. (2012). Fluorescent dye-doped silica nanoparticles: new tools for bioapplications. Chem. Commun. (Camb. ) 48(17), 2270-2282.

5. Baker, G. L., Gupta, A., Clark, M. L., Valenzuela, B. R., Staska, L. M., Harbo, S. J., Pierce, J. T., and Dill, J. A. (2008). Inhalation toxicity and lung toxicokinetics of C60 fullerene nanoparticles and microparticles. Toxicol. Sci. 101(1), 122-131.

6. Baky, N. A., Faddah, L. M., Al-Rasheed, N. M., Al-Rasheed, N. M., and Fatani, A. J. (2013). Induction of Inflammation, DNA Damage and Apoptosis in Rat Heart after Oral Exposure to Zinc Oxide Nanoparticles and the Cardioprotective Role of alpha-lipoic Acid and Vitamin E. Drug Res. (Stuttg) 63(5), 228-236.

7. Banerjee, S. (2013). Molecular dynamics study of self-agglomeration of charged fullerenes in solvents. J Chem Phys 138(4), 044318.

8. Bauer, A. T., Strozyk, E. A., Gorzelanny, C., Westerhausen, C., Desch, A., Schneider, M. F., and Schneider, S. W. (2011). Cytotoxicity of silica nanoparticles through exocytosis of von Willebrand factor and necrotic cell death in primary human endothelial cells. Biomaterials 32(33), 8385-8393.

9. Bevan, J. A., and Laher, I. (1991). Pressure and flow-dependent vascular tone. FASEB J 5(9), 2267-2273.

10. Borak, B., Arkowski, J., Skrzypiec, M., Ziolkowski, P., Krajewska, B., Wawrzynska, M., Grotthus, B., Gliniak, H., Szelag, A., Mazurek, W., Bialy, D., and Maruszewski, K. (2007). Behavior of silica particles introduced into an isolated rat heart as potential drug carriers. Biomed. Mater. 2(4), 220-223.

11. Borm, P. J., and Muller-Schulte, D. (2006). Nanoparticles in drug delivery and environmental exposure: same size, same risks? Nanomedicine. (Lond) 1(2), 235249. 
12. Borm, P. J., Robbins, D., Haubold, S., Kuhlbusch, T., Fissan, H., Donaldson, K., Schins, R., Stone, V., Kreyling, W., Lademann, J., Krutmann, J., Warheit, D., and Oberdorster, E. (2006). The potential risks of nanomaterials: a review carried out for ECETOC. Part Fibre. Toxicol. 3, 11.

13. Boyes, W. K., Chen, R., Chen, C., and Yokel, R. A. (2012). The neurotoxic potential of engineered nanomaterials. Neurotoxicology 33(4), 902-910.

14. Brook, R. D. (2008). Cardiovascular effects of air pollution. Clin. Sci. (Lond) 115(6), 175-187.

15. Brook, R. D., Bard, R. L., Burnett, R. T., Shin, H. H., Vette, A., Croghan, C., Phillips, M., Rodes, C., Thornburg, J., and Williams, R. (2011). Differences in blood pressure and vascular responses associated with ambient fine particulate matter exposures measured at the personal versus community level. Occup. Environ. Med. 68(3), 224-230.

16. Brook, R. D., Rajagopalan, S., Pope, C. A., III, Brook, J. R., Bhatnagar, A., ezRoux, A. V., Holguin, F., Hong, Y., Luepker, R. V., Mittleman, M. A., Peters, A., Siscovick, D., Smith, S. C., Jr., Whitsel, L., and Kaufman, J. D. (2010). Particulate matter air pollution and cardiovascular disease: An update to the scientific statement from the American Heart Association. Circulation 121(21), 2331-2378.

17. Brun, E., Barreau, F., Veronesi, G., Fayard, B., Sorieul, S., Chaneac, C., Carapito, C., Rabilloud, T., Mabondzo, A., Herlin-Boime, N., and Carriere, M. (2014). Titanium dioxide nanoparticle impact and translocation through ex vivo, in vivo and in vitro gut epithelia. Part Fibre. Toxicol. 11, 13.

18. Campen, M. J., McDonald, J. D., Gigliotti, A. P., Seilkop, S. K., Reed, M. D., and Benson, J. M. (2003). Cardiovascular effects of inhaled diesel exhaust in spontaneously hypertensive rats. Cardiovasc. Toxicol. 3(4), 353-361.

19. Carll, A. P., Haykal-Coates, N., Winsett, D. W., Hazari, M. S., Ledbetter, A. D., Richards, J. H., Cascio, W. E., Costa, D. L., and Farraj, A. K. (2015). Cardiomyopathy confers susceptibility to particulate matter-induced oxidative stress, vagal dominance, arrhythmia and pulmonary inflammation in heart failureprone rats. Inhal. Toxicol. 27(2), 100-112.

20. Cassee, F. R., Campbell, A., Boere, A. J., McLean, S. G., Duffin, R., Krystek, P., Gosens, I., and Miller, M. R. (2012). The biological effects of subacute inhalation of diesel exhaust following addition of cerium oxide nanoparticles in atherosclerosis-prone mice. Environ. Res. 115, 1-10.

21. Cassee, F. R., van Balen, E. C., Singh, C., Green, D., Muijser, H., Weinstein, J., and Dreher, K. (2011). Exposure, health and ecological effects review of engineered nanoscale cerium and cerium oxide associated with its use as a fuel additive. Crit Rev. Toxicol. 41(3), 213-229. 
22. Celardo, I., Traversa, E., and Ghibelli, L. (2011). Cerium oxide nanoparticles: a promise for applications in therapy. J. Exp. Ther. Oncol. 9(1), 47-51.

23. Centers for Disease Control and Prevention. NIOSH Recommends New Level of Exposure for Nanomaterials. 4-24-0013. 6-6-0013.

24. Chen, X., Yin, J., Wu, X., Li, R., Fang, J., Chen, R., Zhang, B., and Zhang, W. (2013). Effects of magnetically labeled exogenous endothelial progenitor cells on cerebral blood perfusion and microvasculature alterations after traumatic brain injury in rat model. Acta Radiol. 54(3), 313-323.

25. Cho, W. S., Duffin, R., Poland, C. A., Howie, S. E., MacNee, W., Bradley, M., Megson, I. L., and Donaldson, K. (2010). Metal oxide nanoparticles induce unique inflammatory footprints in the lung: important implications for nanoparticle testing. Environ. Health Perspect. 118(12), 1699-1706.

26. Chorley, B., Ward, W., Simmons, S. O., Vallanat, B., and Veronesi, B. (2014). The cellular and genomic response of rat dopaminergic neurons (N27) to coated nanosilver. Neurotoxicology 45, 12-21.

27. Chuang, H. C., Juan, H. T., Chang, C. N., Yan, Y. H., Yuan, T. H., Wang, J. S., Chen, H. C., Hwang, Y. H., Lee, C. H., and Cheng, T. J. (2013). Cardiopulmonary toxicity of pulmonary exposure to occupationally-relevant zinc oxide nanoparticles. Nanotoxicology.

28. Colon, J., Hsieh, N., Ferguson, A., Kupelian, P., Seal, S., Jenkins, D. W., and Baker, C. H. (2010). Cerium oxide nanoparticles protect gastrointestinal epithelium from radiation-induced damage by reduction of reactive oxygen species and upregulation of superoxide dismutase 2. Nanomedicine. 6(5), 698-705.

29. Consumer Products Inventory (2015) An Inventory of Nanotechnology-based Consumer Products Introduced on the Market. Wilson Center and Virginia Tech. http://www.nanotechproject.org/cpi/. Accessed July 29, 2015.

30. Corbalan, J. J., Medina, C., Jacoby, A., Malinski, T., and Radomski, M. W. (2012). Amorphous silica nanoparticles aggregate human platelets: potential implications for vascular homeostasis. Int. J. Nanomedicine. 7, 631-639.

31. Courtois, A., Andujar, P., Ladeiro, Y., Baudrimont, I., Delannoy, E., Leblais, V., Begueret, H., Galland, M. A., Brochard, P., Marano, F., Marthan, R., and Muller, B. (2008). Impairment of NO-dependent relaxation in intralobar pulmonary arteries: comparison of urban particulate matter and manufactured nanoparticles. Environ. Health Perspect. 116(10), 1294-1299.

32. CRONE, C. (1963). THE PERMEABILITY OF CAPILLARIES IN VARIOUS ORGANS AS DETERMINED BY USE OF THE 'INDICATOR DIFFUSION' METHOD. Acta Physiol Scand. 58, 292-305. 
33. de Mel, A., Chaloupka, K., Malam, Y., Darbyshire, A., Cousins, B., and Seifalian, A. M. (2012). A silver nanocomposite biomaterial for blood-contacting implants. J. Biomed. Mater. Res. A 100(9), 2348-2357.

34. Degnan, A. J., Patterson, A. J., Tang, T. Y., Howarth, S. P., and Gillard, J. H. (2012). Evaluation of ultrasmall superparamagnetic iron oxide-enhanced MRI of carotid atherosclerosis to assess risk of cerebrovascular and cardiovascular events: follow-up of the ATHEROMA trial. Cerebrovasc. Dis. 34(2), 169-173.

35. Demczyk, B. G., Wang, Y. M., Cumings, J., Hetman, M., Han, W., Zettl, A., and Ritchie, R. O. (2002). Direct Mechanical Measurement of the Tensile Strength and Elastic Modulus of Multiwalled Carbon Nanotubes. Materials Science and Engineering A334, 173-178.

36. Dorato, M. A., and Engelhardt, J. A. (2005). The no-observed-adverse-effect-level in drug safety evaluations: use, issues, and definition(s). Regul. Toxicol. Pharmacol. 42(3), 265-274.

37. Driscoll, K. E., Costa, D. L., Hatch, G., Henderson, R., Oberdorster, G., Salem, H., and Schlesinger, R. B. (2000). Intratracheal instillation as an exposure technique for the evaluation of respiratory tract toxicity: uses and limitations. Toxicol. Sci 55(1), 24-35.

38. Du, Z., Zhao, D., Jing, L., Cui, G., Jin, M., Li, Y., Liu, X., Liu, Y., Du, H., Guo, C., Zhou, X., and Sun, Z. (2013). Cardiovascular Toxicity of Different Sizes Amorphous Silica Nanoparticles in Rats After Intratracheal Instillation. Cardiovasc. Toxicol.

39. Duan, J., Yu, Y., Li, Y., Yu, Y., Li, Y., Zhou, X., Huang, P., and Sun, Z. (2013). Toxic effect of silica nanoparticles on endothelial cells through DNA damage response via Chk1-dependent G2/M checkpoint. PLoS. One. 8(4), e62087.

40. Erdakos, G. B., Bhave, P. V., Pouliot, G. A., Simon, H., and Mathur, R. (2014). Predicting the effects of nanoscale cerium additives in diesel fuel on regional-scale air quality. Environ. Sci. Technol. 48(21), 12775-12782.

41. Geraets, L., Oomen, A. G., Schroeter, J. D., Coleman, V. A., and Cassee, F. R. (2012). Tissue distribution of inhaled micro- and nano-sized cerium oxide particles in rats: results from a 28-day exposure study. Toxicol. Sci. 127(2), 463-473.

42. Gobre, V. V., and Tkatchenko, A. (2013). Scaling laws for van der Waals interactions in nanostructured materials. Nat. Commun. 4, 2341.

43. Gojova, A., Lee, J. T., Jung, H. S., Guo, B., Barakat, A. I., and Kennedy, I. M. (2009). Effect of cerium oxide nanoparticles on inflammation in vascular endothelial cells. Inhal. Toxicol. 21 Suppl 1, 123-130. 
44. Gordan, R., Gwathmey, J. K., and Xie, L. H. (2015). Autonomic and endocrine control of cardiovascular function. World J. Cardiol. 7(4), 204-214.

45. Hartmann, P., Brezesinski, T., Sann, J., Lotnyk, A., Eufinger, J. P., Kienle, L., and Janek, J. (2013). Defect chemistry of oxide nanomaterials with high surface area: ordered mesoporous thin films of the oxygen storage catalyst $\mathrm{CeO} 2-\mathrm{ZrO} 2$. ACS Nano. 7(4), 2999-3013.

46. Heckert, E. G., Karakoti, A. S., Seal, S., and Self, W. T. (2008). The role of cerium redox state in the SOD mimetic activity of nanoceria. Biomaterials 29(18), 27052709.

47. Helfand, W. H., Lazarus, J., and Theerman, P. (2001). Donora, Pennsylvania: an environmental disaster of the 20th century. Am. J. Public Health 91(4), 553.

48. Henderson, R. F., Driscoll, K. E., Harkema, J. R., Lindenschmidt, R. C., Chang, I. Y., Maples, K. R., and Barr, E. B. (1995). A comparison of the inflammatory response of the lung to inhaled versus instilled particles in F344 rats. Fundam. Appl. Toxicol. 24(2), 183-197.

49. Henrion, D. (2005). Pressure and flow-dependent tone in resistance arteries. Role of myogenic tone. Arch. Mal Coeur Vaiss. 98(9), 913-921.

50. Hirst, S. M., Karakoti, A., Singh, S., Self, W., Tyler, R., Seal, S., and Reilly, C. M. (2013). Bio-distribution and in vivo antioxidant effects of cerium oxide nanoparticles in mice. Environ. Toxicol. 28(2), 107-118.

51. Hubbs, A. F., Mercer, R. R., Benkovic, S. A., Harkema, J., Sriram, K., SchweglerBerry, D., Goravanahally, M. P., Nurkiewicz, T. R., Castranova, V., and Sargent, L. M. (2011). Nanotoxicology--a pathologist's perspective. Toxicol. Pathol. 39(2), 301-324.

52. Hussain, S., Al-Nsour, F., Rice, A. B., Marshburn, J., Ji, Z., Zink, J. I., Yingling, B., Walker, N. J., and Garantziotis, S. (2012). Cerium dioxide nanoparticles do not modulate the lipopolysaccharide-induced inflammatory response in human monocytes. Int. J. Nanomedicine. 7, 1387-1397.

53. Ide, T., Tsutsui, H., Kinugawa, S., Suematsu, N., Hayashidani, S., Ichikawa, K., Utsumi, H., Machida, Y., Egashira, K., and Takeshita, A. (2000). Direct evidence for increased hydroxyl radicals originating from superoxide in the failing myocardium. Circ. Res. 86(2), 152-157.

54. Imai, M., and Kokko, J. P. (1972). Effect of peritubular protein concentration on reabsorption of sodium and water in isolated perfused proxmal tubules. J. Clin. Invest 51(2), 314-325.

55. Iversen, N. K., Frische, S., Thomsen, K., Laustsen, C., Pedersen, M., Hansen, P. B., Bie, P., Fresnais, J., Berret, J. F., Baatrup, E., and Wang, T. (2013). 
Superparamagnetic iron oxide polyacrylic acid coated gamma-Fe2O3 nanoparticles do not affect kidney function but cause acute effect on the cardiovascular function in healthy mice. Toxicol. Appl. Pharmacol. 266(2), 276288.

56. Jani, P., Halbert, G. W., Langridge, J., and Florence, A. T. (1990). Nanoparticle uptake by the rat gastrointestinal mucosa: quantitation and particle size dependency. J. Pharm. Pharmacol. 42(12), 821-826.

57. Janz, A., Kockritz, A., Yao, L., and Martin, A. (2010). Fundamental calculations on the surface area determination of supported gold nanoparticles by alkanethiol adsorption. Langmuir 26(9), 6783-6789.

58. Ji, Z., Wang, X., Zhang, H., Lin, S., Meng, H., Sun, B., George, S., Xia, T., Nel, A. E., and Zink, J. I. (2012). Designed synthesis of $\mathrm{CeO} 2$ nanorods and nanowires for studying toxicological effects of high aspect ratio nanomaterials. ACS Nano. 6(6), 5366-5380.

59. Johnston, A. P., Kamphuis, M. M., Such, G. K., Scott, A. M., Nice, E. C., Heath, J. K., and Caruso, F. (2012b). Targeting cancer cells: controlling the binding and internalization of antibody-functionalized capsules. ACS Nano. 6(8), 6667-6674.

60. Johnston, A. P., Kamphuis, M. M., Such, G. K., Scott, A. M., Nice, E. C., Heath, J. K., and Caruso, F. (2012a). Targeting cancer cells: controlling the binding and internalization of antibody-functionalized capsules. ACS Nano. 6(8), 6667-6674.

61. Jung, S. Y., Ahn, S., Nam, K. H., Lee, J. P., and Lee, S. J. (2012). In vivo measurements of blood flow in a rat using X-ray imaging technique. Int. J. Cardiovasc. Imaging 28(8), 1853-1858.

62. Kaittanis, C., Santra, S., Asati, A., and Perez, J. M. (2012). A cerium oxide nanoparticle-based device for the detection of chronic inflammation via optical and magnetic resonance imaging. Nanoscale. 4(6), 2117-2123.

63. Kan, H., Wu, Z., Lin, Y. C., Chen, T. H., Cumpston, J. L., Kashon, M. L., Leonard, S., Munson, A. E., and Castranova, V. (2013). The role of nodose ganglia in the regulation of cardiovascular function following pulmonary exposure to ultrafine titanium dioxide. Nanotoxicology.

64. Kang, K., Lim, D. H., Choi, I. H., Kang, T., Lee, K., Moon, E. Y., Yang, Y., Lee, M. S., and Lim, J. S. (2011). Vascular tube formation and angiogenesis induced by polyvinylpyrrolidone-coated silver nanoparticles. Toxicol. Lett. 205(3), 227-234.

65. Kasper, J., Hermanns, M. I., Bantz, C., Maskos, M., Stauber, R., Pohl, C., Unger, R. E., and Kirkpatrick, J. C. (2011). Inflammatory and cytotoxic responses of an alveolar-capillary coculture model to silica nanoparticles: comparison with conventional monocultures. Part Fibre. Toxicol. 8(1), 6. 
66. Katwa, P., Wang, X., Urankar, R. N., Podila, R., Hilderbrand, S. C., Fick, R. B., Rao, A. M., Ke, P. C., Wingard, C. J., and Brown, J. M. (2012). A carbon nanotube toxicity paradigm driven by mast cells and the IL-(3)(3)/ST(2) axis. Small 8(18), 2904-2912.

67. Kelkar, S. S., and Reineke, T. M. (2011). Theranostics: combining imaging and therapy. Bioconjug. Chem. 22(10), 1879-1903.

68. Khaisman, E. B. (1975). A histochemical study of vegetative innervation of bloodvessels of serosa. Arch. Anat. Microsc. Morphol. Exp. 64(4), 337-358.

69. Kim, C. K., Kim, T., Choi, I. Y., Soh, M., Kim, D., Kim, Y. J., Jang, H., Yang, H. S., Kim, J. Y., Park, H. K., Park, S. P., Park, S., Yu, T., Yoon, B. W., Lee, S. H., and Hyeon, T. (2012). Ceria nanoparticles that can protect against ischemic stroke. Angew. Chem Int. Ed Engl. 51(44), 11039-11043.

70. Knuckles, T. L., Yi, J., Frazer, D. G., Leonard, H. D., Chen, B. T., Castranova, V., and Nurkiewicz, T. R. (2011). Nanoparticle inhalation alters systemic arteriolar vasoreactivity through sympathetic and cyclooxygenase-mediated pathways. Nanotoxicology.

71. Kreyling, W. G., Semmler, M., Erbe, F., Mayer, P., Takenaka, S., Schulz, H., Oberdorster, G., and Ziesenis, A. (2002). Translocation of ultrafine insoluble iridium particles from lung epithelium to extrapulmonary organs is size dependent but very low. J. Toxicol. Environ. Health A 65(20), 1513-1530.

72. LeBlanc, A. J., Cumpston, J. L., Chen, B. T., Frazer, D., Castranova, V., and Nurkiewicz, T. R. (2009). Nanoparticle inhalation impairs endothelium-dependent vasodilation in subepicardial arterioles. J. Toxicol. Environ. Health A 72(24), 15761584.

73. LeBlanc, A. J., Moseley, A. M., Chen, B. T., Frazer, D., Castranova, V., and Nurkiewicz, T. R. (2010). Nanoparticle inhalation impairs coronary microvascular reactivity via a local reactive oxygen species-dependent mechanism. Cardiovasc. Toxicol. 10(1), 27-36.

74. Lee, L. Y. (2009). Respiratory sensations evoked by activation of bronchopulmonary C-fibers. Respir. Physiol Neurobiol. 167(1), 26-35.

75. Legramante, J. M., Valentini, F., Magrini, A., Palleschi, G., Sacco, S., lavicoli, I., Pallante, M., Moscone, D., Galante, A., Bergamaschi, E., Bergamaschi, A., and Pietroiusti, A. (2009). Cardiac autonomic regulation after lung exposure to carbon nanotubes. Hum. Exp. Toxicol. 28(6-7), 369-375.

76. Ley, K., Laudanna, C., Cybulsky, M. I., and Nourshargh, S. (2007). Getting to the site of inflammation: the leukocyte adhesion cascade updated. Nat. Rev. Immunol. 7(9), 678-689. 
77. Limbach, L. K., Li, Y., Grass, R. N., Brunner, T. J., Hintermann, M. A., Muller, M., Gunther, D., and Stark, W. J. (2005). Oxide nanoparticle uptake in human lung fibroblasts: effects of particle size, agglomeration, and diffusion at low concentrations. Environ. Sci. Technol. 39(23), 9370-9376.

78. Liu, X., and Sun, J. (2010). Endothelial cells dysfunction induced by silica nanoparticles through oxidative stress via JNK/P53 and NF-kappaB pathways. Biomaterials 31(32), 8198-8209.

79. Longmire, M., Choyke, P. L., and Kobayashi, H. (2008). Clearance properties of nano-sized particles and molecules as imaging agents: considerations and caveats. Nanomedicine. (Lond) 3(5), 703-717.

80. Lundqvist, M., Stigler, J., Elia, G., Lynch, I., Cedervall, T., and Dawson, K. A. (2008). Nanoparticle size and surface properties determine the protein corona with possible implications for biological impacts. Proc. Natl. Acad. Sci. U. S. A 105(38), 14265-14270.

81. Lv, J., and Zhu, L. (2013). Highly efficient indoor air purification using adsorptionenhanced-photocatalysis-based microporous $\mathrm{TiO} 2$ at short residence time. Environ. Technol 34(9-12), 1447-1454.

82. Ma, J. Y., Zhao, H., Mercer, R. R., Barger, M., Rao, M., Meighan, T., SchweglerBerry, D., Castranova, V., and Ma, J. K. (2011). Cerium oxide nanoparticle-induced pulmonary inflammation and alveolar macrophage functional change in rats. Nanotoxicology. 5(3), 312-325.

83. Madero-Visbal, R. A., Alvarado, B. E., Colon, J. F., Baker, C. H., Wason, M. S., Isley, B., Seal, S., Lee, C. M., Das, S., and Manon, R. (2012). Harnessing nanoparticles to improve toxicity after head and neck radiation. Nanomedicine. 8(7), 1223-1231.

84. Magari, S. R., Hauser, R., Schwartz, J., Williams, P. L., Smith, T. J., and Christiani, D. C. (2001). Association of heart rate variability with occupational and environmental exposure to particulate air pollution. Circulation 104(9), 986-991.

85. Mao, H., Chen, W., Laurent, S., Thirifays, C., Burtea, C., Rezaee, F., and Mahmoudi, M. (2013). Hard corona composition and cellular toxicities of the graphene sheets. Colloids Surf B Biointerfaces. 109, 212-218.

86. Maynard, A. D., and Kuempel, E. (2005). Airborne nanostructured particles and occupational health. J. Nanopart. Res. 7(6), 587-614.

87. Mercer, R. R., Hubbs, A. F., Scabilloni, J. F., Wang, L., Battelli, L. A., Friend, S., Castranova, V., and Porter, D. W. (2011). Pulmonary fibrotic response to aspiration of multi-walled carbon nanotubes. Part Fibre. Toxicol. 8, 21. 
88. Mercer, R. R., Hubbs, A. F., Scabilloni, J. F., Wang, L., Battelli, L. A., SchweglerBerry, D., Castranova, V., and Porter, D. W. (2010). Distribution and persistence of pleural penetrations by multi-walled carbon nanotubes. Part Fibre. Toxicol. 7 , 28.

89. Mikkelsen, L., Sheykhzade, M., Jensen, K. A., Saber, A. T., Jacobsen, N. R., Vogel, U., Wallin, H., Loft, S., and Moller, P. (2011). Modest effect on plaque progression and vasodilatory function in atherosclerosis-prone mice exposed to nanosized TiO(2). Part Fibre. Toxicol. 8, 32.

90. Miller, S. B. (2006). Prostaglandins in health and disease: an overview. Semin. Arthritis Rheum. 36(1), 37-49.

91. Nalabotu, S. K., Kolli, M. B., Triest, W. E., Ma, J. Y., Manne, N. D., Katta, A., Addagarla, H. S., Rice, K. M., and Blough, E. R. (2011). Intratracheal instillation of cerium oxide nanoparticles induces hepatic toxicity in male Sprague-Dawley rats. Int. J. Nanomedicine. 6, 2327-2335.

92. Napierska, D., Quarck, R., Thomassen, L. C., Lison, D., Martens, J. A., Delcroix, M., Nemery, B., and Hoet, P. H. (2013). Amorphous silica nanoparticles promote monocyte adhesion to human endothelial cells: size-dependent effect. Small 9(3), 430-438.

93. Nemery, B., Hoet, P. H., and Nemmar, A. (2001). The Meuse Valley fog of 1930: an air pollution disaster. Lancet 357(9257), 704-708.

94. Niu, J., Wang, K., and Kolattukudy, P. E. (2011). Cerium oxide nanoparticles inhibit oxidative stress and nuclear factor-kappaB activation in H9c2 cardiomyocytes exposed to cigarette smoke extract. J. Pharmacol. Exp. Ther. 338(1), 53-61.

95. Nurkiewicz, T. R., Porter, D. W., Barger, M., Castranova, V., and Boegehold, M. A. (2004). Particulate matter exposure impairs systemic microvascular endothelium-dependent dilation. Environ. Health Perspect. 112(13), 1299-1306.

96. Nurkiewicz, T. R., Porter, D. W., Hubbs, A. F., Cumpston, J. L., Chen, B. T., Frazer, D. G., and Castranova, V. (2008). Nanoparticle inhalation augments particledependent systemic microvascular dysfunction. Part Fibre. Toxicol. 5, 1.

97. Nurkiewicz, T. R., Porter, D. W., Hubbs, A. F., Stone, S., Chen, B. T., Frazer, D. G., Boegehold, M. A., and Castranova, V. (2009). Pulmonary nanoparticle exposure disrupts systemic microvascular nitric oxide signaling. Toxicol. Sci. 110(1), 191-203.

98. Nurkiewicz, T. R., Porter, D. W., Hubbs, A. F., Stone, S., Moseley, A. M., Cumpston, J. L., Goodwill, A. G., Frisbee, S. J., Perrotta, P. L., Brock, R. W., Frisbee, J. C., Boegehold, M. A., Frazer, D. G., Chen, B. T., and Castranova, V. (2011). Pulmonary particulate matter and systemic microvascular dysfunction. Res Rep Health Eff Inst. (164):3-48.. 
99. Oberdorster, G., Oberdorster, E., and Oberdorster, J. (2005). Nanotoxicology: an emerging discipline evolving from studies of ultrafine particles. Environ. Health Perspect. 113(7), 823-839.

100. Oberdorster, G., Sharp, Z., Atudorei, V., Elder, A., Gelein, R., Kreyling, W., and Cox, C. (2004). Translocation of inhaled ultrafine particles to the brain. Inhal. Toxicol. 16(6-7), 437-445.

101. Ohyanagi, M., Faber, J. E., and Nishigaki, K. (1991). Differential activation of alpha 1- and alpha 2-adrenoceptors on microvascular smooth muscle during sympathetic nerve stimulation. Circ. Res. 68(1), 232-244.

102. Pacurari, M., Castranova, V., and Vallyathan, V. (2010). Single- and multi-wall carbon nanotubes versus asbestos: are the carbon nanotubes a new health risk to humans? J. Toxicol. Environ. Health A 73(5), 378-395.

103. Pacurari, M., Qian, Y., Fu, W., Schwegler-Berry, D., Ding, M., Castranova, V., and Guo, N. L. (2012). Cell permeability, migration, and reactive oxygen species induced by multiwalled carbon nanotubes in human microvascular endothelial cells. J. Toxicol. Environ. Health A 75(2), 112-128.

104. Pagliari, F., Mandoli, C., Forte, G., Magnani, E., Pagliari, S., Nardone, G., Licoccia, S., Minieri, M., Di, N. P., and Traversa, E. (2012). Cerium oxide nanoparticles protect cardiac progenitor cells from oxidative stress. ACS Nano. 6(5), 3767-3775.

105. Pairon, J. C., Roos, F., Sebastien, P., Chamak, B., bd-Alsamad, I., Bernaudin, J. F., Bignon, J., and Brochard, P. (1995). Biopersistence of cerium in the human respiratory tract and ultrastructural findings. Am. J. Ind. Med. 27(3), 349-358.

106. Park, K., Tuttle, G., Sinche, F., and Harper, S. L. (2013). Stability of citrate-capped silver nanoparticles in exposure media and their effects on the development of embryonic zebrafish (Danio rerio). Arch. Pharm. Res. 36(1), 125-133.

107. Pasupuleti, S., Alapati, S., Ganapathy, S., Anumolu, G., Pully, N. R., and Prakhya, B. M. (2012). Toxicity of zinc oxide nanoparticles through oral route. Toxicol. Ind. Health 28(8), 675-686.

108. Pok, S., Vitale, F., Eichmann, S. L., Benavides, O. M., Pasquali, M., and Jacot, J. G. (2014). Biocompatible carbon nanotube-chitosan scaffold matching the electrical conductivity of the heart. ACS Nano. 8(10), 9822-9832.

109. Porter, D. W., Hubbs, A. F., Mercer, R. R., Wu, N., Wolfarth, M. G., Sriram, K., Leonard, S., Battelli, L., Schwegler-Berry, D., Friend, S., Andrew, M., Chen, B. T., Tsuruoka, S., Endo, M., and Castranova, V. (2010). Mouse pulmonary dose- and time course-responses induced by exposure to multi-walled carbon nanotubes. Toxicology 269(2-3), 136-147. 
110. Prades, R., Guerrero, S., Araya, E., Molina, C., Salas, E., Zurita, E., Selva, J., Egea, G., Lopez-Iglesias, C., Teixido, M., Kogan, M. J., and Giralt, E. (2012). Delivery of gold nanoparticles to the brain by conjugation with a peptide that recognizes the transferrin receptor. Biomaterials 33(29), 7194-7205.

111. Prewitt, R. L., Rice, D. C., and Dobrian, A. D. (2002). Adaptation of resistance arteries to increases in pressure. Microcirculation. 9(4), 295-304.

112. Ragaseema, V. M., Unnikrishnan, S., Kalliyana, K., V, and Krishnan, L. K. (2012). The antithrombotic and antimicrobial properties of PEG-protected silver nanoparticle coated surfaces. Biomaterials 33(11), 3083-3092.

113. Rahmer, J., Antonelli, A., Sfara, C., Tiemann, B., Gleich, B., Magnani, M., Weizenecker, J., and Borgert, J. (2013). Nanoparticle encapsulation in red blood cells enables blood-pool magnetic particle imaging hours after injection. Phys. Med. Biol. 58(12), 3965-3977.

114. Raieszadeh, H., Noaman, V., and Yadegari, M. (2013). Echocardiographic assessment of cardiac structural and functional indices in broiler chickens treated with silver nanoparticles. ScientificWorldJournal. 2013, 931432.

115. Reddy, A. R., Krishna, D. R., Reddy, Y. N., and Himabindu, V. (2010). Translocation and extra pulmonary toxicities of multi wall carbon nanotubes in rats. Toxicol. Mech. Methods 20(5), 267-272.

116. Renkin, E. M. (1984). Control of microcirculation and blood-tissue exchange. In Handbook of Physiology (Renkin E.M. and Michel C.C., Eds.), pp. 627-687. American Physiology Society, Bethesda, MD.

117. Rhoden, C. R., Wellenius, G. A., Ghelfi, E., Lawrence, J., and Gonzalez-Flecha, B. (2005). PM-induced cardiac oxidative stress and dysfunction are mediated by autonomic stimulation. Biochim. Biophys. Acta 1725(3), 305-313.

118. Richards, J. M., Semple, S. I., MacGillivray, T. J., Gray, C., Langrish, J. P., Williams, M., Dweck, M., Wallace, W., McKillop, G., Chalmers, R. T., Garden, O. J., and Newby, D. E. (2011). Abdominal aortic aneurysm growth predicted by uptake of ultrasmall superparamagnetic particles of iron oxide: a pilot study. Circ. Cardiovasc. Imaging 4(3), 274-281.

119. Roco, M. C., Mirkin, C. A., and Hersam, M. C. Nanotechnology Research Directions for Societal Needs in 2020 Retrospective and Outlook. 9-30-2010. World Technology Evaluation Center, Inc.

120. Schwartzkopff, B., Mundhenke, M., and Strauer, B. E. (1998). Alterations of the architecture of subendocardial arterioles in patients with hypertrophic cardiomyopathy and impaired coronary vasodilator reserve: a possible cause for myocardial ischemia. J Am. Coll. Cardiol. 31(5), 1089-1096. 
121. Shaffer, F., McCraty, R., and Zerr, C. L. (2014). A healthy heart is not a metronome: an integrative review of the heart's anatomy and heart rate variability. Front Psychol. 5, 1040.

122. Shannahan, J. H., Podila, R., Aldossari, A. A., Emerson, H., Powell, B. A., Ke, P. C., Rao, A. M., and Brown, J. M. (2015). Formation of a protein corona on silver nanoparticles mediates cellular toxicity via scavenger receptors. Toxicol. Sci. 143(1), 136-146.

123. Sheikpranbabu, S., Kalishwaralal, K., Lee, K. J., Vaidyanathan, R., Eom, S. H., and Gurunathan, S. (2010). The inhibition of advanced glycation end-productsinduced retinal vascular permeability by silver nanoparticles. Biomaterials 31(8), 2260-2271.

124. Singh, S., Kumar, A., Karakoti, A., Seal, S., and Self, W. T. (2010). Unveiling the mechanism of uptake and sub-cellular distribution of cerium oxide nanoparticles. Mol. Biosyst. 6(10), 1813-1820.

125. Spitzer, A., and Windhager, E. E. (1970). Effect of peritubular oncotic pressure changes on proximal tubular fluid reabsorption. Am. J. Physiol 218(4), 1188-1193.

126. Srinivas, A., Rao, P. J., Selvam, G., Murthy, P. B., and Reddy, P. N. (2011). Acute inhalation toxicity of cerium oxide nanoparticles in rats. Toxicol. Lett. 205(2), 105115.

127. Stampfl, A., Maier, M., Radykewicz, R., Reitmeir, P., Gottlicher, M., and Niessner, R. (2011). Langendorff heart: a model system to study cardiovascular effects of engineered nanoparticles. ACS Nano. 5(7), 5345-5353.

128. Stankovich, S., Dikin, D. A., Dommett, G. H., Kohlhaas, K. M., Zimney, E. J., Stach, E. A., Piner, R. D., Nguyen, S. T., and Ruoff, R. S. (2006). Graphene-based composite materials. Nature 442(7100), 282-286.

129. Stapleton, P. A., Minarchick, V. C., Cumpston, A. M., McKinney, W., Chen, B. T., Sager, T. M., Frazer, D. G., Mercer, R. R., Scabilloni, J. F., Andrew, M., Castranova, V., and Nurkiewicz, T. R. (2012). Impairment of Coronary Arteriolar Endothelium-Dependent Dilation after Multi-Walled Carbon Nanotube Inhalation: A Time-Course Study. International Journal of Molecular Science 13, 1378113803.

130. Stapleton, P. A., Minarchick, V. C., McCawley, M., Knuckles, T. L., and Nurkiewicz, T. R. (2011). Xenobiotic Particle Exposure and Microvascular Endpoints: A Call to Arms. Microcirculation.

131. Stapleton, P. A., Minarchick, V. C., Yi, J., Engels, K., McBride, C. R., and Nurkiewicz, T. R. (2013). Maternal engineered nanomaterial exposure and fetal microvascular function: does the Barker hypothesis apply? Am. J Obstet. Gynecol. 
132. Stapleton, P. A., and Nurkiewicz, T. R. (2014). Vascular distribution of nanomaterials. Wiley. Interdiscip. Rev. Nanomed. Nanobiotechnol. 6(4), 338-348.

133. Stevens, B. R., Kaunitz, J. D., and Wright, E. M. (1984). Intestinal transport of amino acids and sugars: advances using membrane vesicles. Annu. Rev. Physiol 46, 417-433.

134. Subcommittee on Nanoscale Science, E. a. T., Committee on Technology, and National Science and Technology Council. The National Nanotechnology Initiative. 2014. Washington, D.C., Executive Office of the President of the United States. Supplement to the President's Budget for Fiscal Year 2015.

135. Suttiponparnit, K., Jiang, J., Sahu, M., Suvachittanont, S., Charinpanitkul, T., and Biswas, P. (2011). Role of Surface Area, Primary Particle Size, and Crystal Phase on Titanium Dioxide Nanoparticle Dispersion Properties. Nanoscale Res Lett 6(27).

136. Tankersley, C. G., Bierman, A., and Rabold, R. (2007). Variation in heart rate regulation and the effects of particle exposure in inbred mice. Inhal. Toxicol. 19(8), 621-629.

137. Taylor, A. J., McClure, C. D., Shipkowski, K. A., Thompson, E. A., Hussain, S., Garantziotis, S., Parsons, G. N., and Bonner, J. C. (2014). Atomic layer deposition coating of carbon nanotubes with aluminum oxide alters pro-fibrogenic cytokine expression by human mononuclear phagocytes in vitro and reduces lung fibrosis in mice in vivo. PLoS. One. 9(9), e106870.

138. Tok AIY, Du SW, Boey FYC, and Chong WK (2013). Hydrothermal sysnthesis and characterization of rare earth doped ceria nanoparticles. Mater Sci Eng(466), 223229.

139. Toya, T., Takata, A., Otaki, N., Takaya, M., Serita, F., Yoshida, K., and Kohyama, N. (2010). Pulmonary toxicity induced by intratracheal instillation of coarse and fine particles of cerium dioxide in male rats. Ind. Health 48(1), 3-11.

140. Trickler, W. J., Lantz, S. M., Murdock, R. C., Schrand, A. M., Robinson, B. L., Newport, G. D., Schlager, J. J., Oldenburg, S. J., Paule, M. G., Slikker, W., Jr., Hussain, S. M., and Ali, S. F. (2010). Silver nanoparticle induced blood-brain barrier inflammation and increased permeability in primary rat brain microvessel endothelial cells. Toxicol. Sci. 118(1), 160-170.

141. Urankar, R. N., Lust, R. M., Mann, E., Katwa, P., Wang, X., Podila, R., Hilderbrand, S. C., Harrison, B. S., Chen, P., Ke, P. C., Rao, A. M., Brown, J. M., and Wingard, C. J. (2012). Expansion of cardiac ischemia/reperfusion injury after instillation of three forms of multi-walled carbon nanotubes. Part Fibre. Toxicol. 9, 38. 
142. Utembe, W., Potgieter, K., Stefaniak, A. B., and Gulumian, M. (2015). Dissolution and biodurability: Important parameters needed for risk assessment of nanomaterials. Part Fibre. Toxicol. 12(1), 11.

143. Wingard, C. J., Walters, D. M., Cathey, B. L., Hilderbrand, S. C., Katwa, P., Lin, S., Ke, P. C., Podila, R., Rao, A., Lust, R. M., and Brown, J. M. (2011). Mast cells contribute to altered vascular reactivity and ischemia-reperfusion injury following cerium oxide nanoparticle instillation. Nanotoxicology. 5(4), 531-545.

144. Wittmaack, K. (2007). In search of the most relevant parameter for quantifying lung inflammatory response to nanoparticle exposure: particle number, surface area, or what? Environ. Health Perspect. 115(2), 187-194.

145. Wong, B. A. (2007). Inhalation exposure systems: design, methods and operation. Toxicol. Pathol. 35(1), 3-14.

146. Wong, M. S., and Vanhoutte, P. M. (2010). COX-mediated endothelium-dependent contractions: from the past to recent discoveries. Acta Pharmacol. Sin. 31(9), 1095-1102.

147. Woods, S. C., and Ramsay, D. S. (2007). Homeostasis: beyond Curt Richter. Appetite 49(2), 388-398.

148. Yao, M., Xiao, H., and McClements, D. J. (2014). Delivery of lipophilic bioactives: assembly, disassembly, and reassembly of lipid nanoparticles. Annu. Rev. Food Sci. Technol. 5, 53-81.

149. Yokel, R. A., Au, T. C., Macphail, R., Hardas, S. S., Butterfield, D. A., Sultana, R., Goodman, M., Tseng, M. T., Dan, M., Haghnazar, H., Unrine, J. M., Graham, U. M., Wu, P., and Grulke, E. A. (2012). Distribution, Elimination, and Biopersistence to 90 Days of a Systemically Introduced $30 \mathrm{~nm}$ Ceria-Engineered Nanomaterial in Rats. Toxicol. Sci. 127(1), 256-268.

150. Yokel, R. A., Hussain, S., Garantziotis, S., Demokritou, P., Castranova, V., and Cassee, F. R. (2014). The Yin: An adverse health perspective of nanoceria: uptake, distribution, accumulation, and mechanisms of its toxicity. Environ. Sci. Nano. 1(5), 406-428.

151. Yu, L., Scherlag, B. J., Dormer, K., Nguyen, K. T., Pope, C., Fung, K. M., and Po, S. S. (2010). Autonomic denervation with magnetic nanoparticles. Circulation 122(25), 2653-2659.

152. Yu, Y., Li, Y., Wang, W., Jin, M., Du, Z., Li, Y., Duan, J., Yu, Y., and Sun, Z. (2013). Acute toxicity of amorphous silica nanoparticles in intravenously exposed ICR mice. PLoS. One. 8(4), e61346.

153. Zareba, W., Couderc, J. P., Oberdorster, G., Chalupa, D., Cox, C., Huang, L. S., Peters, A., Utell, M. J., and Frampton, M. W. (2009). ECG parameters and 
exposure to carbon ultrafine particles in young healthy subjects. Inhal. Toxicol. 21(3), 223-233.

154. Zhang, W., Yao, Y., Sullivan, N., and Chen, Y. (2011). Modeling the primary size effects of citrate-coated silver nanoparticles on their ion release kinetics. Environ. Sci. Technol. 45(10), 4422-4428.

155. Zhang, Y., Deng, J., Zhang, Y., Guo, F., Li, C., Zou, Z., Xi, W., Tang, J., Sun, Y., Yang, P., Han, Z., Li, D., and Jiang, C. (2013). Functionalized single-walled carbon nanotubes cause reversible acute lung injury and induce fibrosis in mice. $J \mathrm{Mol}$. Med. (Berl) 91(1), 117-128.

156. Zhang, Y., Li, W., Ou, L., Wang, W., Delyagina, E., Lux, C., Sorg, H., Riehemann, K., Steinhoff, G., and Ma, N. (2012). Targeted delivery of human VEGF gene via complexes of magnetic nanoparticle-adenoviral vectors enhanced cardiac regeneration. PLoS. One. 7(7), e39490.

157. Zhu, M. T., Feng, W. Y., Wang, Y., Wang, B., Wang, M., Ouyang, H., Zhao, Y. L., and Chai, Z. F. (2009). Particokinetics and extrapulmonary translocation of intratracheally instilled ferric oxide nanoparticles in rats and the potential health risk assessment. Toxicol. Sci. 107(2), 342-351.

158. Zweifach, B. W. (1984). Pressure-flow relations in blood and lymph microcirculation. In Handbook of Physiology (Renkin E.M. and Michel C.C., Eds.), pp. 251-308. American Physiological Society, Bethesda, MD.

159. Zwicker, B. L., and Agellon, L. B. (2013). Transport and biological activities of bile acids. Int. J. Biochem. Cell Biol. 45(7), 1389-1398. 


\section{Chapter 2}

Pulmonary Cerium Dioxide Nanoparticles Exposure Differentially Impairs Coronary and Mesenteric Arteriolar Reactivity.

\section{Running Title: Cerium Dioxide and Arteriolar Reactivity}

Citation: Minarchick VC, Stapleton PA, Porter DW, Wolfarth MC, Ciftyürek E, Barger M, Sabolsky EM, Nurkiewicz TR. (2013) Pulmonary Cerium Dioxide Nanoparticle Exposure Differentially Impairs Coronary and Mesenteric Arteriolar Reactivity. Cardiovasc Toxicol. 13 (4): 323-37. PMID: 23645470

\section{Authors:}

Valerie C Minarchick 1,2

Phoebe A Stapleton ${ }^{1,2}$

Dale W Porter ${ }^{2,3}$

Michael G Wolfarth ${ }^{3}$

Engin Çiftyürek ${ }^{4}$

Mark Barger ${ }^{3}$

Edward M. Sabolsky 4

Timothy R Nurkiewicz 1,2,3

\section{Affiliations:}

1. Center for Cardiovascular and Respiratory Sciences, West Virginia University School of Medicine, Morgantown, WV 26506-9105

2. Department of Physiology and Pharmacology, West Virginia University School of Medicine, Morgantown, WV 26506

3. Pathology and Physiology Research Branch, Health Effects Laboratory Division, National Institute for Occupational Safety and Health, Morgantown, WV, 26505

4. Department of Mechanical and Aerospace Engineering, West Virginia University, Morgantown, WV 26506

Disclaimer: The findings and conclusions in this report are those of the authors and do not necessarily represent the views of the National Institute for Occupational Safety and Health 


\section{Abstract:}

Cerium dioxide nanoparticles $\left(\mathrm{CeO}_{2} \mathrm{NPs}\right)$ are an engineered nanomaterial that possesses unique catalytic, oxidative, and reductive properties. Currently, $\mathrm{CeO}_{2} \mathrm{NPs}$ are being used as a fuel catalyst but these properties are also utilized in the development of potential drug treatments for radiation and stroke protection. These uses of $\mathrm{CeO}_{2} \mathrm{NPs}$ present a risk for human exposure; however, to date no studies have investigated the effects of $\mathrm{CeO}_{2} \mathrm{NPs}$ on the microcirculation following pulmonary exposure. Previous studies in our laboratory with other nanomaterials have shown impairments in normal microvascular function after pulmonary exposures. Therefore, we predicted that $\mathrm{CeO}_{2} \mathrm{NP}$ exposure would cause microvascular dysfunction that is dependent on the tissue bed and dose. Twenty-four hour post exposure to $\mathrm{CeO}_{2} \mathrm{NPs}(0-400 \mu \mathrm{g})$, mesenteric and coronary arterioles were isolated and microvascular function was assessed. Our results provided evidence that pulmonary $\mathrm{CeO}_{2} \mathrm{NP}$ exposure impairs endothelium-dependent and independent arteriolar dilation in a dose-dependent manner. The $\mathrm{CeO}_{2} \mathrm{NP}$ exposure dose that causes a $50 \%$ impairment in arteriolar function $\left(\mathrm{EC}_{50}\right)$ was calculated and ranged from 15-100 $\mu \mathrm{g}$ depending on the chemical agonist and microvascular bed. Microvascular assessments with acetylcholine revealed a $33-75 \%$ reduction in function following exposure. Additionally, there was a greater sensitivity to $\mathrm{CeO}_{2} \mathrm{NP}$ exposure in the mesenteric microvasculature due to the $40 \%$ decrease in the calculated $\mathrm{EC}_{50}$ compared to the coronary microvasculature $\mathrm{EC}_{50} . \mathrm{CeO}_{2} \mathrm{NP}$ exposure increased mean arterial pressure in some groups. Taken together these observed microvascular changes may likely have detrimental effects on local blood flow regulation and contribute to cardiovascular dysfunction associated with particle exposure. 
Key Words: Cerium dioxide, mesentery, coronary, arteriole, microcirculation, engineered nanomaterial 


\section{Introduction:}

Engineered nanomaterials (ENM) have recently emerged both as integral components in manufacturing, and as innovative materials to address challenges in therapeutics and diagnostics, ranging from drug delivery to imaging. However, answers to questions regarding ENM toxicity remain far behind production. ENM are defined as a homogenous mixture of particles that are less than $100 \mathrm{~nm}$ in size in at least one direction, and are engineered to take advantage of unique physical characteristics displayed at this size (1). Additionally, the Environmental Protection Agency (EPA) recently recognized that ENM have different inherent characteristics and should be considered distinctly different from their larger counterparts of the same composition (2).

ENM are being developed specifically for use in food, drug delivery, and numerous industrial and household products $(3 ; 4)$. Cerium dioxide nanoparticles $\left(\mathrm{CeO}_{2} \mathrm{NPs}\right)$ have been implemented for public use, in the United States and Europe, widely as a diesel fuel additive (5). In this regard, $\mathrm{CeO}_{2}$ NPs act as a catalyst to increase combustion efficiency, which decreases the large soot emissions commonly associated with diesel engines $(5 ; 6)$. This use holds great promise in decreasing particulate matter (PM) air pollution emissions that have been historically associated with increases in cardiovascular morbidity and mortality; however, because $\mathrm{CeO}_{2} \mathrm{NPs}$ is released in emissions, a widespread inhalation hazard exists (1). Furthermore, aerosolized nano- $\mathrm{CeO}_{2}$ poses a serious environmental hazard as well. Although the half-life of $\mathrm{CeO}_{2} \mathrm{NPs}$ in water or soil is unknown, it is reasonable to speculate that $\mathrm{CeO}_{2} \mathrm{NPs}$ will remain in the environment for an indefinite amount of time due to the extreme conditions needed for degradation (7). Additionally, $\mathrm{CeO}_{2}$ NPs has been shown to be biopersistent in the body and can remain in the lungs for 
at least 15 years (8-10). This evidence supports the concept that $\mathrm{CeO}_{2} \mathrm{NPs}$ may potentially enter the water supply or food chain, ultimately posing an additional human exposure risk.

Aside from its catalytic properties, nano- $\mathrm{CeO}_{2}$ also possesses the ability to drive reduction- oxidation (redox) chemistry (11). $\mathrm{CeO}_{2} \mathrm{NPs}$ exists in two valence states $\left(\mathrm{Ce}^{3+}\right.$ and $\left.\mathrm{Ce}^{4+}\right)$ and shifts between these states by reacting with free radicals such as superoxide $(11 ; 12)$. Researchers are taking advantage of this shift between valence states and using $\mathrm{CeO}_{2}$ nanoparticles to help reduce cellular damage from radiation therapy and strokes $(13 ; 14)$.

Due to its unique properties, $\mathrm{CeO}_{2} \mathrm{NPs}$ have the potential to enter the body by multiple exposure routes (inhalation, injection, and ingestion), and may therefore pose a threat to human health (15). $\mathrm{CeO}_{2}$ nanoparticle toxicity research has focused essentially on pulmonary exposures. Pulmonary $\mathrm{CeO}_{2}$ nanoparticle exposure has been shown to increase neutrophils and eosinophils and stimulate granuloma formation in the lungs, as determined by the increase in cellular damage $(16 ; 17)$. Additionally, there has been increased alveolar macrophage activation and death after pulmonary $\mathrm{CeO}_{2} \mathrm{NP}$ exposure (16).

The microcirculation needs to be thoroughly examined following ENM exposure because normal function at this critical level of the vasculature contributes significantly to total peripheral resistance and blood flow distribution. Furthermore, many pathological conditions (e.g. hypertension and diabetes) initially manifest in the microcirculation $(18 ; 19)$. The microcirculation is broadly defined as the arterioles, capillaries and venules contained within an organ. The arterioles are primarily responsible for resistance, thereby distributing blood flow and decreasing pressure to a level that does not cause damage to downstream capillaries $(20 ; 21)$. The arterioles respond to a variety of chemical, mechanical, and 
metabolic stimuli; if these resistance vessels do not respond appropriately to these factors, a change in total peripheral resistance may occur that could alter mean arterial pressure (MAP), blood flow distribution and/or cause downstream over or under perfusion (19). The impact of $\mathrm{CeO}_{2} \mathrm{NP}$ exposure on cardiovascular function is poorly understood. This ENM has shown signs of liver toxicity, as well as vascular impairment in the aorta; however, to date, no studies have focused on identifying the impact of pulmonary $\mathrm{CeO}_{2}$ nanoparticle exposure on systemic microvascular function $(22 ; 23)$.

Previous work in our laboratory has determined that pulmonary ultrafine titanium dioxide $\left(\mathrm{TiO}_{2}\right)$ exposure causes systemic microvascular dysfunction, despite relatively minor lung inflammation; however, pulmonary inflammation following $\mathrm{CeO}_{2} \mathrm{NP}$ exposure is greater than that reported for ultrafine $\mathrm{TiO}_{2}$ at similar doses $(16 ; 24 ; 25)$. Based on these differences in inflammation, we hypothesize thatCeO ${ }_{2}$ NP exposure will impair microvascular function to a greater degree than that of ultrafine $\mathrm{TiO}_{2}$. The goals of this study were: (1) to examine the effects of pulmonary $\mathrm{CeO}_{2} \mathrm{NP}$ exposure on mesenteric and coronary arterioles and (2) to identify a dose response curve. These two microvascular beds were selected to determine if there was a difference in microvascular function after ENM exposure between microvascular beds with high (coronary) and low (mesentery) metabolic demand. Because the metabolic state of a given tissue may influence the ultimate impact of any toxicant associated mechanism, it is important to study divergent microvascular beds. 


\section{Methods and Materials:}

\section{Cerium Dioxide Nanoparticle $\left(\mathrm{CeO}_{2} \mathrm{NP}\right)$ Production and Characterization:}

$\mathrm{CeO}_{2} \mathrm{NP}$ powders were synthesized by a hydrothermal process (26). Cerium (IV) ammonium nitrate $\left(99+\%\right.$ Alfa Aesar) was added to de-ionized water $\left(\mathrm{H}_{2} \mathrm{O}\right)$ and this solution was added drop-wise into a basic solution of tetramethylammonium hydroxide pentahydrate (TMAOH) and de-ionized $\mathrm{H}_{2} \mathrm{O}$. The $\mathrm{pH}$ of the dispersion was altered to $\sim 10.5$ with ammonium hydroxide and was maintained throughout the reaction. The dispersion was placed in a $300 \mathrm{ml}$ Autoclave Engineers EZE-Seal ${ }^{\circledR}$ autoclave at $240^{\circ} \mathrm{C}$ for $1 \mathrm{~h}$. Once removed from the autoclave vessel, the dispersion was placed into a centrifuge and the liquid was removed and replaced with ethanol. After the washing step, the dispersion was dried at $60^{\circ} \mathrm{C}$ overnight and sieved through a 200 mesh screen for characterization. The synthesized $\mathrm{CeO}_{2}$ nanoparticles displayed an average surface area of $81.36 \mathrm{~m}^{2} / \mathrm{g}$ measured by Micromeritics ASAP 2020. The average agglomerate size in Normosol (isotonic saline) and $5 \%$ fetal bovine serum (FBS) was determined using dynamic light scattering (DLS) technique using a Malvern Zetasizer version 7.01.

The chemical states on the surface of the nanomaterials from the Ce $3 \mathrm{~d}$ orbital, $\mathrm{C}$ and $\mathrm{O} 1 \mathrm{~s}$ orbitals were characterized by $\mathrm{x}$-ray photoelectron spectroscopy (XPS, PHI 5000 Versaprobe XPS). The x-ray source was operated at $15 \mathrm{kV}$ and 25 watts using Al Ka (1486.6 eV) radiation. A $0.05 \mathrm{eV}$ step was used for the detailed scan. All coatings surfaces were cleaned prior to spectral analysis to remove atmospheric and post-depositional contamination with Argon ion sputter cleaning at $2 \mathrm{kV}$ accelerating voltage for $30 \mathrm{sec}$. The analysis chamber pressure was maintained at $\left(\sim 10^{-11}\right.$ Torr $)$ during the measurement. The nanomaterial morphology and agglomerate size was imaged using a JEOL JEM-2100 High Resolution Transmission Electron Microscope (TEM). 
Experimental Animals and Exposure: Male Sprague-Dawley rats (8-11 weeks old) were purchased from Hilltop Laboratories (Scottdale, PA). The rats were housed at the National Institute for Occupational Safety and Health (NIOSH) or West Virginia University animal facilities. The rats were housed in ventilated cages, under controlled humidity and temperature, with a $12 \mathrm{~h}$ light/dark cycle and food and water were provided ad libitum. The animals were acclimated for at least 2 days prior to use. All procedures were approved by the Animal Care and Use Committees at West Virginia University and $\mathrm{NIOSH}$.

$\mathrm{CeO}_{2}$ Nanoparticle Exposure: For the stock solutions, the dry powder was weighed and added to $10 \mathrm{ml}$ of saline (Normosol) with $5 \%$ (FBS) to reduce agglomeration. The $\mathrm{CeO}_{2}$ NPs were vortexed for 5 minutes and then sonicated on ice for another 5 minutes. Rats were lightly anesthetized with isoflurane gas ( $5 \%$ induction) and intratracheally instilled with a $300 \mu \mathrm{l}$ bolus dose of $\mathrm{CeO}_{2} \mathrm{NPs}$ stock solution to achieve the following final doses: 0,10 , 50, 100, 200, and $400 \mu \mathrm{g}$. Rats were monitored after instillation until they regained consciousness. All animals recovered for $24 \mathrm{~h}$ prior to bronchoalveolar lavage (BAL) or isolated microvessel experiments. Previous studies have shown that the saline and FBS vehicle do not induce mechanical artifacts in terms of BAL and systemic microcirculation in control rats $(25 ; 27)$.

Pulmonary Inflammation Assessment: A subset of 8 rats per dose $(0,10,100$, and $400 \mu \mathrm{g}$ of $\mathrm{CeO}_{2} \mathrm{NPs}$ ) were euthanized with sodium pentobarbital $(\geq 100 \mathrm{mg} / \mathrm{kg}$, intraperitoneal injection). The trachea was cannulated and BAL was performed using icecold $\mathrm{Ca}^{2+} / \mathrm{Mg}^{2+}$-free phosphate buffered saline (PBS). The first lavage $(6 \mathrm{ml})$ was kept separate from the rest of the lavage sample. Subsequent lavages used $10 \mathrm{ml}$ PBS until 40 $\mathrm{ml}$ lavage fluid was collected. The samples were centrifuged at $650 \times \mathrm{g}, 5 \mathrm{~min}$ at $4^{\circ} \mathrm{C}$. The 
supernatant from the first lavage was saved for lactate dehydrogenase (LDH) and albumin assays. The pooled cells were resuspended in HEPES-buffered medium and cell counts were determined with an electronic cell counter equipped with a cell-sizing attachment. Cytospin Preparation: $1 \times 10^{6}$ BAL cells [both alveolar macrophages (AM) and polymorphonuclear leukocytes (PMN)] in $200 \mu$ HEPES-buffered medium were prepared with a cytocentrifuge. The cytospin preparations were stained with modified Wright-Giemsa stain and cell differentials were determined by light microscopy. The differential cell counts were calculated by multiplying the total cell count by the cell differential percentage obtained from the cytospin preparations. $\underline{L D H}$ Activity and albumin protein assays: LDH and albumin measurements were taken the same day as the BAL was performed. The techniques have previously been described (28). Briefly, the LDH activity was used as a marker of cytotoxicity and was measured by monitoring the LDH driven oxidation of pyruvate coupled with the reduction of nicotinamide adenine dinucleotide at $340 \mathrm{~nm}$ using a commercial assay kit (Roche Diagnostic Systems, NJ). The concentration of albumin was monitored as an indicator of the cellular integrity. This measurement was made with a commercially available kit (Sigma Chemical Co., MO) and was based on albumin binding to bromcresol green and measuring the color change at $628 \mathrm{~nm}$. $\underline{A M \text { Chemiluminescence: }}$ Resting AM chemiluminescence was identified by incubating $1 \times 10^{6} \mathrm{AM} / \mathrm{mL}$ at $37^{\circ} \mathrm{C}$ for $20 \mathrm{~min}$, followed by the addition of luminol $(0.08 \mu \mathrm{g} / \mathrm{mL})$ and then the chemiluminescence was measured. To identify zymosan-stimulated chemiluminescence, unopsonized zymosan $(2 \mathrm{mg} / \mathrm{mL})$ was added immediately prior to measurement. All measurements were made with an automated luminometer at $390-620 \mathrm{~nm}$ for $15 \mathrm{~min}$

MAP Acquisition and Microvessel Preparation: Rats were anesthetized with isoflurane gas (5\% induction, $3-3.5 \%$ maintenance). The animals were placed on a heating pad to 
maintain a $37^{\circ} \mathrm{C}$ rectal temperature. The trachea was intubated to ensure an open airway and the right carotid artery was cannulated to acquire MAP. The MAP will be recorded via a pressure transducer and recorded by PowerLab830. The heart and/or the mesentery were removed and placed in a dissecting dish with physiological salt solution (PSS) maintained at $4^{\circ} \mathrm{C}$. Coronary arterioles from the $3^{\text {rd }}-5^{\text {th }}$ branch off the left anterior descending (LAD) artery, and $4^{\text {th }}$ or $5^{\text {th }}$ order mesenteric arterioles were isolated, transferred to a vessel chamber, cannulated between two glass pipettes, and tied with silk sutures in the vessel chamber (Living Systems Instrumentation, Burlington, VT). The chamber was superfused with fresh oxygenated $\left(5 \% \mathrm{CO}_{2} / 21 \% \mathrm{O}_{2}\right) \mathrm{PSS}$ and warmed to $37^{\circ} \mathrm{C}$. Arterioles were pressurized to $45 \mathrm{~mm} \mathrm{Hg}$ (coronary) or $80 \mathrm{~mm} \mathrm{Hg}$ (mesenteric) using a servo control system and extended to their in situ length $(29 ; 30)$. Internal and external arteriolar diameters were measured using video callipers (Colorado Video, Boulder, CO). Arteriolar Reactivity: Arterioles were allowed to develop spontaneous tone. After equilibration, various parameters of arteriolar function were analyzed. Endotheliumdependent dilation: The arterioles were exposed to increasing concentrations of acetylcholine (ACh, $10^{-9}-10^{-4} \mathrm{M}$ ) or A23187, a Ca ${ }^{2+}$ ionophore $\left(10^{-9}-10^{-5} \mathrm{M}\right)$ added to the vessel chamber. Endothelium-independent dilation: Increasing concentrations of either sodium nitroprusside (SNP, $10^{-9}-10^{-4} \mathrm{M}$ ) or a spontaneous NO donor, spermine NONOate (SPR, $10^{-9}-10^{-4} \mathrm{M}$ ) were used to assess arteriolar smooth muscle responsiveness. Myogenic Responsiveness: Myogenic responses were analyzed by increasing the intraluminal pressure by $15 \mathrm{~mm} \mathrm{Hg}$ increments from $0-90 \mathrm{~mm} \mathrm{Hg}$ for coronary arterioles and 0-105 mm Hg for mesenteric arterioles. Arteriolar Vasoconstriction: The arterioles were exposed to increasing concentrations of phenylephrine $\left(P E, 10^{-9}-10^{-4} \mathrm{M}\right)$ or serotonin (5HT, $\left.10^{-9}-10^{-4} \mathrm{M}\right)$. The steady state diameter of the vessel was recorded for at least 2 min 
after each dose. After each dose curve was completed, the vessel chamber was washed to remove excess chemicals by carefully removing the superfusate and replacing it with fresh warmed oxygenated PSS. After all experimental treatments were complete, the PSS was replaced with $\mathrm{Ca}^{2+}$-free PSS until maximum passive diameter was established. All arterioles with $\leq 20 \%$ spontaneous tone or $\geq 150 \mu \mathrm{m}$ were not analyzed.

Equations and Statistics: Data are expressed as means \pm standard error. Spontaneous tone was calculated by the following equation: Spontaneous tone $(\%)=\left[\left(D_{M}-D_{I}\right) / D_{M}\right] x$ 100 , where $D_{M}$ is the maximal diameter and $D_{1}$ is the initial steady state diameter recorded prior to the experiment. Active responses to pressure were normalized to the maximal diameter using the following formula: Normalized Diameter $=D_{S S} / D_{M}$, where Dss is the steady state diameter recorded during each pressure change. The experimental responses to ACh, A23187, SNP, and SPR are expressed using the following equation: Diameter (percent maximal response $\left.)=\left[D_{s s}-D_{\text {con }}\right) /\left(D_{M^{-}} D_{\text {con }}\right)\right] \times 100$, where $D_{\text {con }}$ is the control diameter recorded prior to the dose curve, Dss is the steady state diameter at each dose of the curve. The experimental response to PE and 5-HT are expressed using the following equation: Diameter (percent maximal response) $\left.=-\left[D_{\text {con }}-D_{s s}\right) / D_{\text {con }}\right] \times 100$. Wall thickness (WT) was calculated from the measurement of both inner (ID) and outer (OD) steady state arteriolar diameters at the end of the $\mathrm{Ca}^{2+}$ free wash using the following equation: $W T=$ $(O D-I D) / 2$. Wall-to-lumen ratio (WLR) was calculated using the following equation: $W L R=$ wall thickness (WT)/ ID. Point-to-point differences in the dose response curves were evaluated using two-way repeated measures analysis of variance (ANOVA) with a Bonferroni post-hoc analysis when significance was found. The slopes of the dose response curves were determined through a nonlinear regression. The BAL data, animal characteristics, vessel characteristics, and dose response curve slopes were analyzed 
using a one-way ANOVA with a Bonferroni post-hoc analysis when significance was found. The concentration at which a $50 \%$ impairment in function $\left(\mathrm{EC}_{50}\right)$ was determined using a four parameter logistics analysis. All statistical analysis was completed with GraphPad Prism 5 (San Diego, CA) and SigmaPlot 11.0 (San Jose, CA). Significance was set at $p<$ 0.05 . 


\section{Results:}

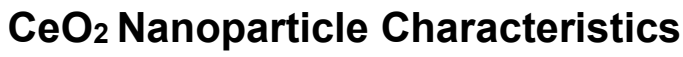

Figure 1A displays the low magnification TEM image of the particles; the micrograph shows that the dried synthesized suspension leads to a highly agglomerated state. The higher magnification micrograph (Figure 1B) shows that the primary $\mathrm{CeO}_{2}$ nanoparticles were $\sim 4 \mathrm{~nm}$ in average size with a spherical morphology and a calculated surface area of $81.36 \mathrm{~m}^{2} / \mathrm{g}$. The average agglomerate size in normosol and FBS stock solution was measured to be $191 \pm 77 \mathrm{~nm}$ with a wide Gaussian distribution (Figure 1C).

Initially, XPS data was collected for the 3d orbital photo-electron line for Ce between 870-930 eV (not shown). The deconvolution of the Ce $3 \mathrm{~d}$ orbital data is very complex due to the multiple states that exist for the Ce $4 \mathrm{f}$ orbital level occupancy (31). Therefore, the distinction of the $\mathrm{Ce}^{3+}$ and $\mathrm{Ce}^{4+}$ contribution is difficult to extract with the overlapping $\mathrm{Ce}$ $3 \mathrm{~d}$ orbital features of each $\mathrm{Ce}$ ion (7). An indirect method to separate the presence of $\mathrm{Ce}^{3+}$ and $\mathrm{Ce}^{4+}$ is through the analysis of the $\mathrm{O}$ ion through the $\mathrm{O}$ 1s orbital XPS spectra. It is known that the binding energy of $\mathrm{O}$ to $\mathrm{Ce}^{3+}$ is approximately $1-2 \mathrm{eV}$ higher than the binding energy to $\mathrm{Ce}^{4+}(7 ; 32)$. Before completing the $\mathrm{O}$ 1s orbital analysis, an XPS scan was completed between 281-294 eV to determine the state of the residual $\mathrm{C}$, and more importantly, the presence of $\mathrm{C}$ bonded to $\mathrm{O}$. As displayed in the XPS graph (Figure 2A), carbon has four different chemical states on $\mathrm{CeO}_{2} \mathrm{NPs}$ surface; the spectra identified $\mathrm{C}$ (284.7 eV), C-O (alcohols and carboxyl at $286.4 \mathrm{eV}$ and $288.4 \mathrm{eV}$, respectively) and C-N $(287.8 \mathrm{eV})$ remaining on the dried surface (33), which may be the result of surface reactions with the ammonia additives, washing process, and saline suspension in this work. This data provides evidence that the $\mathrm{O} 1 \mathrm{~s}$ orbital spectra will display a contribution of the $\mathrm{C}-\mathrm{O}$ 
bonding, and this knowledge will need to be considered in the deconvolutions of the $\mathrm{O}$ 1s orbital scan.

Figure 2B displays the XPS scan of the $\mathrm{O}$ 1s orbital scan between the binding energies of 525-538 eV. The data graph displays that oxygen has five different chemical states on the $\mathrm{CeO}_{2}$ NPs surface. As discussed for Figure 2A, the oxygen is bound within alcohols and carboxyls, but the data also provides evidence that a portion of the oxygen is also bound within various nitrates ( $534.50 \mathrm{eV}$ for $\mathrm{O} 1 \mathrm{~s}$ orbital in nitrates). It is important to note that nearly $50 \%$ of $\mathrm{O}^{-2}$ measured was bound within alcohols, carboxyls and nitrates on the $\mathrm{CeO}_{2} \mathrm{NPs}$ surface. The remaining part of the $\mathrm{O}^{-2}$ spectra was bound to $\mathrm{Ce}$. By including these contributions within the analysis, the measured XPS spectrum provides evidence that the nanomaterial surface consists of $\sim 19 \% \mathrm{Ce}^{3+}(530.6 \mathrm{eV}$ for $\mathrm{O}$ 1s orbital $\left.\mathrm{Ce}_{2} \mathrm{O}_{3}\right)$ and $\sim 81 \% \mathrm{Ce}^{4+}\left(529.1 \mathrm{eV}\right.$ for $\mathrm{O}$ 1s orbital in $\left.\mathrm{CeO}_{2}\right)$.

\section{Group Characteristics}

There were no significant differences found in body weight, age, or heart weight when comparing the control and exposed groups (Table I). A significant difference was found between the $10 \mu \mathrm{g}$ and $100 \mu \mathrm{g}$ exposure groups for MAP (Table I). There may also be a significant difference between the control group and the $100 \mu \mathrm{g}$ group $(p=0.055)$ which warrants further investigation into the changes in MAP after $\mathrm{CeO}_{2} \mathrm{NP}$ exposure.

\section{Pulmonary Inflammation}

BAL was performed to assess pulmonary inflammation post $\mathrm{CeO}_{2} \mathrm{NP}$ exposure. There was a significant increase in LDH $24 \mathrm{~h}$ post instillation in the 100 and $400 \mu \mathrm{CeO}_{2}$ NP exposure groups (Figure 3A). This indicated an increase in cytotoxicity; however, there was no change in albumin indicating the epithelial-endothelium gas exchange barrier was intact (Figure 3B). The activation of AM was also measured through zymogen stimulated 
chemiluminescence. There was a significant increase in the activated AM after exposure to 100 and $400 \mu \mathrm{geO}_{2} \mathrm{NPs}$ (Figure 3C). Finally, there was a significant increase in PMNs in the groups exposed to the two highest doses of $\mathrm{CeO}_{2} \mathrm{NPs}$ (Figure 3D). Taken together, these data provide evidence that dose-dependent pulmonary inflammation is present after exposure to $\mathrm{CeO}_{2} \mathrm{NPs}$.

\section{Vessel Characteristics}

There were no significant differences in vessel size, spontaneous tone, wall to lumen ratio or wall thickness between the control and exposed coronary arterioles; similar results were obtained in the mesenteric arterioles (Table II). This provides evidence that basal arteriolar tone and/or anatomy are not affected after $\mathrm{CeO}_{2} \mathrm{NP}$ exposure. However, this assessment was made in vitro, and while the effects on basal tone in vivo may be different; this assessment is outside the scope of this manuscript.

\section{Endothelium-Dependent Dilation}

Endothelium-dependent dilation was stimulated with increasing concentrations of either ACh or A23187. There was a reduced endothelium-dependent response to ACh in coronary and mesenteric arterioles (Figure $\mathbf{3 A}$ and $\mathbf{B}$ ). Additionally, from the $\mathrm{CeO}_{2} \mathrm{NP}$ dose response curve, $100 \mu \mathrm{geO}_{2} \mathrm{NPs}$ were determined to be maximum effect dose in the mesenteric arterioles (Figure 4A) and $200 \mu \mathrm{g} \mathrm{CeO} 2$ NPs in coronary arterioles (Figure 4B). The lowest observable dose could not be determined based on the concentrations used for these experiments (Figure 4A and B).

Because ACh activates additional pathways other than nitric oxide (NO) production, A23187, a $\mathrm{Ca}^{2+}$ iontophore, was also used to more directly activate nitric oxide synthase (NOS). Arterioles from both microvascular beds showed a significant impairment in responsiveness to increasing concentrations of A23187 (Figure 5A and B). When 
analyzing the responses to $\mathrm{A} 23187$ for mesenteric microvessels, it was noted that at $1 \mathrm{x}$ $10^{-5} \mathrm{M}$, the arterioles constricted. This may indicate that either exposure to $\mathrm{CeO}_{2} \mathrm{NPs}$ alters the arterioles sensitivity of A23187 or this concentration of A23187 is stimulating greater changes in smooth muscle intracellular $\mathrm{Ca}^{2+}$, which would promote constriction (Figure 5A). Due to this constriction, $1 \times 10^{-6} \mathrm{M}$ was used to determine the maximum effect dose $(200 \mu \mathrm{g})$ of $\mathrm{CeO}_{2} \mathrm{NPs}$ for mesenteric arterioles. The constriction, at $1 \times 10^{-5} \mathrm{M}$ was not observed in the coronary arterioles; therefore this concentration of A23187 was used to determine the maximum effect dose $(200 \mu \mathrm{g})$ of $\mathrm{CeO}_{2} \mathrm{NPs}$. Taken together, these data provided evidence of an impaired endothelium-dependent dilation after $\mathrm{CeO}_{2} \mathrm{NP}$ exposure.

\section{Endothelium-Independent Dilation}

Vascular smooth muscle (VSM) NO sensitivity was assessed with the NO donor, SNP. In both coronary and mesenteric arterioles, there was a decreased NO sensitivity 24 h after exposure to $100 \mu \mathrm{CeO}_{2}$ NPs (Figure 6A and B), which impairs the arterioles ability to dilate. However, since SNP needs to contact a biological membrane in order to release NO, we also used a spontaneous NO donor, SPR, to exclude the possibility that the results obtained from SNP were due to the differential release of NO from SNP (34). A similar attenuated dilation was observed in response to SPR (Figure 7A and B). This response appeared to be dependent on the $\mathrm{CeO}_{2} \mathrm{NP}$ dose and the maximal effect dose for both microvascular beds was $200 \mu \mathrm{g} \mathrm{CeO} 2$ NPs (Figure 7A and B). Taken together, the data for the NO donor provides evidence that impaired endothelium-independent dilation may be attributed to a decrease in $\mathrm{NO}$ sensitivity after $\mathrm{CeO}_{2} \mathrm{NP}$ exposure.

\section{Vasoconstriction}

Arteriolar vasoconstriction was assessed initially by exposing the vessel to the $\alpha$ adrenergic receptor agonist, PE. There were no significant differences in the response to 
increases in PE regardless of $\mathrm{CeO}_{2} \mathrm{NP}$ concentration or microvascular bed (Figure 8A and B). Since PE is a poor vasoconstrictor in the coronary vasculature, a more equitable vasoconstrictor was also used. Serotonin caused a constriction in both microvascular beds (Figure 9A and B). There were no significant differences in mesenteric arterioles, but there was an augmented response in coronary arterioles after pulmonary exposure to $400 \mu \mathrm{g}$ $\mathrm{CeO}_{2} \mathrm{NPs}$ (Figure 9A and B). These data provide evidence that adrenergic and 5-HT sensitivity are intact after exposure to $\mathrm{CeO}_{2} \mathrm{NPs}$.

\section{$\mathrm{CeO}_{2}$ Nanoparticle $\mathrm{EC}_{50}$}

The calculated $\mathrm{EC}_{50}$ was determined for each agonist and ranged from 15 to 101 $\mu \mathrm{g}$ of $\mathrm{CeO}_{2}$ NPs (Table III). The $\mathrm{EC}_{50}$ was dependent on not only the chemical agonist, but also the microvascular bed. The differential $\mathrm{EC}_{50}$ may be attributed to the different metabolic demands of the tissue beds investigated and/or direct or indirect exposure toCeO 2 NPs.

\section{Myogenic Responsiveness}

Independent of microvascular bed or $\mathrm{CeO}_{2} \mathrm{NP}$ exposure, the arterioles responded similarly to changes in transmural pressure (Figure 10A and B). These data provide evidence that the arteriolar myogenic responsiveness is intact after $\mathrm{CeO}_{2} \mathrm{NP}$ instillation. 


\section{Discussion}

This study is the first to investigate the influence of pulmonary $\mathrm{CeO}_{2} \mathrm{NP}$ exposure on microvascular function. The major finding of this paper is: microvascular dysfunction follows pulmonary $\mathrm{CeO}_{2} \mathrm{NP}$ exposure, characterized by impaired endothelium-dependent and -independent dilation.

One of the primary objectives of this investigation was to determine the microvascular function following $\mathrm{CeO}_{2} \mathrm{NP}$ exposure at occupationally relevant doses. To accomplish this, rats were exposed by IT instillation to $\mathrm{CeO}_{2} \mathrm{NP}$ doses which ranged up to $400 \mu \mathrm{g}$ per rat. In order to evaluate the relevance of the doses used in this in vivo rat study to humans, we need to determine if the $\mathrm{CeO}_{2} \mathrm{NP}$ doses tested in rats are relevant to human exposures. With a rat alveolar epithelium surface area of $0.4 \mathrm{~m}^{2}$ (35), the $400 \mu \mathrm{g} \mathrm{CeO} 2 \mathrm{NP}$ lung burden would result in $1 \mathrm{mg} \mathrm{CeO} / \mathrm{m}^{2}$ alveolar epithelium. For a $5 \mu \mathrm{g} / \mathrm{m}^{3}$ aerosol of $\mathrm{CeO}_{2} \mathrm{NPs}$ with a mass median aerodynamic diameter $(\mathrm{MMAD})=1.5 \mu \mathrm{m}$, minute ventilation of $20 \mathrm{~L} /$ minute for a person performing light work (36), a deposition fraction of $30 \%$ (37) and human alveolar epithelium surface area of $102 \mathrm{~m}^{2}$ (35), the $400 \mu \mathrm{g} \mathrm{CeO} 2 \mathrm{NP}$ lung burden in rat approximates deposition for a person performing light work for 30 years (assuming 240 work days per year). Currently, no exposure limits for $\mathrm{CeO}_{2}$ have been set by OSHA, and thus the Permissible Exposure Limit (PEL) for $\mathrm{CeO}_{2}$ is that for Particulates Not Otherwise Regulated (PNOR), which is $5 \mathrm{mg} / \mathrm{m}^{3}$ for the respirable fraction. Thus, the highest rat $\mathrm{CeO}_{2} \mathrm{NP}$ dose in this study approximates a human working for 30 years at an exposure level 1,000-fold below the current OSHA PEL for $\mathrm{CeO}_{2}$. The current study focused on identifying the microvascular effects in young healthy male rats, representative of a similar human population; however, we speculate that human populations with increased susceptibility to cardiovascular disease (i.e. age, smoking, 
diagnosed cardiovascular risk factors), the observed microvascular dysfunction may appear more severe or appear at lower lung burdens than those in this study.

$\mathrm{BAL}$ analysis revealed the presence of pulmonary inflammation following $\mathrm{CeO}_{2} \mathrm{NP}$ exposure in a dose dependent manner. The change in inflammatory status after pulmonary $\mathrm{CeO}_{2} \mathrm{NP}$ exposure was similar to previously reported studies that found an increase in $\mathrm{LDH}, \mathrm{AM}$ activation and PMN infiltration $24 \mathrm{~h}$ after exposure, however, an increase in albumin in the BAL fluid after $\mathrm{CeO}_{2} \mathrm{NP}$ exposure has been reported (16). In our study, the lack of an increase in albumin in the BAL fluid indicates that the lung epithelial-endothelial barrier is intact, and a similar lack of albumin was observed with low doses of $\mathrm{TiO}_{2}$ and residual oil fly ash (ROFA) (25). These differences in the inflammatory profile may be due to changes in the valence state of $\mathrm{CeO}_{2} \mathrm{NPs}$; however, alterations in the $\mathrm{Ce}^{3+} / \mathrm{Ce}^{4+}$ concentration is difficult to monitor in a biologic system, due to the ability of $\mathrm{CeO}_{2} \mathrm{NPs}$ to readily switch between these two valences (11). Because $\mathrm{CeO}_{2} \mathrm{NPs}$ exist in two states, and each state appears to influence different biological outcomes, the role of $\mathrm{Ce}^{3+} / \mathrm{Ce}^{4+}$ warrants further investigation, but is currently outside the scope of this study $(11 ; 12)$.

The results of this study have shown the presence of microvascular dysfunction following $\mathrm{CeO}_{2} \mathrm{NP}$ exposure even in the absence of overt pulmonary inflammation (Figure 3). Previous studies have also shown microvascular dysfunction despite relatively minor inflammation following exposure to ROFA and fine $\mathrm{TiO}_{2}(38)$. This suggests that pulmonary inflammation is not a pre-requisite for systemic dysfunction; however, because at high doses of particles pulmonary and systemic effects are present, it is important to assess the inflammatory state of the lungs. Additionally, it is reasonable to speculate that pulmonary inflammation is not significantly influencing systemic microvascular function at low doses 
of $\mathrm{CeO}_{2} \mathrm{NPs}(10 \mu \mathrm{g})$ but does, at least in part, influence microvascular function at higher doses of $\mathrm{CeO}_{2} \mathrm{NPs}(100$ and $400 \mu \mathrm{g})$.

The sizes of the agglomerates are relevant to occupational and environmental exposures. Studies with particulate matter and diesel exhaust particles have shown that agglomerates between 100 and $1000 \mathrm{~nm}$ deposit in the lungs, however only particles 250 $n m$ or less preferentially deposit in the respiratory zone of the lungs $(15 ; 39)$. Therefore, the agglomerates in this study are capable of reaching the respiratory zone of the lungs.

Normal microvascular function was assessed by endothelium-dependent dilation and -independent dilation, VSM constriction, and myogenic responsiveness. VSM constriction and myogenic responsiveness appear to be intact in both microvascular beds regardless of the dose of $\mathrm{CeO}_{2} \mathrm{NPs}$ used and is consistent with previously reported nanomaterials $(27 ; 40 ; 41)$. This may be due to overlapping VSM signaling cascades in response to these stimuli. In regards to normal arteriolar dilation, our results provide evidence that there is a significantly impaired response to endothelium-dependent dilators, ACh and A23187. This response was consistent with microvascular impairments that were observed $24 \mathrm{~h}$ after pulmonary exposure to multi-walled carbon nanotubes, ultrafine $\mathrm{TiO}_{2}$, and PM $(27 ; 40 ; 41)$. However, exposure to $\mathrm{CeO}_{2}$ NPs also produced an unique endothelium-independent impairment in coronary and mesenteric arterioles.

Endothelium-independent dysfunction following particle exposure was first observed in pulmonary arteries following PM exposure by Courtois et al. (42), and this finding is now extended to the systemic microcirculation after $\mathrm{CeO}_{2} \mathrm{NP}$ exposure. The results in this study provide evidence that arteriolar VSM NO sensitivity is altered after $\mathrm{CeO}_{2} \mathrm{NP}$ exposure. Because PM and ENM are fundamentally different the likelihood of disparate mechanisms is high. This warrants further investigation to the mechanism(s) of 
$\mathrm{CeO}_{2} \mathrm{NP}$ exposure, which may potentially be linked to alterations in NO bioavailability, signaling and/or sensing.

The observed microvascular dysfunction could be due to either impaired NO production, a shift in arachindonic acid metabolites, impaired VSM or a combination of the three. The use of A23187 specifically examined endothelium NO production, however, VSM impairments to NO may interfere with these results. Therefore, at this time we cannot definitely determine the role of NO production and shifts in arachindonic acid metabolites in the observed microvascular dysfunction. Future experiments, using inhibitors and denuted arterioles, are necessary to definitely determine the influence of these factors. In this study, we can infer that the endothelium is at least partially functional because after stimulation with the $\mathrm{Ca}^{2+}$ iontophore $\mathrm{A} 23187$ there is an impaired dilation. Without this limited endothelial function, the A23187 would act primarily on the VSM, resulting in a net constriction. Typically, NO is released from the endothelial cells as a byproduct of Larginine conversion to L-citrulline. The NO then defuses to adjacent smooth muscle where it interacts with soluble guanylyl cyclase and activates a signaling cascade that ultimately sequesters $\mathrm{Ca}^{2+}$ and causes smooth muscle relaxation. A disruption at any point in this pathway may result in a blunted dilation. One such disruption could be an increase of hemoglobin $\alpha$ in the endothelial cell, in this study the level of hemoglobin $\alpha$ is inversely proportional to NO bioavailability (43). In this case, if hemoglobin a concentration is increased, endothelium derived NO could be bound to hemoglobin $\alpha$; thus reducing NO bioavailiblity, which could contribute to an impaired dilation. Alternatively, when hemoglobin $\alpha$ binds NO the iron valence state changes, which is interestingly similar to the valence state changes of $\mathrm{CeO}_{2} \mathrm{NPs}(43)$. If $\mathrm{CeO}_{2}$ nanoparticles translocate, it is reasonable 
to speculate that $\mathrm{CeO}_{2}$ nanoparticles may also bind available $\mathrm{NO}$ thus decreasing $\mathrm{NO}$ bioavailability It remains to be determined if this is the case for $\mathrm{CeO}_{2} \mathrm{NP}$ exposures.

A previous study attributed the VSM dysfunction following PM exposure to changes in the inflammatory state of the animals, independent of changes in oxidative stress; whereas others have attributed impaired microvascular dysfunction to changes in oxidative stress $(40 ; 42)$. The relationship between $\mathrm{CeO}_{2} \mathrm{NPs}$ and changes in oxidative stress warrants further investigation. Due to the changes in valence state, $\mathrm{CeO}_{2} \mathrm{NPs}$ has the ability to react with free radicals like superoxide, thus decreasing the level of oxidative stress (12). Others have indicated that the level of free radicals increases after exposure (44). Therefore, local oxidative stress must be assessed in the vascular wall to determine its influence after exposure and if these changes affect reactivity.

In this study, it is important to note that there are distinct differences in microvascular function and sensitivity between mesenteric and coronary arterioles. This illustrates the importance of selecting the most appropriate microvascular bed for a given research question because the findings from one microvascular bed may not be implicitly extrapolated to another bed. These functional changes may arise from inherent differences between the two microvascular bed such as time blood supply is received (systolic vs. diastolic), metabolic demand (low vs. high), and response to changes in blood flow (varying vs. constant). Each microvascular bed studied in this manuscript is of equal importance but may be influenced by differing mechanisms. Additionally, modest changes in the coronary microvasculature can result dire consequences for the heart due to local ischemia; however, this same local ischemia maybe associated with less deleterious effects in the mesentery where the microcirculation is accustom to changing blood flow and oxygen levels. 
Alterations in microvascular function can have serious health consequences. Notable common pathologies such as hypertension and diabetes initiate at the microvascular level as a result of endothelial dysfunction (18). Of the many ENM we have studied, $\mathrm{CeO}_{2} \mathrm{NPs}$ are the first ENM we have observed to cause a significant increase in MAP (Table I). This change in MAP may be a consequence of the observed alterations in smooth muscle sensitivity to NO. MAP may also be influenced by changes in total peripheral resistance and/or changes in cardiac output. The current ex vivo experimental plan cannot accurately assess cardiac output, total peripheral resistance or their interdependency. Thus, in vivo experiments that address these potential outcomes must to be performed in the future. Alternatively, this change in MAP at the $100 \mu \mathrm{g}$ dose may also be a consequence of changes in autonomic control as a result of $\mathrm{CeO}_{2} \mathrm{NP}$ exposure. Evidence of this potential change may be represented by the lack of an increase in MAP at higher doses. In order assess changes in MAP future studies should use chronic arterial pressure monitoring to determine the influence of dose, time, and mechanistic interactions.

The microvascular dysfunction observed at the $10 \mu \mathrm{g}$ exposure may also be due to direct exposure and/or changes in autonomic control. It has been reported that dependent on the time after pulmonary exposure, 20 to $50 \%$ of the ENM can be cleared from the lungs $(45 ; 46)$. These cleared nanomaterials have several potential fates. The ENM may transition into the systemic blood stream directly from the lung or they may be cleared via the mucociliary escalator $(45 ; 46)$. In animals, ENM cleared from the lungs are ingested and can be either absorbed into the blood, excreted in feces, or remain in the gut wall $(45 ; 46)$. The clearance of $\mathrm{CeO}_{2} \mathrm{NPs}$ from the lungs is significant because it may account for the differences in the calculated $\mathrm{EC}_{50}$ for the vascular beds. The mesenteric arterioles may be exposed both directly and indirectly to the effects of $\mathrm{CeO}_{2}$, NPs whereas the coronary 
arterioles are only indirectly exposed to $\mathrm{CeO}_{2} \mathrm{NPs}$. Additionally, the clearance of $\mathrm{CeO}_{2}$ NPs is significant because calculated lung exposure would be less than reported; however, it should also be noted that the actual deposition in the lungs of $\mathrm{CeO}_{2} \mathrm{NPs}$ post-24 $\mathrm{h}$ was not calculated in this investigation.

In conclusion, this study provides evidence that pulmonary $\mathrm{CeO}_{2} \mathrm{NP}$ exposure causes alterations in MAP, in addition to endothelium-dependent and -independent arteriolar impairment. The mechanism underlying this dysfunction warrants further investigation due to the many potential uses of this ENM that may benefit human health. Additionally, alternate exposure routes must be investigated to determine if this response is unique to the lung exposures. 
Acknowledgments: The authors would like to thank Carroll McBride and Kimberly Wix for their expert technical assistance in this study. The authors would also like to thank Katarzyna Sabolsky for assistance with the TEM characterization of the $\mathrm{CeO}_{2}$ nanoparticles. This work is supported by the National Institutes of Health RO1-ES015022, RC1-ES018274 (TRN), F32-ES023435 (PAS) and the National Science Foundation Cooperative Agreement- 1003907 (TRN and VCM). 


\section{Figure Legends:}

Figure 1: TEM Images of $\mathrm{CeO}_{2}$ nanoparticles at A) low magnification $\mathrm{B}$ ) high magnification. Red dashes indicate individual particles that were estimated to be 4-6 $\mathrm{nm}$. C) DLS distribution curve of the suspended $\mathrm{CeO}_{2} \mathrm{NPs}$ with an average agglomerate size for peak 1: $191 \pm 77 \mathrm{~nm}$; peak 1: $901 \pm 391 \mathrm{~nm}$; peak 3: $5081 \pm 566 \mathrm{~nm}$.

Figure 2: XPS Spectra of the hydrothermally synthesized and dried $\mathrm{CeO}_{2}$ nanoparticles with deconvoluted peaks using a Gaussian fit A) C 1s B) O 1s.

Figure 3: Pulmonary inflammation was altered after exposure to $\mathrm{CeO}_{2} \mathrm{NPs}$. There was a significant increase in LDH (A), AM activation (C), and PNM inflitration (D). However, there was no change in albumin (B) levels after exposure. Values are means $\pm S E . \dagger p \leq 0.05$ vs. control; ${ }^{\wedge} p \leq 0.05$ vs. $100 \mu \mathrm{g} \mathrm{CeO} 2$ NPs.

Figure 4: $A C h-i n d u c e d$ vasodilation was impaired in mesenteric $(A ; n=8-13)$ and coronary (B; $n=7-9)$ arterioles from groups $24 \mathrm{hr}$ post-exposure to $\mathrm{CeO}_{2} \mathrm{NPs}$. Values are means \pm SE. $† p \leq 0.05$ vs. control; ${ }^{*} p \leq 0.05$ vs. $10 \mu g \mathrm{CeO}_{2}$ NPs. The right panel represents the responses of the various doses of $\mathrm{CeO}_{2} \mathrm{NPs}$ and was analyzed by nonlinear regression. The left panel highlights the point-to-point differences between the control and $\mathrm{CeO}_{2} \mathrm{NP}$ exposed group.

Figure 5: The $\mathrm{Ca}^{2+}$ iontophore (A23187)-induced vasodilation was impaired in mesenteric $(A ; n=6-11)$ and coronary ( $B ; n=6-8)$ arterioles from groups $24 \mathrm{~h}$ post-exposure to $\mathrm{CeO}_{2}$ NPs. Values are means \pm SE. $\dagger p \leq 0.05$ vs. control. The right panel represents the 
responses of the various doses of $\mathrm{CeO}_{2} \mathrm{NPs}$ and was analyzed by nonlinear regression. The left panel highlights the point-to-point differences between the control and $\mathrm{CeO}_{2} \mathrm{NP}$ exposed group.

Figure 6: SNP-induced vasodilation was impaired in mesenteric $(A ; n=9-11)$ and coronary (B; $n=6-13$ ) arterioles from groups $24 \mathrm{~h}$ post-exposure to $\mathrm{CeO}_{2} \mathrm{NPs}$. Values are means \pm SE. $\uparrow p \leq 0.05$ vs. control.

Figure 7: SPR-induced vasodilation was impaired in mesenteric $(A ; n=6-12)$ and coronary $(\mathrm{B} ; \mathrm{n}=6-8)$ arterioles from groups $24 \mathrm{~h}$ post-exposure to $\mathrm{CeO}_{2} \mathrm{NPs}$. Values are means \pm SE. $\uparrow p \leq 0.05$ vs. control; ${ }^{*} p \leq 0.05$ vs. $10 \mu \mathrm{CeO}_{2} \mathrm{NPs} ; \ddagger p \leq 0.05$ vs. $50 \mu \mathrm{geO}_{2} \mathrm{NPs}^{\wedge}{ }^{\wedge}$ $p \leq 0.05$ vs. $100 \mu \mathrm{geO}_{2}$ NPs. The right panel represents the responses of the various doses of $\mathrm{CeO}_{2} \mathrm{NPs}$ and was analyzed by nonlinear regression. The left panel highlights the point-to-point differences between the control and $\mathrm{CeO}_{2} \mathrm{NP}$ exposed group.

Figure 8: PE-induced vasoconstriction was not significantly impaired in mesenteric $(A$; $n=5-13)$ and coronary ( $B ; n=6-9)$ arterioles from groups 24 h post-exposure to $\mathrm{CeO}_{2} \mathrm{NPs}_{\text {. }}$ Values are means \pm SE. The right panel represents the responses of the various doses of $\mathrm{CeO}_{2} \mathrm{NPs}$ and was analyzed by nonlinear regression. The left panel highlights the pointto-point differences between the control and $\mathrm{CeO}_{2} \mathrm{NP}$ exposed group.

Figure 9: 5-HT-induced vasoconstriction was not significantly impaired in mesenteric (A; $n=6-10)$ arterioles. An attenuated response was observed only in coronary (B; $n=6-8)$ arterioles from groups $24 \mathrm{~h}$ post-exposure to $400 \mu \mathrm{g} \mathrm{CeO} 2 \mathrm{NPs}$. Values are means SE. $\ddagger$ 
$p \leq 0.05$ vs. $50 \mu \mathrm{g} \mathrm{CeO}_{2} \mathrm{NPs}^{\wedge}{ }^{\wedge} p \leq 0.05$ vs. $100 \mu \mathrm{gCeO}_{2}$ NPs. The right panel represents the responses of the various doses of $\mathrm{CeO}_{2} \mathrm{NPs}$ and was analyzed by nonlinear regression. The left panel highlights the point-to-point differences between the control and $\mathrm{CeO}_{2} \mathrm{NP}$ exposed group.

Figure 10: Myogenic responsiveness was not impaired in mesenteric $(A ; n=10-15)$ and coronary $(B ; n=6-9)$ arterioles from groups 24 h post-exposure to $\mathrm{CeO}_{2} \mathrm{NPs}$. Values are means $\pm \mathrm{SE}$. The right panel represents the responses of the various doses of $\mathrm{CeO}_{2} \mathrm{NPs}$ and was analyzed by nonlinear regression. The left panel highlights the point-to-point differences between the control and $\mathrm{CeO}_{2} \mathrm{NP}$ exposed group. 


\section{Reference List:}

1. Borm, P. J., Robbins, D., Haubold, S., Kuhlbusch, T., Fissan, H., Donaldson, K., Schins, R., Stone, V., Kreyling, W., Lademann, J., Krutmann, J., Warheit, D., and Oberdorster, E. (2006). The potential risks of nanomaterials: a review carried out for ECETOC. Part Fibre Toxicol. 3:11.

2. Hanson N, Harris J, Joseph LA, Ramakrishnan K, Thompson T. EPA Needs to Manage Nanomaterial Risks More Effectively. 2011. Report No.: 12-P-0162.

3. Borm, P. J., Muller-Schulte, D. (2006). Nanoparticles in drug delivery and environmental exposure: same size, same risks? Nanomedicine (Lond). 1 (2):235-49.

4. Aitken, R. J., Chaudhry, M. Q., Boxall, A. B., and Hull, M. (2006). Manufacture and use of nanomaterials: current status in the UK and global trends. Occup Med (Lond). 56 (5):300-6.

5. Cassee, F. R., van Balen, E. C., Singh, C., Green, D., Muijser, H., Weinstein, J., and Dreher, K. (2011). Exposure, health and ecological effects review of engineered nanoscale cerium and cerium oxide associated with its use as a fuel additive. Crit Rev Toxicol. 41 (3):213-29.

6. Cassee, F. R., Campbell, A., Boere, A. J., McLean, S. G., Duffin, R., Krystek, P., Gosens, I., and Miller, M. R. (2012). The biological effects of subacute inhalation of diesel exhaust following addition of cerium oxide nanoparticles in atherosclerosisprone mice. Environ Res. 115:1-10.

7. Preisler EJ, Marsh OJ, Beach RA, and McGill TC. (2001). Stability of cerium oxide on silicon studied by $x$-ray photoelectron spectroscopy. Journal of Vacuum Science and Technology B. 19 (4):1611-8.

8. Geraets, L., Oomen, A. G., Schroeter, J. D., Coleman, V. A., and Cassee, F. R. (2012). Tissue distribution of inhaled micro- and nano-sized cerium oxide particles in rats: results from a 28-day exposure study. Toxicol Sci. 127 (2):463-73.

9. Yokel, R. A., Au, T. C., Macphail, R., Hardas, S. S., Butterfield, D. A., Sultana, R., Goodman, M., Tseng, M. T., Dan, M., Haghnazar, H., Unrine, J. M., Graham, U. M., Wu, P., and Grulke, E. A. (2012). Distribution, Elimination, and Biopersistence to 90 Days of a Systemically Introduced $30 \mathrm{~nm}$ Ceria-Engineered Nanomaterial in Rats. Toxicol Sci. 127 (1):256-68. 
10. Pairon, J. C., Roos, F., Sebastien, P., Chamak, B., bd-Alsamad, I., Bernaudin, J. F., Bignon, J., and Brochard, P. (1995). Biopersistence of cerium in the human respiratory tract and ultrastructural findings. Am J Ind Med. 27 (3):349-58.

11. Celardo, I., Traversa, E., and Ghibelli, L. (2011). Cerium oxide nanoparticles: a promise for applications in therapy. J Exp Ther Oncol. 9 (1):47-51.

12. Heckert, E. G., Karakoti, A. S., Seal, S., and Self, W. T. (2008). The role of cerium redox state in the SOD mimetic activity of nanoceria. Biomaterials. 29 (18):2705-9.

13. Colon, J., Herrera, L., Smith, J., Patil, S., Komanski, C., Kupelian, P., Seal, S., Jenkins, D. W., and Baker, C. H. (2009). Protection from radiation-induced pneumonitis using cerium oxide nanoparticles. Nanomedicine. 5 (2):225-31.

14. Kim, C. K., Kim, T., Choi, I. Y., Soh, M., Kim, D., Kim, Y. J., Jang, H., Yang, H. S., Kim, J. Y., Park, H. K., Park, S. P., Park, S., Yu, T., Yoon, B. W., Lee, S. H., and Hyeon, T. (2012). Ceria nanoparticles that can protect against ischemic stroke. Angew Chem Int Ed Engl. 51 (44):11039-43.

15. Stapleton, P. A., Minarchick, V. C., McCawley, M., Knuckles, T. L., and Nurkiewicz, T. R. (2011). Xenobiotic Particle Exposure and Microvascular Endpoints: A Call to Arms. Microcirculation.

16. Ma, J. Y., Zhao, H., Mercer, R. R., Barger, M., Rao, M., Meighan, T., Schwegler-Berry, D., Castranova, V., and Ma, J. K. (2011). Cerium oxide nanoparticle-induced pulmonary inflammation and alveolar macrophage functional change in rats. Nanotoxicology. 5 (3):312-25.

17. Toya, T., Takata, A., Otaki, N., Takaya, M., Serita, F., Yoshida, K., and Kohyama, N. (2010). Pulmonary toxicity induced by intratracheal instillation of coarse and fine particles of cerium dioxide in male rats. Ind Health. 48 (1):3-11.

18. Schwartzkopff, B., Mundhenke, M., and Strauer, B. E. (1998). Alterations of the architecture of subendocardial arterioles in patients with hypertrophic cardiomyopathy and impaired coronary vasodilator reserve: a possible cause for myocardial ischemia. J Am Coll Cardiol. 31 (5):1089-96.

19. Prewitt, R. L., Rice, D. C., and Dobrian, A. D. (2002). Adaptation of resistance arteries to increases in pressure. Microcirculation. 9 (4):295-304. 
20. Zweifach, B.W. (1984). Pressure-flow relations in blood and lymph microcirculation, in Handbook of Physiology. (Renkin EM, Michel CC, eds.), American Physiological Society, Bethesda, MD, pp. 251-308.

21. Renkin EM. (1984). Control of microcirculation and blood-tissue exchange, in Handbook of Physiology. (Renkin EM, Michel CC, eds.), American Physiology Society, Bethesda, MD, pp. 627-87.

22. Wingard, C. J., Walters, D. M., Cathey, B. L., Hilderbrand, S. C., Katwa, P., Lin, S., Ke, P. C., Podila, R., Rao, A., Lust, R. M., and Brown, J. M. (2011). Mast cells contribute to altered vascular reactivity and ischemia-reperfusion injury following cerium oxide nanoparticle instillation. Nanotoxicology. 5 (4):531-45.

23. Nalabotu, S. K., Kolli, M. B., Triest, W. E., Ma, J. Y., Manne, N. D., Katta, A., Addagarla, H. S., Rice, K. M., and Blough, E. R. (2011). Intratracheal instillation of cerium oxide nanoparticles induces hepatic toxicity in male Sprague-Dawley rats. Int J Nanomedicine. 6:2327-35.

24. LeBlanc, A. J., Cumpston, J. L., Chen, B. T., Frazer, D., Castranova, V., and Nurkiewicz, T. R. (2009). Nanoparticle inhalation impairs endothelium-dependent vasodilation in subepicardial arterioles. J Toxicol Environ Health A. 72 (24):1576-84.

25. Nurkiewicz, T. R., Porter, D. W., Barger, M., Millecchia, L., Rao, K. M., Marvar, P. J., Hubbs, A. F., Castranova, V., and Boegehold, M. A. (2006). Systemic microvascular dysfunction and inflammation after pulmonary particulate matter exposure. Environ Health Perspect. 114 (3):412-9.

26. Tok AIY, Du SW, Boey FYC, and Chong WK. (2013). Hydrothermal sysnthesis and characterization of rare earth doped ceria nanoparticles. Mater Sci Eng. (466):223-9.

27. Nurkiewicz, T. R., Porter, D. W., Barger, M., Castranova, V., and Boegehold, M. A. (2004). Particulate matter exposure impairs systemic microvascular endotheliumdependent dilation. Environ Health Perspect. 112 (13):1299-306.

28. Porter, D. W., Barger, M., Robinson, V. A., Leonard, S. S., Landsittel, D., and Castranova, V. (2002). Comparison of low doses of aged and freshly fractured silica on pulmonary inflammation and damage in the rat. Toxicology. 175 (1-3):63-71.

29. Sun, D., Messina, E. J., Kaley, G., and Koller, A. (1992). Characteristics and origin of myogenic response in isolated mesenteric arterioles. Am J Physiol. 263 (5 Pt 2):H1486-H1491. 
30. Chilian, W. M., Eastham, C. L., and Marcus, M. L. (1986). Microvascular distribution of coronary vascular resistance in beating left ventricle. Am J Physiol. 251 (4 Pt 2): $\mathrm{H} 779-\mathrm{H} 788$.

31. Kotani A, Jo T, and Parlebas JC. (2013). Many-body effects in core-level spectroscopy of rare-earth compounds. Adv Phys. 37:8952-61.

32. Burroughs P, Hamnett A, Orchard AF, and Thomton G. (2013). Satellite structure in the X-ray photoelectron spectra of some binary and mixed oxides of lanthanum and cerium. J Chem Soc Dalton Trans. 17:1686-98.

33. Kumar S, Butcher KSA, and Tansley TL. (2013). X-ray photoelectron spectroscopy characterization of radio frequency reactively sputtered carbon nitride thin films. J Vac Sci Technol A. 14 (5):2687-92.

34. Grossi, L., D'Angelo, S. (2005). Sodium nitroprusside: mechanism of NO release mediated by sulfhydryl-containing molecules. J Med Chem. 48 (7):2622-6.

35. Stone, K. C., Mercer, R. R., Gehr, P., Stockstill, B., and Crapo, J. D. (1992). Allometric relationships of cell numbers and size in the mammalian lung. Am J Respir Cell Mol Biol. 6 (2):235-43.

36. Galer, D. M., Leung, H. W., Sussman, R. G., and Trzos, R. J. (1992). Scientific and practical considerations for the development of occupational exposure limits (OELs) for chemical substances. Regul Toxicol Pharmacol. 15 (3):291-306.

37. Phalen RF. (1984). Basic Morphology and Physiology of the Respiratory Tract, in Inhalation Studies: Foundattions and Techniques. CRC Press, Boca Raton.

38. Nurkiewicz, T. R., Porter, D. W., Hubbs, A. F., Stone, S., Moseley, A. M., Cumpston, J. L., Goodwill, A. G., Frisbee, S. J., Perrotta, P. L., Brock, R. W., Frisbee, J. C., Boegehold, M. A., Frazer, D. G., Chen, B. T., and Castranova, V. (2011). Pulmonary particulate matter and systemic microvascular dysfunction. Res Rep Health Eff Inst. (164):3-48.

39. Menache, M. G., Miller, F. J., and Raabe, O. G. (1995). Particle inhalability curves for humans and small laboratory animals. Ann Occup Hyg. 39 (3):317-28.

40. LeBlanc, A. J., Moseley, A. M., Chen, B. T., Frazer, D., Castranova, V., and Nurkiewicz, T. R. (2010). Nanoparticle inhalation impairs coronary microvascular 
reactivity via a local reactive oxygen species-dependent mechanism. Cardiovasc Toxicol. 10 (1):27-36.

41. Stapleton, P. A., Minarchick, V. C., Cumpston, A. M., McKinney, W., Chen, B. T., Sager, T. M., Frazer, D. G., Mercer, R. R., Scabilloni, J., Andrew, M. E., Castranova, V., and Nurkiewicz, T. R. (2012). Impairment of coronary arteriolar endotheliumdependent dilation after multi-walled carbon nanotube inhalation: a time-course study. Int J Mol Sci. 13 (11):13781-803.

42. Courtois, A., Andujar, P., Ladeiro, Y., Baudrimont, I., Delannoy, E., Leblais, V., Begueret, H., Galland, M. A., Brochard, P., Marano, F., Marthan, R., and Muller, B. (2008). Impairment of NO-dependent relaxation in intralobar pulmonary arteries: comparison of urban particulate matter and manufactured nanoparticles. Environ Health Perspect. 116 (10):1294-9.

43. Straub, A. C., Lohman, A. W., Billaud, M., Johnstone, S. R., Dwyer, S. T., Lee, M. Y., Bortz, P. S., Best, A. K., Columbus, L., Gaston, B., and Isakson, B. E. (2012). Endothelial cell expression of haemoglobin alpha regulates nitric oxide signalling. Nature. 491 (7424):473-7.

44. Park, E. J., Choi, J., Park, Y. K., and Park, K. (2008). Oxidative stress induced by cerium oxide nanoparticles in cultured BEAS-2B cells. Toxicology. 245 (1-2):90-100.

45. Driscoll, K. E., Costa, D. L., Hatch, G., Henderson, R., Oberdorster, G., Salem, H., and Schlesinger, R. B. (2000). Intratracheal instillation as an exposure technique for the evaluation of respiratory tract toxicity: uses and limitations. Toxicol Sci. 55 (1):2435.

46. He, X., Zhang, H., Ma, Y., Bai, W., Zhang, Z., Lu, K., Ding, Y., Zhao, Y., and Chai, Z. (2010). Lung deposition and extrapulmonary translocation of nano-ceria after intratracheal instillation. Nanotechnology. 21 (28):285103. 


\section{Table I: Animal Characteristics}

\begin{tabular}{|c|c|c|c|c|c|}
\hline Groups & $N$ & $\begin{array}{c}\text { Age } \\
\text { (weeks) }\end{array}$ & $\begin{array}{l}\text { Weight } \\
\text { (g) }\end{array}$ & $\begin{array}{c}\text { MAP } \\
(\mathrm{mm} \mathrm{Hg})\end{array}$ & $\begin{array}{c}\text { Heart } \\
\text { Weight (g) }\end{array}$ \\
\hline Control-Saline & 34 & $10 \pm 0.4$ & $357 \pm 4$ & $103 \pm 2$ & $1.27 \pm 0.02$ \\
\hline $10 \mu \mathrm{geO}_{2} \mathrm{NPs}$ & 12 & $8 \pm 0.3$ & $370 \pm 11$ & $90 \pm 4$ & $1.29 \pm 0.05$ \\
\hline $50 \mu \mathrm{g} \mathrm{CeO} 2 \mathrm{NPs}$ & 17 & 2 & $366 \pm 7$ & $101 \pm 3$ & \pm 0.04 \\
\hline $100 \mu \mathrm{g} \mathrm{CeO}_{2} \mathrm{NPs}$ & 35 & $10 \pm 0.4$ & $352 \pm 4$ & $111 \pm 3^{*}$ & $1.23 \pm 0.02$ \\
\hline $200 \mu \mathrm{g} \mathrm{CeO}_{2} \mathrm{NPs}$ & 14 & $9 \pm 0.3$ & $362 \pm 7$ & $102 \pm 2$ & $1.29 \pm 0.05$ \\
\hline $400 \mu \mathrm{g} \mathrm{CeO}{ }_{2} \mathrm{NPs}$ & 14 & $9 \pm 0.3$ & $374 \pm 6$ & $100 \pm 2$ & $1.33 \pm 0.04$ \\
\hline
\end{tabular}




\section{Table IIA: Mesentery Arteriole Characteristics}

\begin{tabular}{|c|c|c|c|c|c|c|}
\hline \multirow[t]{2}{*}{ Groups } & \multirow[b]{2}{*}{$\mathrm{n}$} & \multicolumn{2}{|c|}{ Diameter $(\mu \mathrm{m})$} & \multirow{2}{*}{$\begin{array}{c}\text { Tone } \\
(\%)\end{array}$} & \multirow{2}{*}{$\begin{array}{l}\text { WT } \\
(\mu \mathrm{m})\end{array}$} & \multirow[t]{2}{*}{ WLR } \\
\hline & & $\begin{array}{c}\text { Steady } \\
\text { State }\end{array}$ & Max & & & \\
\hline Control-Saline & 31 & $70 \pm 3$ & $101 \pm 3$ & $31 \pm 1$ & $11 \pm 1$ & $0.11 \pm 0.01$ \\
\hline $10 \mu \mathrm{g} \mathrm{CeO}{ }_{2} \mathrm{NPs}$ & 14 & $73 \pm 4$ & $105 \pm 5$ & $31 \pm 2$ & $10 \pm 1$ & $0.09 \pm 0.01$ \\
\hline $50 \mu \mathrm{g} \mathrm{CeO}_{2} \mathrm{NPs}$ & 15 & $73 \pm 3$ & $101 \pm 4$ & $28 \pm 1$ & $10 \pm 1$ & $0.10 \pm 0.01$ \\
\hline $100 \mu \mathrm{g} \mathrm{CeO} 2$ NPs & 24 & $76 \pm 3$ & $109 \pm 3$ & $31 \pm 1$ & $10 \pm 1$ & $0.10 \pm 0.01$ \\
\hline $200 \mu \mathrm{g} \mathrm{CeO}_{2}$ NPs & 13 & $72 \pm 4$ & $105 \pm 5$ & $31 \pm 2$ & $10 \pm 1$ & $0.10 \pm 0.01$ \\
\hline $400 \mu \mathrm{g} \mathrm{CeO}{ }_{2}$ NPs & 12 & $68 \pm 3$ & $96 \pm 4$ & $30 \pm 2$ & $11 \pm 1$ & $0.11 \pm 0.01$ \\
\hline
\end{tabular}




\section{Table IIB: Coronary Arteriole Characteristics}

\begin{tabular}{|c|c|c|c|c|c|c|}
\hline \multirow[t]{2}{*}{ Groups } & \multirow[b]{2}{*}{$n$} & \multicolumn{2}{|c|}{ Diameter $(\mu \mathrm{m})$} & \multirow{2}{*}{$\begin{array}{c}\text { Tone } \\
(\%)\end{array}$} & \multirow{2}{*}{$\begin{array}{l}\text { WT } \\
(\mu \mathrm{m})\end{array}$} & \multirow[t]{2}{*}{ WLR } \\
\hline & & $\begin{array}{c}\text { Steady } \\
\text { State }\end{array}$ & Max & & & \\
\hline Control-Saline & 21 & $83 \pm 5$ & $119 \pm 6$ & $31 \pm 2$ & $21 \pm 1$ & $0.18 \pm 0.01$ \\
\hline $10 \mu \mathrm{g} \mathrm{CeO}{ }_{2}$ NPs & 8 & $67 \pm 4$ & $100 \pm 6$ & $32 \pm 3$ & $16 \pm 2$ & $0.16 \pm 0.02$ \\
\hline $50 \mu \mathrm{g} \mathrm{CeO}{ }_{2} \mathrm{NPs}$ & 10 & $78 \pm 6$ & $116 \pm 5$ & $33 \pm 4$ & $17 \pm 1$ & $0.15 \pm 0.01$ \\
\hline $100 \mu \mathrm{g} \mathrm{CeO}{ }_{2}$ NPs & 22 & $78 \pm 4$ & $111 \pm 5$ & $30 \pm 2$ & $21 \pm 2$ & $0.20 \pm 0.02$ \\
\hline $200 \mu \mathrm{g} \mathrm{CeO}_{2} \mathrm{NPs}$ & 10 & $82 \pm 6$ & $114 \pm 7$ & $29 \pm 1$ & $15 \pm 1$ & $0.13 \pm 0.01$ \\
\hline $400 \mu \mathrm{gCeO}_{2} \mathrm{NPs}$ & 10 & $77 \pm 6$ & $115 \pm 7$ & $33 \pm 3$ & $17 \pm 2$ & $0.15 \pm 0.02$ \\
\hline
\end{tabular}




\section{Table III: $\mathrm{CeO}_{2}$ Nanoparticles $\mathrm{EC}_{50}$}

\begin{tabular}{|c|c|c|}
\hline Chemical & Coronary & Mesentery \\
\hline ACh & $100.60 \mu \mathrm{g}$ & $61.95 \mu \mathrm{g}$ \\
\hline A23187 & $64.24 \mu \mathrm{g}$ & $88.51 \mu \mathrm{g}$ \\
\hline SPR & $69.50 \mu \mathrm{g}$ & $69.08 \mu \mathrm{g}$ \\
\hline PE & $15.00 \mu \mathrm{g}$ & $49.82 \mu \mathrm{g}$ \\
\hline 5-HT & $23.34 \mu \mathrm{g}$ & $18.48 \mu \mathrm{g}$ \\
\hline $\begin{array}{l}\text { Values are the calculated EC } \\
\text { curve. }\end{array}$ & for each dose \\
\hline
\end{tabular}




\section{Figure 1:}

A: TEM Image of $\mathrm{CeO}_{2}$ Nanoparticles

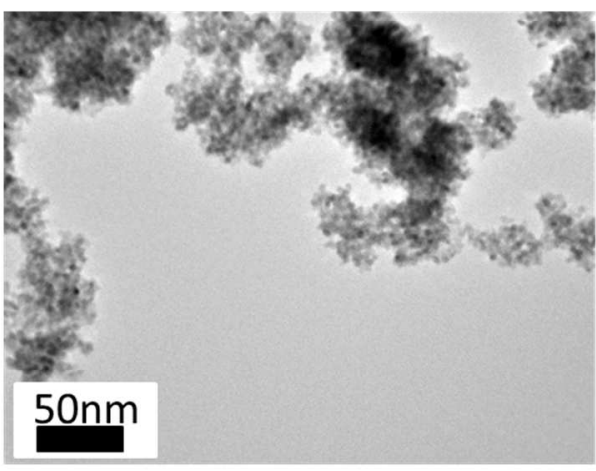

B: TEM Image of $\mathrm{CeO}_{2}$ Nanoparticles

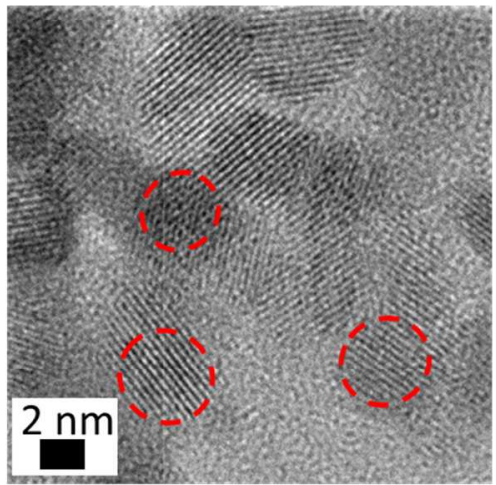

C: Distribution of $\mathrm{CeO}_{2}$ Nanoparticles agglomerates

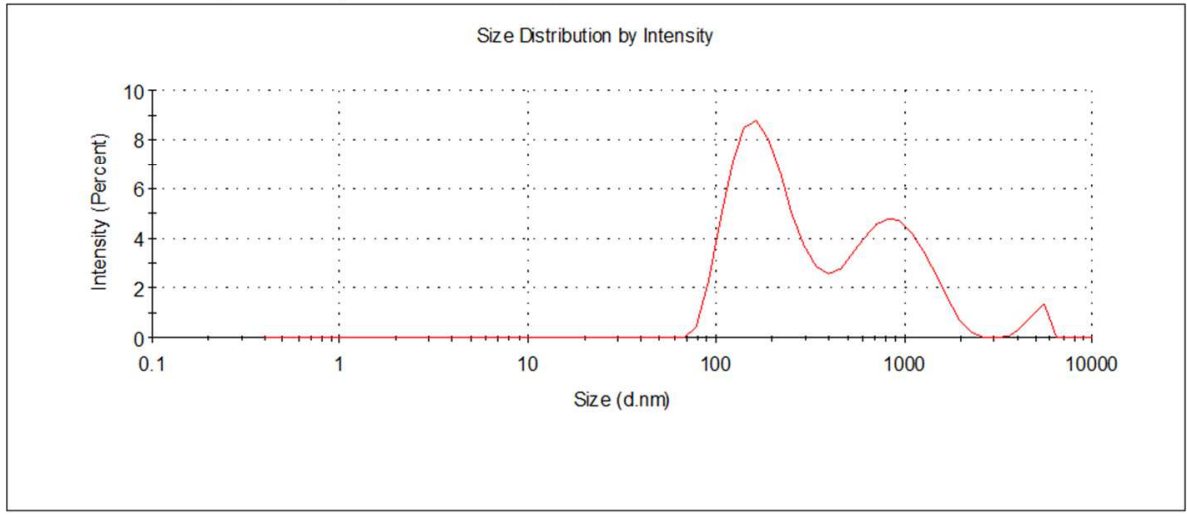


Figure 2:

\section{A: XPS Spectra for bonded C}

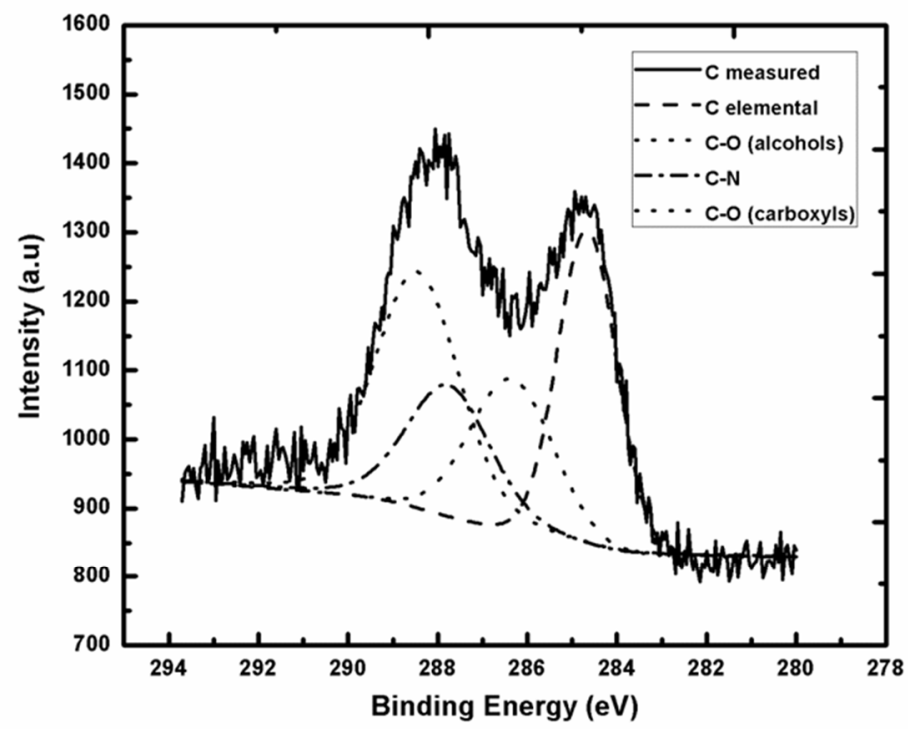

B: XPS Spectra for bonded O

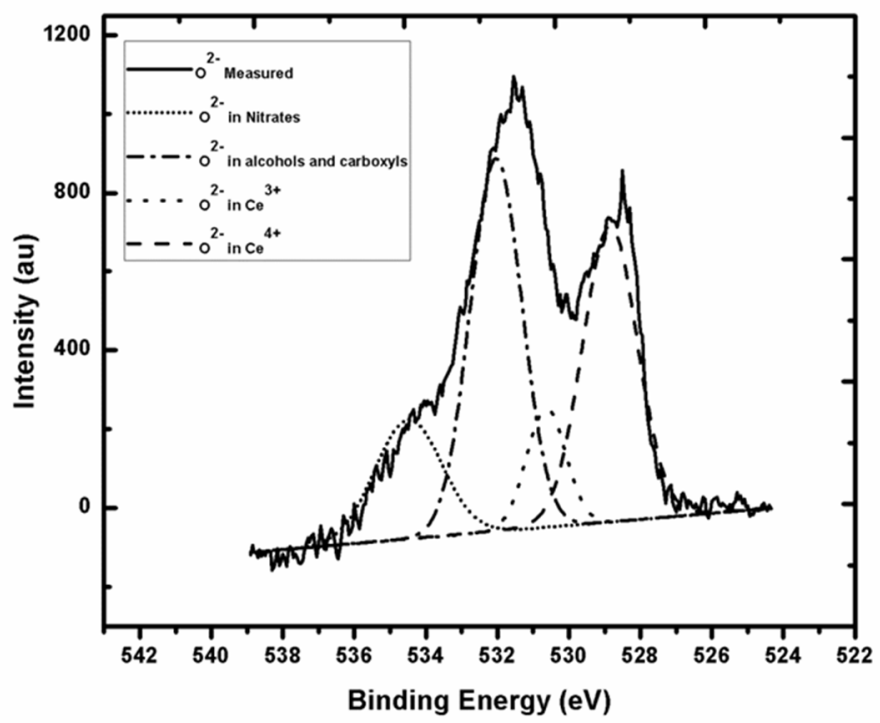


Figure 3:
A: LDH


B: Albumin

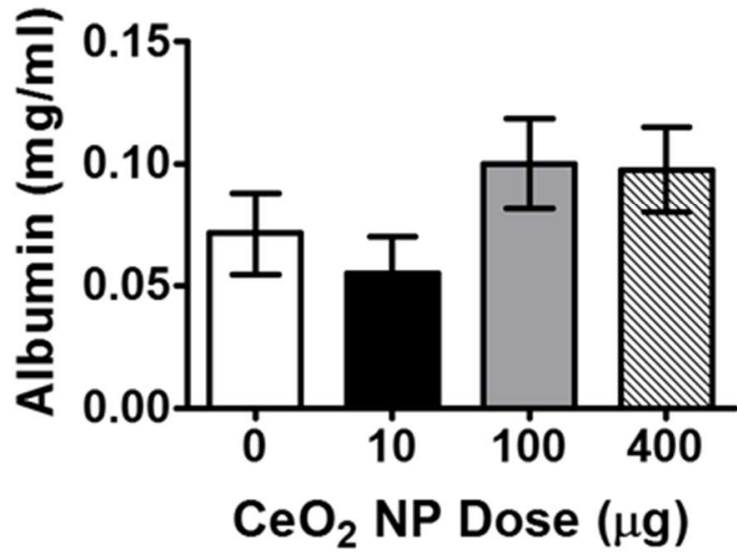
C: Activated AM
D: PMN
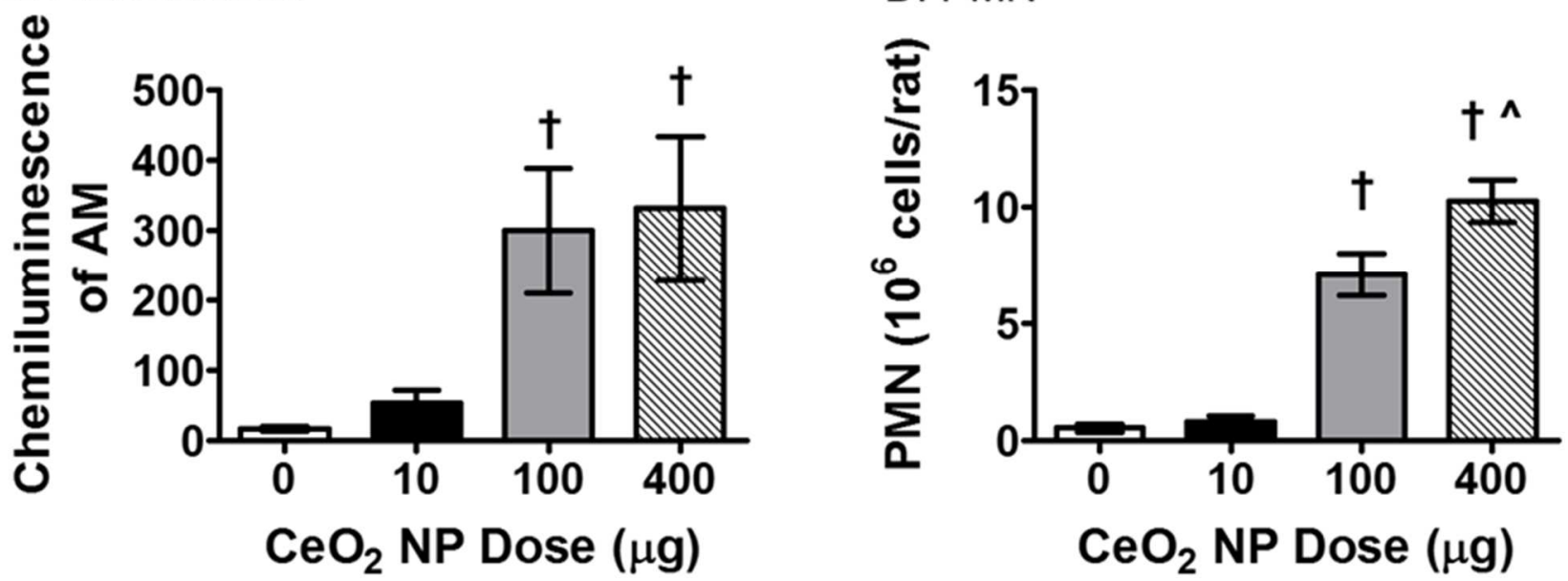
Figure 4:

A: Mesenteric Arterioles

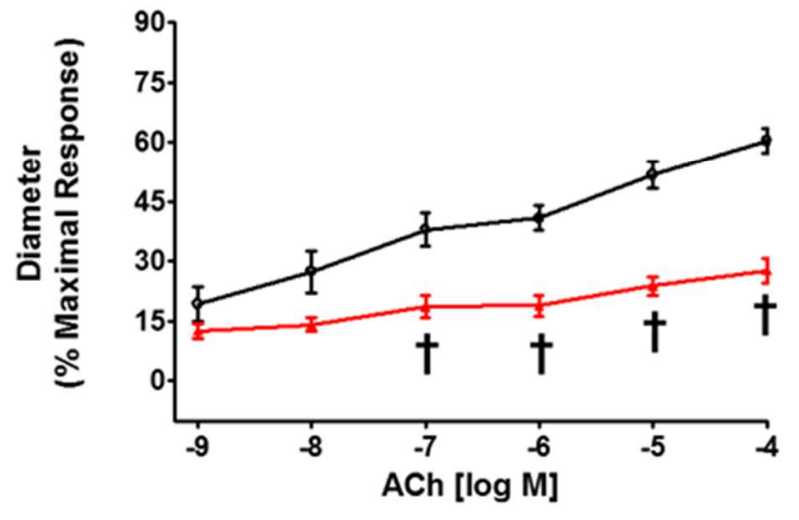

B: Coronary Arterioles

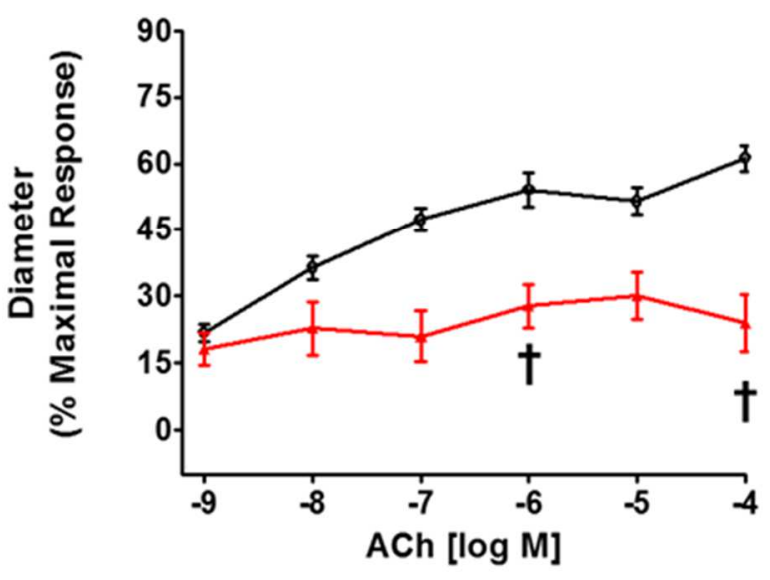

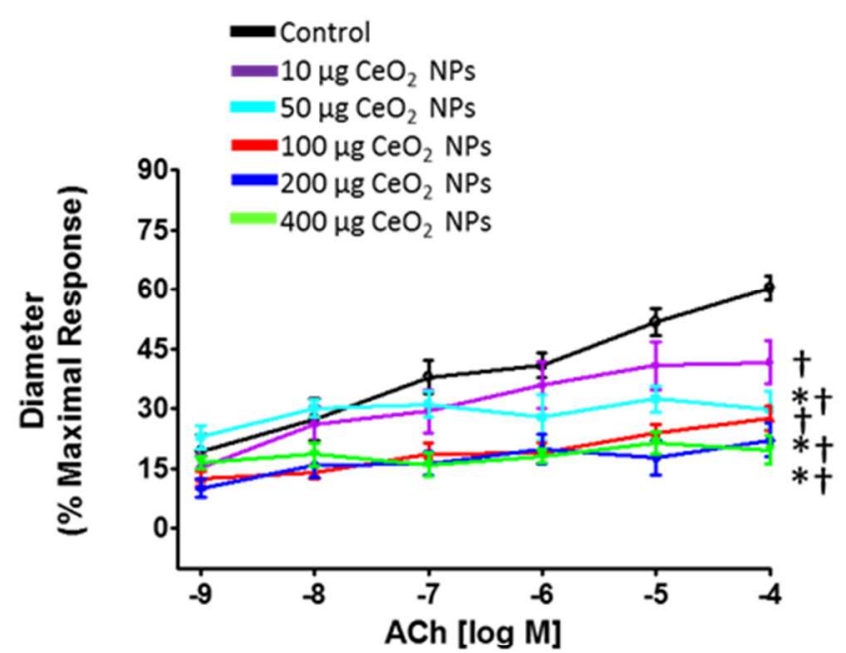

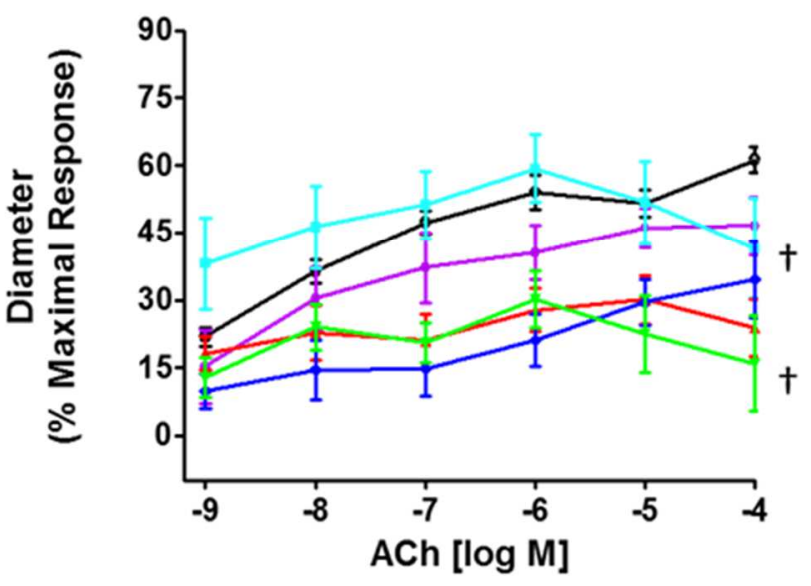


Figure 5:

A: Mesenteric Arterioles
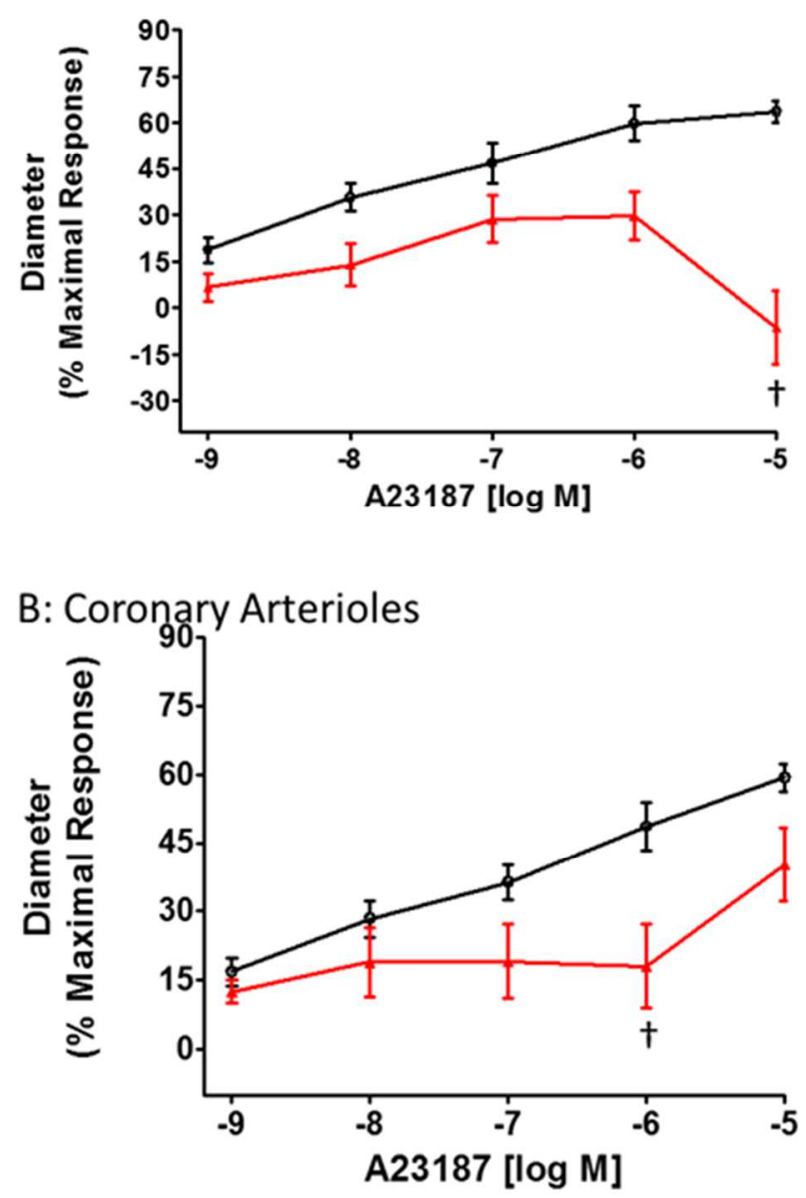
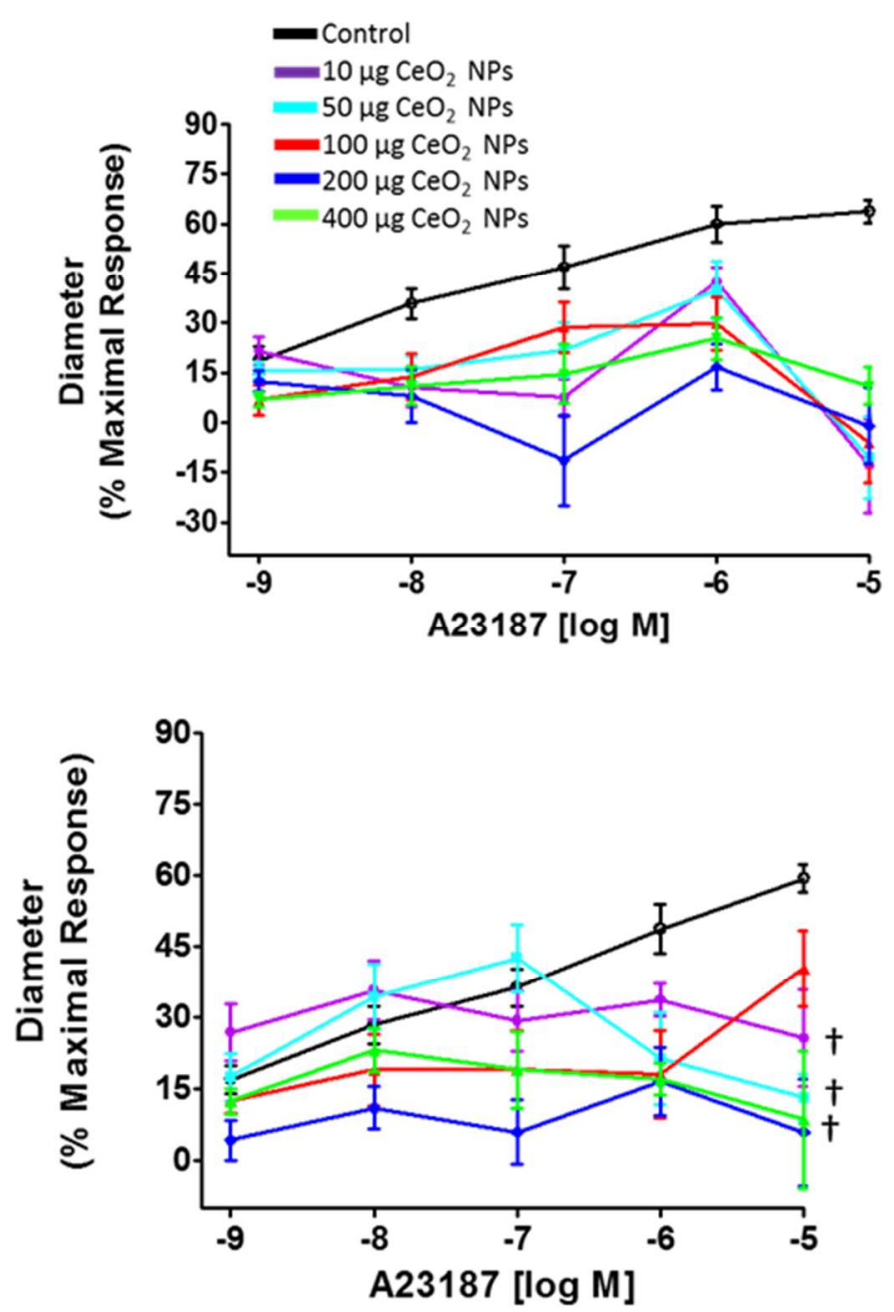
Figure 6:

A: Mesenteric Arterioles

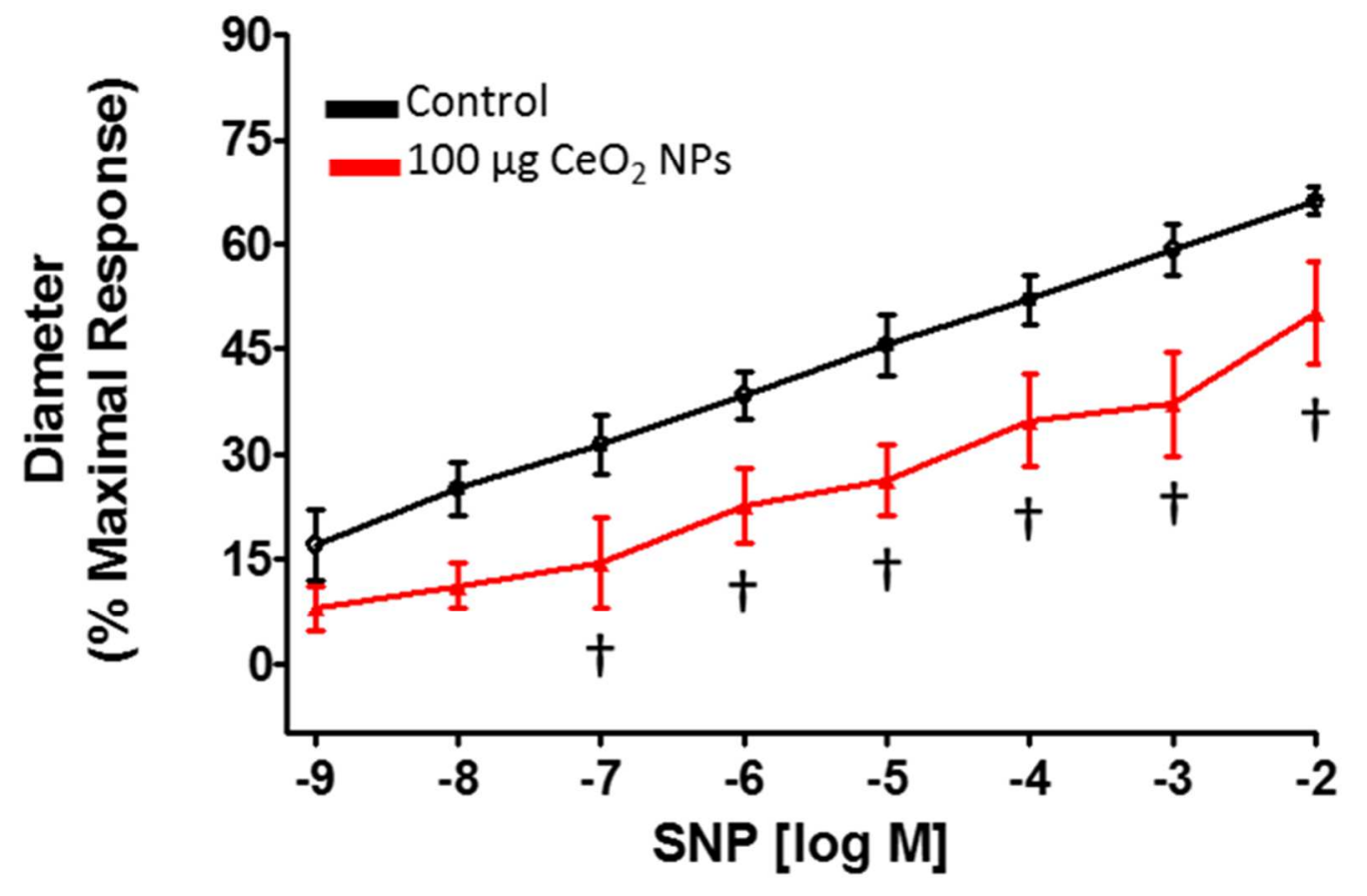

B: Coronary Arterioles

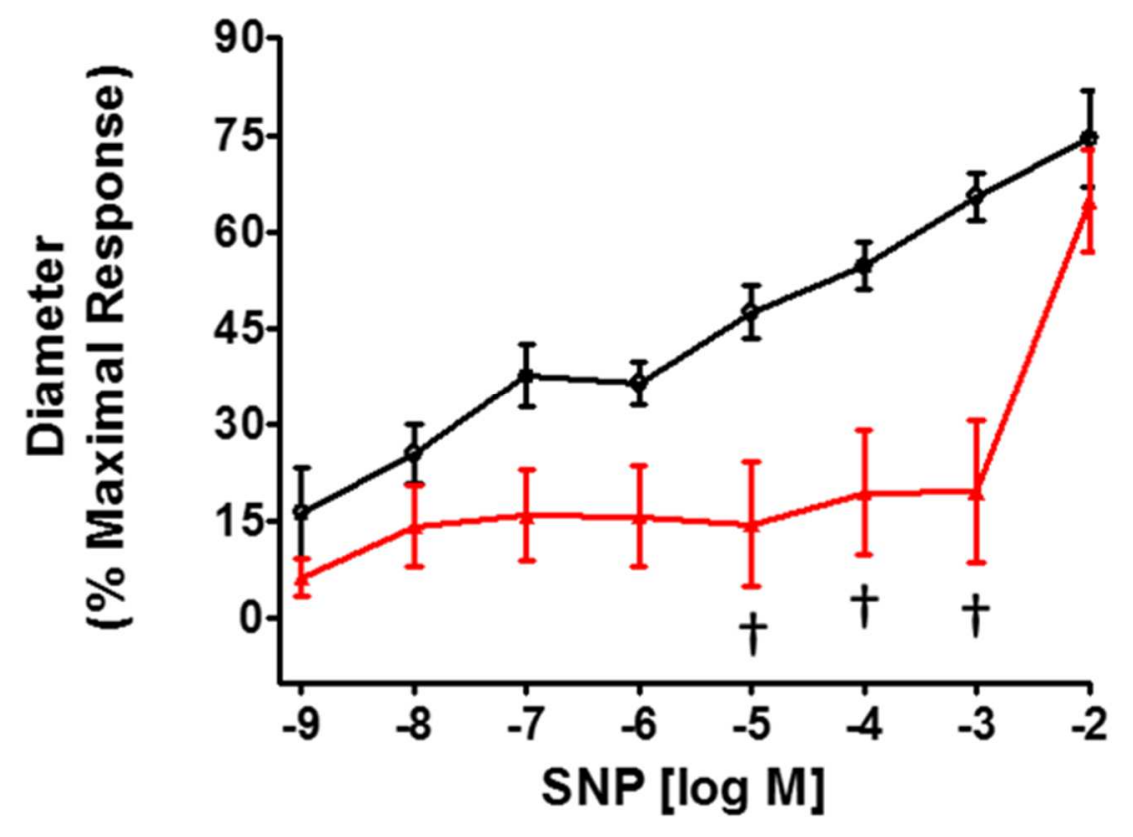


Figure 7:

A: Mesenteric Arterioles

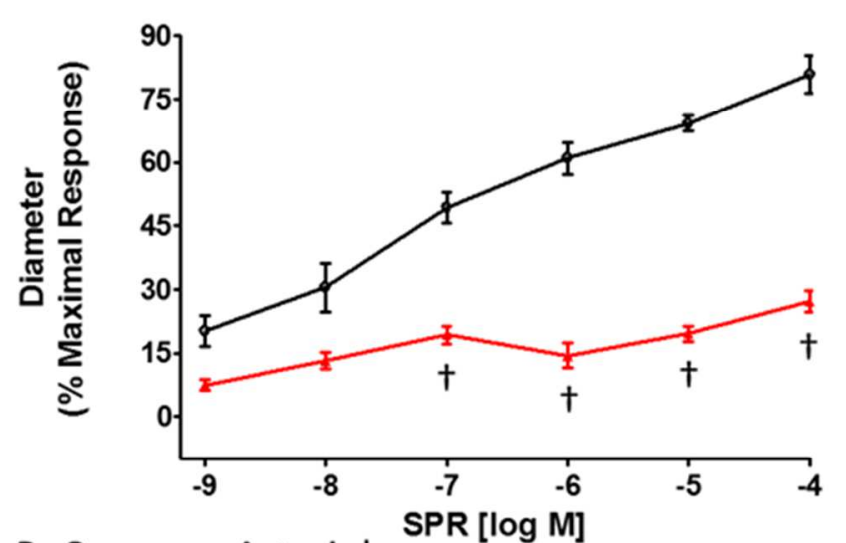

B: Coronary Arterioles

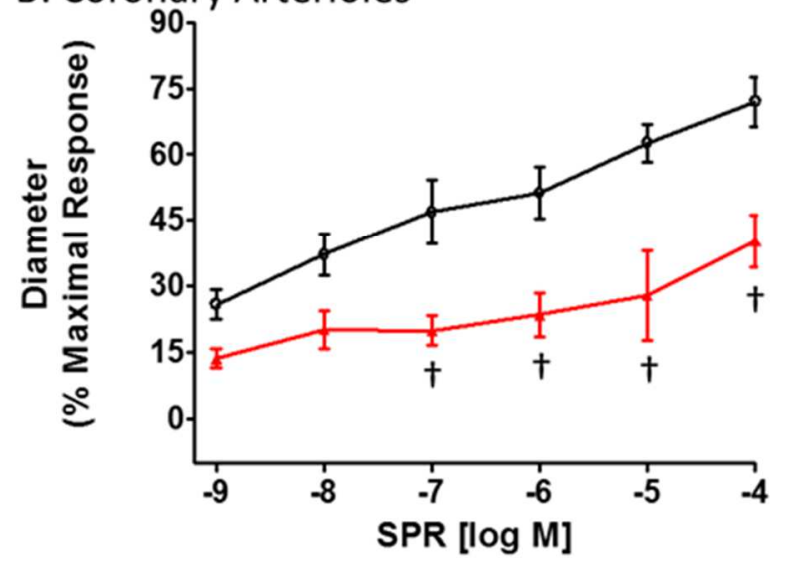

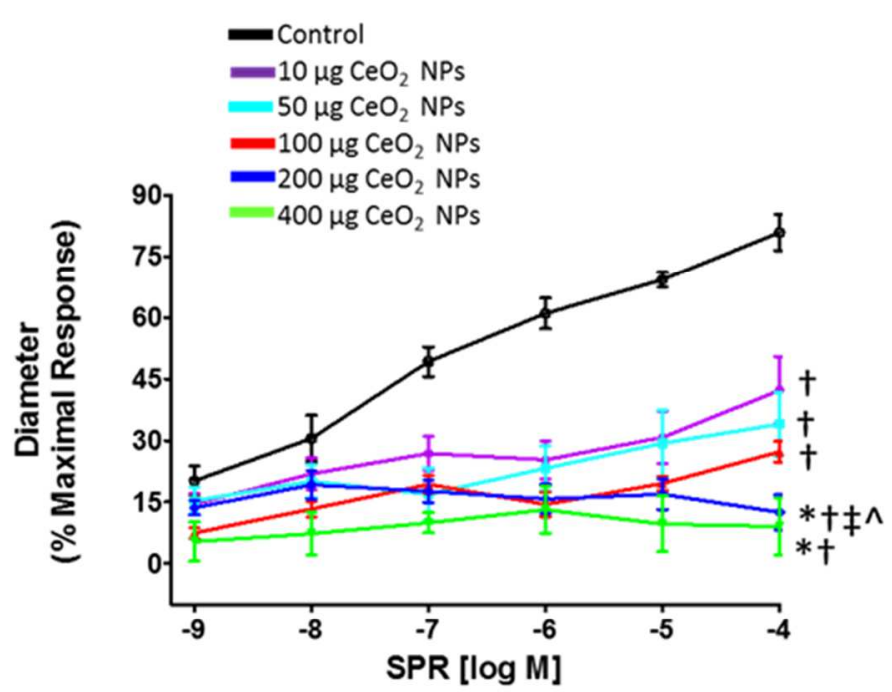

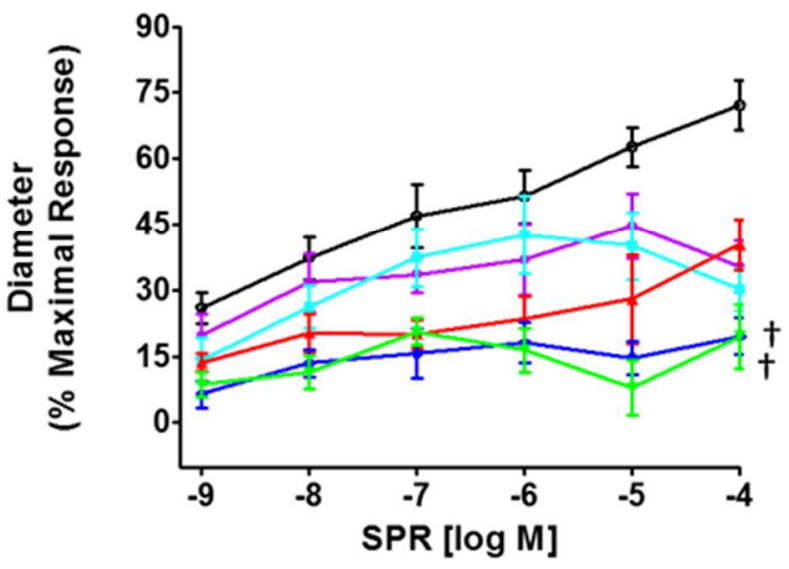


Figure 8:

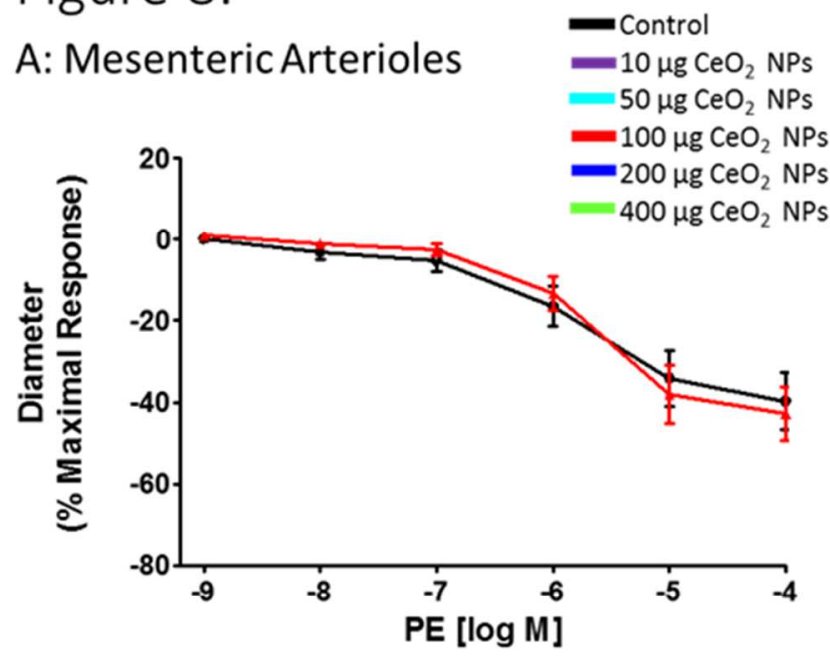

B: Coronary Arterioles

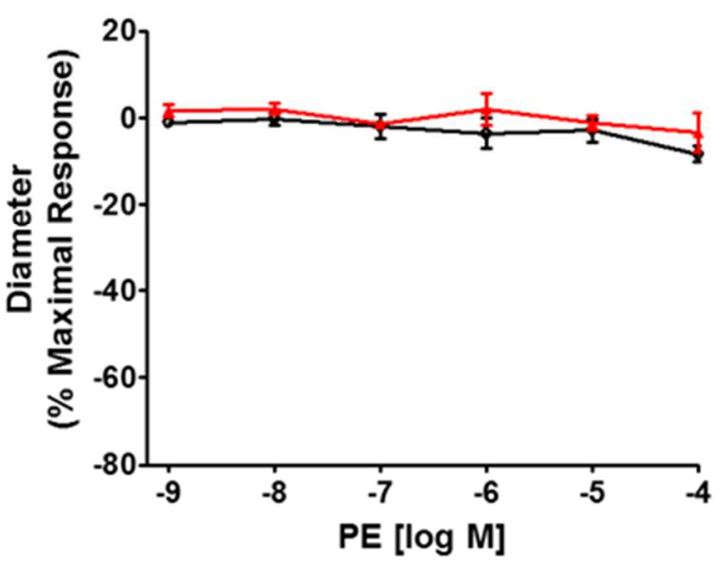

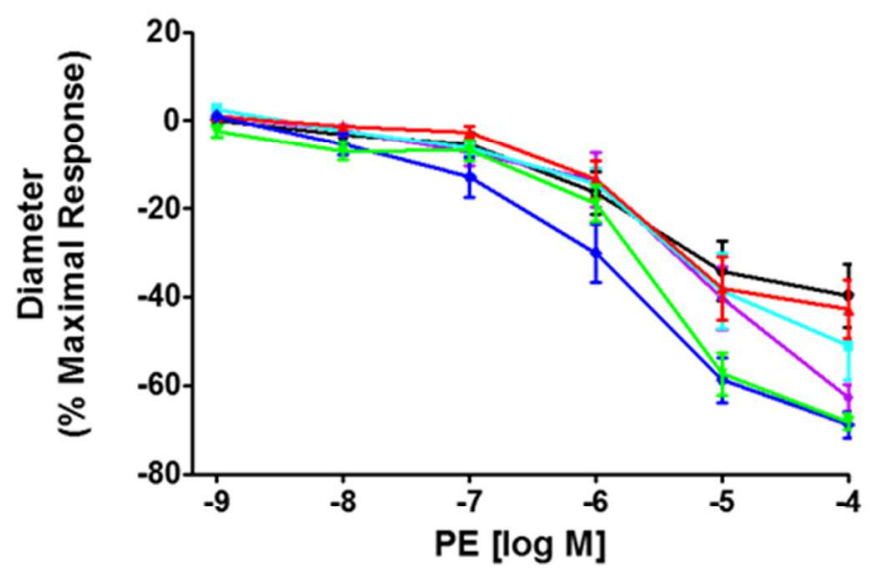

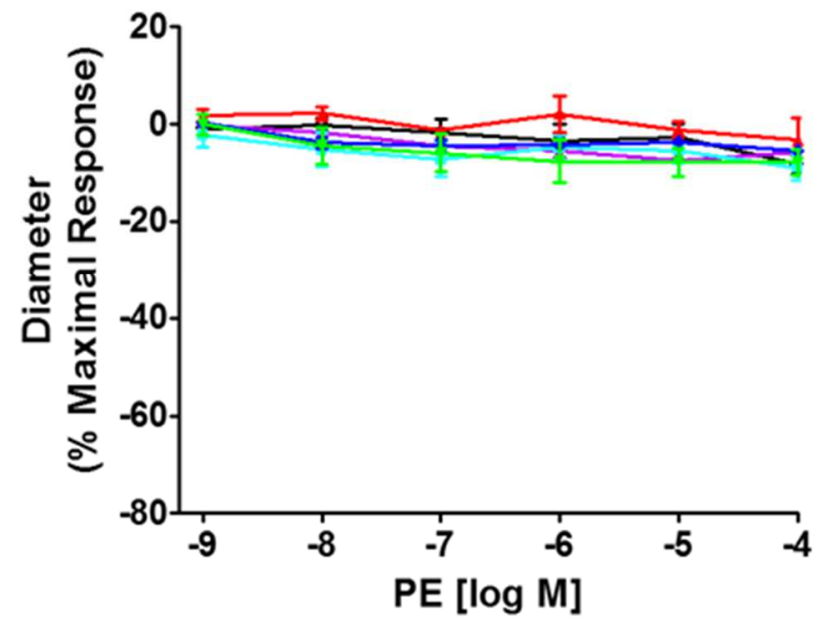


Figure 9:

A: Mesenteric Arterioles
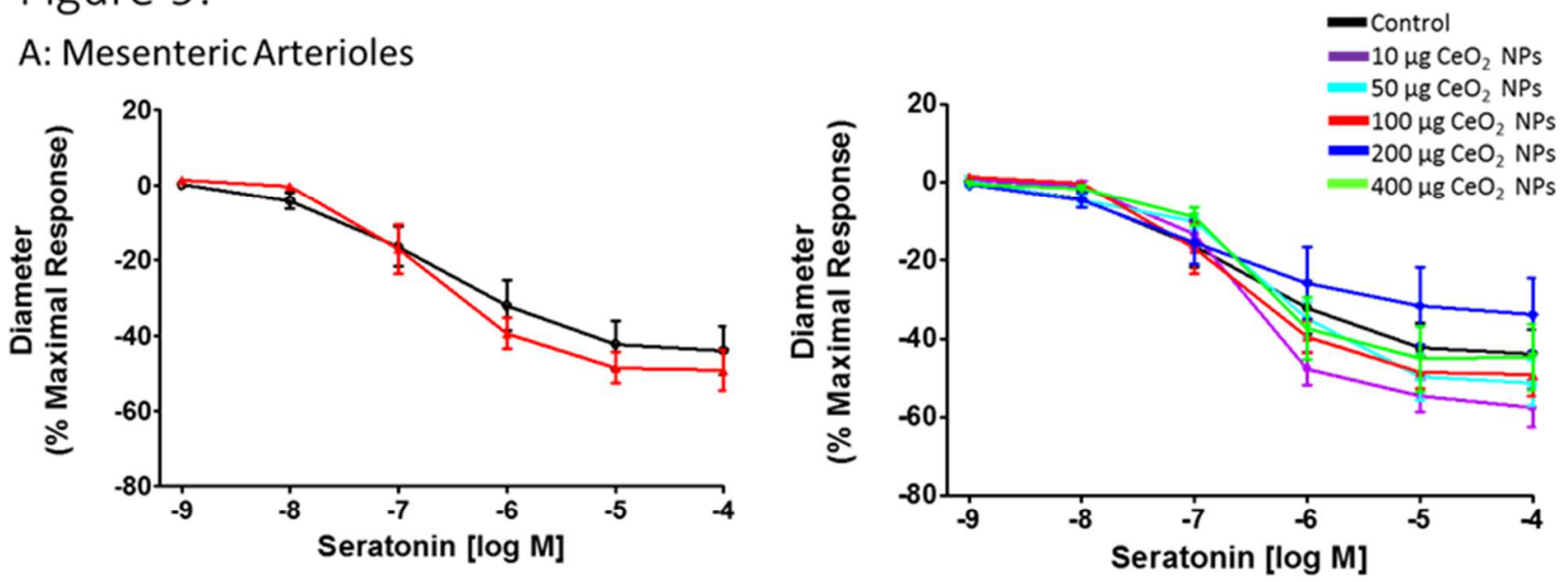

\section{B: Coronary Arterioles}
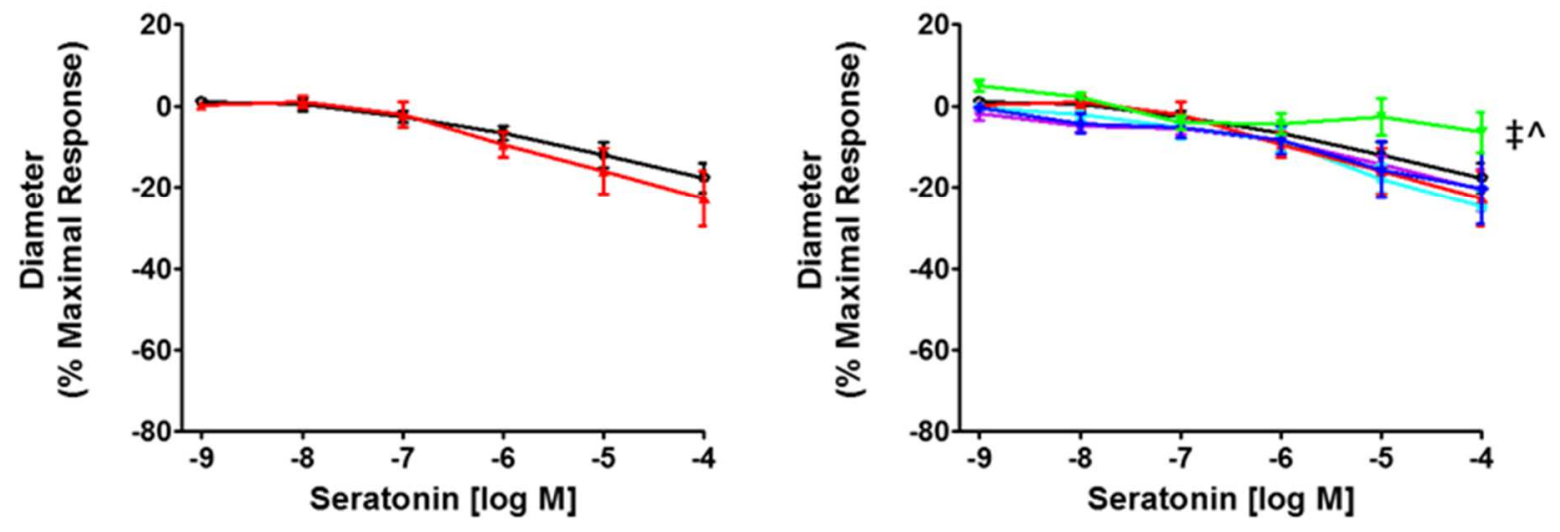
Figure 10:

A: Mesenteric Arterioles

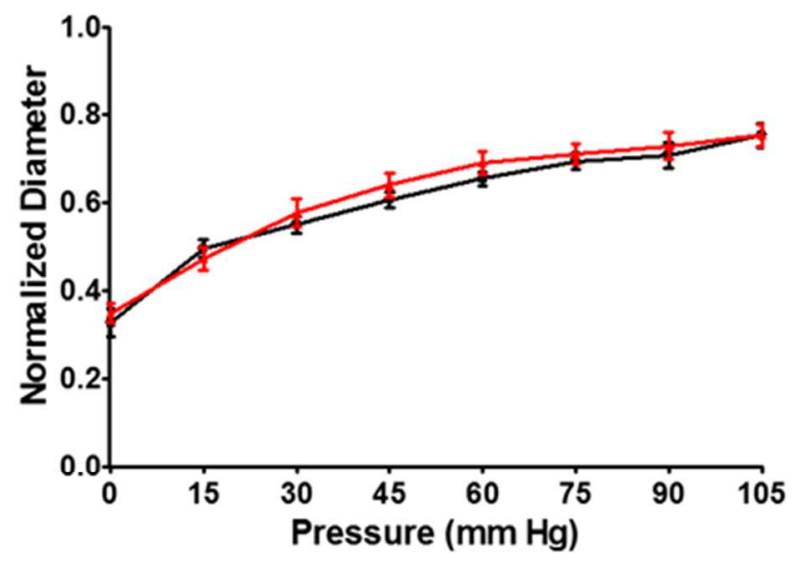

B: Coronary Arterioles

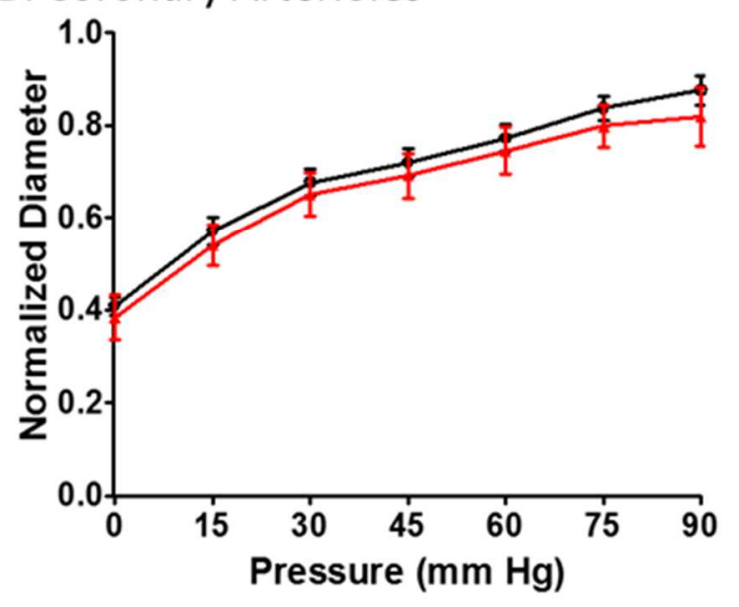

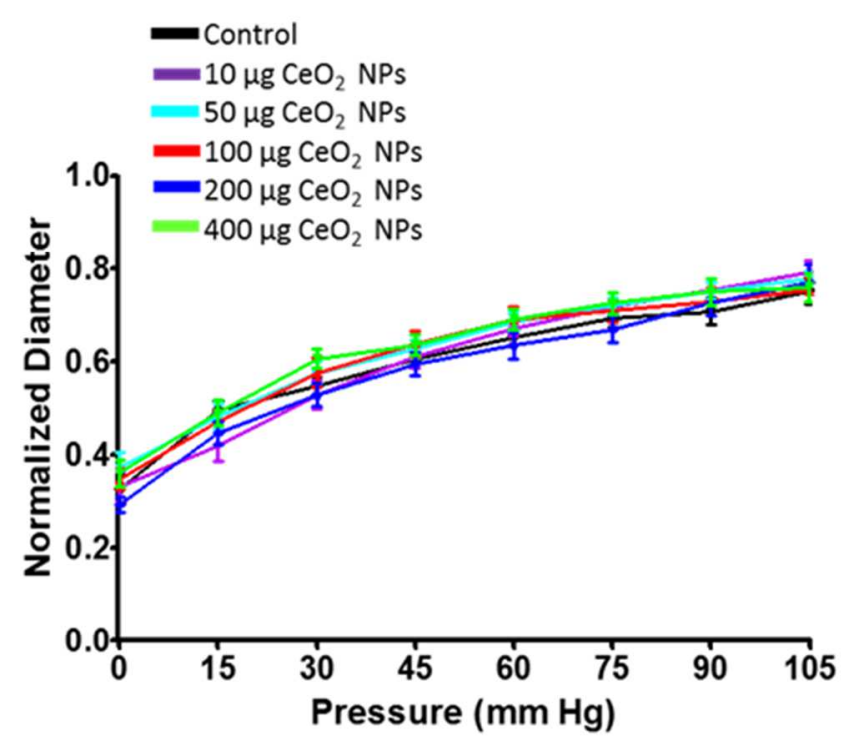

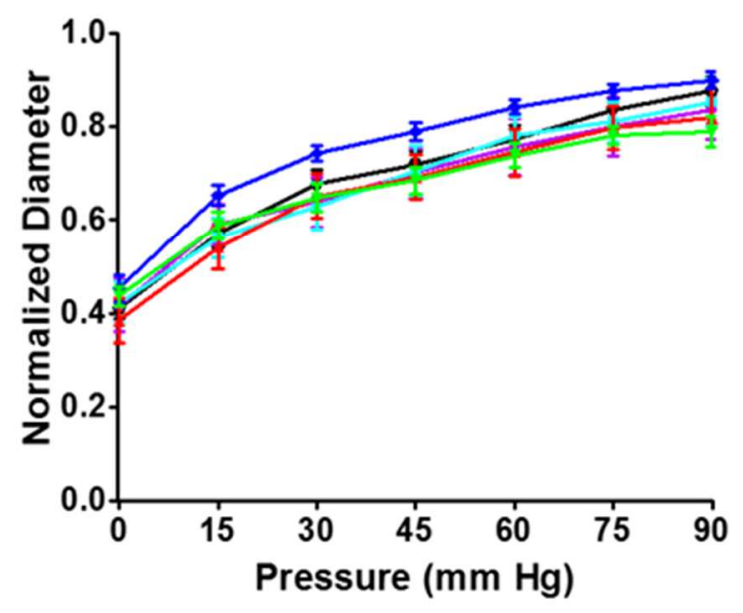




\section{Chapter 3}

\section{Intravenous and Gastric Cerium Dioxide Nanoparticle Exposure Disrupts Microvascular Smooth Muscle Signaling}

\section{Running Title: Cerium Dioxide Nanoparticles and Exposure Routes}

Citation: Minarchick VC, Stapleton PA, Fix NR, Leonard SS, Sabolsky EM, Nurkiewicz TR. (2015) Intravenous and Gastric Cerium Dioxide Nanoparticle Exposure Disrupts Microvascular Smooth Muscle Signaling. Toxicol Sci. 144 (1): 77-89. PMID: 25481005

\section{Authors:}

Valerie C. Minarchick ${ }^{*}, \dagger$

Phoebe A. Stapleton * ${ }^{*}$

Natalie R. Fix $\ddagger$

Stephen S. Leonard ₹

Edward M. Sabolsky $\$$

Timothy R. Nurkiewicz ${ }^{*},+\ddagger$

\section{Affiliations:}

*. Center for Cardiovascular and Respiratory Sciences, West Virginia University School of Medicine, Morgantown, WV 26506

†. Department of Physiology and Pharmacology, West Virginia University School of Medicine, Morgantown, WV 26506

‡. Pathology and Physiology Research Branch, Health Effects Laboratory Division, National Institute for Occupational Safety and Health, Morgantown, WV 26506

$\S$. Department of Mechanical and Aerospace Engineering, West Virginia University, Morgantown, WV 26506 


\section{Abstract:}

Cerium dioxide nanoparticles $\left(\mathrm{CeO}_{2} \mathrm{NP}\right)$ hold great therapeutic potential, but the in vivo effects of non-pulmonary exposure routes are unclear. The first aim was to determine whether microvascular function is impaired after intravenous and gastric $\mathrm{CeO}_{2} \mathrm{NP}$ exposure. The second aim was to investigate the mechanism(s) of action underlying microvascular dysfunction following $\mathrm{CeO}_{2} \mathrm{NP}$ exposure. Rats were exposed to $\mathrm{CeO}_{2} \mathrm{NP}$ (primary diameter: $4 \pm 1 \mathrm{~nm}$, surface area: $81.36 \mathrm{~m}^{2} / \mathrm{g}$ ) by intratracheal instillation, intravenous injection, or gastric gavage. Mesenteric arterioles were harvested $24 \mathrm{~h}$ postexposure and vascular function was assessed using an isolated arteriole preparation. Endothelium-dependent and -independent function and vascular smooth muscle (VSM) signaling [soluble guanylyl cyclase (sGC), and cyclic guanosine monophosphate (cGMP)] were assessed. Reactive oxygen species (ROS) generation and nitric oxide (NO) production were analyzed. Compared to controls, endothelium-dependent and independent dilation were impaired following intravenous injection (by $61 \%$ and $45 \%$ ) and gastric gavage (by $63 \%$ and $49 \%$ ). However, intravenous injection resulted in greater microvascular impairment (16\% and 35\%) compared to gastric gavage at an identical dose $(100 \mu \mathrm{g})$. Furthermore, sGC activation and cGMP responsiveness were impaired following pulmonary, intravenous, and gastric $\mathrm{CeO}_{2} \mathrm{NP}$ treatment. Finally, nanoparticle exposure resulted in route-dependent, increased ROS generation and decreased NO production. These results indicate that $\mathrm{CeO}_{2} \mathrm{NP}$ exposure route differentially impairs microvascular function, which may be mechanistically linked to decreased NO production and subsequent VSM signaling. Fully understanding the mechanisms behind $\mathrm{CeO}_{2} \mathrm{NP}$ in vivo effects is a critical step in the continued therapeutic development of this nanoparticle. 
Keywords: Cerium dioxide nanoparticles, microvascular function, nitric oxide, mesentery 


\section{Introduction:}

Cerium dioxide nanoparticles $\left(\mathrm{CeO}_{2} \mathrm{NP}\right)$ are an anthropogenic homogenous mixture of particles with one dimension $\leq 100 \mathrm{~nm}$ (Borm et al. 2006). Unique physical characteristics displayed at this size contribute to $\mathrm{CeO}_{2} \mathrm{NP}$ diverse applications. Presently, $\mathrm{CeO}_{2} \mathrm{NP}$ are widely used as a fuel additive because they increase the combustion efficiency of diesel engines (via enhanced catalytic activity) (Cassee et al. 2011). $\mathrm{CeO}_{2} \mathrm{NP}$ may also potentially protect against tissue damage associated with radiation treatments and stroke in biomedical applications (Celardo et al. 2011). Tissue damage in these conditions is largely derived from increased reactive oxygen species (ROS) generation. $\mathrm{CeO}_{2} \mathrm{NP}$ may prevent tissue damage from ROS due to their anti-oxidant capabilities (Kim et al. 2012). This anti-oxidant potential comes from the ability of $\mathrm{CeO}_{2} \mathrm{NP}$ to react with ROS, which in turn alters its valence state (cycling between $\mathrm{Ce}^{4+}$ and $\left.\mathrm{Ce}^{3+}\right)($ Heckert et al. 2008). The diverse and potentially widespread future applications mandate that the concept of intentional and unintentional $\mathrm{CeO}_{2} \mathrm{NP}$ exposure (via multiple routes) be given full toxicological consideration.

Currently, the lungs are the most common $\mathrm{CeO}_{2} \mathrm{NP}$ exposure route. This is largely due to the occupational inhalation risk associated with the manufacturing process where $\mathrm{CeO}_{2} \mathrm{NP}$ are easily aerosolized (Department of Health and Human Services 2009). Furthermore, the risk of environmental pulmonary exposures may increase due the presence of $\mathrm{CeO}_{2} \mathrm{NP}$ in diesel engine emissions. The lack of governmental regulations in Europe and the United States further elevates this exposure risk (Cassee et al. 2011). Pulmonary $\mathrm{CeO}_{2} \mathrm{NP}$ exposure has been associated with inflammation and granuloma formation (Ma et al. 2011). These exposures have also resulted in extra-pulmonary biological effects including inflammation, organ toxicity, and vascular impairments 
(Minarchick et al. 2013; Nalabotu et al. 2011; Wingard et al. 2011). While pulmonary $\mathrm{CeO}_{2}$ NP exposure is associated with several untoward biological outcomes, neither these effects nor their intensities have been extensively studied or compared when the nanoparticles are given by alternate exposure routes.

At this time, $\mathrm{CeO}_{2} \mathrm{NP}$ exposure by non-pulmonary routes (intravenous and oral) is not an obvious risk. However, if $\mathrm{CeO}_{2} \mathrm{NP}$ are to be fully developed for systemic therapeutic applications, the biological effects that follow $\mathrm{CeO}_{2} \mathrm{NP}$ exposure by these clinicallyrelevant exposure routes must be better understood. In vivo, studies investigating the outcomes of intravenous and oral $\mathrm{CeO}_{2} \mathrm{NP}$ exposures have largely focused on long-term biological responses (1 - 3 months post-exposure), including organ distribution, and overt organ toxicity (Hirst et al. 2013; Yokel et al. 2012). Despite the fundamental role of the microcirculation in blood flow control, pressure regulation, and permeability in all tissues (Renkin 1984; Zweifach 1984), no investigation to date has analyzed the effects of intravenous and oral $\mathrm{CeO}_{2} \mathrm{NP}$ exposures on normal microvascular function.

In the microcirculation, the arterioles respond to a variety of chemical and mechanical stimuli (Gewaltig and Kojda 2002). Under normal conditions, nitric oxide (NO) diffuses freely from endothelial cells to vascular smooth muscle (VSM) cells. This initiates a signaling cascade that activates soluble guanylyl cyclase (sGC), increases cyclic guanosine monophosphate (cGMP), and stimulates cGMP-protein kinase (PKG) (Schlossmann et al. 2003; Taylor et al. 2004). This signaling cascade decreases intracellular calcium $\left(\mathrm{Ca}^{2+}\right)$ and, ultimately, relaxes VSM (Taylor et al. 2004). Disruptions in VSM signaling may compromise microvascular function and, if unresolved, may contribute to the development of numerous pathological conditions ( $\mathrm{Li}$ and Forstermann 2000). 
We have previously established that pulmonary $\mathrm{CeO}_{2} \mathrm{NP}$ exposure results in systemic microvascular dysfunction (Minarchick et al. 2013). However, the presence of microvascular dysfunction following alternate exposure routes and the possible mechanism of these impairments are currently unknown. Therefore, the aims of this study were two-fold. The first aim was to determine if microvascular impairment followed intravenous injection and gastric gavage of $\mathrm{CeO}_{2} \mathrm{NP}$. The second aim was to provide mechanistic insight into the link between $\mathrm{CeO}_{2} \mathrm{NP}$ exposure and microvascular function following three distinct exposure routes (intratracheal instillation, intravenous injection, and gastric gavage). Based on our pulmonary results, we hypothesized that intravenous and gastric exposures will also result in microvascular impairment, but to differing degrees, and the source of this dysfunction will be, at least partly, due to changes in NO bioavailability and/or VSM signaling. Microvascular impairment and NO bioavailability were assessed in freshly isolated arterioles $24 \mathrm{~h}$ following $\mathrm{CeO}_{2} \mathrm{NP}$ exposure. 


\section{Materials and Methods:}

$\mathrm{CeO}_{2}$ NP Production and Characterization: $\mathrm{CeO}_{2} \mathrm{NP}$ powders were synthesized by a hydrothermal process as previously described (Minarchick et al. 2013). Briefly, cerium (IV) ammonium nitrate [99+\%, (Alfa Aesar, Ward Hill, MA)] was added to de-ionized water $\left(\mathrm{H}_{2} \mathrm{O}\right)$ and this solution was added drop-wise into a basic solution of tetramethylammonium hydroxide pentahydrate (TMAOH) and de-ionized $\mathrm{H}_{2} \mathrm{O}$. The $\mathrm{pH}$ of the dispersion was altered to $\sim 10.5$ with ammonium hydroxide and was maintained throughout the reaction. The dispersion was placed in a $300 \mathrm{ml}$ Autoclave Engineers EZE-Seal ${ }^{\circledR}$ autoclave (Erie, PA) at $240{ }^{\circ} \mathrm{C}$ for $1 \mathrm{~h}$. Once removed from the autoclave, the dispersion was placed into a centrifuge and the liquid was removed and replaced with ethanol. After the washing step, the dispersion was dried at $60{ }^{\circ} \mathrm{C}$ overnight and sieved through a 200 mesh screen for characterization. The nanoparticles were previously characterized (Minarchick et al. 2013).

The $\mathrm{CeO}_{2} \mathrm{NP}$ had a surface area of $81.36 \mathrm{~m}^{2} / \mathrm{g}$ measured by Micromeritics ASAP 2020 (Norcross, GA). Transmission electron micrographs were used to analyze $\sim 20$ nanoparticles to determine the primary size $(4 \pm 1 \mathrm{~nm})$ and shape (spherical) [JEOL JEM2100 High Resolution Transmission Electron Microscope (TEM) (Peabody, MA)]. The average agglomerate size in saline [Normosol-R, (Nospira Inc., Lake Forest, IL)] and 5\% fetal bovine serum (FBS) was $191 \mathrm{~nm}$ as determined by dynamic light scattering [Malvern Zetasizer version 7.01, (Westborough, MA)]. FBS was added to the solution because it has the propensity to reduce nanoparticle agglomeration (Porter et al. 2008). Finally, the valence state of the $\mathrm{CeO}_{2} \mathrm{NP}$ was $81 \% \mathrm{Ce}^{4+}$ and $19 \% \mathrm{Ce}^{3+}$ determined by $\mathrm{x}$-ray photoelectron spectroscopy [PHI 5000 Versaprobe XPS, (Chanhassen, MN)].

Experimental Animals: Male Sprague-Dawley rats ( 8 - 11 wk old) were purchased from Hilltop Laboratories (Scottsdale, PA). The rats were housed at the West Virginia University 
Health Sciences Center Vivarium, in laminar flow cages, under controlled humidity and temperature, with a $12 \mathrm{~h}$ light/dark cycle, and food and water were provided ad libitum. Prior to use, the animals were acclimated for at least 2 days. All procedures were approved by the Institutional Animal Care and Use Committee at West Virginia University.

$\mathrm{CeO}_{2}$ NP Exposure Models: For the stock suspensions, the dry powder was weighed (0 - $10 \mathrm{mg}$ ) and added to $10 \mathrm{ml}$ of Normosol-R with 5\% FBS. The amount of dried powder weighed initially was adjusted to obtain the following final $\mathrm{CeO}_{2} \mathrm{NP}$ concentrations: 0 (saline and 5\% FBS), 50, 65, 100, 300, 400, 600, and $900 \mu \mathrm{g}$ per rat. The doses selected for the intravenous injection $(50,100$, and $900 \mu g)$ and gastric gavage $(100,300$, and 600 $\mu g)$ groups were selected to establish individual dose-response determinations for each exposure route. They were selected in attempt to encompass the minimal and maximal microvascular responses. We also anticipated these responses to be different for each exposure route. These doses cover a range of $0.14 \mathrm{mg} / \mathrm{kg}$ to $2.57 \mathrm{mg} / \mathrm{kg}$ (based on representative animal weight of $350 \mathrm{~g}$ ) (Tables 1 and 2). This range is within those previously reported for other in vivo studies with this nanoparticle (Hirst et al. 2013; Kim et al. 2012; Yokel et al. 2012). The $\mathrm{CeO}_{2}$ NP were vortexed for 5 min and then sonicated on ice for an additional $5 \mathrm{~min}$. Rats were lightly anesthetized with isoflurane gas ( $5 \%$ induction, $2-3.5 \%$ maintenance) and exposed by one of the following exposure routes. Intravenous Injection: Rats were injected in the tail vein with a bolus dose $(900 \mu \mathrm{l})$ of $\mathrm{CeO}_{2}$ NP stock suspension using a $23 \mathrm{G}$ needle. The final doses were 0 (saline and $5 \%$ FBS), 50, 100 , and $900 \mu \mathrm{g}$ per rat. Although the $100 \mu \mathrm{g}$ dose was part of the initial dose-response determination, this was also the dose that caused a $50 \%$ impairment in arteriolar reactivity $\left(E_{50}\right)$ and was then used for the subsequent experiments utilizing the $\mathrm{EC}_{50}$. Gastric Gavage: Rats were gavaged with a bolus dose $(300 \mu \mathrm{l})$ of $\mathrm{CeO}_{2} \mathrm{NP}$ stock suspension via 
a ball tipped needle. The final doses were 0 (saline and 5\% FBS), 100, 300, 400, and 600 $\mu \mathrm{g}$ per rat. The $400 \mu \mathrm{g}$ dose was the result of the $\mathrm{EC}_{50}$ calculation, and was only used after the initial dose-response was determined. Intratracheal Instillation: The dose-dependent microvascular effects of $\mathrm{CeO}_{2} \mathrm{NP}$ after pulmonary instillation have been investigated previously (Hirst et al. 2013; Minarchick et al. 2013); however, the mechanism(s) of toxicity involved is still unknown. Therefore, intratracheal instillation, intravenous injection, and gastric gavage were used to study the mechanism(s) of action for $\mathrm{CeO}_{2} \mathrm{NP}$. In the current study, rats were instilled with a bolus dose $(300 \mu \mathrm{l})$ of $\mathrm{CeO}_{2} \mathrm{NP}$ stock suspension via a ball tipped needle. The final dose was $65 \mu \mathrm{g}$ per rat. This dose was selected because previous experiments established that $65 \mu \mathrm{g}$ of $\mathrm{CeO}_{2} \mathrm{NP}$ was the $\mathrm{EC}_{50}$ for this exposure route (Minarchick et al. 2013). Furthermore, this dose was also determined to be relevant to occupational exposures (Minarchick et al. 2013). Rats were monitored after treatment until they regained consciousness. All animals were allowed to recover for $24 \mathrm{~h}$ prior to experimental assessments.

Arterial Pressure Acquisition and Isolated Arteriole Preparation: Arterial pressure and microvascular assessments were completed $24 \mathrm{~h}$ post- $\mathrm{CeO}_{2} \mathrm{NP}$ exposure.

Rats were anesthetized with isoflurane gas ( $5 \%$ induction, $2-3.5 \%$ maintenance) and placed on a heating pad to maintain a $37^{\circ} \mathrm{C}$ rectal temperature. The trachea was intubated to ensure an open airway and the right carotid artery was cannulated to measure arterial pressure. Data was measured with a pressure transducer and recorded with PowerLab830 (ADInstruments, Colorado Springs, CO). Animals were euthanized by removal of the heart. The mesentery was then removed and placed in a dissecting dish with physiological salt solution (PSS) maintained at $4{ }^{\circ} \mathrm{C}$. Multiple $(1-3) 4^{\text {th }}$ and $5^{\text {th }}$ order mesenteric arterioles were isolated, excised, and transferred to individual vessel chambers, cannulated between 
two glass pipettes, and secured with silk sutures (Living Systems Instrumentation, Burlington, VT). Each chamber was superfused with fresh, oxygenated $\left(5 \% \mathrm{CO}_{2} / 21 \% \mathrm{O}_{2}\right)$ PSS and warmed to $37^{\circ} \mathrm{C}$. Arterioles were pressurized to $80 \mathrm{~mm} \mathrm{Hg}$ using a servo control system and extended to their in situ length (Sun et al. 1992). Internal and external arteriolar diameters were measured with video calipers (Colorado Video, Boulder, CO).

Arteriolar Reactivity: During equilibration, arterioles were allowed to develop spontaneous tone $(\geq 20 \%$ ) after which various parameters of arteriolar function were analyzed. Spontaneous tone is a unitless number that ranges from 0 to $100 \%$, where $0 \%$ indicates an arteriole with no tone (or is at its maximal diameter) and $100 \%$ indicates an arteriole that is fully constricted. This number was calculated using the following equation: $\left[\left(D_{M}-D_{I}\right) / D_{M}\right] \times 100$, where $D_{M}$ is the maximal diameter (obtained at the conclusion of the experiment) of the arteriole and $D_{1}$ is the initial steady state diameter at the beginning of the experiment. Steady state diameter is defined as an arteriolar diameter that is constant for at least 1 min. Endothelium-Dependent Dilation: Arterioles were exposed to increasing concentrations of acetylcholine ( $\mathrm{ACh}, 10^{-9}-10^{-4} \mathrm{M}$ ) added to the vessel bath. Arterioles were also incubated with $\mathrm{N}^{\mathrm{G}}$-monomethyl-L-arginine (L-NMMA, $10^{-4} \mathrm{M}$ ), a NO synthase inhibitor (NOS), and/or indomethacin (INDO, $10^{-5} \mathrm{M}$ ), a cyclooxygenase (COX) inhibitor, prior to the ACh dose-response determination when indicated. These inhibitors were used to assess the influence of NO and COX products, respectively. Endothelium-Independent Dilation: Increasing concentrations of the spontaneous NO donor, spermine NONOate (SPR, $10^{-9}-10^{-4} \mathrm{M}$ ) were used to assess VSM responsiveness. Mechanotransduction: The VSM response to transmural pressure changes was analyzed by increasing the intraluminal pressure in $15 \mathrm{~mm} \mathrm{Hg}$ increments from 0 to $120 \mathrm{~mm} \mathrm{Hg}$. The endothelial response to shear stress was assessed by increasing intraluminal flow in $5 \mu \mathrm{l} / \mathrm{min}$ 
increments from 0 to $30 \mu \mathrm{l} / \mathrm{min}$. Arteriolar Vasoconstriction: The arterioles were exposed to increasing concentrations of the $\alpha$-adrenoceptor agonist, phenylephrine (PE, $\left.10^{-9}-10^{-4} \mathrm{M}\right)$. Vascular Smooth Muscle Signaling: The arterioles were exposed to increasing concentrations of the sGC activator, 3-(5'-hydroxymethyl-2'-furyl)-1-benzylindazole [YC-1, $\left.\left(10^{-9}-10^{-4} \mathrm{M}\right)\right]$ and the cGMP mimetic, 8-bromo-cGMP $\left(10^{-7}-10^{-4} \mathrm{M}\right)$, to assess VSM signaling. YC-1 was used to determine NO independent activation of SGC; however, YC-1 is capable of increasing SGC sensitivity to NO. Therefore, the YC-1 dose determination was completed in the presence of $1 \mathrm{H}-[1,2,4]$ oxadiazolo[4,3-a]quinoxalin-1-one (ODQ, $10^{-}$ $\left.{ }^{4} \mathrm{M}\right)$, an irreversible NOS inhibitor.

In all experiments, the steady state diameter of the arteriole was recorded for at least $1 \mathrm{~min}$ at each dose. Once a dose-response determination was completed, the vessel chamber was washed by carefully removing the superfusate and replacing it with fresh, warmed, oxygenated PSS. The dose-response determinations (typically 3 - 5) were performed in random order, expect for YC-1, which was performed last because of the irreversible nature of ODQ. After all experimental treatments were completed, the PSS was replaced with $\mathrm{Ca}^{2+}$-free PSS until the maximum passive diameter was established. All arterioles with $\leq 20 \%$ spontaneous tone or $\geq 150 \mu \mathrm{m}$ internal diameter were not analyzed. NO Measurements: NO measurements were obtained using a free radical analyzer [Apollo 4000, (World Precision Instruments, Inc., Sarasota, FL)]. A four-port water jacketed $\left(34^{\circ} \mathrm{C}\right)$, biosensing chamber was used for the NO measurements. Three ports contained electrochemical probes that were covered with a semi-permeable membrane that was NO selective (ISO-NOP, World Precision Instruments, Inc., Sarasota, FL). The probes were connected to the Apollo 4000 unit to make direct electrochemical NO measurements in real time (Nurkiewicz et al. 2009; Zhang 2004). The $4^{\text {th }}$ port contained a temperature probe 
that was removed to add reagents with a digital micropipettor. Electrodes were calibrated prior to use via S-nitroso-N-acetyl-D,L-penicillamine (SNAP, $4 \times 10^{-5}-1.6 \times 10^{-4} \mathrm{M}$ ) decomposition to NO in a copper catalyst solution (cuprous chloride, $0.1 \mathrm{M}$ ). Data were collected at a rate of 10 samples per sec and measurements were made only during steady state responses that were at least $30 \mathrm{sec}$ in duration. Acellular Measurements: $\mathrm{CeO}_{2} \mathrm{NP}$ $(0-2 \mu \mathrm{g} / \mathrm{ml})$ were placed in the water-jacketed chamber that contained $2 \mathrm{ml}$ cuprous chloride $(0.1 \mathrm{M})$. NO was measured in response to SNAP $\left(1.6 \times 10^{-4} \mathrm{M}\right)$ decomposition in this solution. Vascular Measurements: Mesenteric arteries and arterioles were dissected (24 h post- $\mathrm{CeO}_{2} \mathrm{NP}$ exposure via all three exposure routes) in $4^{\circ} \mathrm{C}$ PSS, excised, and pooled to form a loose pellet. The pellet was placed into the water jacketed chamber that contained $2 \mathrm{ml}$ Dulbecco's phosphate buffered saline with $\mathrm{Ca}^{2+}(3.6 \mathrm{mM}), \mathrm{L}$-arginine $(0.2$ $\mathrm{mM})$ and tetrahydrobiopterin $\left(\mathrm{BH}_{4}, 4 \mu \mathrm{M}\right)$. NO production was stimulated with a bolus dose of the $\mathrm{Ca}^{2+}$ ionophore, $\mathrm{A} 23187\left(10^{-5} \mathrm{M}\right)$. Data were normalized to tissue mass $(\mathrm{nM} / \mathrm{mg})$.

Free Radical Assessments: Electron spin resonance (ESR) was used for the detection of short-lived free radicals (superoxide and hydroxyl). Since these free radicals are highly reactive, an indirect method (spin-trapping) was used to measure these changes. This method required binding with a paramagnetic compound to form a longer-lived free radical product (spin adduct) and was ideal for detection and identification because of its specificity and sensitivity. All ESR measurements were collected using a Bruker EMX spectrometer (Billerica, MA). Hyperfine couplings were measured (to $0.1 \mathrm{G}$ ) directly from magnetic field separation using potassium tetraperoxochromate $\left(\mathrm{K}_{3} \mathrm{CrO}_{3}\right)$ and 1,1-diphenyl-2picrylhydrazyl (DPPH) as reference standards (Buettner 1987; Janzen et al. 1987). The instrument settings were consistent for all experiments [center field (3475 G), sweep width (100 G), resolution (1024 points), gain $\left(2.52 \times 10^{4}\right)$, mod frequency $(100 \mathrm{kHz})$, mod 
amplitude $(1 \mathrm{G})]$. All spectra measured were the accumulation of multiple $(1-3)$ scans. The relative free radical concentration was estimated by measuring the peak-to-peak height $(\mathrm{mm})$ of the observed spectra. Acellular Measurements: Xanthine $(14 \mathrm{mM})$, xanthine oxidase $(2 \mathrm{U})$ and the spin trap 5,5-dimethyl-1-pyrroline-N-oxide [DMPO, $(100 \mathrm{mM})$ ] were added to an ESR flat cell and measured immediately to detect the generation of superoxide free radicals. Iron sulfate $(0.001 \mathrm{mM})$, hydrogen peroxide $(0.1 \mathrm{mM})$ and DMPO $(100 \mathrm{mM})$ were added to an ESR flat cell and measured immediately to detect the generation of hydroxyl free radicals. These reactions were completed in both the presence and absence of $\mathrm{CeO}_{2} \mathrm{NP}(0.5$ and $2 \mathrm{mg} / \mathrm{ml})$. Cellular Measurements: Alveolar macrophages (AM) from control and $\mathrm{CeO}_{2} \mathrm{NP}$ exposed rats (via all three exposure routes) were harvested $24 \mathrm{~h}$ post- $\mathrm{CeO}_{2}$ NP exposure via bronchoalveolar lavage (BAL) (Minarchick et al. 2013). AM were suspended in phosphate buffered saline $\left(3 \times 10^{6} \mathrm{cells} / \mathrm{ml}\right)$ and incubated with DMPO $(200 \mathrm{mM})$ in the presence and absence of a positive control, hexavalent chromium $\left(\mathrm{Cr}^{6+}, 2\right.$ $\mathrm{mM})$ and $\mathrm{CeO}_{2} \mathrm{NP}(1 \mathrm{mg} / \mathrm{ml})$ for 2 min at $37{ }^{\circ} \mathrm{C}$ prior to being transferred to an ESR flat cell for measurements.

Equations: Spontaneous tone was calculated using the following equation: Spontaneous tone $(\%)=\left[\left(D_{M}-D_{l}\right) / D_{M}\right] \times 100$, where $D_{M}$ is the maximal diameter and $D_{1}$ is the initial steady state diameter recorded prior to any experimental assessments. Active responses to pressure were normalized to the maximal diameter using the following formula: Normalized diameter $=D_{S S} / D_{M}$, where Dss is the steady state diameter recorded during each pressure change. The experimental responses to ACh, SPR, and flow are expressed using the following equation: Diameter (percent maximal response) $\left.=\left[D_{s s}-D_{\text {con }}\right) /\left(D_{M}-D_{\text {con }}\right)\right] \times 100$, where $\mathrm{Dcon}$ is the control diameter recorded immediately prior to the dose-response determination, Dss is the steady state diameter at each dose of the determination. Shear 
stress ( $(T)$ was calculated from volumetric flow $(Q)$ using the following formula: $T=4 \eta Q / \pi r^{3}$, where $\eta$ is viscosity $(0.8 \mathrm{cp}), Q$ is volumetric flow rate [measured with a calibrated flow indicator (Living System Instruments, Burlington, VT)], and $r$ is arteriole radius. The experimental response to PE is expressed using the following equation: Diameter (percent maximal response) $\left.=-\left[D_{\text {con }}-D_{S S}\right) / D_{\text {con }}\right] \times 100$. Wall thickness $(\mathrm{WT})$ was calculated from the measurement of both inner (ID) and outer (OD) steady state arteriolar diameters at the end of the $\mathrm{Ca}^{2+}$-free wash using the following equation: $W T=(O D-I D) / 2$. Wall-to-lumen ratio (WLR) was calculated using the following equation: $W L R=W T / I D$.

Statistics: Data are expressed as means \pm standard error (SE). Point-to-point differences in the dose-response determinations were evaluated using two-way repeated measures analysis of variance (ANOVA) with a Student-Newman-Keuls post-hoc analysis when significance was found. Statistical differences among the slopes of the dose-response determinations were determined by either a linear or nonlinear regression analysis. Regression analysis was used to determine differences among collective data sets. Linear regression analysis was performed for predictable data sets where a step-wise stimuli or a typical biological response were observed. However, in biological systems a typical linear response is not always observed. In this case, a nonlinear regression analysis was applied to the data set. The animal characteristics, arteriolar characteristics, free radical peak height, and NO levels were analyzed using a one-way ANOVA with a Student-NewmanKeuls post-hoc analysis when significance was found. The $\mathrm{EC}_{50}$ was determined using a four parameter logistic analysis. All statistical analyses were completed with GraphPad Prism 5 (San Diego, CA) and SigmaPlot 11.0 (San Jose, CA). Significance was set at $p \leq$ 0.05 and $\mathrm{n}$ is the number of arterioles. 


\section{Results:}

Animal and Arteriolar Characteristics: There were no differences in animal age (Table 1). Similarly, $\mathrm{CeO}_{2}$ NP exposure route did not influence animal weight, mean arterial pressure or heart weight (Table 1). Basal arteriolar diameter, spontaneous tone, WT, or WLR were also not affected by exposure route or dose (Table 2). These data suggest that basal arteriolar tone and/or anatomy are not affected by exposure route or $\mathrm{CeO}_{2} \mathrm{NP}$. However, it remains to be determined if such exposures influence arteriolar tone in vivo.

Endothelium-Dependent Dilation: Endothelium-dependent arteriolar dilation was impaired significantly in a dose-dependent fashion following intravenous $\mathrm{CeO}_{2} \mathrm{NP}$ injections of 50,100, and $900 \mu \mathrm{g}$ (Figure 1A). Gastric $\mathrm{CeO}_{2}$ NP exposure impaired dilation to a lesser extent at the 100 and $300 \mu \mathrm{g}$ doses, but the effect was similar at the higher doses $(600 \mu \mathrm{g}$ and $900 \mu \mathrm{g}$, Figures 1A vs.1B). Taken together, these results indicate that $\mathrm{CeO}_{2} \mathrm{NP}$ exposure impairs endothelium-dependent microvascular function via nonpulmonary exposure routes.

Endothelium-Independent Dilation: Vasodilation in response to $\mathrm{NO}$ donation was impaired significantly following intravenous $\mathrm{CeO}_{2}$ NP injection, but this effect was not dosedependent (Figure 2A). Exposure via gastric gavage also altered arteriolar VSM responsiveness. Interestingly, there was an augmented response to NO following $100 \mu \mathrm{g}$ of $\mathrm{CeO}_{2} \mathrm{NP}$; however, $600 \mu \mathrm{g}$ of $\mathrm{CeO}_{2} \mathrm{NP}$ significantly attenuated the response to $\mathrm{NO}$ (Figure 2B). These results provide evidence that $\mathrm{CeO}_{2} \mathrm{NP}$ exposure also impairs endothelium-independent arteriolar VSM signaling.

Mechanotransduction: Myogenic responsiveness was assessed from step-wise increases in transmural pressure. There were no significant differences in the myogenic responsiveness to pressure independent of $\mathrm{CeO}_{2} \mathrm{NP}$ exposure route or dose (Figure 3A 
and B). It is worthwhile to note that there was an augmentation of the myogenic response at the highest pressure $(120 \mathrm{~mm} \mathrm{Hg})$ following gastric gavage of $100 \mu \mathrm{g}$ of $\mathrm{CeO}_{2} \mathrm{NP}$ (Figure 3B). Because there were no overall differences in the slopes of these determinations and this augmentation occurred at a single pressure, the biological relevance of this observation is unclear. Vasodilation in response to changes in shear stress was assessed via increases in intraluminal flow. Independent of exposure route, there were no significant differences in the response to changes in intraluminal flow or endothelial shear stress (Figures 4A - D). These data demonstrate that the ability of arterioles to transduce physical forces is unaffected by $\mathrm{CeO}_{2} \mathrm{NP}$ given by alternate exposure routes.

Arteriolar Vasoconstriction: There was an augmented response to $\mathrm{PE}\left(10^{-6}\right.$ and $\left.10^{-5} \mathrm{M}\right)$ following $100 \mu \mathrm{g}$ of intravenously injected $\mathrm{CeO}_{2} \mathrm{NP}$; however, there were no differences in the overall slopes of the determinations for any dose (Figure 5A). $\mathrm{CeO}_{2} \mathrm{NP}(100 \mu \mathrm{g})$ given by gastric gavage resulted in an augmented response to PE $\left(10^{-5} \mathrm{M}\right)$, but there were no differences in the overall slopes of the determinations for any $\mathrm{CeO}_{2} \mathrm{NP}$ dose (Figure 5B). These data provide evidence that VSM adrenergic sensitivity may be augmented following intravenous $\mathrm{CeO}_{2} \mathrm{NP}$ injections, but additional studies with other vasoactive agonists are necessary.

$\mathrm{CeO}_{2} \mathrm{NP} \mathrm{EC}_{50}$ : The calculated $\mathrm{EC}_{50}$ for $\mathrm{ACh}$ and SPR was determined for each exposure route (Figures $6 \mathrm{~A}$ and $\mathrm{B}$ ). The $\mathrm{CeO}_{2} \mathrm{NP} \mathrm{EC}_{50}$ ranged from 62 to $450 \mu \mathrm{g}$ and was exposure route-dependent. Because we wanted to compare the influence of different exposure routes on microvascular function, the remainder of the experiments in this study used an average $\mathrm{CeO}_{2} \mathrm{NP}$ dose derived from the $\mathrm{EC}_{50}$ calculation (Tables 1 and 2). The scatter plot represents the maximal response to $\mathrm{ACh}\left(10^{-4} \mathrm{M}\right)$ for all exposure routes (Figure $6 \mathrm{C}$ ). 
The maximal impairment occurred at the highest doses. However, these doses were different between the exposure routes (Figure 6C). This suggests that further increasing the dose from a given exposure route's current highest dose would have further impaired microvascular function only minimally. The similar maximal responses for each exposure route at the highest dose and the variable $\mathrm{EC}_{50}$ highlights that the severity of the microvascular dysfunction following $\mathrm{CeO}_{2} \mathrm{NP}$ administration is exposure route-dependent. Contribution of NO and COX Products to ACh-Induced Vasodilation: There were no significant differences in the responses of control arterioles among all the exposure routes (data not shown). This indicates that no experimental artifact resulted from the different exposure routes and, therefore, results from control animals were pooled for the analyses reported in Figures 7 - 10. Incubation of control arterioles with either L-NMMA or INDO significantly reduced vasodilation in response to $\mathrm{ACh}$, and incubation with both inhibitors abolished arteriolar dilation (Figure 7A). Intratracheal instillation of $\mathrm{CeO}_{2} \mathrm{NP}$ significantly impaired endothelium-dependent arteriolar dilation; however, L-NMMA incubation restored vasodilation in response to $\mathrm{ACh}\left(10^{-5}\right.$ and $\left.10^{-4} \mathrm{M}\right)$ (Figure 7B). Intravenous $\mathrm{CeO}_{2} \mathrm{NP}$ injection significantly impaired the ACh response and this was further impaired during INDO incubation (Figure 7C). Finally, the significantly impaired dilation response to ACh that followed gastric gavage of $\mathrm{CeO}_{2} \mathrm{NP}$ was attenuated further during L-NMMA incubation (Figure 7D). Overall, these data provide initial evidence that the differential contribution of $\mathrm{NO}$ and $\mathrm{COX}$ products to vasodilation after $\mathrm{CeO}_{2} \mathrm{NP}$ exposure is a function of the different routes through which these materials enter the body.

NO Measurements: The ability of $\mathrm{CeO}_{2} \mathrm{NP}$ to react with $\mathrm{NO}$ was assessed first in an acellular environment. NO was spontaneously released using a bolus dose of SNAP (1.6 $x 10^{-4} \mathrm{M}$ ) in the presence of increasing doses of $\mathrm{CeO}_{2} \mathrm{NP}$. As the $\mathrm{CeO}_{2} \mathrm{NP}$ concentration 
increased, the amount of detectable $\mathrm{NO}$ decreased, indicating that $\mathrm{CeO}_{2} \mathrm{NP}$ are capable of reacting with NO (Figure $\mathbf{8 A}$ ). In a second set of experiments, microvascular tissue was used to assess its ability to produce NO. In these experiments, vascular NO production was stimulated by a bolus dose of the $\mathrm{Ca}^{2+}$ ionophore, $\mathrm{A} 23187\left(10^{-5} \mathrm{M}\right)$. This stimulation increased significantly the amount of $\mathrm{NO}$ detected. In the $\mathrm{CeO}_{2} \mathrm{NP}$ intravenous injection group, this response was significantly impaired (relative to control and intratracheal instillation exposure groups) (Figure 8B). These results suggest that intravenous injection of $\mathrm{CeO}_{2} \mathrm{NP}$ may have a greater impact on $\mathrm{NO}$ bioavailability than either intratracheal instillation or gastric gavage.

Free Radical Assessments: ESR was used to determine if $\mathrm{CeO}_{2} \mathrm{NP}$ were capable of generating and/or scavenging free radicals. There was a significant reduction in the level of free radicals detected in the presence of $\mathrm{CeO}_{2} \mathrm{NP}$ (Figure 9A). This finding supports that $\mathrm{CeO}_{2} \mathrm{NP}$ are capable of reacting with free radicals in an acellular environment, and this is consistent with anti-oxidant behavior. AM alone did not generate a significant amount of free radicals; however, when directly exposed to $\mathrm{CeO}_{2} \mathrm{NP}(1 \mathrm{mg} / \mathrm{ml})$, there was a significant increase in free radical generation (Figure 9B). Furthermore, in a positive control experiment, AM generated a significant increase in free radical generation during incubation with $\mathrm{Cr}^{6+}(2 \mathrm{mM})$ (Figure 9B). Interestingly, when $\mathrm{CeO}_{2} \mathrm{NP}$ and $\mathrm{Cr}^{6+}$ were simultaneously incubated with the AM there was a significant decrease in the amount of free radicals detected compared to $\mathrm{Cr}^{6+}$ alone (Figure 9B). It appears that $\mathrm{CeO}_{2} \mathrm{NP}$ are capable of generating and scavenging free radicals in a cellular environment. Further experimentation with additional $\mathrm{CeO}_{2} \mathrm{NP}$ doses would not have revealed more insight into their anti-oxidant potential because the current experiments determined that, although the doses used did affect the level of free radicals in vitro, the effect was not dose-dependent. 
AM were harvested from rats that had been exposed via intratracheal instillation, intravenous injection, or gastric gavage. The AM alone from these animals did not generate any detectable free radicals (Figure 9C). In contrast, there was a significant increase in free radical generation compared to the controls in all exposure groups when $\mathrm{CeO}_{2} \mathrm{NP}$ were incubated with the AM (Figure 9C). However, the AM generated significantly fewer free radicals [following an additional $\mathrm{CeO}_{2} \mathrm{NP}(1 \mathrm{mg} / \mathrm{ml})$ dose] from intratracheal instillation and intravenous injection exposure groups compared to the control and gastric gavage exposure groups (Figure 9C). While it is not surprising that the $\mathrm{CeO}_{2} \mathrm{NP}$ are capable of stimulating AM free radical generation, it is interesting that in the correct environment, they may alternatively function as a reducing agent.

Smooth Muscle Signaling: There was a significant decrease in vasodilation at low YC-1 concentrations $\left(10^{-7}-10^{-5} \mathrm{M}\right)$ in all exposure groups (Figure 10A). The responsiveness to increasing concentrations of cGMP was also assessed. Similarly, there was a significant impairment in the response to increasing levels of 8 -bromo-cGMP $\left(10^{-4} \mathrm{M}\right)$ in all three exposure groups (Figure 10B). These results provide evidence that $\mathrm{CeO}_{2} \mathrm{NP}$ exposure impairs VSM relaxation via a signaling mechanism downstream of initial SGC activation. 


\section{Discussion:}

There are three major findings in this investigation. To our knowledge, this study is the first to establish the presence of both endothelium-dependent and -independent microvascular dysfunction following intravenous and gastric $\mathrm{CeO}_{2}$ NP exposure. This observed microvascular dysfunction was similar to those impairments following intratracheal instillation (Minarchick et al. 2013). However, the severity of this dysfunction was route-dependent (intratracheal instillation $>$ intravenous injection $>$ gastric gavage). The second major finding was that there were exposure route-dependent decreases in NO production and increases in ROS generation. Finally, independent of exposure route, $\mathrm{CeO}_{2}$ NP significantly impaired sGC activation and cGMP responsiveness.

$\mathrm{CeO}_{2} \mathrm{NP}$ hold great potential for future therapeutics, and investigations of the biological effects associated with $\mathrm{CeO}_{2} \mathrm{NP}$ need to encompass therapeutically-relevant dose ranges (Celardo et al. 2011). Our initial toxicological assessments utilized a range that ensured overlap between exposure routes, while also being therapeutically-relevant. In terms of therapeutic applications, intravenous and oral exposures are common in human pharmaceutical uses and often expose patients to several milligrams of drug per dose (Brannon-Peppas and Blanchette 2004; Sastry et al. 2000). To our knowledge, $\mathrm{CeO}_{2} \mathrm{NP}$ have yet to be used therapeutically via ingestion. The intravenous doses used in this experiment are similar to $\mathrm{CeO}_{2} \mathrm{NP}$ concentrations that are being tested for protection against ischemic stroke in animals (Kim et al. 2012). Therefore, the doses used to establish the $\mathrm{EC}_{50}$ for intravenous and gastric exposures here are relevant as they are within therapeutic or pharmaceutical ranges.

It is reasonable to speculate that different blood nanoparticle concentrations could be achieved by administering $\mathrm{CeO}_{2} \mathrm{NP}$ via different exposure routes and the levels of direct 
nanoparticle-endothelial interaction within $24 \mathrm{~h}$ would vary (Stapleton and Nurkiewicz 2014). Intravenous exposure, undoubtedly, resulted in the highest level of direct nanoparticle-endothelial contact. We can assume that at time naught (initial injection) all the $\mathrm{CeO}_{2} \mathrm{NP}$ are in the plasma (Stapleton and Nurkiewicz 2014). Over time, these nanoparticles could be distributed to other organs and/or cleared from the body (Yokel et al. 2012). From a pulmonary standpoint, ferric oxide nanoparticles translocate from the lung to other systemic organs at a rate of $3.06 \mu \mathrm{g} /$ day (Zhu et al. 2009). It is possible that a similar amount of $\mathrm{CeO}_{2} \mathrm{NP}$ translocates from the lungs, but the exact rate is currently unknown. This migration of nanoparticles may result in direct endothelial interaction for some of the nanoparticles. It has been shown that within 24 to $48 \mathrm{~h}$ after inhalation or intravenous injection of $\mathrm{CeO}_{2} \mathrm{NP}$, the nanoparticles translocate to various organs, specifically the liver and spleen (Geraets et al. 2012; Yokel et al. 2012). Following inhalation, $0.10 \%$ of the inhaled dose was observed in the liver and $0.006 \%$ in the spleen (Geraets et al. 2012). Intravenous injection increased this translocation to as high as $10 \%$ of the dose in the same organs (Yokel et al. 2012). Furthermore, accumulation in various organs may also impact microvascular function following different exposure routes due to indirect effects from these organs.

Gastric exposure resulted in the delivery of a bolus dose of $\mathrm{CeO}_{2} \mathrm{NP}$ directly into the stomach. Peristalsis then contributes to the distribution of the nanoparticles throughout the small and large intestines. Titanium dioxide nanoparticles have been shown to translocate from the gut and it is possible that $\mathrm{CeO}_{2} \mathrm{NP}$ may respond in a similar fashion (Brun et al. 2014). Additionally, studies have shown that following gastric $\mathrm{CeO}_{2} \mathrm{NP}$ exposure $\sim 5 \%$ of the total dose is absorbed, which indicates the actual exposure dose for gastric gavage may be lower than the initial bolus dose (Hirst et al. 2013). This difference 
in the absorbed and initial concentrations may account for why there is minimal dysfunction at the lower $\mathrm{CeO}_{2} \mathrm{NP}$ gastric gavage doses. It may also account for larger microvascular impairment following $600 \mu \mathrm{g}$ of $\mathrm{CeO}_{2} \mathrm{NP}$ because the nanoparticles may be absorbed in more areas (and to a greater extent) throughout the gastrointestinal tract. Furthermore, $\mathrm{pH}$, vascularization, and water content varies throughout the digestive tract (e.g. stomach, small and large intestines) and may affect the reactivity, concentration, and translocation of the nanoparticles (Hayes et al. 2002; Xu and Qu 2014). Our study did not assess $\mathrm{CeO}_{2}$ NP blood concentration or clearances following the three exposure routes. Therefore, the blood concentrations prior to microvascular assessments are unknown.

Finally, it should be noted that the likelihood of direct endothelial interaction does not implicitly predict the severity of microvascular dysfunction. Pulmonary exposure resulted in the greatest microvascular dysfunction despite likely having lower $\mathrm{CeO}_{2} \mathrm{NP}$ endothelial contact. This indicates that other factors (e.g. inflammation, neurogenic stimuli, and free cerium ions) may play a role in the resultant microvascular dysfunction. The influences and identification of these factors warrant further investigation.

Endothelium-dependent dilation is the net product of many factors, and $\mathrm{CeO}_{2} \mathrm{NP}$ exposure may alter the origin and/or targets of these factors. For example, after pulmonary $\mathrm{CeO}_{2} \mathrm{NP}$ exposure, NOS inhibition restores microvascular function at the highest ACh concentrations (Figure 7B). This could be partially due to the activation of endotheliumderived hyperpolarizing factor (EDHF), which NO has been shown to inhibit (Nishikawa et al. 2000). It is possible that when NO production is inhibited, EDHF may promote VSM relaxation through a pathway independent of sGC/cGMP signaling (Parkington et al. 2008). Additional experiments are needed to deduce the activation and roles of compensatory vasodilatation mechanisms following $\mathrm{CeO}_{2} \mathrm{NP}$ exposure. 
$\mathrm{CeO}_{2} \mathrm{NP}$ are capable of being internalized by cardiac progenitor cells, potentially through clathrin- and/or caveolae-mediated endocytic pathways (Pagliari et al. 2012; Singh et al. 2010). If $\mathrm{CeO}_{2} \mathrm{NP}$ are internalized by endothelial cells, the function of enzymes (e.g. NOS), substrates (e.g. L-arginine), and organelles (e.g. mitochondria) are potentially compromised. Diesel exhaust exposure and decreased L-arginine availability lead to increased superoxide via NOS uncoupling (Boger and Bode-Boger 2000; Cherng et al. 2011). Therefore, changes in NOS activity may also be mechanistically linked to microvascular impairment and decreased $\mathrm{NO}$ bioavailability following $\mathrm{CeO}_{2} \mathrm{NP}$ exposure.

The observed changes in NO bioavailability may be linked to the valence state of the cerium. $\mathrm{CeO}_{2} \mathrm{NP}$ exist in two valence states $\left(\mathrm{Ce}^{4+}\right.$ and $\left.\mathrm{Ce}^{3+}\right)$ and readily switch between them based on local environmental factors (e.g. ROS, and pH) (Hayes et al. 2002; Xu and Qu 2014). The ratio of the valence states may be predicative of reactivity in a biological environment. The $\mathrm{CeO}_{2} \mathrm{NP}$ used in this study were $81 \% \mathrm{Ce}^{4+} / 19 \% \mathrm{Ce}^{3+}$. This ratio would be consistent with decreased NO bioavailability following intravenous exposure as $\mathrm{Ce}^{4+}$ is more prone than $\mathrm{Ce}^{3+}$ to reacting with $\mathrm{NO}\left(\mathrm{Xu}\right.$ and Qu 2014). Furthermore, $\mathrm{CeO}_{2}$ NP valence state alterations may also account for the lack of decreased NO bioavailability following pulmonary exposure. Previous studies with other nanoparticles have resulted in a decreased NO bioavailability due to increased ROS production following pulmonary exposure (Nurkiewicz et al. 2009). It is possible that the valence state of the $\mathrm{CeO}_{2} \mathrm{NP}$ (either as a reductant or oxidant) protects/preserves NO bioavailability following pulmonary exposure due to its ability to react with ROS. Gastric exposure to $\mathrm{CeO}_{2} \mathrm{NP}$ also results in contact with stomach acid $(\mathrm{pH} \sim 2)$. This exposure to a highly acidic environment may increase the $\mathrm{Ce}^{3+}$ concentration, thereby decreasing its reactivity with $\mathrm{NO}$ (Hayes et al. 2002). However, it is unclear if the altered $\mathrm{Ce}^{3+}$ concentration is maintained once the $\mathrm{CeO}_{2}$ 
NP exit the acidic environment of the stomach and enter the basic environment of the intestine. This potential valence state shift may be a contributing factor to the absence of significant changes in $\mathrm{NO}$ bioavailability and a higher $\mathrm{CeO}_{2} \mathrm{NP} \mathrm{EC}_{50}$ following gastric exposures.

NO bioavailability is also influenced by changes in local ROS levels, which can impair microvascular function (LeBlanc et al. 2010). Many factors, including mitochondrial dysfunction, NOS uncoupling, and possibly $\mathrm{CeO}_{2}$ NP themselves, influence ROS generation (Cherng et al. 2011; Dabkowski et al. 2009). $\mathrm{CeO}_{2} \mathrm{NP}$ exposure has been associated with decreased or unaffected ROS, thus characterizing the $\mathrm{CeO}_{2} \mathrm{NP}$ as an antioxidant, whereas other studies have documented increased ROS generation following either co-incubation, pulmonary, or intravenous exposure (Gojova et al. 2009; Pagliari et al. 2012; Srinivas et al. 2011; Yokel et al. 2012). Our study contributes conflicting results when comparing the influence of $\mathrm{CeO}_{2} \mathrm{NP}$ and ROS. Initial exposure to $\mathrm{CeO}_{2} \mathrm{NP}$ did not affect ROS generation; however, a subsequent $\mathrm{CeO}_{2} \mathrm{NP}$ treatment did cause an increase in ROS generation, indicating that the first exposure activated and/or primed AM following intratracheal instillation and intravenous injection. We speculate that the activated AM, are already producing ROS (although undetectable with ESR) so that in the presence of an additional $\mathrm{CeO}_{2} \mathrm{NP}$ exposure, the nanoparticles may begin to act as an anti-oxidant and react with surrounding ROS. The increased ROS production following this dose in the control and gastric gavage groups may be because the AM are seeing the nanoparticles for the first time (Figure 9). In this environment, $\mathrm{CeO}_{2} \mathrm{NP}$ act as a pro-oxidant to increase basal ROS production in order to shift valence states. It appears the initial environment and the basal ROS concentration may influence $\mathrm{CeO}_{2}$ NP pro- and anti-oxidant activity. We speculate that in a low ROS environment (e.g. unstimulated $\mathrm{AM}$ ), $\mathrm{CeO}_{2} \mathrm{NP}$ react with 
surrounding cells, which lead to increased ROS generation. This elevated level of ROS may be needed for $\mathrm{CeO}_{2} \mathrm{NP}$ to shift between $\mathrm{Ce}^{4+}$ and $\mathrm{Ce}^{3+}$ valence states. However, in a high ROS environment, these nanoparticles may not generate additional ROS because the level is sufficient to shift valence states. The influence of $\mathrm{CeO}_{2} \mathrm{NP}$ treatment on AM activation requires additional investigation, but is currently outside the scope of this manuscript. Finally, this study focused on harvested AM and ROS generation and/or scavenging, so the influence of ROS at the microvascular level following $\mathrm{CeO}_{2} \mathrm{NP}$ exposure is still unknown.

The observed endothelium-independent impairment is, at least partially, due to VSM dysfunction, as sGC and downstream elements (e.g. cGMP) were observed to display attenuated responses to YC-1 and 8-bromo-cGMP. Changes in cGMP signaling may disrupt myoendothelial junction regulation, which can lead to an increase in intracellular $\mathrm{Ca}^{2+}$ in the VSM and impair relaxation (Dora et al. 1997). Cyclic GMP is critical for PKG activation by binding to specific sites on the enzyme (Taylor et al. 2004). If activation is insufficient and intracellular $\mathrm{Ca}^{2+}$ does not decrease, the VSM cannot relax properly. Furthermore, it is possible that PKG formation and/or functional levels decrease after $\mathrm{CeO}_{2}$ NP exposure. If PKG function is decreased, there may be a change in the enzyme's kinetics and intracellular $\mathrm{Ca}^{2+}$ may not be adequately sequestered, thus impairing dilation (Perri et al. 2006). Lastly, increased phosphodiesterase activity can impair VSM relaxation by prematurely or rapidly decreasing cGMP (Rybalkin et al. 2003). Investigations into the specific roles of cGMP, PKG, and phosphodiesterase are necessary to determine their impact on endothelium-independent microvascular impairment following $\mathrm{CeO}_{2} \mathrm{NP}$ exposure. 
In conclusion, we provide evidence that intravenous and gastric $\mathrm{CeO}_{2} \mathrm{NP}$ exposures cause endothelium-dependent and -independent arteriolar dysfunction. Furthermore, these impairments may be mechanistically linked to decreased NO bioavailability and altered VSM signaling, specifically involving cGMP. These results increase our insight of the effects of exposure to $\mathrm{CeO}_{2} \mathrm{NP}$; however, the effects reported here must be, ultimately, directly tested in vivo. This understanding is critical for the continued and expanded development of therapeutic applications for $\mathrm{CeO}_{2} \mathrm{NP}$. 
Funding Information: This work is supported by the National Institutes of Health R01 - ES015022 (TRN), F32 - ES023435 (PAS), the National Science Foundation Cooperative Agreement - 1003907 (VCM and TRN), and DGE - 1144676 (VCM).

Acknowledgements: The authors would like to thank Carroll McBride for his expert technical assistance in this study. The authors disclose no conflicts of interest.

Disclaimer: The findings and conclusions in this report are those of the authors and do not necessarily represent the views of the National Institute for Occupational Safety and Health $(\mathrm{NIOSH})$. Mention of brand name does not constitute product endorsement by $\mathrm{NIOSH}$. 


\section{Reference List:}

Boger, R. H., and Bode-Boger, S. M. (2000). Asymmetric dimethylarginine, derangements of the endothelial nitric oxide synthase pathway, and cardiovascular diseases. Semin. Thromb. Hemost. 26(5), 539-545.

Borm, P. J., Robbins, D., Haubold, S., Kuhlbusch, T., Fissan, H., Donaldson, K., Schins, R., Stone, V., Kreyling, W., Lademann, J., Krutmann, J., Warheit, D., and Oberdorster, E. (2006). The potential risks of nanomaterials: a review carried out for ECETOC. Part Fibre. Toxicol. 3, 11.

Brannon-Peppas, L., and Blanchette, J. O. (2004). Nanoparticle and targeted systems for cancer therapy. Adv. Drug Deliv. Rev. 56(11), 1649-1659.

Brun, E., Barreau, F., Veronesi, G., Fayard, B., Sorieul, S., Chaneac, C., Carapito, C., Rabilloud, T., Mabondzo, A., Herlin-Boime, N., and Carriere, M. (2014). Titanium dioxide nanoparticle impact and translocation through ex vivo, in vivo and in vitro gut epithelia. Part Fibre. Toxicol. 11, 13.

Buettner, G. R. (1987). Spin trapping: ESR parameters of spin adducts. Free Radic. Biol. Med. 3(4), 259-303.

Cassee, F. R., van Balen, E. C., Singh, C., Green, D., Muijser, H., Weinstein, J., and Dreher, K. (2011). Exposure, health and ecological effects review of engineered nanoscale cerium and cerium oxide associated with its use as a fuel additive. Crit Rev. Toxicol. 41(3), 213-229.

Celardo, I., Traversa, E., and Ghibelli, L. (2011). Cerium oxide nanoparticles: a promise for applications in therapy. J. Exp. Ther. Oncol. 9(1), 47-51.

Cherng, T. W., Paffett, M. L., Jackson-Weaver, O., Campen, M. J., Walker, B. R., and Kanagy, N. L. (2011). Mechanisms of diesel-induced endothelial nitric oxide synthase dysfunction in coronary arterioles. Environ. Health Perspect. 119(1), 98-103.

Dabkowski, E. R., Williamson, C. L., Bukowski, V. C., Chapman, R. S., Leonard, S. S., Peer, C. J., Callery, P. S., and Hollander, J. M. (2009). Diabetic cardiomyopathy-associated dysfunction in spatially distinct mitochondrial subpopulations. Am. J. Physiol Heart Circ. Physiol 296(2), H359-H369.

Department of Health and Human Services. (2009). Current Intelligence Bulletin 60: Interim Guidance for Medical Screening and Hazard Surveillance for Workers Potentially Exposed to Engineered Nanoparticles. 2009-116. 2National Institute for Occupational Safety and Health; Centers for Disease Control and Prevention. 
Dora, K. A., Doyle, M. P., and Duling, B. R. (1997). Elevation of intracellular calcium in smooth muscle causes endothelial cell generation of $\mathrm{NO}$ in arterioles. Proc. Natl. Acad. Sci. U. S. A 94(12), 6529-6534.

Geraets, L., Oomen, A. G., Schroeter, J. D., Coleman, V. A., and Cassee, F. R. (2012). Tissue distribution of inhaled micro- and nano-sized cerium oxide particles in rats: results from a 28-day exposure study. Toxicol. Sci. 127(2), 463-473.

Gewaltig, M. T., and Kojda, G. (2002). Vasoprotection by nitric oxide: mechanisms and therapeutic potential. Cardiovasc. Res. 55(2), 250-260.

Gojova, A., Lee, J. T., Jung, H. S., Guo, B., Barakat, A. I., and Kennedy, I. M. (2009). Effect of cerium oxide nanoparticles on inflammation in vascular endothelial cells. Inhal. Toxicol. 21 Suppl 1, 123-130.

Hayes, S. A., Yu, P., O'Keefe, T. J., O'Keefe, M. J., and Stoffer, J. O. (2002). The Phase Stability of Cerium Species in Aqueous Systems I. E-pH Diagram for the Ce-HClO4-H2O System. Journal of The Electrochemical Society 149(12), C623-C630.

Heckert, E. G., Karakoti, A. S., Seal, S., and Self, W. T. (2008). The role of cerium redox state in the SOD mimetic activity of nanoceria. Biomaterials 29(18), 2705-2709.

Hirst, S. M., Karakoti, A., Singh, S., Self, W., Tyler, R., Seal, S., and Reilly, C. M. (2013). Bio-distribution and in vivo antioxidant effects of cerium oxide nanoparticles in mice. Environ. Toxicol. 28(2), 107-118.

Janzen, E. G., Towner, R. A., and Haire, D. L. (1987). Detection of free radicals generated from the in vitro metabolism of carbon tetrachloride using improved ESR spin trapping techniques. Free Radic. Res. Commun. 3(6), 357-364.

Kim, C. K., Kim, T., Choi, I. Y., Soh, M., Kim, D., Kim, Y. J., Jang, H., Yang, H. S., Kim, J. Y., Park, H. K., Park, S. P., Park, S., Yu, T., Yoon, B. W., Lee, S. H., and Hyeon, T. (2012). Ceria nanoparticles that can protect against ischemic stroke. Angew. Chem Int. Ed Engl. 51(44), 11039-11043.

LeBlanc, A. J., Moseley, A. M., Chen, B. T., Frazer, D., Castranova, V., and Nurkiewicz, T. R. (2010). Nanoparticle inhalation impairs coronary microvascular reactivity via a local reactive oxygen species-dependent mechanism. Cardiovasc. Toxicol. 10(1), 27-36.

$\mathrm{Li}, \mathrm{H}$. , and Forstermann, U. (2000). Nitric oxide in the pathogenesis of vascular disease. J. Pathol. 190(3), 244-254.

Ma, J. Y., Zhao, H., Mercer, R. R., Barger, M., Rao, M., Meighan, T., Schwegler-Berry, D., Castranova, V., and Ma, J. K. (2011). Cerium oxide nanoparticle-induced pulmonary inflammation and alveolar macrophage functional change in rats. Nanotoxicology. 5(3), 312-325. 
Minarchick, V. C., Stapleton, P. A., Porter, D. W., Wolfarth, M. G., Ciftyurek, E., Barger, M., Sabolsky, E. M., and Nurkiewicz, T. R. (2013). Pulmonary cerium dioxide nanoparticle exposure differentially impairs coronary and mesenteric arteriolar reactivity. Cardiovasc. Toxicol. 13(4), 323-337.

Nalabotu, S. K., Kolli, M. B., Triest, W. E., Ma, J. Y., Manne, N. D., Katta, A., Addagarla, H. S., Rice, K. M., and Blough, E. R. (2011). Intratracheal instillation of cerium oxide nanoparticles induces hepatic toxicity in male Sprague-Dawley rats. Int. J. Nanomedicine. 6, 2327-2335.

Nishikawa, Y., Stepp, D. W., and Chilian, W. M. (2000). Nitric oxide exerts feedback inhibition on EDHF-induced coronary arteriolar dilation in vivo. Am. J. Physiol Heart Circ. Physiol 279(2), H459-H465.

Nurkiewicz, T. R., Porter, D. W., Hubbs, A. F., Stone, S., Chen, B. T., Frazer, D. G., Boegehold, M. A., and Castranova, V. (2009). Pulmonary nanoparticle exposure disrupts systemic microvascular nitric oxide signaling. Toxicol. Sci. 110(1), 191-203.

Pagliari, F., Mandoli, C., Forte, G., Magnani, E., Pagliari, S., Nardone, G., Licoccia, S., Minieri, M., Di, N. P., and Traversa, E. (2012). Cerium oxide nanoparticles protect cardiac progenitor cells from oxidative stress. ACS Nano. 6(5), 3767-3775.

Parkington, H. C., Tare, M., and Coleman, H. A. (2008). The EDHF story: the plot thickens. Circ. Res. 102(10), 1148-1150.

Perri, R. E., Langer, D. A., Chatterjee, S., Gibbons, S. J., Gadgil, J., Cao, S., Farrugia, G., and Shah, V. H. (2006). Defects in cGMP-PKG pathway contribute to impaired NOdependent responses in hepatic stellate cells upon activation. Am. J. Physiol Gastrointest. Liver Physiol 290(3), G535-G542.

Porter, D., Sriram, K., Wolfarth, M., Jefferson, A., Schwegler-Berry, D., Anderw, M. E., and Castranova, V. (2008). A biocompatible medium for nanoparticle dispersion. Nanotoxicolgy 2(3), 144-145.

Renkin, E. M. (1984). Control of microcirculation and blood-tissue exchange. In Handbook of Physiology (Renkin E.M. and Michel C.C., Eds.), pp. 627-687. American Physiology Society, Bethesda, MD.

Rybalkin, S. D., Yan, C., Bornfeldt, K. E., and Beavo, J. A. (2003). Cyclic GMP phosphodiesterases and regulation of smooth muscle function. Circ. Res. 93(4), 280-291.

Sastry, S. V., Nyshadham, J. R., and Fix, J. A. (2000). Recent technological advances in oral drug delivery - a review. Pharm. Sci. Technolo. Today 3(4), 138-145.

Schlossmann, J., Feil, R., and Hofmann, F. (2003). Signaling through NO and cGMPdependent protein kinases. Ann. Med. 35(1), 21-27. 
Singh, S., Kumar, A., Karakoti, A., Seal, S., and Self, W. T. (2010). Unveiling the mechanism of uptake and sub-cellular distribution of cerium oxide nanoparticles. Mol. Biosyst. 6(10), 1813-1820.

Srinivas, A., Rao, P. J., Selvam, G., Murthy, P. B., and Reddy, P. N. (2011). Acute inhalation toxicity of cerium oxide nanoparticles in rats. Toxicol. Lett. 205(2), 105-115.

Stapleton, P. A., and Nurkiewicz, T. R. (2014). Vascular distribution of nanomaterials. Wiley. Interdiscip. Rev. Nanomed. Nanobiotechnol. 6(4), 338-348.

Sun, D., Messina, E. J., Kaley, G., and Koller, A. (1992). Characteristics and origin of myogenic response in isolated mesenteric arterioles. Am. J Physiol 263(5 Pt 2), H1486H1491.

Taylor, M. S., Okwuchukwuasanya, C., Nickl, C. K., Tegge, W., Brayden, J. E., and Dostmann, W. R. (2004). Inhibition of cGMP-dependent protein kinase by the cellpermeable peptide DT-2 reveals a novel mechanism of vasoregulation. Mol. Pharmacol. 65(5), 1111-1119.

Wingard, C. J., Walters, D. M., Cathey, B. L., Hilderbrand, S. C., Katwa, P., Lin, S., Ke, P. C., Podila, R., Rao, A., Lust, R. M., and Brown, J. M. (2011). Mast cells contribute to altered vascular reactivity and ischemia-reperfusion injury following cerium oxide nanoparticle instillation. Nanotoxicology. 5(4), 531-545.

Xu, C., and Qu, X. (2014). Cerium oxide nanoparticle: a remarkably versatile rare earth nanomaterial for biological applications. NPG Asia Materials 6, 1-16.

Yokel, R. A., Au, T. C., Macphail, R., Hardas, S. S., Butterfield, D. A., Sultana, R., Goodman, M., Tseng, M. T., Dan, M., Haghnazar, H., Unrine, J. M., Graham, U. M., Wu, P., and Grulke, E. A. (2012). Distribution, Elimination, and Biopersistence to 90 Days of a Systemically Introduced $30 \mathrm{~nm}$ Ceria-Engineered Nanomaterial in Rats. Toxicol. Sci. 127(1), 256-268.

Zhang, X. (2004). Real time and in vivo monitoring of nitric oxide by electrochemical sensors--from dream to reality. Front Biosci. 9, 3434-3446.

Zhu, M. T., Feng, W. Y., Wang, Y., Wang, B., Wang, M., Ouyang, H., Zhao, Y. L., and Chai, Z. F. (2009). Particokinetics and extrapulmonary translocation of intratracheally instilled ferric oxide nanoparticles in rats and the potential health risk assessment. Toxicol. Sci. 107(2), 342-351.

Zweifach, B. W. (1984). Pressure-flow relations in blood and lymph microcirculation. In Handbook of Physiology (Renkin E.M. and Michel C.C., Eds.), pp. 251-308. American Physiological Society, Bethesda, MD. 


\section{Figure Legends:}

Figure 1: ACh-induced vasodilation was impaired in arterioles following intravenous injection (A: $n=8-15)$ and gastric gavage (B: $n=9-13)$ of $\mathrm{CeO}_{2} N P .{ }^{*} p \leq 0.05$ vs. control, $\dagger p \leq 0.05$ vs. low dose $\mathrm{CeO}_{2} \mathrm{NP}(50 \mu \mathrm{g}$ for intravenous injection and $100 \mu \mathrm{g}$ for gastric gavage), $\ddagger p \leq 0.05$ vs. middle dose $\mathrm{CeO}_{2} \mathrm{NP}(100 \mu \mathrm{g}$ for intravenous injection and $300 \mu \mathrm{g}$ for gastric gavage). The brackets indicate differences in the overall slope of the determination.

Figure 2: NO-induced vasodilation (via SPR) was impaired in mesenteric arterioles following intravenous injection (A: $n=8-12)$ and gastric gavage $(B: n=8-10)$ of $\mathrm{CeO}_{2}$ NP. ${ }^{*} p \leq 0.05$ vs. control, $\uparrow p \leq 0.05$ vs. low dose $\mathrm{CeO}_{2} \mathrm{NP}(50 \mu \mathrm{g}$ for intravenous injection and $100 \mu$ for gastric gavage $), \ddagger p \leq 0.05$ vs. middle dose $\mathrm{CeO}_{2} \mathrm{NP}(100 \mu \mathrm{g}$ for intravenous injection and $300 \mu \mathrm{g}$ for gastric gavage), ${ }^{\wedge} \mathrm{p} \leq 0.05$ vs. high dose $\mathrm{CeO}_{2} \mathrm{NP}$ (900 $\mu \mathrm{g}$ for intravenous injection and $600 \mu \mathrm{g}$ for gastric gavage). The brackets indicate differences in the overall slope of the determination.

Figure 3: Vasodilation in response increasing intraluminal pressure following intravenous injection (A: $n=8-13)$ and gastric gavage $(B: n=9-10)$ of $\mathrm{CeO}_{2}$ NP was not significantly different. ${ }^{*} p \leq 0.05$ vs. control.

Figure 4: The left panels are vasodilation in response to increases in intraluminal flow following intravenous injection ( $A: n=5-10)$ and gastric gavage $(B: n=6-8)$ of $\mathrm{CeO}_{2} N P$. The right panels are vasodilation in response to increasing shear stress following 
intravenous injection (C: $n=6-10)$ and gastric gavage $(D: n=6-8)$ of $\mathrm{CeO}_{2} N P$. ${ }^{*} p \leq$ 0.05 vs. control.

Figure 5: Vasoconstriction stimulated by PE following intravenous injection (A: $n=7-12)$ and gastric gavage (B: $n=9-11$ ) of $\mathrm{CeO}_{2} \mathrm{NP}$ was not significantly different. ${ }^{*} p \leq 0.05$ vs. control.

Figure 6: Calculated of $\mathrm{EC}_{50}$ for $\mathrm{ACh}(\mathrm{A})$ and SPR (B) for intratracheal instillation, intravenous injection, and gastric gavage. The scatter plot (C) shows dilation response to ACh $\left(10^{-4} M\right)$ for all exposure routes. The following linear equations $(y=m x+b)$ and $r^{2}$ values were obtained for each exposure route: intratracheal instillation: $y=-0.07 x+41.26$, $r^{2}=0.2513$, intravenous injection: $y=-0.03 x+49.39, r^{2}=0.1994$, and gastric gavage: $y=$ $-0.05 x+54.71, r^{2}=0.2465$

Figure 7: Vasodilation in response to ACh following incubation with either L-NMMA $\left(10^{-4}\right.$ M), INDO $\left(10^{-5} \mathrm{M}\right)$ or both inhibitors. There was a significant impairment in dilation of control arterioles following incubation with L-NMMA and INDO $(A: n=14-34)$. There was a partial restoration in function following incubation with L-NMMA after intratracheal instillation of 65 $\mu \mathrm{g} \mathrm{CeO} 2 \mathrm{NP}(\mathrm{B}: \mathrm{n}=5$ - 14). Intravenous injection of $100 \mu \mathrm{g} \mathrm{CeO} 2 \mathrm{NP}$ caused an attenuated response to ACh after incubation with INDO that was significantly different from the $\mathrm{CeO}_{2}$ NP exposure alone (C: $n=5$ - 9). Gastric gavage of $400 \mu g \mathrm{CeO}_{2} \mathrm{NP}$ ) caused a significant impairment in arteriolar dilation following L-NMMA incubation compared to the $\mathrm{CeO}_{2} \mathrm{NP}$ exposure alone (D: $n=8-15) .{ }^{*} p \leq 0.05$ vs. L-NMMA $\left(10^{-4} M\right), \dagger p \leq 0.05$ vs. INDO $\left(10^{-5}\right.$ 
M), $\ddagger p \leq 0.05$ vs. both inhibitors, ${ }^{\wedge} p \leq 0.05$ vs. $\mathrm{CeO}_{2}$ NP exposure. The brackets indicate differences in the overall slope of the determination.

Figure 8: $\mathrm{CeO}_{2} \mathrm{NP}$ reacted with $\mathrm{NO}$ in an acellular environment $(\mathrm{A})$. There was a significant decrease in the amount of NO detected following intravenous injection (B: $n=$ 14 - 21). NO was released with SNAP $\left(1.6 \times 10^{-4} \mathrm{M}\right)$ for the acellular assessments and with A23187 $\left(10^{-5} \mathrm{M}\right)$ for the cellular assessments. ${ }^{*} p \leq 0.05$ vs. control, $\dagger p \leq 0.05$ vs. intratracheal instillation.

Figure 9: $\mathrm{CeO}_{2} \mathrm{NP}$ ability to scavenge and/or generate free radicals was assessed in an acellular environment $(A: n=3)$, with control $A M(B: n=4-7)$, and with $A M$ from $\mathrm{CeO}_{2}$ exposed animals via different exposure routes (C: $n=7-9)$. Images of representative superoxide and hydroxyl free radical spectra are inset in panel A. ${ }^{*} p \leq 0.05$ vs. control, $\dagger$ $p \leq 0.05$ vs. $\mathrm{Cr}^{6+}$ alone, $\ddagger \mathrm{p} \leq 0.05$ vs. control $\mathrm{AM}+\mathrm{CeO}_{2} \mathrm{NP}, \wedge p \leq 0.05$ vs. gastric gavage $\mathrm{AM}+\mathrm{CeO}_{2} \mathrm{NP} . \mathrm{NoP}=$ No detectable ESR peaks.

Figure 10: VSM function was impaired following $\mathrm{CeO}_{2} \mathrm{NP}$ exposure and was not exposure route-dependent. Soluble GC activation was assessed with YC-1 (A: $n=8-11)$. Cyclic GMP responsiveness was assessed with 8-bromo-cGMP (B: $n=10)$. * $p \leq 0.05$ vs. control, $\dagger p \leq 0.05$ vs. intratracheal instillation. The brackets indicate differences in the overall slope of the determination. 
Tables:

\section{Table 1: Animal Characteristics}

\begin{tabular}{|c|c|c|c|c|c|}
\hline Groups & $\mathbf{N}$ & $\begin{array}{l}\text { Age } \\
\text { (weeks) }\end{array}$ & $\begin{array}{l}\text { Weight } \\
\text { (g) }\end{array}$ & $\begin{array}{l}\text { MAP } \\
(\mathrm{mm} \mathrm{Hg})\end{array}$ & $\begin{array}{l}\text { Heart Weight } \\
\text { (g) }\end{array}$ \\
\hline Control-Saline & 41 & $10.61 \pm 0.4$ & $392 \pm 10$ & $105 \pm 4$ & $1.28 \pm 0.03$ \\
\hline \multicolumn{6}{|c|}{ Intravenous Injection Dose-Response Determination } \\
\hline $50 \mu \mathrm{g} \mathrm{CeO}_{2} \mathrm{NP}$ & 7 & $8.43 \pm 0.3$ & $338 \pm 8$ & $102 \pm 2$ & $1.22 \pm 0.02$ \\
\hline $100 \mu \mathrm{g} \mathrm{CeO}_{2} \mathrm{NP}$ & 8 & $9.76 \pm 0.09$ & $382 \pm 3$ & $112 \pm 3$ & $1.34 \pm 0.01$ \\
\hline $900 \mu \mathrm{g} \mathrm{CeO}_{2} \mathrm{NP}$ & 8 & $9.50 \pm 0.28$ & $364 \pm 6$ & $107 \pm 2$ & $1.31 \pm 0.02$ \\
\hline \multicolumn{6}{|c|}{ Gastric Gavage Dose-Response Determination } \\
\hline $100 \mu \mathrm{g} \mathrm{CeO}_{2} \mathrm{NP}$ & 9 & $10.11 \pm 0.4$ & $383 \pm 11$ & $98 \pm 4$ & $1.30 \pm 0.03$ \\
\hline $300 \mu \mathrm{g} \mathrm{CeO}_{2} \mathrm{NP}$ & 8 & $9.38 \pm 0.6$ & $371 \pm 17$ & $100 \pm 3$ & $1.33 \pm 0.04$ \\
\hline $600 \mu \mathrm{g} \mathrm{CeO}_{2} \mathrm{NP}$ & 8 & $8.88 \pm 0.4$ & $376 \pm 18$ & $96 \pm 4$ & $1.29 \pm 0.06$ \\
\hline \multicolumn{6}{|c|}{ Calculated EC 50 Doses $(\mu \mathrm{g})$} \\
\hline $\begin{array}{l}65 \mu \mathrm{g} \mathrm{CeO} 2 \mathrm{NP} \\
(0.19 \mathrm{mg} / \mathrm{kg} \text { via } \\
\text { intratracheal } \\
\text { instillation) }\end{array}$ & 14 & $9.45 \pm 0.1$ & $381 \pm 4$ & $99 \pm 2$ & $1.29 \pm 0.02$ \\
\hline $\begin{array}{l}100 \mu \mathrm{g} \mathrm{CeO}{ }_{2} \mathrm{NP} \\
(0.29 \mathrm{mg} / \mathrm{kg} \text { via } \\
\text { intravenous } \\
\text { injection) }\end{array}$ & 11 & $9.27 \pm 0.1$ & $384 \pm 5$ & $109 \pm 1$ & $1.32 \pm 0.03$ \\
\hline $\begin{array}{l}400 \mu \mathrm{Mg} \mathrm{CeO}_{2} \mathrm{NP} \\
(1.14 \mathrm{mg} / \mathrm{kg} \text { via } \\
\text { gastric gavage })\end{array}$ & 21 & $9.59 \pm 0.2$ & $365 \pm 8$ & $98 \pm 5$ & $1.36 \pm 0.07$ \\
\hline
\end{tabular}

Values are means \pm SE. $\mathrm{N}=$ number of animals. MAP = Mean Arterial Pressure. The $\mathrm{mg} / \mathrm{kg}$ concentrations were calculated based on a representative animal weight of $350 \mathrm{~g}$. 
Table 2: Basal Arteriolar Characteristics

\begin{tabular}{|c|c|c|c|c|c|c|}
\hline \multirow[b]{2}{*}{ Groups } & \multirow[b]{2}{*}{$\mathbf{n}$} & \multicolumn{2}{|c|}{ Diameter $(\mu \mathrm{m})$} & \multirow[b]{2}{*}{$\begin{array}{l}\text { Tone } \\
(\%)\end{array}$} & \multirow[b]{2}{*}{$\begin{array}{l}\text { WT } \\
(\mu \mathrm{m})\end{array}$} & \multirow[b]{2}{*}{ WLR } \\
\hline & & $\begin{array}{l}\text { Steady } \\
\text { State }\end{array}$ & Max & & & \\
\hline Control-Saline & 57 & $81 \pm 2$ & $117 \pm 14$ & $27 \pm 2$ & $16 \pm 1.6$ & $0.18 \pm 0.01$ \\
\hline \multicolumn{7}{|c|}{ Intravenous Injection Dose-Response Determination } \\
\hline $50 \mu \mathrm{g} \mathrm{CeO}_{2} \mathrm{NP}$ & 9 & $73 \pm 3$ & $104 \pm 4$ & $29 \pm 2$ & $13 \pm 0.4$ & $0.18 \pm 0.01$ \\
\hline $100 \mu \mathrm{g} \mathrm{CeO}_{2} \mathrm{NP}$ & 10 & $74 \pm 3$ & $104 \pm 3$ & $29 \pm 3$ & $12 \pm 0.6$ & $0.17 \pm 0.01$ \\
\hline $900 \mu \mathrm{g} \mathrm{CeO}_{2} \mathrm{NP}$ & 12 & $77 \pm 3$ & $111 \pm 3$ & $30 \pm 2$ & $13 \pm 0.9$ & $0.16 \pm 0.01$ \\
\hline \multicolumn{7}{|c|}{ Gastric Gavage Dose-Response Determination } \\
\hline $100 \mu \mathrm{g} \mathrm{CeO}_{2} \mathrm{NP}$ & 13 & $76 \pm 4$ & $104 \pm 5$ & $28 \pm 2$ & $12 \pm 0.8$ & $0.16 \pm 0.01$ \\
\hline $300 \mu \mathrm{g} \mathrm{CeO}_{2} \mathrm{NP}$ & 11 & $80 \pm 3$ & $113 \pm 4$ & $28 \pm 2$ & $14 \pm 0.5$ & $0.17 \pm 0.01$ \\
\hline $600 \mu \mathrm{g} \mathrm{CeO}_{2} \mathrm{NP}$ & 12 & $78 \pm 4$ & $107 \pm 5$ & $27 \pm 2$ & $12 \pm 0.5$ & $0.16 \pm 0.01$ \\
\hline \multicolumn{7}{|c|}{ Calculated EC 50 Doses $(\mu \mathrm{g})$} \\
\hline $\begin{array}{l}65 \mu \mathrm{CeO}_{2} \mathrm{NP} \\
(0.19 \mathrm{mg} / \mathrm{kg} \text { via } \\
\text { intratracheal } \\
\text { instillation) }\end{array}$ & 13 & $80 \pm 3$ & $110 \pm 4$ & $27 \pm 2$ & $11 \pm 0.5$ & $0.14 \pm 0.01$ \\
\hline $\begin{array}{l}100 \mu \mathrm{g} \mathrm{CeO}_{2} \mathrm{NP} \\
(0.29 \mathrm{mg} / \mathrm{kg} \text { via } \\
\text { intravenous } \\
\text { injection) }\end{array}$ & 11 & $75 \pm 4$ & $108 \pm 3$ & $30 \pm 3$ & $12 \pm 1.1$ & $0.16 \pm 0.01$ \\
\hline $\begin{array}{l}400 \mu \mathrm{CeO}_{2} \mathrm{NP} \\
(1.14 \mathrm{mg} / \mathrm{kg} \text { via } \\
\text { gastric gavage })\end{array}$ & 20 & $75 \pm 2$ & $101 \pm 3$ & $26 \pm 1$ & $12 \pm 0.5$ & $0.15 \pm 0.01$ \\
\hline
\end{tabular}

Values are means \pm SE. $n=$ number of vessels. WT $=$ Wall Thickness WLR $=$ Wall to Lumen Ratio. The $\mathrm{mg} / \mathrm{kg}$ concentrations were calculated based on a representative animal weight of $350 \mathrm{~g}$. 


\section{Figure 1:}

\section{A: Intravenous Injection}

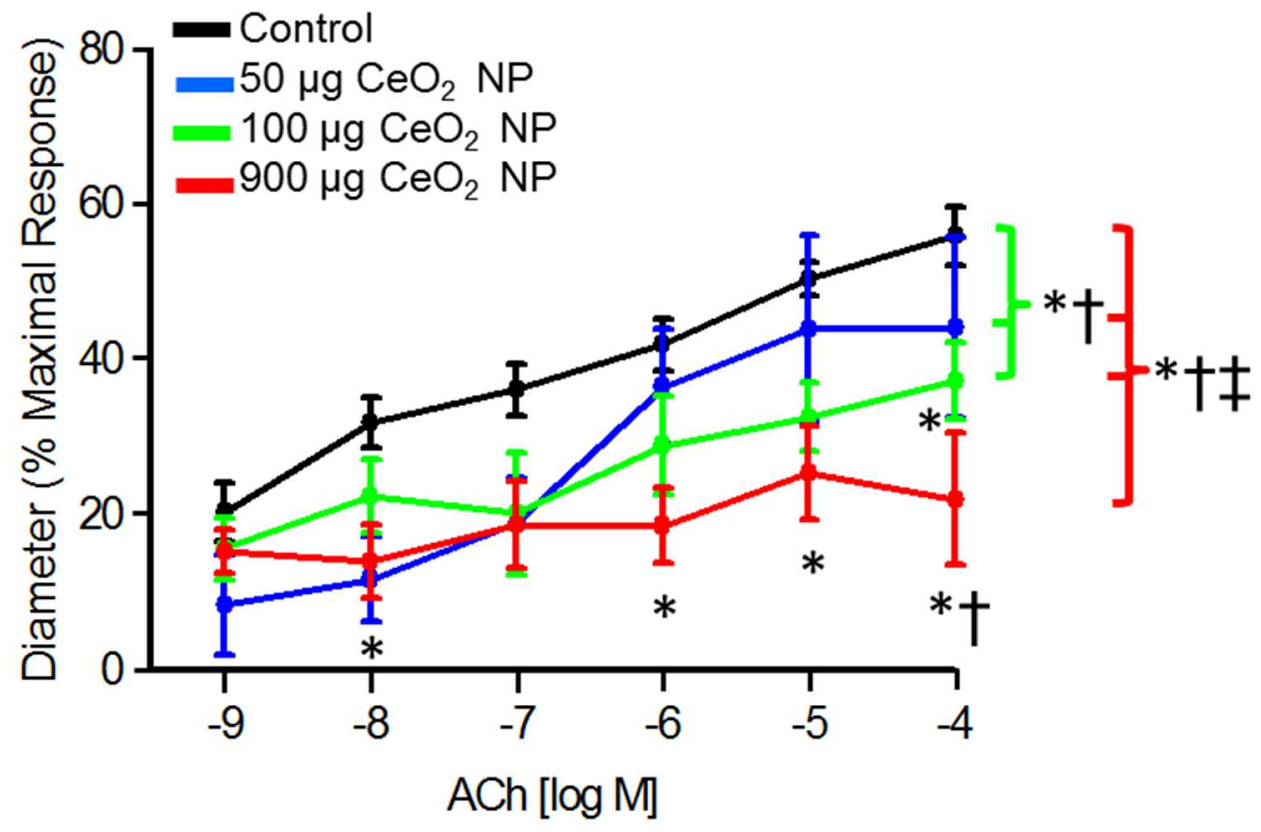

\section{B: Gastric Gavage}

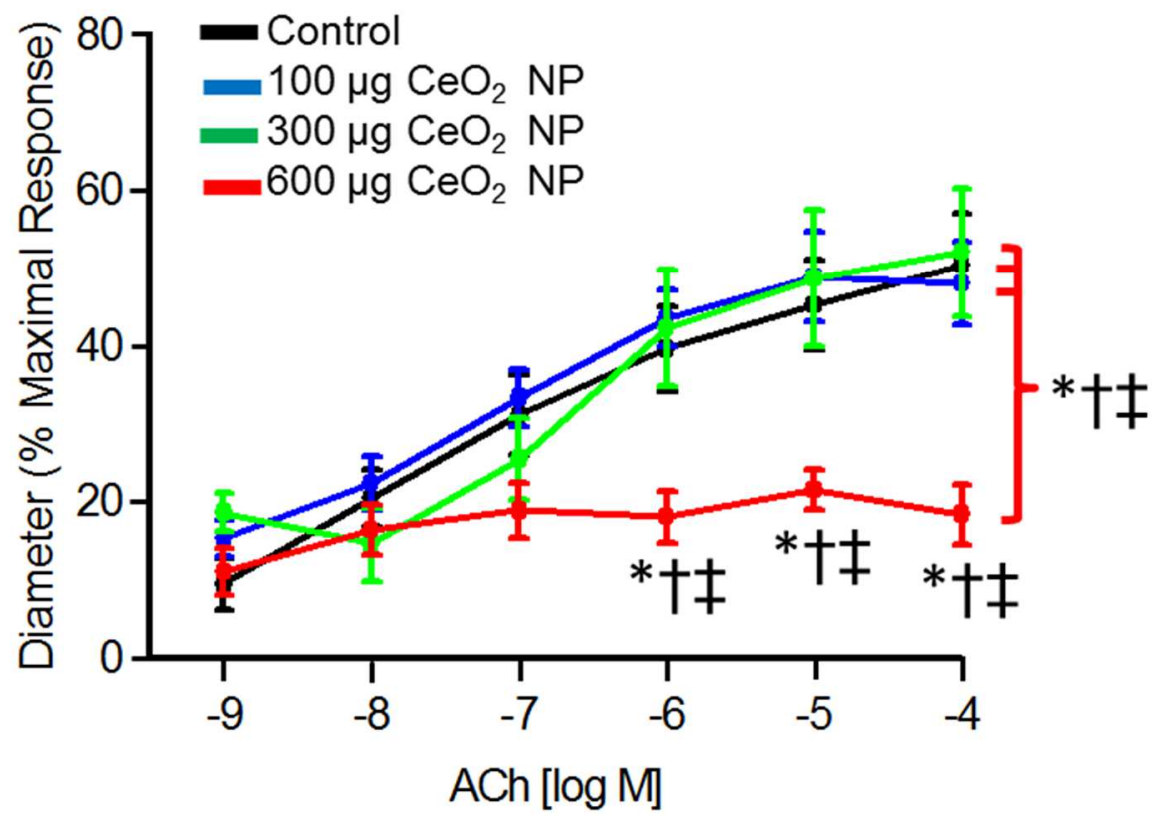


Figure 2:

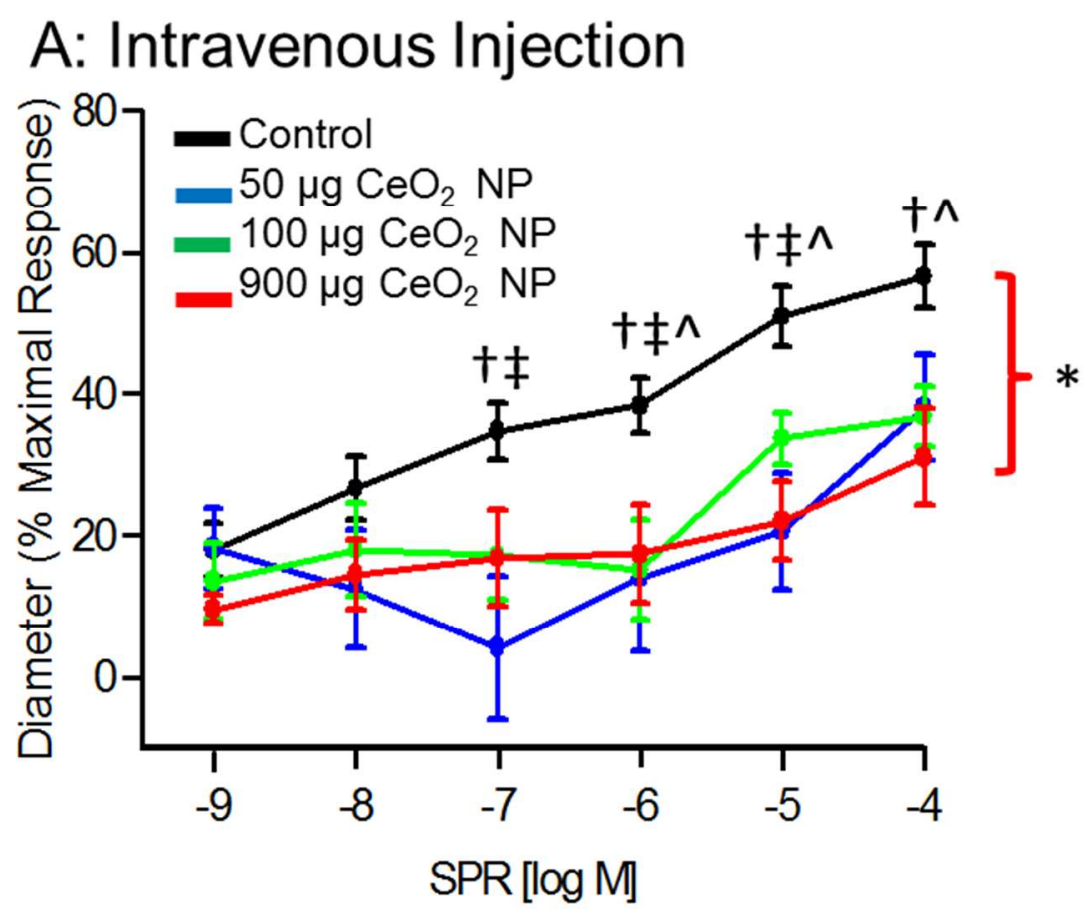

\section{B: Gastric Gavage}

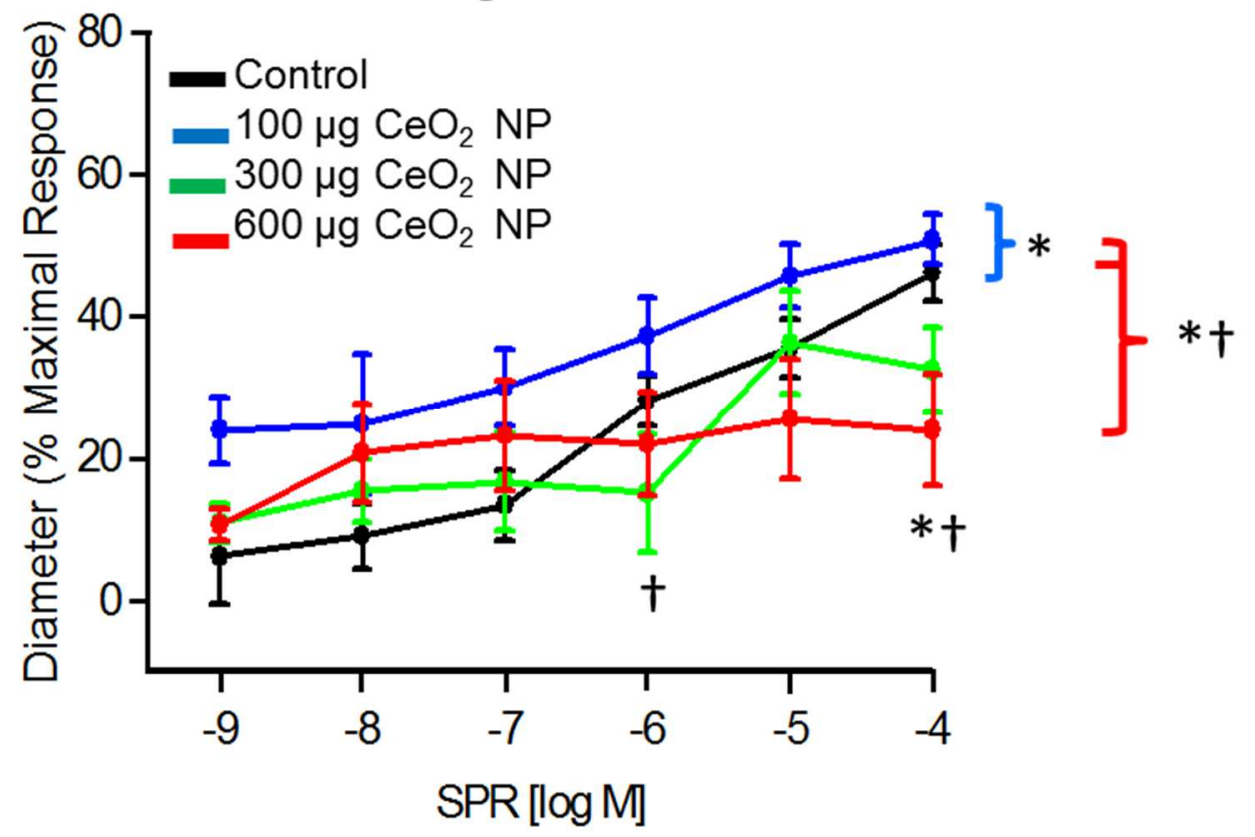


Figure 3:

A: Intravenous Injection

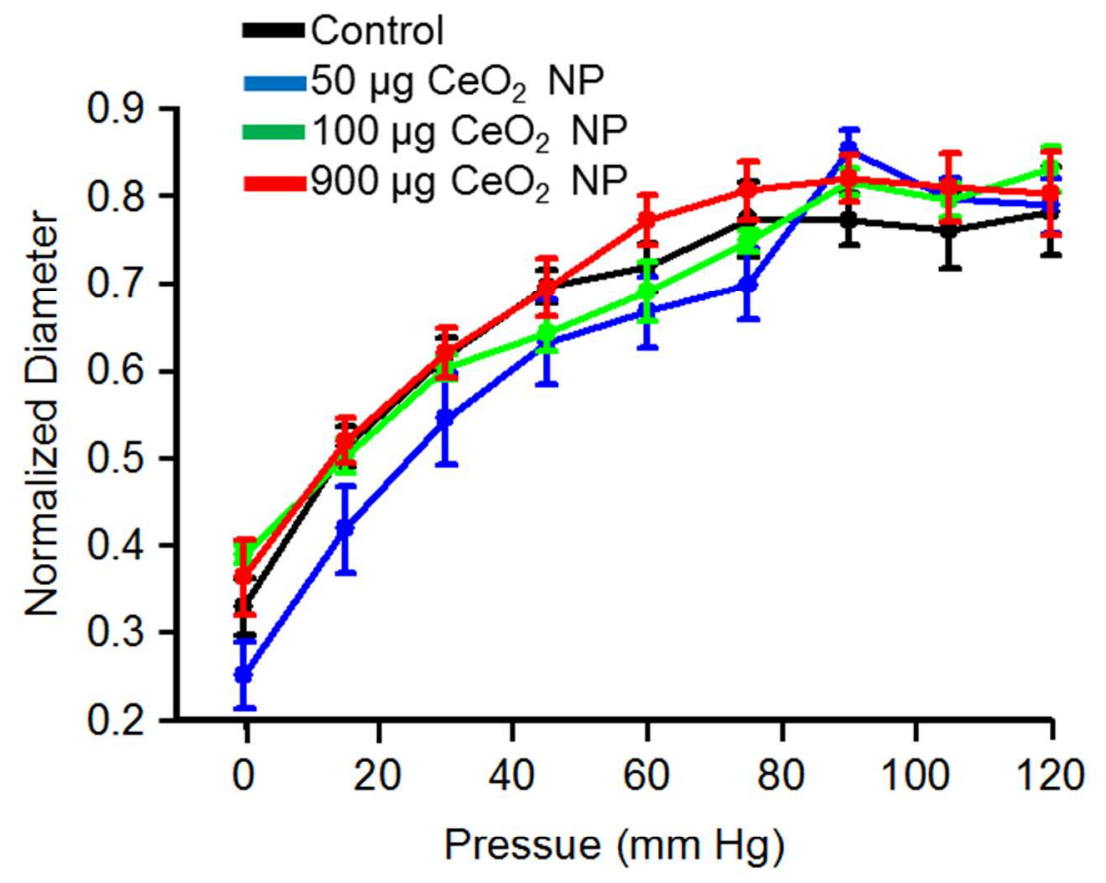

B: Gastric Gavage

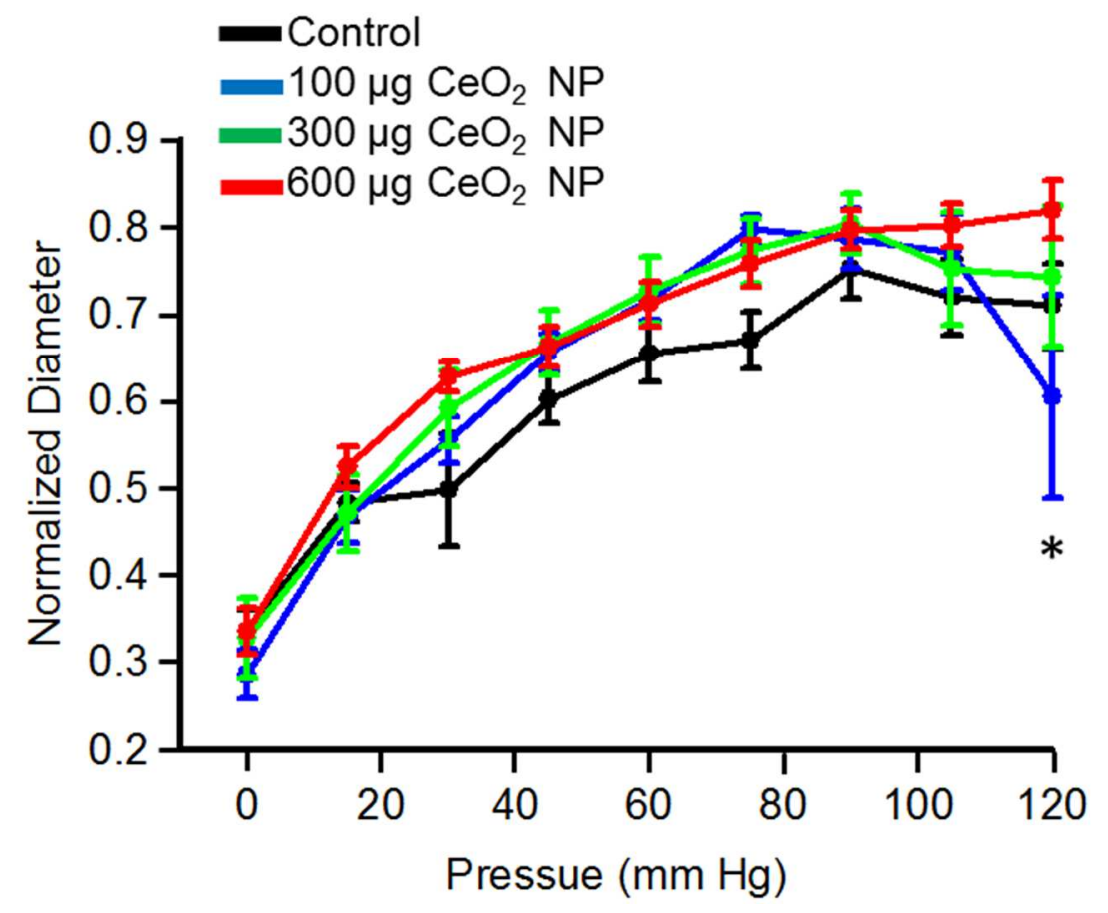


Figure 4:

\section{A: Intravenous Injection}

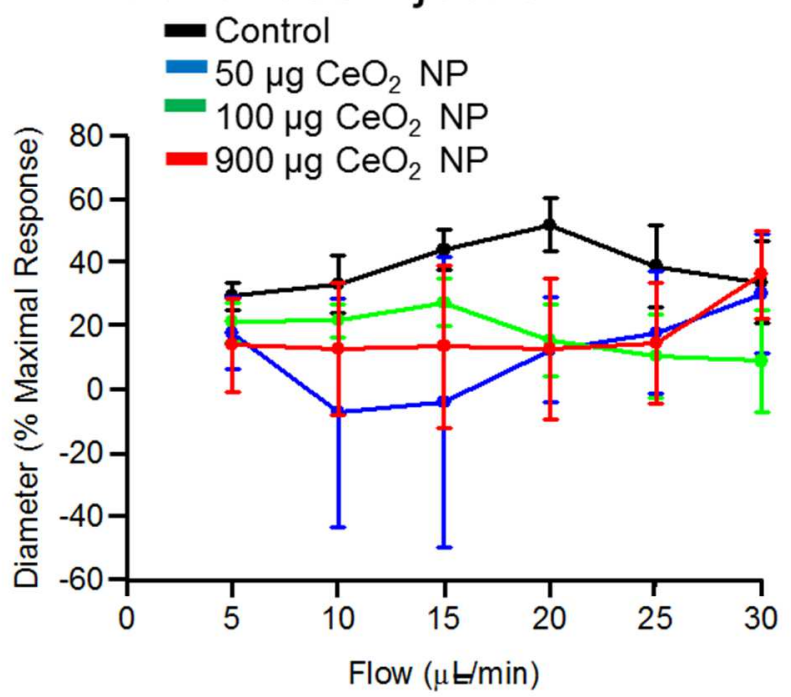

C: Gastric Gavage

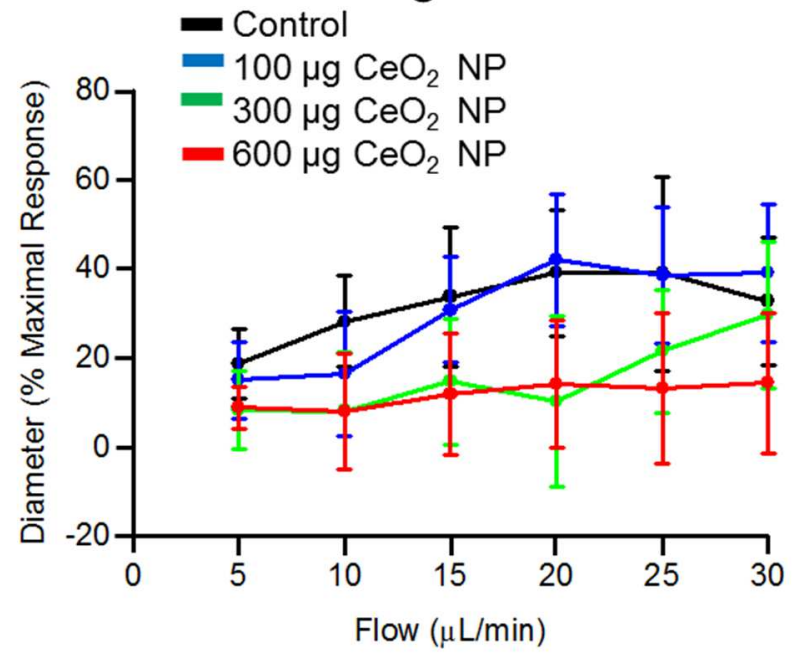

B: Intravenous Injection

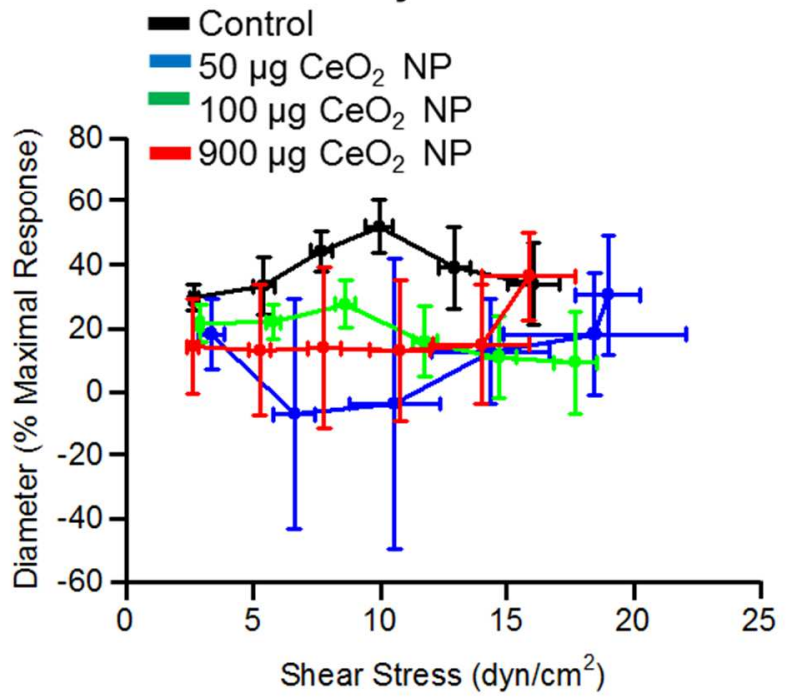

D: Gastric Gavage

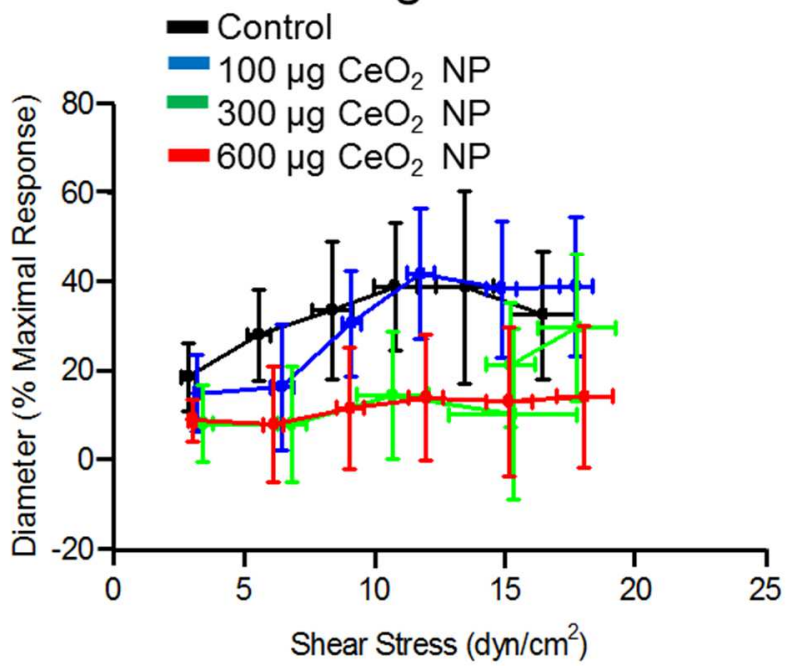




\section{Figure 5:}

\section{A: Intravenous Injection}

Figure 6:
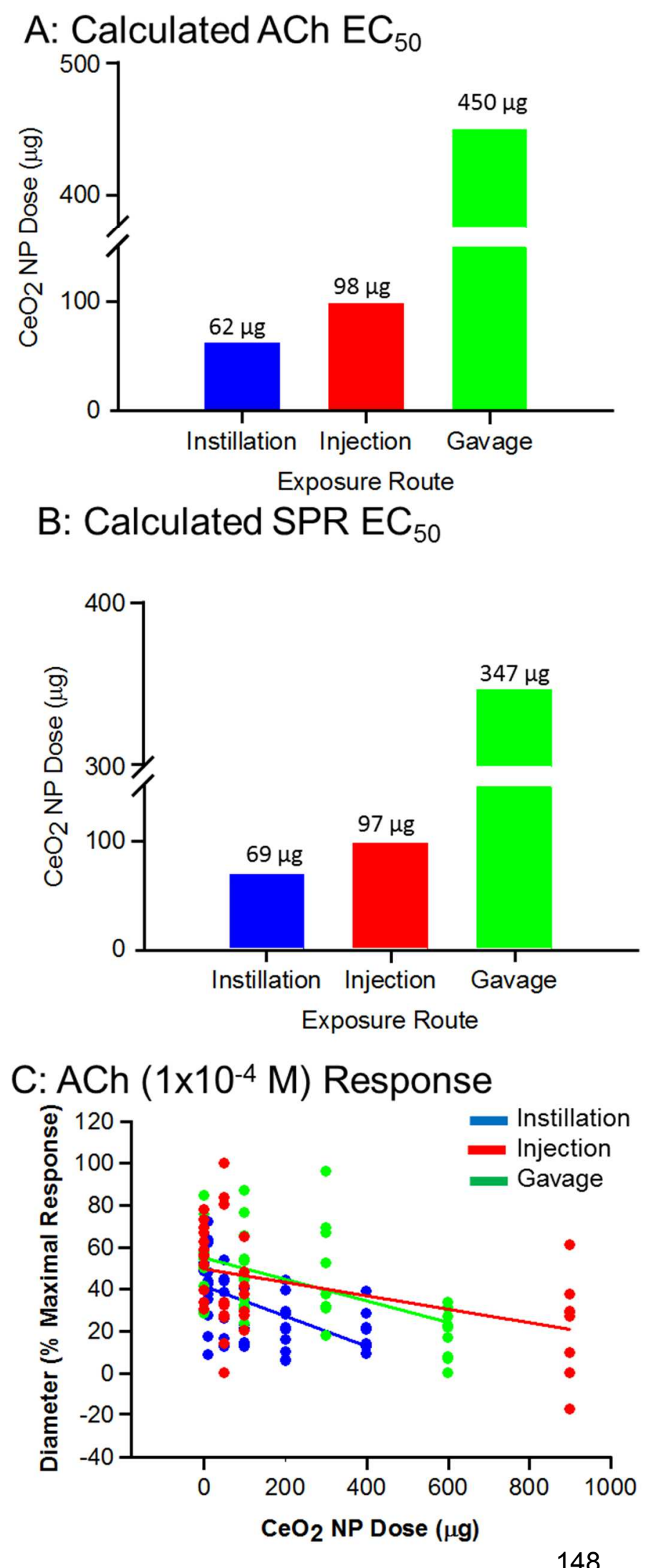
Figure 7:

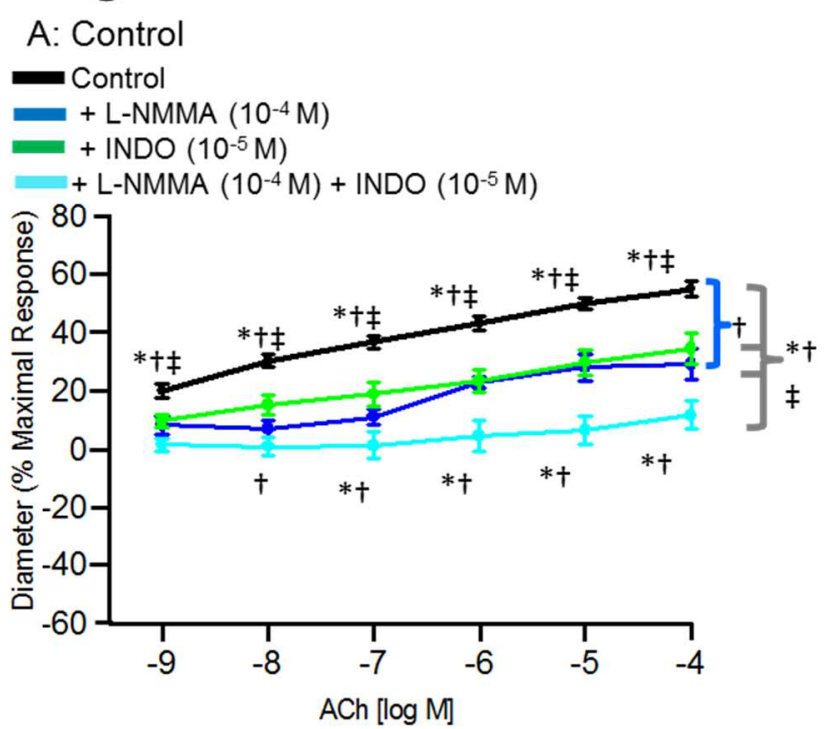

B: Intratracheal Instillation

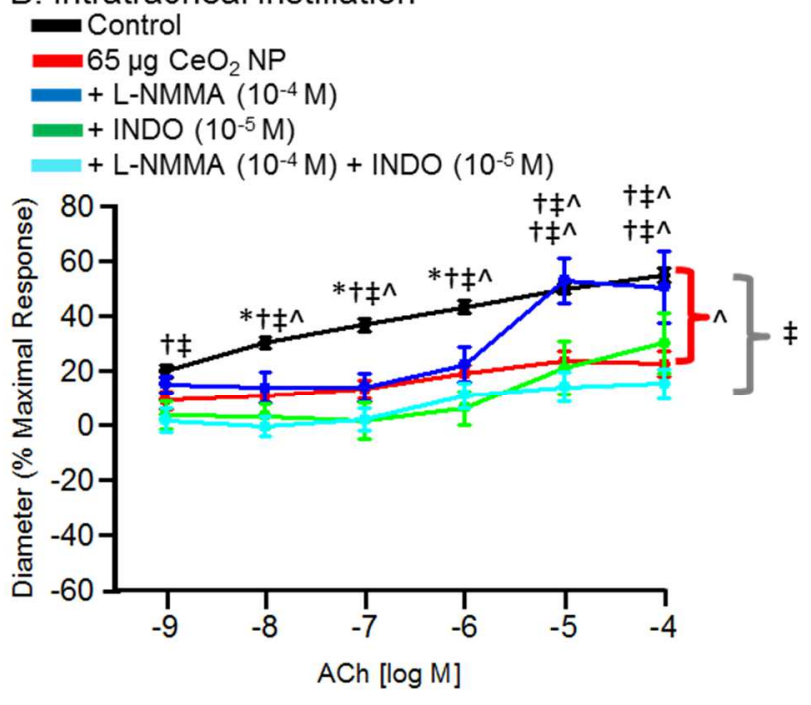

C: Intravenous Injection
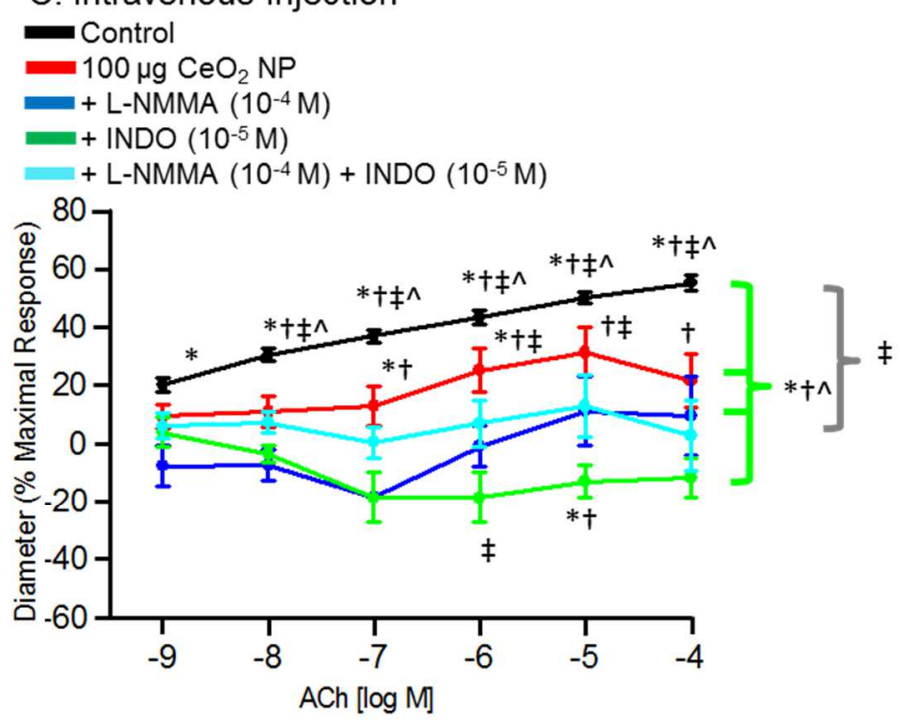

D: Gastric Gavage

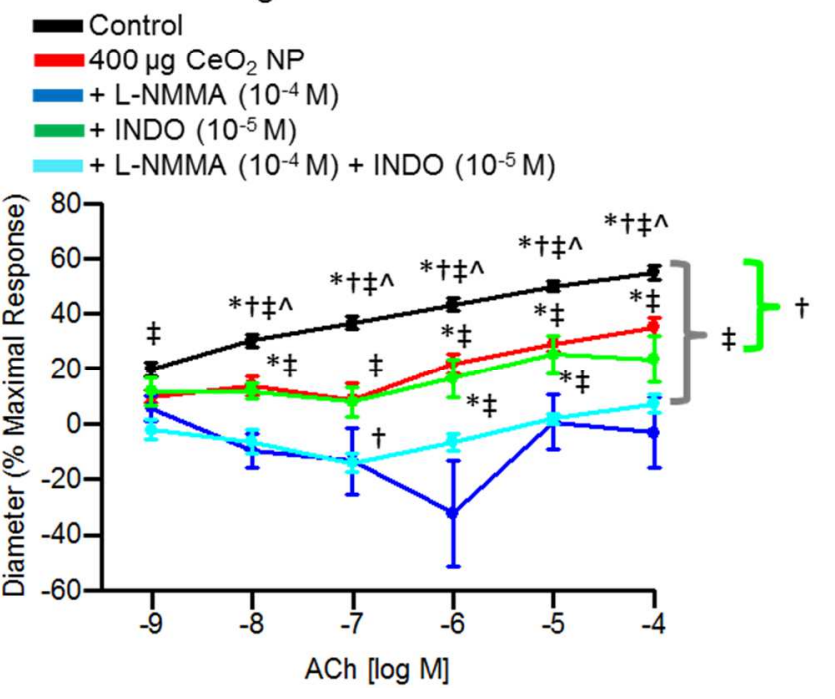




\section{Figure 8:}

\section{A: Acellular}
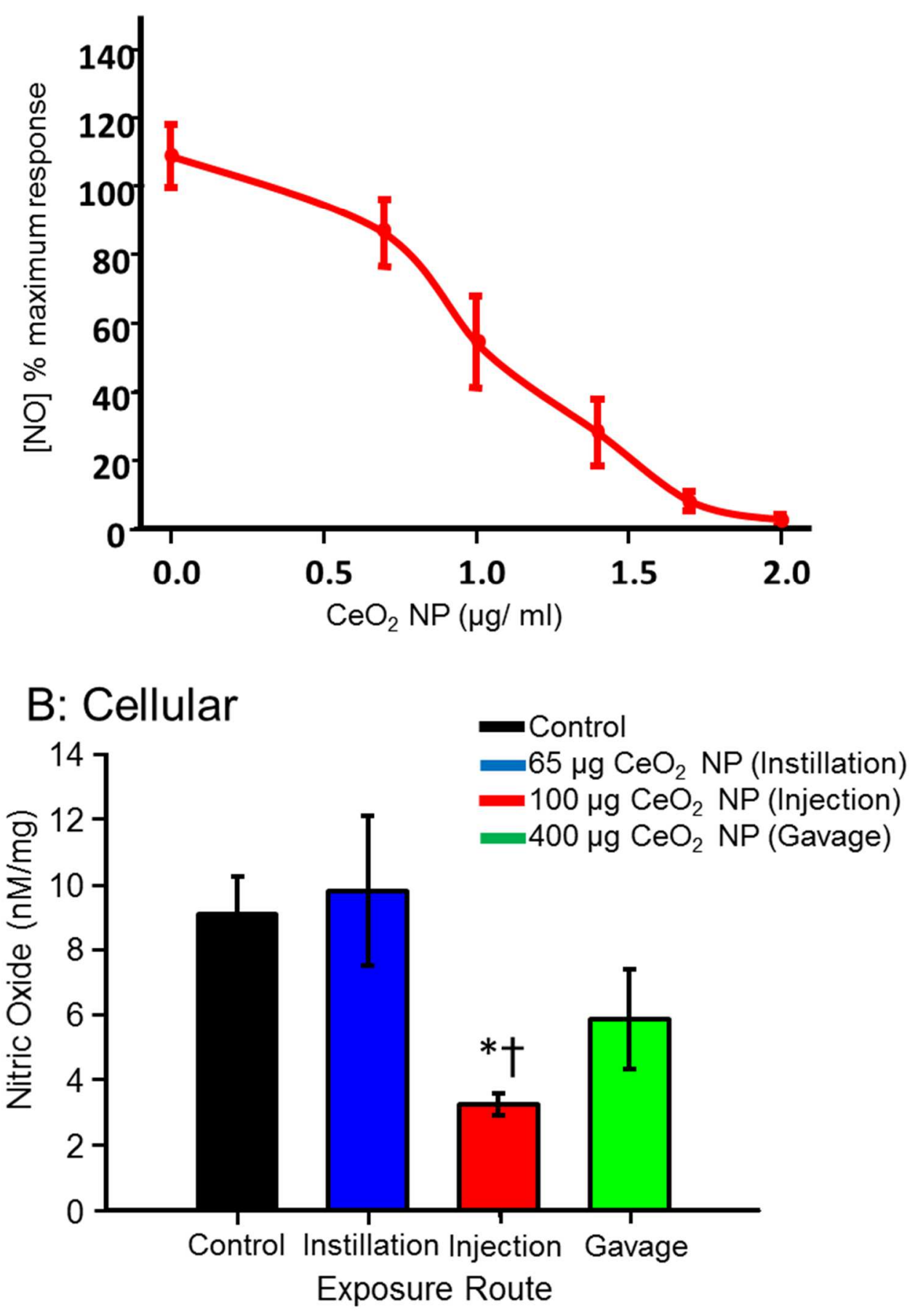
Figure 9:

A: Acellular Free Radical Scavenging



Superoxide Spectra

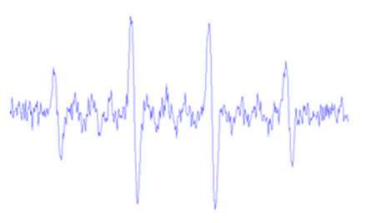

Hydroxyl Spectra
$\mathrm{B}: \mathrm{AM}+\mathrm{CeO}_{2} \mathrm{NP}+\mathrm{Cr}^{6+}$

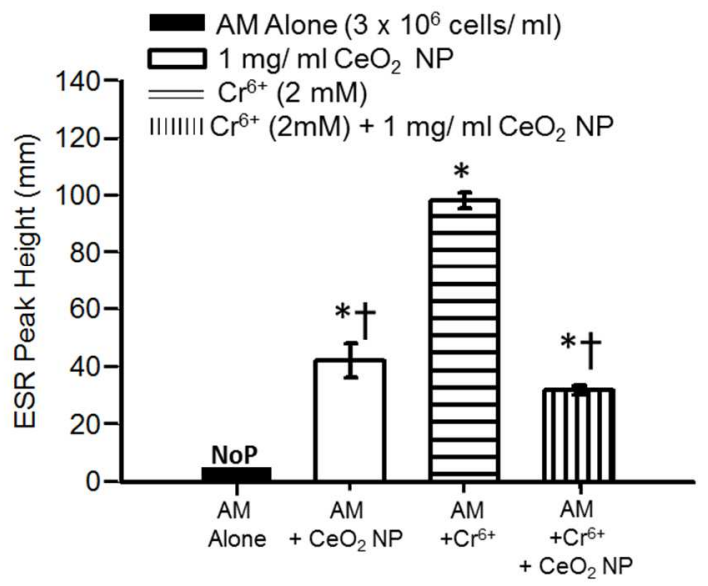

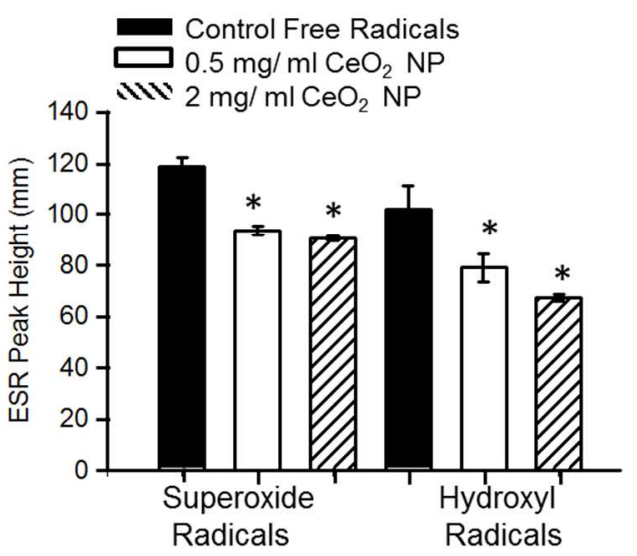

C: $\mathrm{AM}+\mathrm{CeO}_{2} \mathrm{NP}$

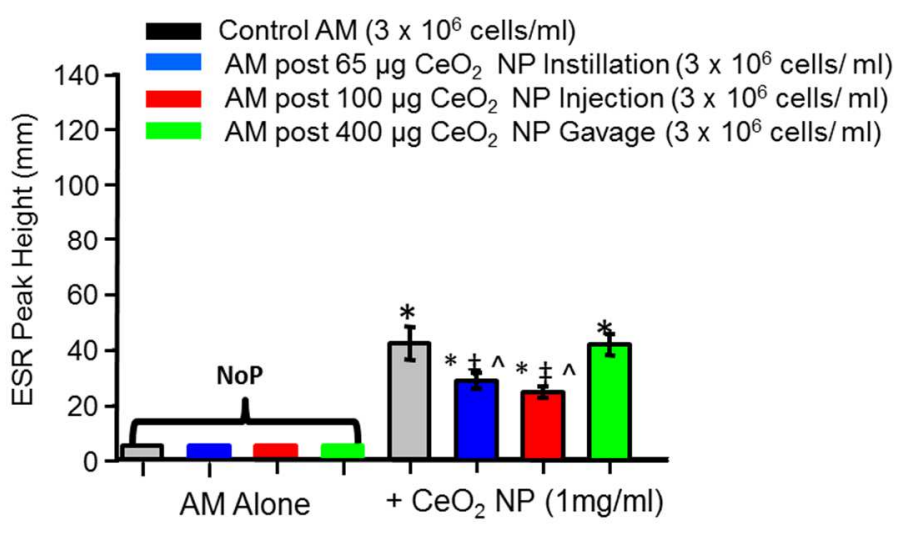


Figure 10:

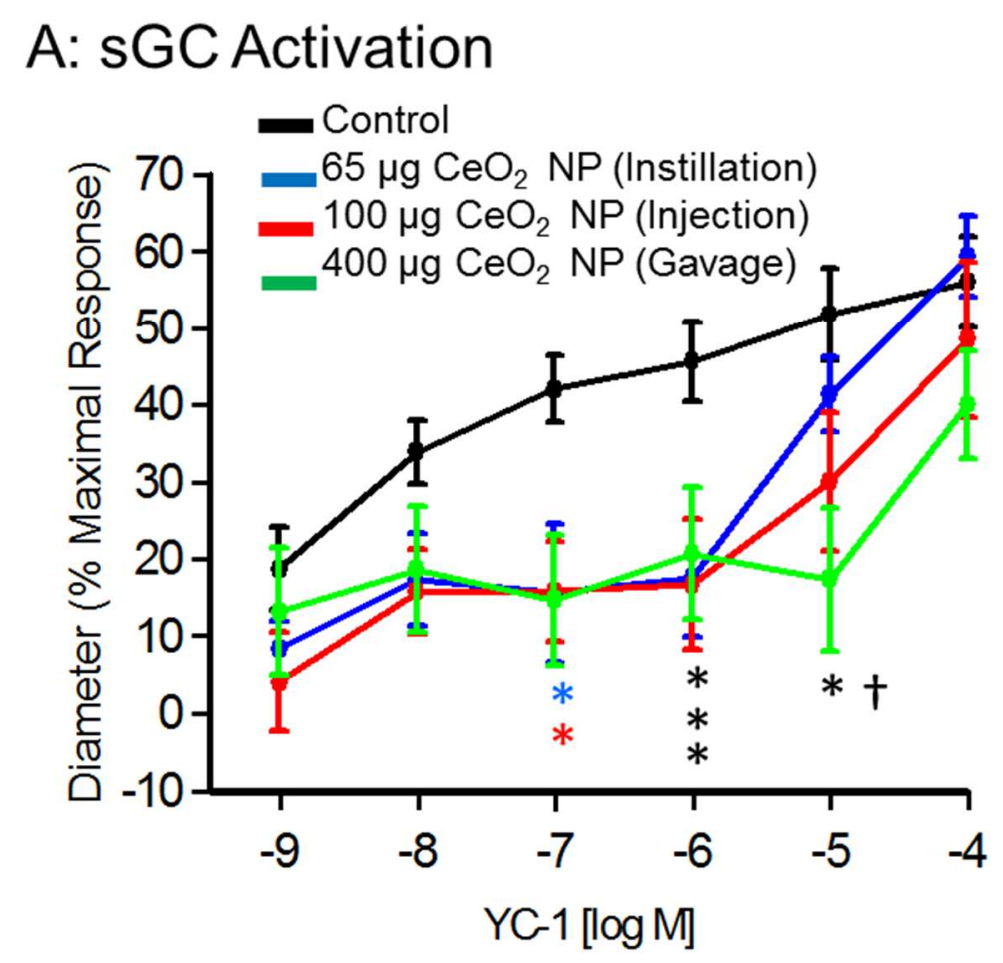

B: cGMP Responsiveness

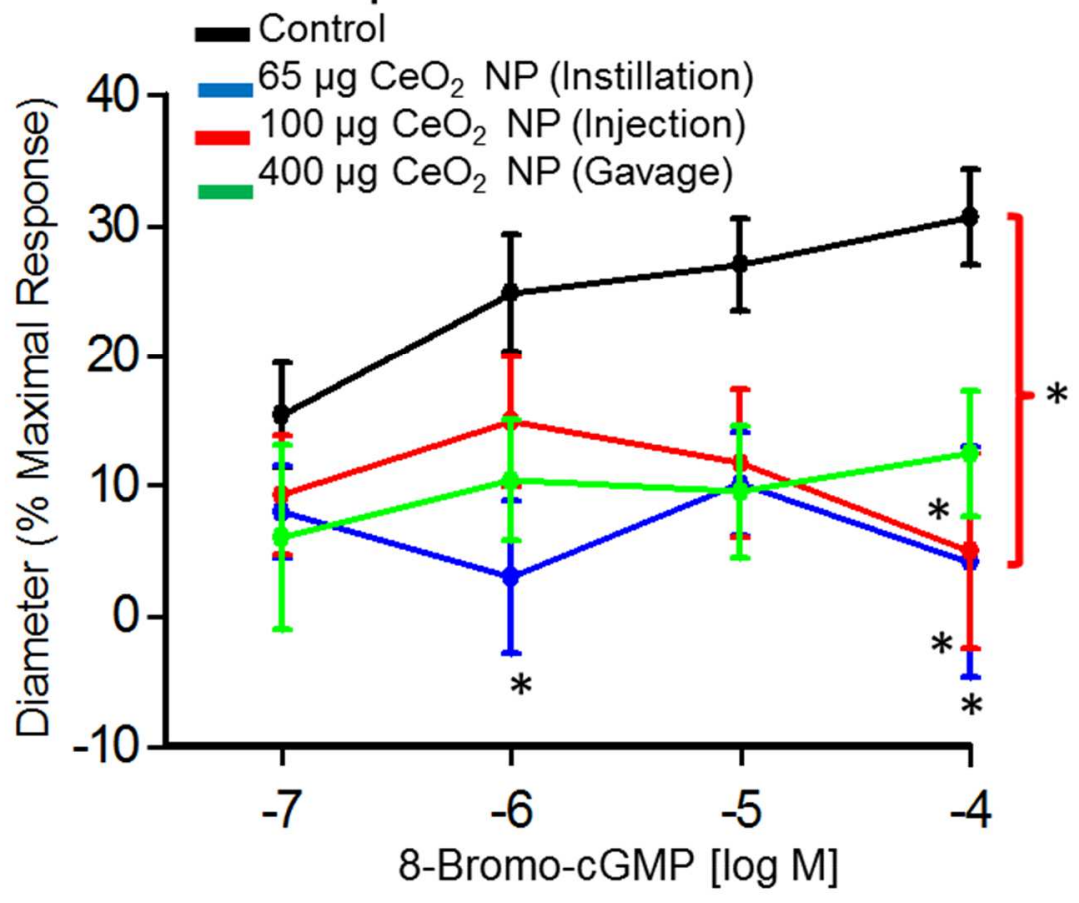




\section{Chapter 4}

Cerium Dioxide Nanoparticles Improve Microvascular Dysfunction and Reduce Oxidative Stress in Spontaneously Hypertensive Rats

Running Title: Cerium Dioxide Nanoparticle Exposure and Hypertension

\section{Authors:}

Valerie C. Minarchick ${ }^{*}, \dagger$

Phoebe A. Stapleton ${ }^{*}, \dagger$

Edward M. Sabolsky $\ddagger$

Timothy R. Nurkiewicz ${ }^{*} \dagger$

\section{Affiliations:}

*. Center for Cardiovascular and Respiratory Sciences, West Virginia University School of Medicine, Morgantown, WV 26506

†. Department of Physiology and Pharmacology, West Virginia University School of Medicine, Morgantown, WV 26506

‡. Department of Mechanical and Aerospace Engineering, West Virginia University, Morgantown, WV 26506 


\section{Abstract:}

Cerium dioxide nanoparticles $\left(\mathrm{CeO}_{2} \mathrm{NP}\right)$ hold great theranostic potential, but their in vivo anti-oxidant activity is unclear. Due to this anti-oxidant action and previous microvascular assessments, we hypothesize that $\mathrm{CeO}_{2} \mathrm{NP}$ injection would result in decreased microvascular dysfunction and oxidative stress associated with hypertension. In order to simulate a therapeutic application, spontaneously hypertensive (SH) and WistarKyoto (WKY) rats were intravenously injected with either saline or $\mathrm{CeO}_{2} \mathrm{NP}$. Twenty-four hours post-exposure mesenteric arteriolar reactivity was assessed via intravital microscopy. Endothelium-dependent and -independent function was assessed via acetylcholine and sodium nitroprusside. Microvascular oxidative stress was analyzed using fluorescent staining in isolated mesenteric arterioles. Finally, systemic inflammation was examined using a multiplex analysis and venular leukocyte flux. Endothelium-dependent dilation was significantly decreased in the $\mathrm{SH}$ rats and this microvascular dysfunction was significantly improved following $\mathrm{CeO}_{2} \mathrm{NP}$ exposure. There was also an increase in oxidative stress in the $\mathrm{SH}$ rats, which was abolished following $\mathrm{CeO}_{2} \mathrm{NP}$ treatment. These results provided evidence that $\mathrm{CeO}_{2} \mathrm{NP}$ act as an anti-oxidant in vivo. There were also changes in the inflammatory profile in the WKY and SH rats. In WKY rats, IL-10 and TNFa were increased following $\mathrm{CeO}_{2} \mathrm{NP}$ treatment. Finally, leukocyte flux was increased in the $\mathrm{SH}$ rats, but this activation was decreased following exposure. These results indicated that $\mathrm{CeO}_{2} \mathrm{NP}$ may alter the inflammatory response in both $\mathrm{SH}$ and WKY rats. Taken together, these results provide evidence that $\mathrm{CeO}_{2} \mathrm{NP}$ act an anti-oxidant in vivo and may improve the health outcomes associated with hypertension. 
Keywords: microcirculation, cerium dioxide nanoparticles, hypertension, reactive oxygen species, anti-oxidant 


\section{Introduction:}

The term "theranostic" is an emerging concept that combines the terms therapeutic and diagnostic (Kelkar and Reineke 2011). Theranostic research aims to identify agents that possess both therapeutic and diagnostic properties, which ideally would result in more precise and individualize treatments (Kelkar and Reineke 2011). Engineered nanomaterials (ENM) are prime candidates for theranostic applications for several reasons (Kelkar and Reineke 2011). First, the size of ENM ( $\leq 100 \mathrm{~nm}$ in at least on dimension) creates a large surface area for the attachment of various pharmaceuticals and/or imaging agent (Borm et al. 2006). Secondly, by altering the surface chemistry and/or using specific ENM, they may be precisely aimed at target areas in the body, which (in conjunction with a high surface) reduces the dosage needed to treat certain pathologies (Roco et al. 2010; Yu et al. 2010a). Finally, many ENM possess inherent unique characteristics (e.g. autofluorescence, and anti-oxidant activity) that can be exploited to increase their pharmaceutical relevance (Borm et al. 2006).

Cerium dioxide nanoparticles $\left(\mathrm{CeO}_{2} \mathrm{NP}\right)$, an $\mathrm{ENM}$, are being researched for their possible theranostic significance (Colon et al. 2009; Kim et al. 2012; Madero-Visbal et al. 2012). $\mathrm{CeO}_{2} \mathrm{NP}$ have catalytic activity, which arises from the presence of two valances states $\left(\mathrm{Ce}^{3+}\right.$ and $\left.\mathrm{Ce}^{4+}\right)$ in the nanoparticles (Celardo et al. 2011). Due to the oxygen vacancies present in these nanoparticles, they are able to react with surrounding reactive oxygen species (ROS), thus introducing $\mathrm{CeO}_{2} \mathrm{NP}$ as a potential in vivo mimetic for endogenous anti-oxidants like superoxide dismutase (Dunnick et al. 2015; Heckert et al. 2008; Xu and Qu 2014).

However, like many pharmaceuticals, $\mathrm{CeO}_{2} \mathrm{NP}$ research has produced conflicting results about the efficiency of its potential anti-oxidant activity. In vitro analysis has resulted 
in an increase in ROS and inflammation following $\mathrm{CeO}_{2} \mathrm{NP}$ co-incubation; however, other studies with cardiac progenitor and endothelial cells have shown a decrease in both these parameters (Gojova et al. 2009; Horie et al. 2011; Pagliari et al. 2012; Park et al. 2008; Wingard et al. 2011). The in vivo analysis of these particles is even more complex. Experimentally, injected $\mathrm{CeO}_{2} \mathrm{NP}$ have shown decreased tissue damage and area of infarct associated with radiation treatment and stroke (Colon et al. 2009; Kim et al. 2012). Despite these promising results, $\mathrm{CeO}_{2} \mathrm{NP}$ injected into young healthy rats may have detrimental effects that result in microvascular dysfunction (Minarchick et al. 2015). Currently, it is unclear if the potential positive effects of $\mathrm{CeO}_{2} \mathrm{NP}$ are pathology specific. Furthermore, it is also unknown how these alterations in ROS production affect microvascular function.

Hypertension affects one out of three Americans and is a leading factor in the development of cardiovascular disease (Nwankwo T et al. 2013). This increase in blood pressure is associated with microvascular dysfunction, increased sympathetic stimulation and increased wall-to-lumen ratios (Feletou and Vanhoutte 2006; Okamoto et al. 1967). Microvascular dysfunction is, at least partially, attributed to increased ROS generation due to chronic inflammation, mitochondrial dysfunction, and/or nitric oxide synthase (NOS) uncoupling (Brito et al. 2015). In addition to decreasing vasoactive factors directly, the elevated levels of ROS are capable of increasing steroid hormone production, which can impair NOS activity and prostaglandin formation (Suzuki et al. 1995). These changes may result in endothelium dysfunction, which increases the risk of organ damage, and the development of hypertension. These influences of ROS on microvascular function in hypertension has led to the investigation of anti-oxidants as a therapeutic treatment (Brito 
et al. 2015). If the anti-oxidant potential of $\mathrm{CeO}_{2} \mathrm{NP}$ were better understood, this ENM could be developed to decrease the high levels of ROS associated with hypertension.

Therefore, the purpose of this study was to assess the in vivo anti-oxidant potential of $\mathrm{CeO}_{2} \mathrm{NP}$ in a high ROS environment, specifically hypertension. Previous in vitro studies have shown that in the presence of elevated $\mathrm{ROS} \mathrm{CeO}_{2} \mathrm{NP}$ act as an anti-oxidant and can decrease ROS levels (Minarchick et al. 2015). Based on these results, we hypothesize that following injection the $\mathrm{CeO}_{2} \mathrm{NP}$ will act as an anti-oxidant and reduce the oxidative stress and microvascular dysfunction that is associated with hypertension. Microvascular dysfunction and oxidative stress were assessed in the mesentery of spontaneously hypertensive rats $24 \mathrm{~h}$ post-exposure to $\mathrm{CeO}_{2} \mathrm{NP}$ via intravital microscopy and the isolated arteriole technique. 


\section{Methods and Materials:}

Cerium Dioxide Nanoparticle $\left(\mathrm{CeO}_{2} \mathrm{NP}\right)$ Production and Characterization: $\mathrm{CeO}_{2} \mathrm{NP}$ powders were synthesized by a hydrothermal process as previously described (Minarchick et al. 2013). Cerium (IV) ammonium nitrate (99+\% Alfa Aesar, Ward Hill, MA) was added to de-ionized water $\left(\mathrm{H}_{2} \mathrm{O}\right)$ and this solution was added drop-wise into a basic solution of tetramethylammonium hydroxide pentahydrate and de-ionized $\mathrm{H}_{2} \mathrm{O}$. The $\mathrm{pH}$ of the dispersion was altered to $\sim 10.5$ with ammonium hydroxide and was maintained throughout the reaction. The dispersion was placed in a $300 \mathrm{ml}$ Autoclave Engineers EZE-Seal ${ }^{\circledR}$ autoclave (Erie, PA) at $240^{\circ} \mathrm{C}$ for one $\mathrm{h}$. Once removed from the autoclave, the dispersion was placed into a centrifuge and the liquid was removed and replaced with ethanol. After the washing step, the dispersion was dried at $60{ }^{\circ} \mathrm{C}$ overnight and sieved through a 200 mesh screen for characterization. The nanoparticles were previous characterized (Minarchick et al. 2013). Briefly, the $\mathrm{CeO}_{2} \mathrm{NP}$ had a surface area of $81.36 \mathrm{~m}^{2} / \mathrm{g}$ measured by Micromeritics ASAP 2020 (Norocross, GA). JEOL JEM-2100 High Resolution Transmission Electron Microscope (TEM) (Peabody, MA) determined the primary particle size ( 2-4 $\mathrm{nm}$ ) and shape (spherical). The average agglomerate size in saline (Normosol, Nospira Inc., Lake Forest, IL) and 5\% fetal bovine serum (FBS) was $191 \mathrm{~nm}$ as determined by dynamic light scattering via a Malvern Zetasizer version 7.01 (Westborough, MA). Finally, the valence state of the $\mathrm{CeO}_{2} \mathrm{NP}$ was $\sim 81 \% \mathrm{Ce}^{4+}$ and $\sim 19 \% \mathrm{Ce}^{3+}$ determined by x-ray photoelectron spectroscopy (PHI 5000 Versaprobe XPS, Chanhassen, MN).

Experimental Animals: Male spontaneously hypertensive $(\mathrm{SH})$ rats and WistarKyoto (WKY) rats ( 10 weeks old) were purchased from Harlan laboratories (Indianapolis, IN). SH rats were studied because they are a well-established model of microvascular 
dysfunction and local ROS (Bakker et al. 2014; Brito et al. 2015). WKY rats are the appropriate normotensive control for the $\mathrm{SH}$ and were used as the control model for these experiments (Okamoto et al. 1967). The rats were housed at the West Virginia University Health Sciences Center Vivarium, in laminar flow cages, under controlled humidity and temperature, with a $12 \mathrm{~h}$ light/dark cycle, and food and water were provided ad libitum. The animals were acclimated for a minimum of two days prior to use. The Institutional Animal Care and Use Committee at West Virginia University approved all procedures.

$\mathrm{CeO}_{2}$ NP Solution Preparation and Exposure: For the stock suspension, $1.1 \mathrm{mg}$ of dry powder added to $10 \mathrm{ml}$ of Normosol with $5 \%$ FBS to reduce agglomeration. The $\mathrm{CeO}_{2}$ NP were vortexed for five min and then sonicated on ice for an additional five min. Rats were lightly anesthetized with isoflurane gas (5\% induction, $2-3.5 \%$ maintenance). Rats were divided into four groups and were intravenously injected in the tail vein with a $900 \mu \mathrm{l}$ bolus dose of saline (WKY-Sham, SH-Sham) or $\mathrm{CeO}_{2} \mathrm{NP}$ stock suspension (WKY-CeO $\mathrm{NP}, \mathrm{SH}-\mathrm{CeO}_{2} \mathrm{NP}$ ) using a $23 \mathrm{G}$ needle. The final dose was $100 \mu \mathrm{g}$ per rat. This dose was predetermined to be the dose that caused a $50 \%$ impairment in microvascular function in Sprague-Dawley rats (Minarchick et al. 2015). Rats were monitored after treatment until they regained consciousness. All animals were allowed to recover for $24 \mathrm{~h}$ prior to experimental assessments.

Intravital Microscopy Preparation: Animals were anesthetized with Inactin [100 $\mathrm{mg} / \mathrm{kg}$, intraperitoneal (i.p.) injection] and placed on a heating pad to maintain a $37^{\circ} \mathrm{C}$ rectal temperature. The trachea was intubated to maintain a patent airway, and the right carotid artery was cannulated to monitor MAP and heart rate. A loop of the small intestine (ileum) was surgically exteriorized. Once exteriorized, two small incisions $6-10 \mathrm{~cm}$ apart were made along the intestinal wall using thermal cautery and the chyme was flushed from the 
lumen through the incisions. The ileum was then carefully placed over a clear pedestal, and gently secured so that the mesenteric circulation was at its in situ length. Throughout the preparation and experiment, the exposed mesentery was continuously superfused with an electrolyte solution (119 mM NaCl, $25 \mathrm{mM} \mathrm{NaHCO}_{3}, 6 \mathrm{mM} \mathrm{KCl}$, and $3.6 \mathrm{mM} \mathrm{CaCl}_{2}$ ) that was warmed to $37^{\circ} \mathrm{C}$ and equilibrated with $95 \% \mathrm{~N}$ and $2-5 \% \mathrm{CO}_{2}(\mathrm{pH} 7.35-7.40)$. Intestinal motility was suppressed using isoproterenol hydrochloride $(10 \mathrm{mg} / \mathrm{l}$, Sigma-Aldrich, St. Louis MO) and phenytoin (20 mg/l, Sigma-Aldrich, St. Louis MO). At these concentrations, isoproterenol and phenytoin have no significant effect on arteriolar tone (Bohlen et al. 1978). The superfusate rate was maintained at $4-6 \mathrm{ml} / \mathrm{min}$ to minimize equilibration with atmospheric oxygen (Boegehold and Bohlen 1988). The animal preparation was then transferred to the stage of an intravital microscope coupled to a charge-coupled device (CCD) video camera. Observations were made with a $20 x$ water immersion objective. Video images were displayed on a high-resolution color video monitor and recorded for offline analysis. During analysis, arteriolar inner diameters were measured with a video caliper and one to three arterioles were studied per rat.

Microvascular Analysis: Arteriolar endothelium-dependent dilation was evaluated using acetylcholine (ACh, $0.25 \mathrm{M})$. ACh was iontophoretically applied to individual $5^{\text {th }}$ order arterioles (20, 100, and $150 \mathrm{nAmp})$. Glass micropipettes were beveled at $23-25^{\circ}$ angle with 2-4 $\mu \mathrm{m}$ inner diameter tip and filled with ACh (Nurkiewicz et al. 2004). The pipette tip was placed in light contact with the arteriolar wall and a current programmer (model 260; World Precision Instruments, New Haven, CT) was used to deliver continuous ejection currents (two min). A recovery period (at least two min) followed each application. The ACh response determination was repeated in the presence of several chemical interventions which were applied via syringe pump $(0.4 \mathrm{ml} / \mathrm{min})$ into the superfusate delivery line for 30 
min. The mesentery was incubated with $N^{G}$-monomethyl-L-arginine (L-NMMA, $10^{-4} \mathrm{M}$ ), a NOS inhibitor, to assess the influence of NO. Incubation with indomethacin (INDO, $10^{-5} \mathrm{M}$ ), a cyclooxygenase (COX) inhibitor, was used to assess the influence of COX products. The mesentery was also incubated with 2,2,6,6-tetramethylpiperidine-N-oxyl (TEMPOL, 10-4 M), a superoxide dismutase mimetic, and catalase (50 units $/ \mathrm{ml}$ ), a hydrogen peroxide scavenger, to assess the influence of ROS. All four chemical interventions (L-NMMA, INDO, TEMPOL and catalase) were applied to the mesentery to determine influence of NO, COX products, and ROS simultaneously. Vascular smooth muscle responsiveness to NO was assessed using sodium nitroprusside (SNP, $0.05 \mathrm{M})$. SNP was iontophoretically applied to arterioles as previously described (10, 50, and $150 \mathrm{nAmp}$ ) (Nurkiewicz et al. 2004). Microvascular reactivity assessments and ejection currents were randomized and two to three assessments were completed per rat. At the end of each experiment, adenosine $\left(A D O, 10^{-4} \mathrm{M}\right)$ was added to the superfusate via syringe pump to determine the passive diameter of each arteriole studied.

Finally, leukocyte flux was assessed in mesenteric venules to determine potential microvascular inflammation. Leukocytes that were either stationary or moving but maintained consistent contact with the arteriolar wall for at least $200 \mu \mathrm{m}$ were counted for one min in each venule studied.

Oxidative Stress Analysis: A separate subset of animals ( 10 weeks old) was used to determine changes in microvascular oxidative stress via fluorescent analysis. $\mathrm{SH}$ and WKY rats were exposed to either saline or $\mathrm{CeO}_{2} \mathrm{NP}$ as previous described. Twenty-four $\mathrm{h}$ post-exposure, the animals were anesthetized with Inactin $(100 \mathrm{mg} / \mathrm{kg}$, ip injection) and were placed on a heating pad to maintain a $37^{\circ} \mathrm{C}$ rectal temperature. The right carotid artery was cannulated to acquire blood for subsequent cytokine analysis (see Pro- 
Inflammatory Cytokine Analysis). The mesentery was removed and placed in a dissecting dish with physiological salt solution (PSS) maintained at $4{ }^{\circ} \mathrm{C}$ (Minarchick et al. 2015). Mesenteric arterioles ( $4^{\text {th }}$ and $5^{\text {th }}$ order) were isolated, transferred to a vessel chamber, cannulated between two glass pipettes, and tied with silk sutures (Living Systems Instrumentation, Burlington, VT). In the absence of light, dihydroethidium (DHE, 10-4 M) was intraluminally infused for $20 \mathrm{~min}$ followed by a 20 min wash with PSS to remove excess DHE. Prior to imaging, the arterioles were pressurized to $80 \mathrm{~mm} \mathrm{Hg}$ using a servo control system (Sun et al. 1992). The vessel chamber was placed on an Olympus BX51WI upright microscope for imaging. The arteriole was first imaged briefly under traditional bright field settings. The arteriole was illuminated with a mercury lamp for one second with the appropriate excitation and emission filters for detection of ethidium bromide fluorescence (480-550 nm bandpass, $590 \mathrm{~nm}$ barrier) and hydroethidine fluorescence (330-385 nm bandpass, $590 \mathrm{~nm}$ barrier). DHE was used because it easily permeates cell membranes and can be oxidized by superoxide to form ethidium bromide which intercalates into nuclear DNA (Benov et al. 1998; Morgan et al. 1979).

ROS-associated fluorescence was quantified in the arteriolar wall. A user-defined region of interest $(\mathrm{ROI})$ box $(10 \times 100 \mu \mathrm{m})$ was placed vertically on the endothelial cell layer of the bright field image. It was previously determined that the mesenteric arteriolar wall thickness was approximately $13 \mu \mathrm{m}$; therefore, the ROI box encompassed the entire endothelial cell layer and most of the smooth muscle layer. The images were analysed using open access imaging software (ImageJ). The hydroethidine image represented background and non-specific fluorescence, therefore in order to analyse only fluorescence which had been intercalated into the DNA this fluorescence was removed from the ethidium bromide image. The ROI was superimposed on the resulting image in order to acquire the 
mean fluorescence of the arteriole. Total fluorescence intensity was calculated as average fluorescence intensity per pixel x surface area.

Pro-Inflammatory Cytokine Analysis: The blood collected from the SH and WKY rats was centrifuged $(1100 \times \mathrm{g})$ to separate the blood components. The plasma was collected, flash frozen in liquid nitrogen, and stored in a $-80{ }^{\circ} \mathrm{C}$ freezer until analysis. A proinflammatory cytokine multi-spot assay was completed per manufacturer's directions (MesoScale Diagnostics, Rockville, MD). The pro-inflammatory cytokines assessed were:

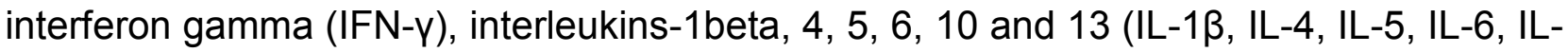
10, and IL-13), tumor necrosis factor alpha (TNF- $\alpha$ ) and keratinocyte chemoattractant/human growth-regulated oncogene (KC/GRO).

Equations: Basal tone was calculated by the following equation,

$$
\text { Basal Tone }(\%)=\left[\left(D_{M}-D_{B D}\right) / D^{M}\right] \times 100 \text {, }
$$

where $D_{B D}$ is the baseline diameter measured prior to any current application, and $D_{M}$ is the passive diameter recorded in the presence of $A D O$. The experimental responses to ACh and SNP are expressed using the following equation:

Diameter $($ Percent Maximal Response $\left.)=\left[D_{s s}-D_{B D}\right) /\left(D_{M}-D_{B D}\right)\right] \times 100$,

where Dss is the maximal diameter recorded at each current.

Statistics: Data are expressed as means \pm standard error (SE). Point-to-point differences in the dose-response determinations were evaluated using two-way repeated measures analysis of variance (ANOVA) with a Student-Newman-Keuls post-hoc analysis 
when significance was found. Statistical differences in the slopes of the dose-response determinations were determined by linear regression analysis. The animal characteristics, arteriole characteristics, oxidative stress, and pro-inflammatory cytokine results were analyzed using a one-way ANOVA with a Student-Newman-Keuls post-hoc analysis when significance was found. All statistical analysis was completed with SigmaPlot 11.0 (San Jose, CA) and GraphPad Prism 5 (San Diego, CA). Significance was set at $p \leq 0.05, n$ is the number of arterioles, and $\mathrm{N}$ is the number of animals. 


\section{Results:}

Animal and Arteriolar Characteristics: There were no significant changes in age or heart rate between the four groups (Table 1). MAP and heart weight were significantly increased in the $\mathrm{SH}-\mathrm{Sham}$ and $\mathrm{SH}-\mathrm{CeO}_{2} \mathrm{NP}$ groups compared to the normotensive WKY groups (Table 1). These findings are consistent with $\mathrm{SH}$ rat characteristics. There was also a significant increase in body weight in the $\mathrm{SH}-\mathrm{CeO}_{2} \mathrm{NP}$ group compared to the WKY groups (Table 1). Finally, there were no observed arteriolar differences in starting diameter, maximal diameter, and basal tone between the four groups (Table 2). These results indicate that $\mathrm{CeO}_{2} \mathrm{NP}$ injection exposure does not influence blood pressure or arteriolar tone, when comparing WKY and SH groups.

Endothelium-Dependent Dilation: Endothelium-dependent dilation was significantly impaired in the SH-Sham group compared to the WKY groups (Figure 1). Following 100 $\mu \mathrm{g}$ injection of $\mathrm{CeO}_{2} \mathrm{NP}$, there was a significant augmentation in endothelium-dependent dilation in the $\mathrm{SH}-\mathrm{CeO}_{2} \mathrm{NP}$ group compared to the $\mathrm{SH}$-Sham group (Figure 1). However, this dilation was still significantly impaired compared to the WKY-Sham group (Figure 1). These data provide evidence that injected $\mathrm{CeO}_{2}$ NP can partially improve the microvascular dysfunction associated with hypertension.

Endothelium-Independent Dilation: Endothelium-independent dilation was not impaired in the $\mathrm{SH}$ or WKY groups (Figure 2). This indicates that $\mathrm{CeO}_{2} \mathrm{NP}$ injection exposure and hypertension, either alone or together, do not impair arteriolar vascular NO smooth muscle signaling.

Contribution of NO, COX Products, and ROS to ACh-Induced Vasodilation: The role of NO in ACh-induced vasodilation was assessed during incubation with L-NMMA. Incubation of the mesentery with L-NMMA significantly reduced vasodilation in response to $A C h$, both in 
terms of the overall slopes and at the highest ejection current, in the WKY-Sham and WKY$\mathrm{CeO}_{2} \mathrm{NP}$ groups (Figures $3 \mathrm{~A}$ and $4 \mathrm{~A}$ ). There was a significant increase in dilation in the SH-Sham during incubation with L-NMMA, but there was no improvement in arteriolar dilation during incubation in the $\mathrm{SH}-\mathrm{CeO}_{2} \mathrm{NP}$ group (Figure 4A).

The role of COX products were assessed during incubation with INDO. There was also a significant impairment in arteriolar reactivity, in regards to the overall slopes and at the highest ejection current, during incubation with INDO in the WKY-Sham and WKY$\mathrm{CeO}_{2} \mathrm{NP}$ groups (Figures 3B and 4B). There was no change in vasodilation during incubation in the SH-Sham group (Figure 4B). Finally, there was a significant increase in vasodilation in the $\mathrm{SH}-\mathrm{CeO}_{2} \mathrm{NP}$ during INDO incubation (Figure 4B).

Local ROS was scavenged during simultaneous incubation with TEMPOL and catalase. There was no change in arteriolar vasodilation during TEMPOL and catalase incubation in the WKY-Sham, WKY-CeO $2 \mathrm{NP}$, and $\mathrm{SH}_{-}-\mathrm{CeO}_{2} \mathrm{NP}$ groups (Figure $3 \mathrm{C}$ and 4C). There was a significant increase in the response to $\mathrm{ACh}$ in the $\mathrm{SH}$-Sham group during incubation with exogenous anti-oxidants (Figure 4C).

Finally, arteriolar dilation was assessed during co-incubation with all four chemical interventions. In regards to the overall slopes and the highest ejection current, there was significant decrease in arteriolar reactivity in the WKY-Sham and $\mathrm{WKY}-\mathrm{CeO}_{2} \mathrm{NP}$ (Figures 3D and 4D). In the SH groups, there was no significant changes in arteriolar vasodilation in the SH-Sham group, but there was a significant increase in dilation in the $\mathrm{SH}-\mathrm{CeO}_{2} \mathrm{NP}$ group (Figure 4D). Overall, these data provide initial evidence that there is differential contributions of $\mathrm{NO}, \mathrm{COX}$ products, and ROS to vasodilation after $\mathrm{CeO}_{2} \mathrm{NP}$ injection exposure in the $\mathrm{SH}$ rats. Additionally, these data provide evidence that $\mathrm{CeO}_{2} \mathrm{NP}$ act as an anti-oxidant in vivo. 
Microvascular Oxidative Stress: There was a significant increase in microvascular oxidative stress in the SH-Sham group compared to the WKY groups (Figures 5A and B). The level of oxidative stress in the $\mathrm{SH}$ rats was significantly decreased following $\mathrm{CeO}_{2} \mathrm{NP}$ exposure and the level of oxidative stress in the $\mathrm{SH}-\mathrm{CeO}_{2} \mathrm{NP}$ was similar to the WKYSham group (Figures 5A and B). There were also no significant differences between the WKY-Sham and WKY-CeO 2 NP groups (Figures 5A and B). Taken together, these results provide evidence that $\mathrm{CeO}_{2} \mathrm{NP}$ have anti-oxidant activity in vivo.

Systemic Inflammation and Biomarkers: Venular leukocyte flux was assessed in all four groups. There was a significant increase in leukocyte activation in the SH-Sham group compared to the WKY-Sham, WKY-CeO 2 NP, and $\mathrm{SH}_{-} \mathrm{CeO}_{2} \mathrm{NP}$ groups (Figure 6A). This activation was significantly decreased in the $\mathrm{SH}$ animals following exposure to $\mathrm{CeO}_{2} \mathrm{NP}$ (Figure 6A). There was also no change in leukocyte activation between the WKY-Sham and WKY-CeO 2 NP (Figure 6A). Pro-inflammatory cytokines were analyzed in harvested plasma. There were no significant differences in IFN-y, IL-4, IL-5, IL-6, IL-13, and KC/GRO between the groups (data not shown). There was a significant increase in IL-10 and TNF$\alpha$ in the WKY-CeO 2 NP group compared to the other three groups (Figures 6B and C). Finally, there was a decrease in IL-1 $\beta$ in the $\mathrm{SH}-\mathrm{Sham}$ and $\mathrm{SH}-\mathrm{CeO}_{2} \mathrm{NP}$ groups compared to both WKY groups (Figure 6D). Taken together these results provide evidence that injected $\mathrm{CeO}_{2} \mathrm{NP}$ may alter inflammatory signaling pathways in both normotensive and hypertensive animals. 


\section{Discussion:}

To our knowledge, this study was the first to investigate the in vivo anti-oxidant potential of $\mathrm{CeO}_{2} \mathrm{NP}$ in a hypertensive animal model. The first major finding of this study is that $\mathrm{CeO}_{2} \mathrm{NP}$ act as an anti-oxidant in vivo resulting in decreased microvascular dysfunction and oxidative stress that is associated with hypertension. The second finding of this study was that there were changes in the pro-inflammatory cytokine profile following $\mathrm{CeO}_{2} \mathrm{NP}$ exposure.

Intravenously injected $\mathrm{CeO}_{2} \mathrm{NP}$ significantly reduced the level of oxidative stress in the $\mathrm{SH}$ rats, which contributed to decreased microvascular dysfunction. This finding supports the notion that $\mathrm{CeO}_{2} \mathrm{NP}$ act as an anti-oxidant, and this finding is corroborated by numerous studies (Colon et al. 2010; Estevez et al. 2011; Kim et al. 2012). Despite this positive result, previous studies have shown a decrease in vascular function following $\mathrm{CeO}_{2}$ NP exposure (Minarchick et al. 2015; Wingard et al. 2011). These disparate effects may be due to several reasons including the basal level of ROS and the animal model.

$\mathrm{SH}$ rats have an increase basal level of ROS, that was not present in the SpragueDawley rats that were used in previous studies (LeBlanc et al. 2010). An increase in ROS generation is also observed during radiation treatments and stroke, where these ENM were shown to be beneficial. This conceptual need for an increased basal level of ROS is also supported in vitro. Cardiac progenitor cells and cardiomyocytes were protected from high ROS levels when $\mathrm{CeO}_{2}$ NP were present (Niu et al. 2011; Pagliari et al. 2012). Furthermore, there were not high initial levels of ROS production in studies that reported an increase in $\mathrm{ROS}$ following $\mathrm{CeO}_{2}$ exposure (Horie et al. 2011; Park et al. 2008). When taken together these studies support the hypothesis that $\mathrm{CeO}_{2} \mathrm{NP}$ work optimally as an anti-oxidant when there are elevated levels of ROS prior to or in conjunction with exposure. 
In addition to the potential changes in ROS, the selected animal model may also influence the lack of microvascular influences following $\mathrm{CeO}_{2} \mathrm{NP}$ in the WKY rats. Both the WKY and SH animals are inbred strains compared to the outbred Sprague-Dawley rat used in other studies with $\mathrm{CeO}_{2} \mathrm{NP}$. Genetic modifications have been shown to alter the effects of ENM exposure. $\mathrm{CeO}_{2} \mathrm{NP}$ exposed mice have an increase in pulmonary inflammation and vascular dysfunction; however, when the mice were genetically modified to knockout mast cell production these effects were absent (Wingard et al. 2011). Therefore, it is reasonable to speculate that genetic differences between the WKY, SH, and SpragueDawley rat lineages may contribute to the differences observed in microvascular reactivity. Further studies are required to investigate potential genetic differences and their influence on the cardiovascular outcomes following ENM exposure.

Despite the partial decrease in microvascular dysfunction, $\mathrm{CeO}_{2} \mathrm{NP}$ could not completely restore normal microvascular function in the $\mathrm{SH}$ animal model (Figure 1). This lack of an overall improvement could be due to arachidonic acid (AA) metabolism via COX. This study provides evidence that $\mathrm{CeO}_{2} \mathrm{NP}$ exposure results in an apparent shift between NOS and COX activity, resulting in a potential increase prostaglandins production, via increased COX activity. Furthermore, the changes in AA signaling appear to be unique to $\mathrm{CeO}_{2} \mathrm{NP}$ exposure in the $\mathrm{SH}$ animal model. An increase in prostaglandin production can affect microvascular reactivity by influencing both vasodilation and vasoconstriction. Based on this data, it can be speculated that $\mathrm{CeO}_{2} \mathrm{NP}$ exposure increases thromboxane $\mathrm{A}_{2}$ activity, which would result in vasoconstriction. This increased influence on vasoconstriction would prevent the arterioles from fully dilating in response to ACh. However, additional studies will need to be completed to determine the influence of $\mathrm{CeO}_{2}$ NP on AA signaling and COX activation. 
This study provides promising evidence of the in vivo anti-oxidant potential of $\mathrm{CeO}_{2}$ $\mathrm{NP}$; however, it is currently unclear if $\mathrm{CeO}_{2} \mathrm{NP}$ are operating at their maximal efficiency in vivo. One of the primary factors that could affect the cardiovascular outcomes of $\mathrm{CeO}_{2} \mathrm{NP}$ (and ENM in general) is the dose. The dose used in this study was approximately 0.42 $\mathrm{mg} / \mathrm{kg}$ based on an average animal weight of $240 \mathrm{~g}$. This dose was on the lower end of the published effective doses $(0.4-0.7 \mathrm{mg} / \mathrm{kg})$ used to protect mice from stroke damage (Kim et al. 2012). Therefore, it is reasonable to speculate that increasing the dose may improve $\mathrm{CeO}_{2} \mathrm{NP}$ anti-oxidant effectiveness in hypertensive animals. Therefore, dose refinement could potentially result in a further improvement in microvascular function and decreased oxidative stress. Understanding the cardiovascular effects particularly in regards to the effective dose is vital if $\mathrm{CeO}_{2} \mathrm{NP}$ are to be developed as a pharmaceutical agent. Additionally, the dose needs to be better understood because research has shown that higher concentrations of $\mathrm{CeO}_{2} \mathrm{NP}$ may result in decreased anti-oxidant activity and an increase in pro-oxidant activity (Horie et al. 2011). This shift in activity highlights the need to investigate various doses within a model, and additional doses will need to be tested to explore the full potential of $\mathrm{CeO}_{2} \mathrm{NP}$ treatment to improve the microvascular dysfunction associated with hypertension.

Another factor that may influence the efficiency of $\mathrm{CeO}_{2} \mathrm{NP}$ anti-oxidant activity is the primary size of the nanoparticles. The ENM used in this study and in another stroke study had a primary size of 3-4 nm; however, studies that used larger ENM (> $20 \mathrm{~nm}$ ) have been associated with an increase in ROS as opposed to a decrease (Kim et al. 2012; Park et al. 2008). This difference in the cellular effects has also been observed with other ENM. Silver nanoparticles with a diameter $<40 \mathrm{~nm}$ had increased cell permeability and toxicity versus their larger counterparts (> $40 \mathrm{~nm}$ ) (Sheikpranbabu et al. 2010; Trickler et al. 2010). 
This not only illustrates the importance of characterizing the size of the ENM used but also how a small change in ENM size can alter the biological effects.

The proposed anti-oxidant activity is most likely connected to the valance states $\left(\mathrm{Ce}^{3+}\right.$ and $\left.\mathrm{Ce}^{4+}\right)$ that are present in $\mathrm{CeO}_{2} \mathrm{NP}$. Both valance states can react with any free radical, but research has shown that depending on the valence state this ENM will preferentially react with various oxidants. Under in vitro conditions, $\mathrm{Ce}^{3+}$ preferentially reacts with superoxide and $\mathrm{Ce}^{4+}$ reacts with $\mathrm{NO}$ (Xu and Qu 2014). The $\mathrm{CeO}_{2} \mathrm{NP}$ used in this study were $\sim 19 \% \mathrm{Ce}^{3+}$ and $81 \% \mathrm{Ce}^{4+}$ indicating they may react more readily with NO and may not be functioning at their maximal level (Minarchick et al. 2013). This potential decreased effectiveness may explain why the level of microvascular ROS was not below control levels. Additionally, it has been shown that $\mathrm{pH}$ can affect the valance state stability of $\mathrm{CeO}_{2} \mathrm{NP}$ suggesting that the ENM may change valance states in an in vivo setting; however, it is currently unknown to what extent $\mathrm{CeO}_{2} \mathrm{NP}$ are modified following in vivo exposure (Hayes et al. 2002).

$\mathrm{CeO}_{2} \mathrm{NP}$ exposure has also been associated with changes in inflammation. Similar to this study, others have shown an increase in pro-inflammatory cytokines, changes in the leukocyte, and inflammatory NOS expression following in vivo $\mathrm{CeO}_{2} \mathrm{NP}$ exposure but these results are often inconsistent (Cho et al. 2010; Hirst et al. 2009; Hussain et al. 2012). In this study, an increase in cytokines expression (e.g. TNF- $\alpha$ and IL-10) was present in the normotensive $\mathrm{CeO}_{2} \mathrm{NP}$ exposed animals and it has been well established that inflammation is associated with microvascular dysfunction (LeBlanc et al. 2009; Nurkiewicz et al. 2006). Furthermore, an increase in TNF- $\alpha$ and IL-10 is associated with the activation of macrophages via toll-like receptors, which further supports $\mathrm{CeO}_{2} \mathrm{NP}$ potential to modify inflammation (Mosser 2003). 
Furthermore, these changes in inflammatory cytokines and leukocyte flux could indicated that $\mathrm{CeO}_{2} \mathrm{NP}$ modify thrombosis development. The increase in leukocyte flux in the $\mathrm{SH}$ rats provide indirect evidence for endothelial cells activation, which results in the production various adhesion proteins and factors essential for impairing fibrinolysis (i.e. plasminogen activator inhibitor-1). Plasminogen activator inhibitor-1 (PAI-1) is secreted by macrophages, endothelial cells and vascular smooth muscle cells. Furthermore, this factor is controlled by oxidative stress. Studies with nano-copper oxide have shown an increase in PAI-1 secretion following exposure and it is possible that this factor is also elevated in the SH-Sham rats, thus increasing risk of thrombosis (Yu et al. 2010b). However, following $\mathrm{CeO}_{2} \mathrm{NP}$ exposure there is a decrease in leukocyte flux in the $\mathrm{SH}$ rats, which could indicate a decreased thrombosis risk.

It should also be noted that in this study there was no microvascular impairment in the normotensive rats despite an increase in pro-inflammatory cytokines. This lack of impairment may be contributed to the time post-exposure $(24 \mathrm{~h})$ when reactivity was assessed and the lack of an increased leukocyte flux in the WKY group further supports this notion. If the animals were exposed for a longer period of time (over $24 \mathrm{~h}$ ), an increase in the activation of adhesion molecules and, ultimately, leukocyte extravasation may lead to an increase in microvascular dysfunction and thrombosis development.

Finally, the time of inflammatory assessments may also have contributed the changes in circulating cytokines. TNF- $\alpha$ is classically considered a pro-inflammatory cytokine that is involved in macrophage activation, whereas IL-10 is often considered an anti-inflammatory cytokine because is it capable of inhibiting TNF- $\alpha$ and IFN-y (Feghali and Wright 1997). In this study, it is possible that at $24 \mathrm{~h} \mathrm{IL-10} \mathrm{is} \mathrm{beginning} \mathrm{to} \mathrm{increase,} \mathrm{whereas}$ TNF- $\alpha$ may be beginning to decrease, and this change in expression could result in the 
brief elevation of both cytokines. Additionally, based on these results, it is reasonable to speculate that $\mathrm{CeO}_{2} \mathrm{NP}$ may have anti-inflammatory potential due to the increase in IL-10. Furthermore, SH rats typically have chronic inflammation, which contributes to their microvascular dysfunction (Sanz-Rosa et al. 2005). This study showed limited changes in inflammation in the $\mathrm{SH}$ animals and this lack of pro-inflammatory cytokine production may due to the age of the animals and/or the assessment time used in this study. Further studies will need to investigate the relationship between $\mathrm{CeO}_{2} \mathrm{NP}$, the inflammatory response, and exposure time in normotensive and hypertensive rats.

In conclusion, this study provides evidence that exposure to $\mathrm{CeO}_{2} \mathrm{NP}$ decrease microvascular dysfunction due to a decrease in microvascular oxidative stress. These results further our understanding of $\mathrm{CeO}_{2} \mathrm{NP}$ behavior in vivo and highlight their therapeutic potential as an anti-oxidant, particularly in pathologies associated with elevated ROS. Furthermore, this study showed changes in the inflammatory profile following $\mathrm{CeO}_{2}$ NP exposure. These changes were primarily observed in the WKY group, which highlight the need for further research on this ENM in order to understand fully its influences on systemic inflammation. Fully understanding how $\mathrm{CeO}_{2} \mathrm{NP}$ act in vivo in both low and high ROS environments is critical for the continued and expanded development of this potential theranostic agent. 
Funding Information: This work was supported by the following sources: National Institutes of Health R01-ES015022 (TRN), K99-ES024783 (PAS), the National Science Foundation Cooperative Agreement-1003907 (TRN), and DGE-1144676 (VCM).

Acknowledgements: The authors would like to thank Carroll McBride for his expert technical assistance in this study. The authors disclose no conflicts of interest. 


\section{Reference List}

1. Bakker, E. N., Groma, G., Spijkers, L. J., de, V. J., van, W. A., van, V. H., Everts, V., Arribas, S. M., and VanBavel, E. (2014). Heterogeneity in arterial remodeling among sublines of spontaneously hypertensive rats. PLoS. One. 9(9), e107998.

2. Benov, L., Sztejnberg, L., and Fridovich, I. (1998). Critical evaluation of the use of hydroethidine as a measure of superoxide anion radical. Free Radic. Biol. Med. 25(7), 826-831.

3. Boegehold, M. A., and Bohlen, H. G. (1988). Arteriolar diameter and tissue oxygen tension during muscle contraction in hypertensive rats. Hypertension 12(2), 184-191.

4. Bohlen, H. G., Henrich, H., Gore, R. W., and Johnson, P. C. (1978). Intestinal muscle and mucosal blood flow during direct sympathetic stimulation. Am. J. Physiol 235(1), $\mathrm{H} 40-\mathrm{H} 45$.

5. Borm, P. J., Robbins, D., Haubold, S., Kuhlbusch, T., Fissan, H., Donaldson, K., Schins, R., Stone, V., Kreyling, W., Lademann, J., Krutmann, J., Warheit, D., and Oberdorster, E. (2006). The potential risks of nanomaterials: a review carried out for ECETOC. Part Fibre. Toxicol. 3, 11.

6. Brito, R., Castillo, G., Gonzalez, J., Valls, N., and Rodrigo, R. (2015). Oxidative Stress in Hypertension: Mechanisms and Therapeutic Opportunities. Exp. Clin. Endocrinol. Diabetes.

7. Celardo, I., Traversa, E., and Ghibelli, L. (2011). Cerium oxide nanoparticles: a promise for applications in therapy. J. Exp. Ther. Oncol. 9(1), 47-51.

8. Cho, W. S., Duffin, R., Poland, C. A., Howie, S. E., MacNee, W., Bradley, M., Megson, I. L., and Donaldson, K. (2010). Metal oxide nanoparticles induce unique inflammatory footprints in the lung: important implications for nanoparticle testing. Environ. Health Perspect. 118(12), 1699-1706.

9. Colon, J., Herrera, L., Smith, J., Patil, S., Komanski, C., Kupelian, P., Seal, S., Jenkins, D. W., and Baker, C. H. (2009). Protection from radiation-induced pneumonitis using cerium oxide nanoparticles. Nanomedicine. 5(2), 225-231.

10. Colon, J., Hsieh, N., Ferguson, A., Kupelian, P., Seal, S., Jenkins, D. W., and Baker, C. H. (2010). Cerium oxide nanoparticles protect gastrointestinal epithelium from radiation-induced damage by reduction of reactive oxygen species and upregulation of superoxide dismutase 2. Nanomedicine. 6(5), 698-705.

11. Dunnick, K. M., Pillai, R., Pisane, K. L., Stefaniak, A. B., Sabolsky, E. M., and Leonard, S. S. (2015). The Effect of Cerium Oxide Nanoparticle Valence State on Reactive Oxygen Species and Toxicity. Biol. Trace Elem. Res 166(1), 96-107. 
12. Estevez, A. Y., Pritchard, S., Harper, K., Aston, J. W., Lynch, A., Lucky, J. J., Ludington, J. S., Chatani, P., Mosenthal, W. P., Leiter, J. C., Andreescu, S., and Erlichman, J. S. (2011). Neuroprotective mechanisms of cerium oxide nanoparticles in a mouse hippocampal brain slice model of ischemia. Free Radic. Biol. Med. 51(6), $1155-1163$.

13. Feghali, C. A., and Wright, T. M. (1997). Cytokines in acute and chronic inflammation. Front Biosci. 2, d12-d26.

14. Feletou, M., and Vanhoutte, P. M. (2006). Endothelial dysfunction: a multifaceted disorder (The Wiggers Award Lecture). Am. J. Physiol Heart Circ. Physiol 291(3), H985-1002.

15. Gojova, A., Lee, J. T., Jung, H. S., Guo, B., Barakat, A. I., and Kennedy, I. M. (2009). Effect of cerium oxide nanoparticles on inflammation in vascular endothelial cells. Inhal. Toxicol. 21 Suppl 1, 123-130.

16. Hayes, S. A., Yu, P., O'Keefe, T. J., O'Keefe, M. J., and Stoffer, J. O. (2002). The Phase Stability of Cerium Species in Aqueous Systems I. E-pH Diagram for the CeHClO4-H2O System. Journal of The Electrochemical Society 149(12), C623-C630.

17. Heckert, E. G., Karakoti, A. S., Seal, S., and Self, W. T. (2008). The role of cerium redox state in the SOD mimetic activity of nanoceria. Biomaterials 29(18), 2705-2709.

18. Hirst, S. M., Karakoti, A. S., Tyler, R. D., Sriranganathan, N., Seal, S., and Reilly, C. M. (2009). Anti-inflammatory properties of cerium oxide nanoparticles. Small 5(24), 2848-2856.

19. Horie, M., Nishio, K., Kato, H., Fujita, K., Endoh, S., Nakamura, A., Miyauchi, A., Kinugasa, S., Yamamoto, K., Niki, E., Yoshida, Y., Hagihara, Y., and Iwahashi, H. (2011). Cellular responses induced by cerium oxide nanoparticles: induction of intracellular calcium level and oxidative stress on culture cells. J. Biochem. 150(4), 461-471.

20. Hussain, S., Al-Nsour, F., Rice, A. B., Marshburn, J., Ji, Z., Zink, J. I., Yingling, B., Walker, N. J., and Garantziotis, S. (2012). Cerium dioxide nanoparticles do not modulate the lipopolysaccharide-induced inflammatory response in human monocytes. Int. J. Nanomedicine. 7, 1387-1397.

21. Kelkar, S. S., and Reineke, T. M. (2011). Theranostics: combining imaging and therapy. Bioconjug. Chem. 22(10), 1879-1903.

22. Kim, C. K., Kim, T., Choi, I. Y., Soh, M., Kim, D., Kim, Y. J., Jang, H., Yang, H. S., Kim, J. Y., Park, H. K., Park, S. P., Park, S., Yu, T., Yoon, B. W., Lee, S. H., and Hyeon, T. (2012). Ceria nanoparticles that can protect against ischemic stroke. Angew. Chem Int. Ed Engl. 51(44), 11039-11043. 
23. LeBlanc, A. J., Cumpston, J. L., Chen, B. T., Frazer, D., Castranova, V., and Nurkiewicz, T. R. (2009). Nanoparticle inhalation impairs endothelium-dependent vasodilation in subepicardial arterioles. J. Toxicol. Environ. Health A 72(24), 15761584.

24. LeBlanc, A. J., Moseley, A. M., Chen, B. T., Frazer, D., Castranova, V., and Nurkiewicz, T. R. (2010). Nanoparticle inhalation impairs coronary microvascular reactivity via a local reactive oxygen species-dependent mechanism. Cardiovasc. Toxicol. 10(1), 27-36.

25. Madero-Visbal, R. A., Alvarado, B. E., Colon, J. F., Baker, C. H., Wason, M. S., Isley, B., Seal, S., Lee, C. M., Das, S., and Manon, R. (2012). Harnessing nanoparticles to improve toxicity after head and neck radiation. Nanomedicine. 8(7), 1223-1231.

26. Minarchick, V. C., Stapleton, P. A., Fix, N. R., Leonard, S. S., Sabolsky, E. M., and Nurkiewicz, T. R. (2015). Intravenous and gastric cerium dioxide nanoparticle exposure disrupts microvascular smooth muscle signaling. Toxicol. Sci. 144(1), 7789.

27. Minarchick, V. C., Stapleton, P. A., Porter, D. W., Wolfarth, M. G., Ciftyurek, E., Barger, M., Sabolsky, E. M., and Nurkiewicz, T. R. (2013). Pulmonary cerium dioxide nanoparticle exposure differentially impairs coronary and mesenteric arteriolar reactivity. Cardiovasc. Toxicol. 13(4), 323-337.

28. Morgan, A. R., Evans, D. H., Lee, J. S., and Pulleyblank, D. E. (1979). Review: ethidium fluorescence assay. Part II. Enzymatic studies and DNA-protein interactions. Nucleic Acids Res. 7(3), 571-594.

29. Mosser, D. M. (2003). The many faces of macrophage activation. J. Leukoc. Biol. 73(2), 209-212.

30. Niu, J., Wang, K., and Kolattukudy, P. E. (2011). Cerium oxide nanoparticles inhibit oxidative stress and nuclear factor-kappaB activation in H9c2 cardiomyocytes exposed to cigarette smoke extract. J. Pharmacol. Exp. Ther. 338(1), 53-61.

31. Nurkiewicz, T. R., Porter, D. W., Barger, M., Castranova, V., and Boegehold, M. A. (2004). Particulate matter exposure impairs systemic microvascular endotheliumdependent dilation. Environ. Health Perspect. 112(13), 1299-1306.

32. Nurkiewicz, T. R., Porter, D. W., Barger, M., Millecchia, L., Rao, K. M., Marvar, P. J., Hubbs, A. F., Castranova, V., and Boegehold, M. A. (2006). Systemic microvascular dysfunction and inflammation after pulmonary particulate matter exposure. Environ. Health Perspect. 114(3), 412-419.

33. Nwankwo $T$, Yoon SS, Burt $\mathrm{V}$, and $\mathrm{u}$ Q. Hypertension among adults in the US: National Health and Nutrition Examination Survey, 2011-2012. NCHS Data Brief. 133. 2013. Hyattsville, MD, National Center for Health Statistics, Centers for Disease 
Control and Prevention, US Dept of Health and Human Services. Ref Type: Report

34. Okamoto, K., Nosaka, S., Yamori, Y., and Matsumoto, M. (1967). Participation of neural factor in the pathogenesis of hypertension in the spontaneously hypertensive rat. Jpn. Heart J. 8(2), 168-180.

35. Pagliari, F., Mandoli, C., Forte, G., Magnani, E., Pagliari, S., Nardone, G., Licoccia, S., Minieri, M., Di, N. P., and Traversa, E. (2012). Cerium oxide nanoparticles protect cardiac progenitor cells from oxidative stress. ACS Nano. 6(5), 3767-3775.

36. Park, E. J., Choi, J., Park, Y. K., and Park, K. (2008). Oxidative stress induced by cerium oxide nanoparticles in cultured BEAS-2B cells. Toxicology 245(1-2), 90-100.

37. Roco, M. C., Mirkin, C. A., and Hersam, M. C. Nanotechnology Research Directions for Societal Needs in 2020 Retrospective and Outlook. 9-30-2010. World Technology Evaluation Center, Inc. Ref Type: Report

38. Sanz-Rosa, D., Oubina, M. P., Cediel, E., de Las, H. N., Vegazo, O., Jimenez, J., Lahera, V., and Cachofeiro, V. (2005). Effect of AT1 receptor antagonism on vascular and circulating inflammatory mediators in SHR: role of NF-kappaB/lkappaB system. Am. J. Physiol Heart Circ. Physiol 288(1), H111-H115.

39. Sheikpranbabu, S., Kalishwaralal, K., Lee, K. J., Vaidyanathan, R., Eom, S. H., and Gurunathan, S. (2010). The inhibition of advanced glycation end-products-induced retinal vascular permeability by silver nanoparticles. Biomaterials 31(8), 2260-2271.

40. Sun, D., Messina, E. J., Kaley, G., and Koller, A. (1992). Characteristics and origin of myogenic response in isolated mesenteric arterioles. Am. J Physiol 263(5 Pt 2), $\mathrm{H} 1486-\mathrm{H} 1491$.

41. Suzuki, H., Swei, A., Zweifach, B. W., and Schmid-Schonbein, G. W. (1995). In vivo evidence for microvascular oxidative stress in spontaneously hypertensive rats. Hydroethidine microfluorography. Hypertension 25(5), 1083-1089.

42. Trickler, W. J., Lantz, S. M., Murdock, R. C., Schrand, A. M., Robinson, B. L., Newport, G. D., Schlager, J. J., Oldenburg, S. J., Paule, M. G., Slikker, W., Jr., Hussain, S. M., and Ali, S. F. (2010). Silver nanoparticle induced blood-brain barrier inflammation and increased permeability in primary rat brain microvessel endothelial cells. Toxicol. Sci. 118(1), 160-170.

43. Wingard, C. J., Walters, D. M., Cathey, B. L., Hilderbrand, S. C., Katwa, P., Lin, S., Ke, P. C., Podila, R., Rao, A., Lust, R. M., and Brown, J. M. (2011). Mast cells contribute to altered vascular reactivity and ischemia-reperfusion injury following cerium oxide nanoparticle instillation. Nanotoxicology. 5(4), 531-545. 
44. Xu, C., and Qu, X. (2014). Cerium oxide nanoparticle: a remarkably versatile rare earth nanomaterial for biological applications. NPG Asia Materials 6, 1-16.

45. Yu, L., Scherlag, B. J., Dormer, K., Nguyen, K. T., Pope, C., Fung, K. M., and Po, S. S. (2010a). Autonomic denervation with magnetic nanoparticles. Circulation 122(25), 2653-2659.

46. Yu, M., Mo, Y., Wan, R., Chien, S., Zhang, X., and Zhang, Q. (2010b). Regulation of plasminogen activator inhibitor-1 expression in endothelial cells with exposure to metal nanoparticles. Toxicol. Lett. 195(1), 82-89. 


\section{Figure Legends:}

Figure 1 Endothelium-Dependent Dilation: ACh-induced vasodilation was impaired in arterioles from $\mathrm{SH}$-Sham animals but was significantly improved in the $\mathrm{SH}-\mathrm{CeO}_{2} \mathrm{NP}$ group comparted to the SH-Sham $(n=12-29) .{ }^{*} p \leq 0.05$ vs. WKY-Sham, $\dagger p \leq 0.05$ vs. WKY$\mathrm{CeO}_{2} \mathrm{NP}, \ddagger \mathrm{p} \leq 0.05$ vs. SH-Sham

Figure 2 Endothelium-Independent Dilation: Vascular smooth muscle responsiveness to $\mathrm{NO}$ was not impaired in the Sham groups or following $\mathrm{CeO}_{2} \mathrm{NP}$ exposure $\left(\mathrm{WKY}-\mathrm{CeO}_{2}\right.$ $\mathrm{NP}$ and $\mathrm{SH}-\mathrm{CeO}_{2} \mathrm{NP}$ groups; $\mathrm{n}=9-19$ ).

Figure 3 Overall Influences of NO, COX products, and ROS: The line graphs are the arterioles overall response to the various chemical interventions. A: The role of NO was assessed during incubation with L-NMMA $(n=14-18)$. This incubation resulted in a significant difference in the overall slopes of the dose-response determination within the WKY groups only. B: The role of COX products was assessed during incubation with INDO $(n=9-14)$. This incubation resulted in a significant difference in the overall slopes of the dose-response determination within the WKY groups only. C: Local ROS was scavenged during incubation with TEMPOL and catalase $(n=6-18)$. This incubation resulted in no changes in the overall slopes of the dose-response determination in any of the four treatment groups. D: ACh-induced vasodilation was assessed during co-incubation with the four chemical interventions $(n=10-15)$. This incubation resulted in a significant difference in the overall slopes of the dose-response determination within the WKY groups only. ${ }^{*} p \leq 0.05$ vs. WKY-Sham, $\uparrow p \leq 0.05$ vs. WKY-CeO 2 NP

Figure 4 Influences of NO, COX products, and ROS at 150 nAmp: The bar graph is the dilation that was observed at 150 nAmp for each animal group in the presence of the 
selected chemical intervention. A: The role of NO was assessed during incubation with LNMMA ( $\mathrm{n}=14-18)$. This incubation resulted in a significant decrease in arteriolar vasodilation in the WKY groups. There was a significant increase in vasodilation during incubation in the SH-Sham group but there was no change in ACh-induced dilation in the $\mathrm{SH}-\mathrm{CeO}_{2} \mathrm{NP}$ group. B: The role of $\mathrm{COX}$ products was assessed during incubation with INDO $(n=9-14)$. This incubation resulted in a significant decrease in arteriolar vasodilation in the WKY groups. There was no change in vasodilation in the SH-Sham group, but there was a significant increase in vasodilation following $\mathrm{CeO}_{2} \mathrm{NP}\left(\mathrm{SH}-\mathrm{CeO}_{2} \mathrm{NP}\right)$. C: Local ROS was scavenged during incubation with TEMPOL and catalase $(n=6-18)$. This incubation resulted in no change in arteriolar vasodilation in the WKY groups and the $\mathrm{SH}-\mathrm{CeO}_{2} \mathrm{NP}$ group. There was increase in vasodilation in the SH-Sham group during incubation. D: ACh-induced vasodilation was assessed during co-incubation with the four chemical interventions $(n=10-15)$. This incubation resulted in a significant decrease in arteriolar vasodilation in the WKY groups. There was no change in vasodilation in the $\mathrm{SH}$-Sham group but there was a significant increase in vasodilation following $\mathrm{CeO}_{2} \mathrm{NP}\left(\mathrm{SH}-\mathrm{CeO}_{2}\right.$ NP). The open bars represent responses to ACh in the presence of a chemical mediator. ${ }^{*} p \leq 0.05$ vs. WKY-Sham, $\uparrow p \leq 0.05$ vs. WKY-CeO 2 NP, $\ddagger p \leq 0.05$ vs. SH-Sham, ${ }^{\wedge} p \leq$ 0.05 vs. $\mathrm{SH}-\mathrm{CeO}_{2} \mathrm{NP}$

Figure 5 Vascular Oxidative Stress: A: Representative ethidium bromide images indicating an increase in oxidative stress in the SH-Sham group. B: Quantitative analysis of the ethidium bromide images revealed a significant increase in vascular oxidative stress in the $\mathrm{SH}-\mathrm{Sham}$ group that was reduced in the $\mathrm{SH}-\mathrm{CeO}_{2}$ group $(n=6-10)$. These levels were similar to the WKY-Sham and WKY-CeO 2 NP groups. ${ }^{*} p \leq 0.05$ vs. WKY-Sham, $\uparrow p$ $\leq 0.05$ vs. WKY $-\mathrm{CeO}_{2} \mathrm{NP}, \ddagger p \leq 0.05$ vs. SH-Sham 
Figure 6 Systemic Inflammation: A: Leukocyte flux was assessed in venules during intravital microscopy. There was a significant increase in leukocyte flux in the SH-Sham group, which was decreased following $\mathrm{CeO}_{2} \mathrm{NP}$ exposure $(n=12-15)$. B: Plasma IL-10 levels were significantly increased in the $\mathrm{WKY}-\mathrm{CeO}_{2} \mathrm{NP}$, but not in the other three groups $(\mathrm{N}=7)$. C: Plasma TNF- $\alpha$ levels were significantly increased in the $\mathrm{WKY}-\mathrm{CeO}_{2} \mathrm{NP}$, but not in the other three groups $(N=6-7)$. D: Plasma IL-1 $1 \beta$ levels were significantly decreased in the SH-Sham and $\mathrm{SH}-\mathrm{CeO}_{2} \mathrm{NP}$ groups, but were unaltered in the WKY$\mathrm{CeO}_{2} \mathrm{NP}$ group $(\mathrm{N}=6-7) .{ }^{*} p \leq 0.05$ vs. WKY-Sham, $\uparrow p \leq 0.05$ vs. WKY-CeO 2 NP, $\neq p \leq$ 0.05 vs. SH-Sham, ${ }^{\wedge} p \leq 0.05$ vs. $\mathrm{SH}-\mathrm{CeO}_{2} \mathrm{NP}$ 


\section{Tables:}

Table 1: Animal Characteristics

\begin{tabular}{|c|c|c|c|c|c|c|}
\hline Treatment & $\mathrm{N}$ & $\begin{array}{c}\text { Age } \\
(\mathrm{wks})\end{array}$ & $\begin{array}{c}\text { Weight } \\
(\mathrm{g})\end{array}$ & $\begin{array}{c}\text { Heart } \\
\text { Weight } \\
(\mathrm{g})\end{array}$ & $\begin{array}{c}\text { MAP } \\
(\mathrm{mm} \mathrm{Hg})\end{array}$ & $\begin{array}{c}\text { Heart Rate } \\
\text { (beats/min) }\end{array}$ \\
\hline WKY-Sham & 22 & $10.48 \pm 0.30$ & $230.5 \pm 5.99$ & $0.97 \pm 0.03$ & $66.25 \pm 2.33$ & $446.20 \pm 25.03$ \\
\hline $\begin{array}{c}\mathrm{WKY}- \\
\mathrm{CeO} 2 \mathrm{NP}\end{array}$ & 19 & $10.42 \pm 0.18$ & $226.7 \pm 3.73$ & $0.93 \pm 0.02$ & $69.29 \pm 2.23$ & $471.24 \pm 7.21$ \\
\hline $\begin{array}{c}\mathrm{SH}- \\
\mathrm{Sham}\end{array}$ & 24 & $10.08 \pm 0.32$ & $245.7 \pm 6.20$ & $1.12 \pm 0.03^{*} \dagger$ & $113.33 \pm 5.37^{\star} \dagger$ & $427.83 \pm 18.49$ \\
\hline $\begin{array}{c}\mathrm{SH}- \\
\mathrm{CeO}_{2} \mathrm{NP}\end{array}$ & 24 & $10.17 \pm 0.33$ & $253.0 \pm 5.41^{*} \dagger$ & $1.14 \pm 0.04^{*} \dagger$ & $106.66 \pm 5.27^{*} \dagger$ & $494.37 \pm 12.69$ \\
\hline
\end{tabular}

Values are means $\pm \mathrm{SE}, \mathrm{N}=$ number of animals, MAP = mean arterial pressure

${ }^{*} p \leq 0.05$ versus $W K Y-S h a m ; \dagger p \leq 0.05$ versus $W K Y-\mathrm{CeO}_{2} \mathrm{NP}$ 
Table 2: Arteriole Characteristics

\begin{tabular}{|c|c|c|c|c|}
\hline Treatment & $\mathrm{n}$ & $\begin{array}{c}\text { Starting } \\
\text { Diameter } \\
(\mu \mathrm{m})\end{array}$ & $\begin{array}{c}\text { Maximal } \\
\text { Diameter } \\
(\mu \mathrm{m})\end{array}$ & $\begin{array}{c}\text { Basal Tone } \\
(\%)\end{array}$ \\
\hline $\begin{array}{c}\text { WKY- } \\
\mathrm{Sham}\end{array}$ & 42 & $59.35 \pm 2.67$ & $88.00 \pm 3.40$ & $32.75 \pm 1.25$ \\
\hline $\begin{array}{c}\mathrm{WKY}- \\
\mathrm{CeO}_{2} \mathrm{NP}\end{array}$ & 40 & $59.04 \pm 2.65$ & $92.60 \pm 3.65$ & $35.42 \pm 1.53$ \\
\hline $\begin{array}{c}\mathrm{SH}- \\
\mathrm{Sham}\end{array}$ & 58 & $57.44 \pm 2.30$ & $85.81 \pm 3.18$ & $32.82 \pm 1.16$ \\
\hline $\begin{array}{c}\mathrm{SH}- \\
\mathrm{CeO}_{2} \mathrm{NP}\end{array}$ & 50 & $60.21 \pm 2.65$ & $96.80 \pm 4.08$ & $37.02 \pm 1.49$ \\
\hline
\end{tabular}

Values are means \pm SE, $n=$ number of arterioles 
Figures:

Figure 1:

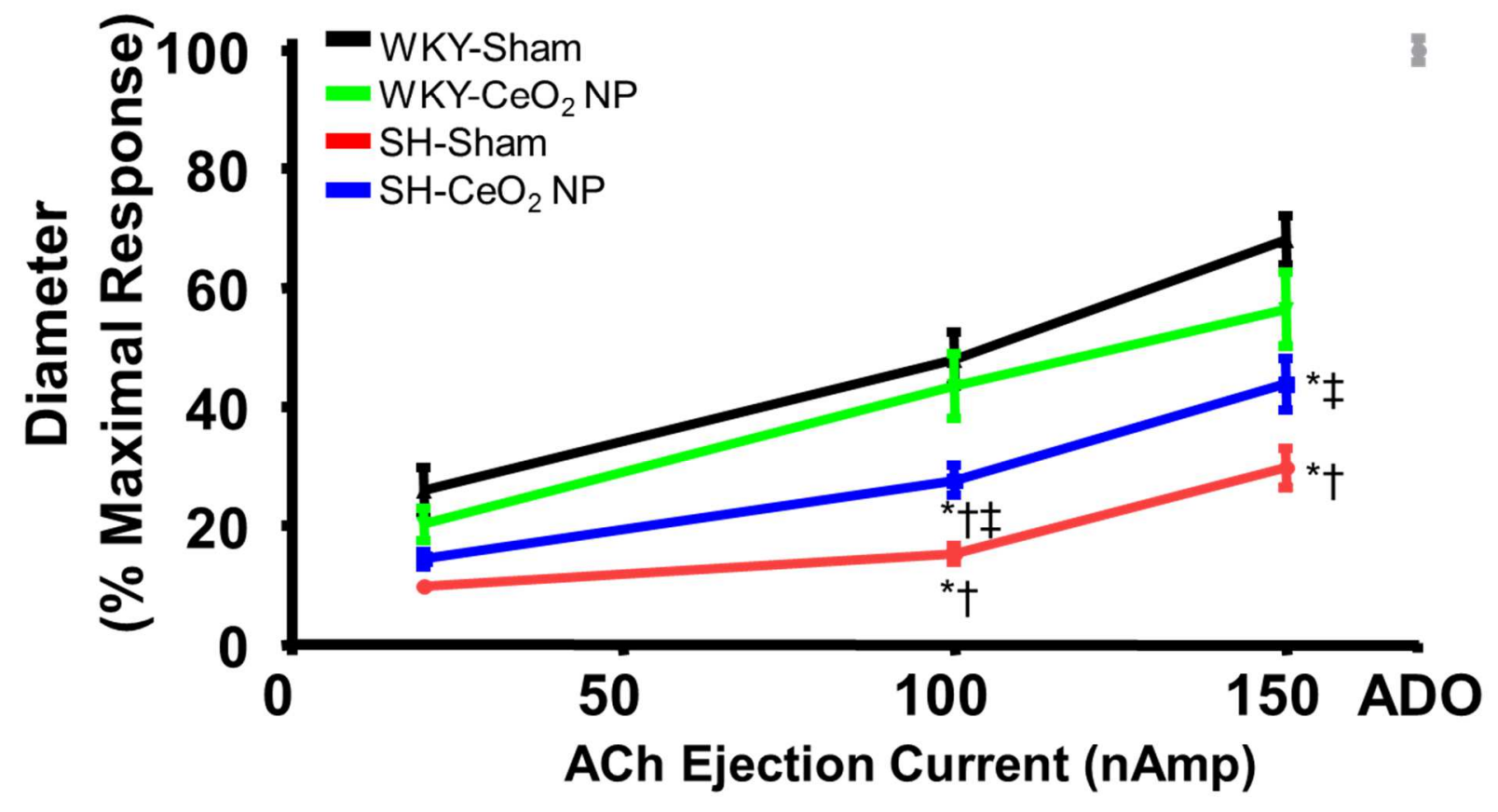




\section{Figure 2:}

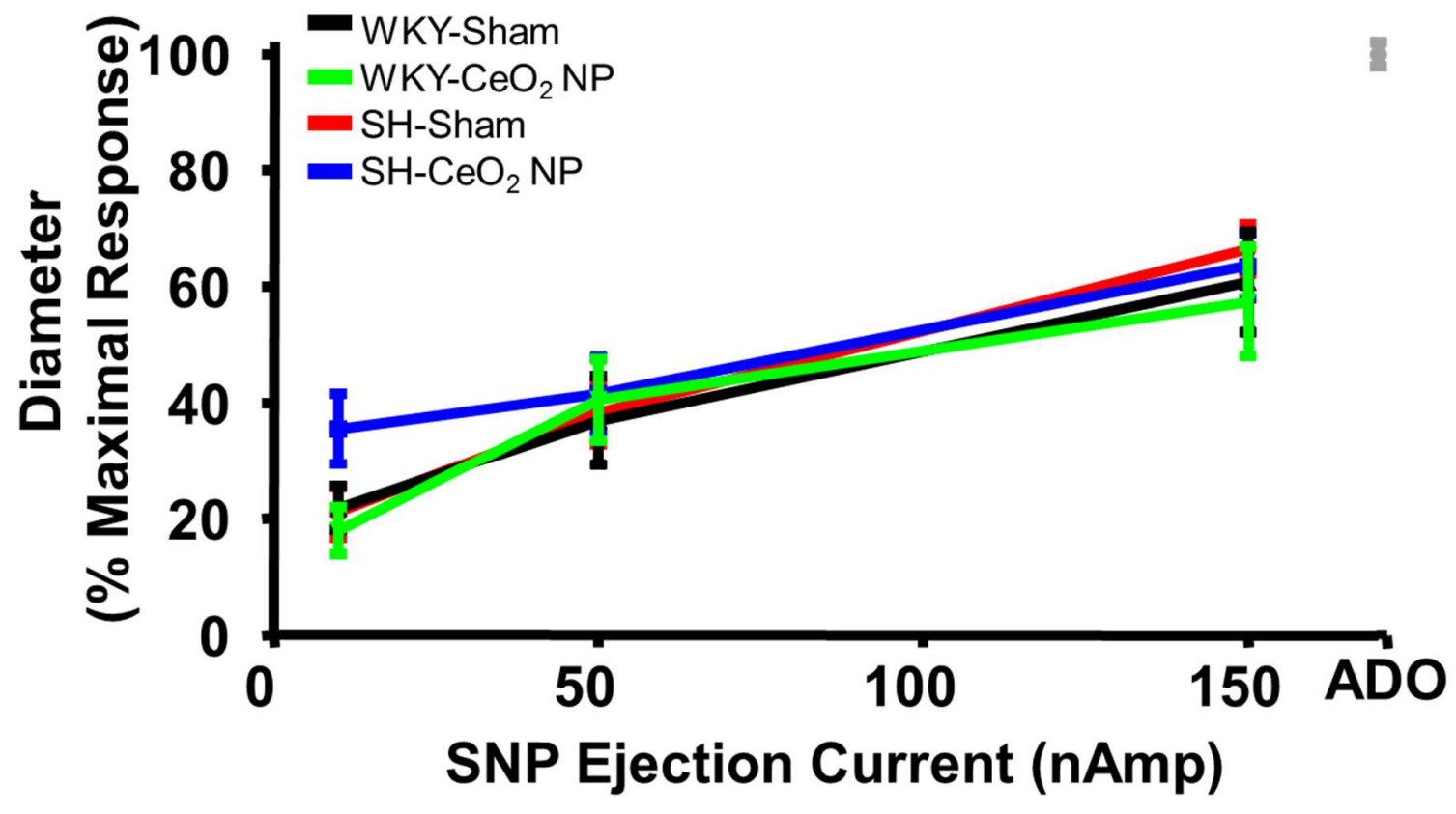


Figure 3:

A: L-NMMA Incubation

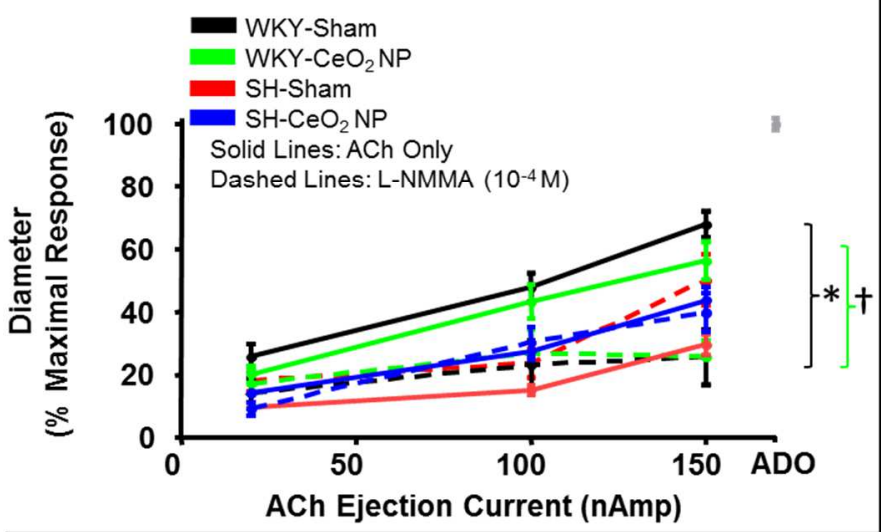

C: TEMPOL and Catalase Incubation

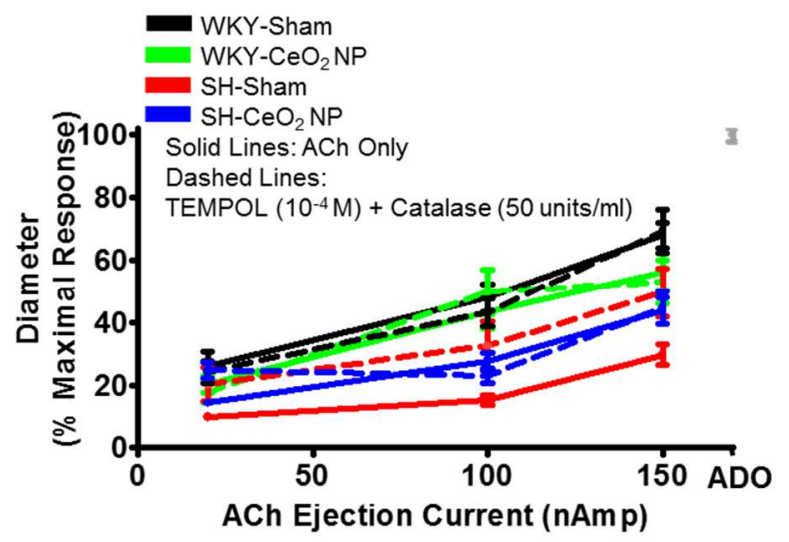

B: INDO Incubation

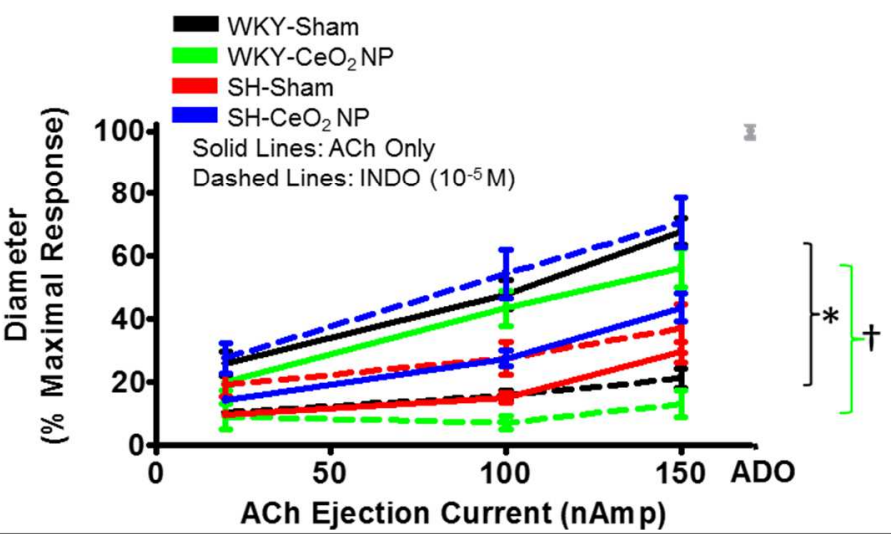

D: All chemical interventions

WKY-Sham

WKY- $\mathrm{CeO}_{2} \mathrm{NP}$

SH-Sham

- $\mathrm{SH}-\mathrm{CeO}_{2} \mathrm{NP}$

Solid Lines: ACh Only

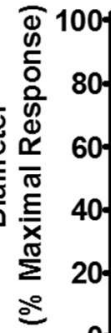

Dashed Lines: All Interventions

(L-NMMA, INDO, TEMPOL, Catalase)

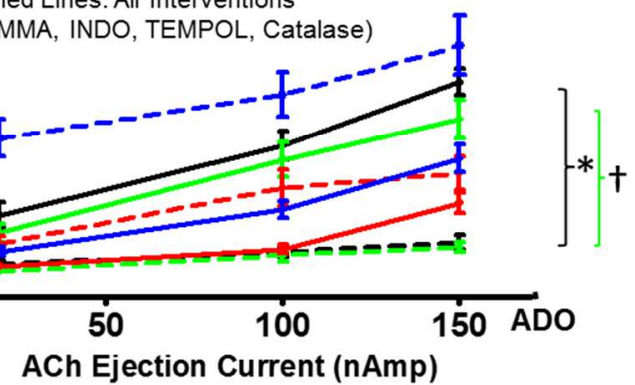


Figure 4:


ACh Ejection Current (nAmp)
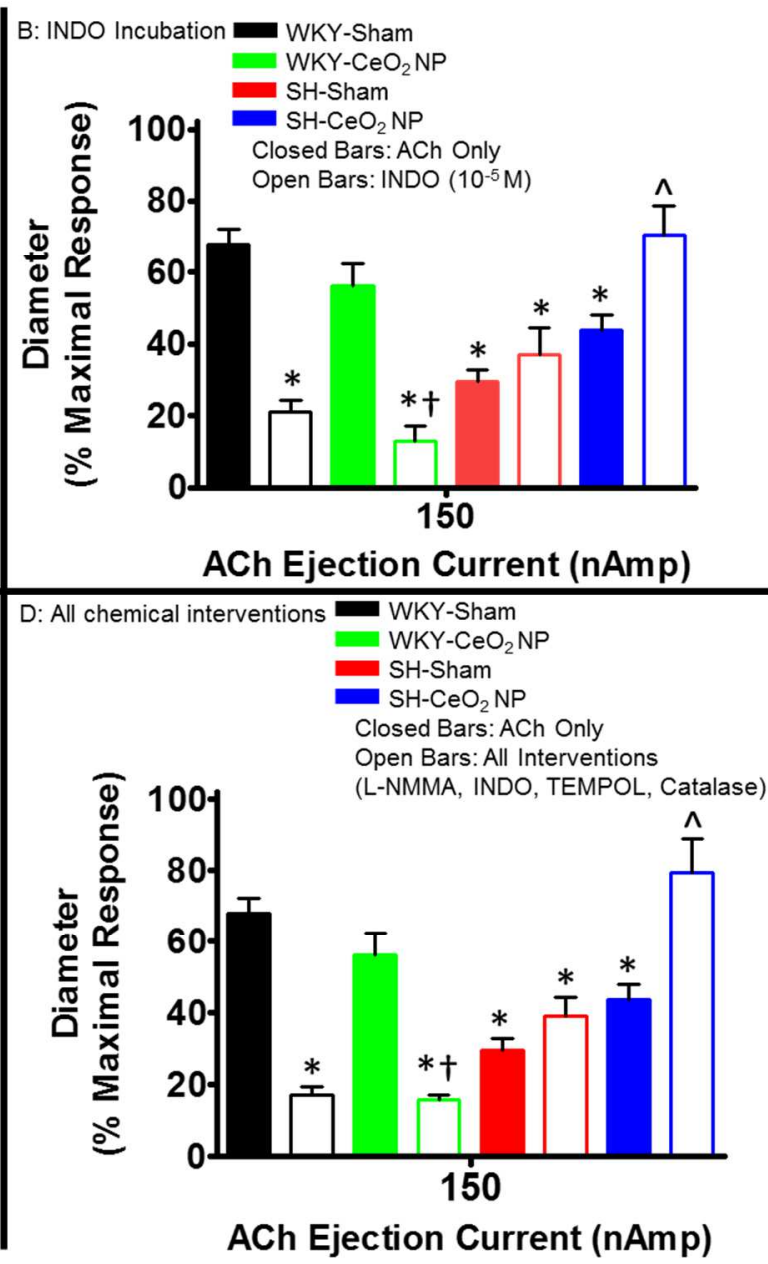
Figure 5:

A

\begin{tabular}{|c|c|c|}
\hline & WKY & SH \\
\hline \multirow{2}{*}{ Sham } & $50 \mu \mathrm{m}$ & \\
& & \\
& & \\
\hline $\mathrm{CeO}_{2} \mathbf{N P}$ & $\vdots$ & \\
$\left(10 \mathbf{H g}^{\prime} \mathbf{g}\right)$ & & \\
\end{tabular}

B

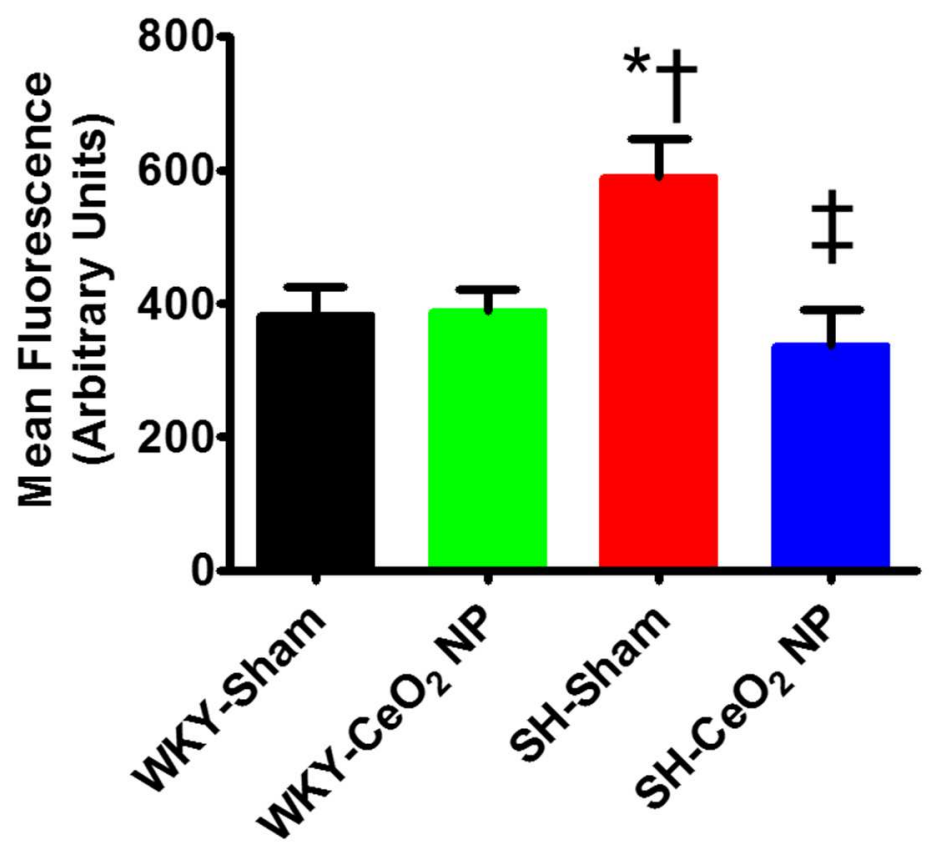


Figure 6:

A: Rolling and Adhering Leukocytes
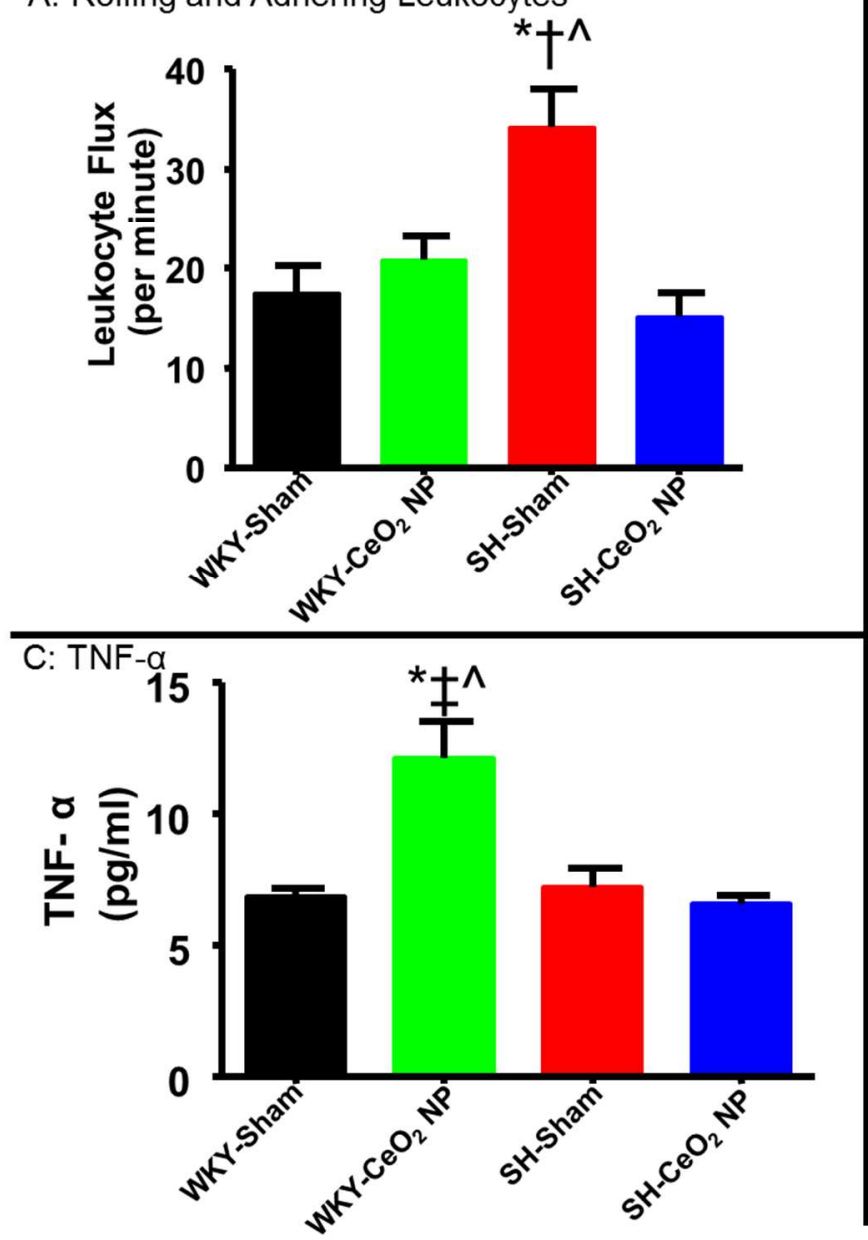

B: IL-10
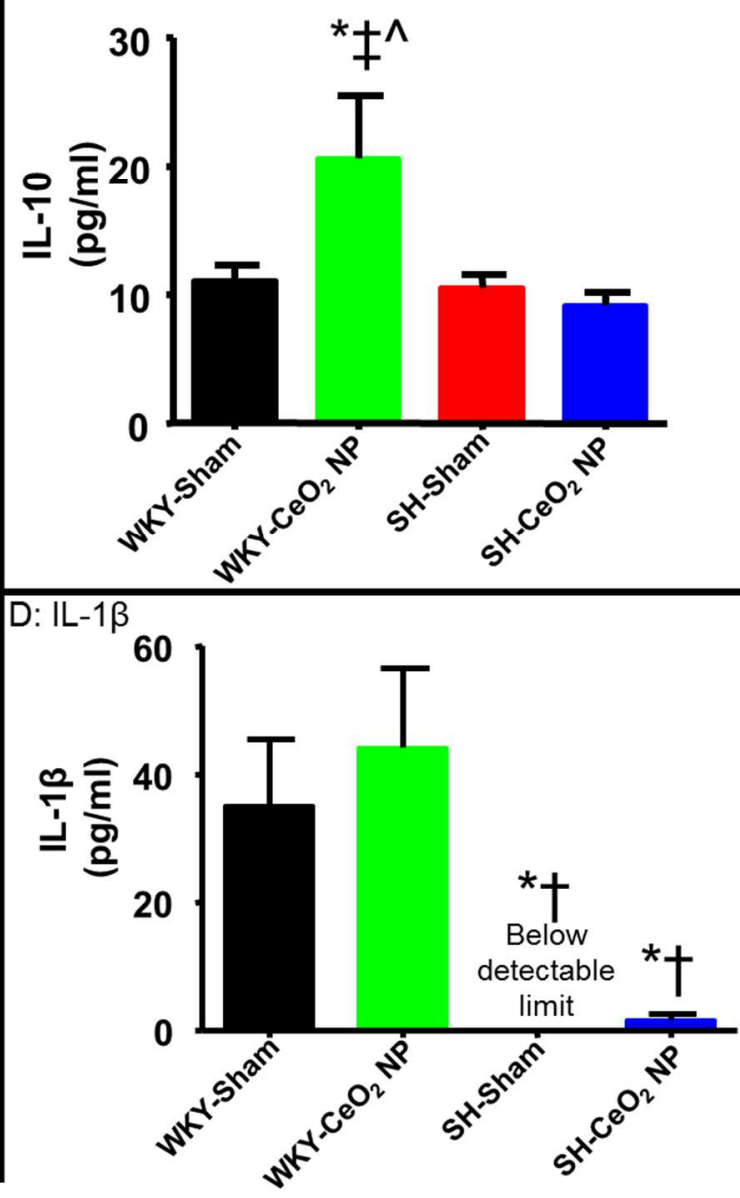


\section{General Discussion}

The microcirculation is essential to maintain vascular homeostasis and unresolved dysfunction can contribute to the development of many pathologies (e.g. hypertension and diabetes) (Prewitt et al. 2002; Zweifach et al. 1981). Despite this knowledge, the microvascular impacts of ENM exposures remain relatively unknown. ENM, such as $\mathrm{CeO}_{2}$ NP, hold great potential for both consumer and therapeutic applications. These uses increase the risk of exposure by non-pulmonary exposure routes; however, many studies do not account for them. Furthermore, if $\mathrm{CeO}_{2} \mathrm{NP}$ are to be developed for therapeutic applications the exposures would occur in individuals with pre-existing diseases, yet very few studies have investigated the impact of $\mathrm{CeO}_{2} \mathrm{NP}$ exposure on various pathologies. Therefore, the first overarching aim of these studies was to investigate the microvascular consequences of $\mathrm{CeO}_{2} \mathrm{NP}$ exposure with respect to microvascular bed, exposure route, pathology, and dose.

\section{Aim 1: Microvascular Consequences}

In general, the results of the three studies presented herein indicate that microvascular alterations are a consequence of $\mathrm{CeO}_{2} \mathrm{NP}$ exposure, and the outcomes are unique based on vascular bed, exposure route, and pathology. The outcomes of Chapter 2: Pulmonary Cerium Dioxide Nanoparticles Exposure Differentially Impairs Coronary and Mesenteric Arteriolar Reactivity establish the influences of pulmonary exposure on microvascular function and highlight the microvascular differences between vascular beds. Pulmonary $\mathrm{CeO}_{2} \mathrm{NP}$ exposure is linked to endothelium-dependent dysfunction, and this dysfunction is consistent with observations made with other ENM (LeBlanc et al. 2010; Stapleton et al. 2012). Furthermore, these effects were not isolated to a singular vascular bed, which indicates that ENM exposure may influence overall systemic microvascular 
function, an observation that again is corroborated by other ENM studies (LeBlanc et al. 2010; Nurkiewicz et al. 2009). Furthermore, this influence on multiple microvascular beds indicates that there may be off-target effects of an ENM, which would result in increases toxicity in multiple organs.

The second significant finding from Chapter 2 was that $\mathrm{CeO}_{2} \mathrm{NP}$ exposure resulted in endothelium-independent dysfunction. Although endothelium-independent dysfunction was a novel finding for ENM exposure, it has been documented following PM exposure in pulmonary arteries (Courtois et al. 2008). Furthermore, this observation was not isolated to pulmonary exposure as indicated by the microvascular assessments performed following the injection and ingestion of $\mathrm{CeO}_{2} \mathrm{NP}$ in Chapter 3: Intravenous and Gastric Cerium Dioxide Nanoparticle Exposure Disrupts Microvascular Smooth Muscle Signaling. These exposure routes were selected since $\mathrm{CeO}_{2} \mathrm{NP}$ have theranostic potential and there are limited studies that focus on non-pulmonary exposure routes. The microvascular dysfunction from these exposure routes were similar to those observed following pulmonary exposure, indicating potential overlapping mechanisms such as changes in NO bioavailability and/or impaired vascular smooth muscle (VSM) signaling (see Aim 2: Potential Mechanisms).

Chapters 2 and 3 also established a dose-response determination for each exposure route and, to our knowledge; these studies (Chapters 2 and 3) were the first to compare microvascular differences between exposure routes. The establishment of a dose-response curve is essential for not only establishing safety and exposure limit guidelines, but also for determining the effective dose when ENM are being developed for theranostic applications. The different toxicities between exposure routes were compared by calculating the $\mathrm{EC}_{50}$ for each exposure route's dose-response determination. Pulmonary 
exposure had the lowest calculated $\mathrm{EC}_{50}$, which indicated that this route was associated with the highest microvascular toxicity. Injection exposure had the second lowest $\mathrm{EC}_{50}$ followed by ingestion $\mathrm{CeO}_{2} \mathrm{NP}$ exposure. These differences in toxicity are also apparent in the literature. In vivo assessments of pulmonary $\mathrm{CeO}_{2} \mathrm{NP}$ exposure have resulted in organ and vascular toxicity, which is likely unique to this exposure route (Ma et al. 2011; Nalabotu et al. 2011; Wingard et al. 2011). There have been few evaluations of the biological effects following injection and ingestion exposures compared to pulmonary assessments; however, these limited studies result in less organ damage indicating these exposure routes may be less toxic (Hirst et al. 2013; Kim et al. 2012; Madero-Visbal et al. 2012). Furthermore, these different $\mathrm{EC}_{50}$ values highlight need to examine the health effects of ENM using multiple exposure routes and doses.

Finally, based on the dose-response detemination and potential anti-oxidant activity established in Chapter 3, we sought to utilize $\mathrm{CeO}_{2} \mathrm{NP}$ in a more therapeutic application. In Chapter 4: Cerium Dioxide Nanoparticles Improve Microvascular Dysfunction and Reduce Oxidative Stress in Spontaneously Hypertensive Rats, in vivo microvascular assessments were analyzed in the presence of a pre-existing pathology, hypertension. The injection of $\mathrm{CeO}_{2} \mathrm{NP}$ in $\mathrm{SH}$ rats resulted in a decrease in microvascular dysfunction. Additionally, there was no microvascular dysfunction observed following $\mathrm{CeO}_{2} \mathrm{NP}$ in the normotensive WKY rats. Other studies have also associated $\mathrm{CeO}_{2} \mathrm{NP}$ with having positive in vivo effects. The injection of $\mathrm{CeO}_{2} \mathrm{NP}$ have been shown to decrease the damage and area of infarct after stroke (Kim et al. 2012). They have also been shown to protect neurons within the hippocampal region of the brain and gastrointestinal (GI) epithelial cells from radiation damage (Colon et al. 2010; Estevez et al. 2011). Taken together, these studies 
indicate that the positive effects of $\mathrm{CeO}_{2} \mathrm{NP}$ are not unique to hypertension and provide preliminary evidence to the possibility of utilizing $\mathrm{CeO}_{2} \mathrm{NP}$ as a pharmaceutical agent.

It should be noted that the disparate microvascular effects between animals used Chapters 2 and 3 and those used in Chapter 4 may be due to the animal model or assessment techniques. The WKY and $\mathrm{SH}$ animals strains are inbred strains that have genetic differences compared to the Sprague-Dawley (SD) rats used in Chapters 2 and 3. It has been established that genetic alterations can influence the biological effects of $\mathrm{CeO}_{2}$ NP (Wingard et al. 2011). Therefore, it is reasonable to speculate that the lack of microvascular dysfunction in the WKY rats may be to due genetic differences, which protect the rat from $\mathrm{CeO}_{2} \mathrm{NP}$, but additional comparative studies between the WKY and SD rats are needed to confirm this hypothesis. Additionally, due to the inbred nature and genetic alterations in the WKY strain it has been speculated that this may not be the best control for SH rats (St et al. 1992). SD rats have been proposed as a more appropriate control for the SH rats (St et al. 1992). The different microvascualar responses of the SD, WKY, and $\mathrm{SH}$ rats highlight the potential influences of genetic alterations and pre-existing pathologies on the effects of $\mathrm{CeO}_{2} \mathrm{NP}$ exposure.

The experimental techniques utilized in Chapters 2-4 may also have contribute to the differential microvascular effects. Initial microvascular assessments were made using the isolated microvessel technique, which allows for determining the specific influences of certain agonists without the influences of blood flow and autonomic innervations. The studies in Chapter 4 were conducted using intravital microscopy to determine if the observations from previous experiments persisted in the whole animal. Therefore, the lack of overt endothelium-dependent and -independent microvascular dysfunction could be due to the activation of compensatory mechanisms, sympathetic stimulation, and/or blood flow, 
which may hide underlying dysfunction when microvascular assessments were made using intravital microscopy.

Overall, these studies (Chapters 2-4) provide evidence that $\mathrm{CeO}_{2} \mathrm{NP}$ disrupt microvascular function and the extent of this dysfunction is dependent on the microvascular bed, exposure route, dose, and pre-existing pathologies. Finally, the range of microvascular consequences, both positive and negative, associated with $\mathrm{CeO}_{2} \mathrm{NP}$ highlight the complexity of this ENM and the need for extensive toxicological evaluations to understand the full potential of $\mathrm{CeO}_{2} \mathrm{NP}$.

The literature has established that $\mathrm{CeO}_{2} \mathrm{NP}$ exposure is associated with physiological alterations and the studies (Chapter 2-4) within this dissertation support this notion from a microvascular perspective (Hirst et al. 2013; Kim et al. 2012; Ma et al. 2011; Nalabotu et al. 2011; Wingard et al. 2011; Yokel et al. 2012). Despite this knowledge, the mechanisms of action for the observed effects are largely unknown. Therefore, a secondary aim of was to investigate the potential changes in inflammation, intracellular signaling and ROS generation, all of which could have contributed to the observed microvascular alterations.

\section{Aim 2: Potential Mechanisms}

The observed alterations in microvascular reactivity could result from a myriad of mechanisms including inflammation, direct nanoparticle interaction, NO bioavailability, internal cellular signaling disruptions and/or ROS alterations. Furthermore, it would be naïve to think that only one of these mechanisms is responsible for the observed microvascular outcomes. In reality, ENM often disrupt one or more of these mechanisms and affect multiple physiological systems; therefore, it is reasonable to speculate that the manifestation of the observed effects is likely the result of multiple mechanisms 
(Legramante et al. 2009; Pacurari et al. 2012; Porter et al. 2010; Stapleton et al. 2012). Therefore, these studies briefly investigated several of these potential mechanisms in an attempt to understand the mechanisms of action for $\mathrm{CeO}_{2} \mathrm{NP}$ exposure.

Within the literature, there are three common hypotheses used to explain the mechanisms of action for ENM (as described in the literature review), and the inflammation hypothesis is the most investigated of the three. Hence, changes in pulmonary and systemic inflammation were assessed throughout these experiments. Lung inflammation was present following pulmonary $\mathrm{CeO}_{2} \mathrm{NP}$ exposure and was characterized by increased LDH activity, AM activation, and increased PMN leukocytes (Chapter 2), which was not present following the injection of $\mathrm{CeO}_{2} \mathrm{NP}$ (Appendix A). The presence of pulmonary inflammation was not assessed following ingestion exposure but it is reasonable to speculate that this exposure route would also not result in pulmonary inflammation. The lack of pulmonary inflammation but the presence of microvascular dysfunction following injection and ingestion exposures indicates that pulmonary inflammation is not required for systemic microvascular disruptions. However, the presence of pulmonary inflammation may be a compounding factor that contributes to increased toxicity associated pulmonary exposure.

Other microvascular studies have also observed pulmonary inflammation and microvascular disruptions but the mechanism between these two outcomes is still unknown (Nurkiewicz et al. 2004). In theory, pulmonary inflammation and/or direct particle interaction could result in systemic inflammation due to cytokine spillover and/or signaling. This increase in systemic inflammation could lead to changes in vascular ROS and increased leukocyte extravasation, both of which can disrupt microvascular function. Following $\mathrm{CeO}_{2}$ NP exposure in SD rats there was no significant increase in circulating pro-inflammatory 
cytokines; however, there was a decrease in circulating IFN- $\gamma$ and IL-13 regardless of exposure route (Appendix B). This decrease in circulating cytokines introduces the notion that $\mathrm{CeO}_{2} \mathrm{NP}$ may have anti-inflammatory properties. This ani-inflammatory acticity may be benifical in pathologies associated with chronic inflammation, however; it may also be deterimental if innate immune responses are compromised, which could increases infection risks. Additional studies will need to be completed to understand the full in vivo impact of $\mathrm{CeO}_{2} \mathrm{NP}$ proposed anti-inflammatory properties and determine this property is assicated with positive or negative outcomes.

These potential anti-inflammatory properties have been documented in the literature but were also observed the $\mathrm{SH}$ rats after the injection of $\mathrm{CeO}_{2} \mathrm{NP}$ due to a decreased leukocyte flux (Hirst et al. 2009). Interestingly, injection exposure also caused an increase in IL-10 and TNF- $\alpha$ in the normotensive WKY rats, which could indicate either anti- or proinflammatory properties. TNF- $\alpha$ is a pro-inflammatory cytokine involved in the activation of macrophages, whereas IL-10 is an anti-inflammatory cytokine that can inhibit the production of many pro-inflammatory cytokines (e.g. TNF- $\alpha$, and IFN- $\gamma$ ) (Feghali and Wright 1997). Hypothetically, an increase in both these markers could indicate that at the time of assessment (24 h), IL-10 is beginning to increase and inhibiting TNF- $\alpha$ production; whereas, TNF- $\alpha$ would be starting to decrease due to this inhibition, which would highlight potential anti-inflammatory action. A second hypothesis that may explain the simultaneous increase in these cytokines is the activation of macrophages via toll-like receptors leading to the secretion of IL-10 and TNF- $\alpha$, thus indicating pro-inflammatory action (Mosser 2003). Overall, additional studies at different time points, exposure routes (e.g. inhalation and ingestion), and pathologies are needed to confirm the anti- or pro-inflammatory activity of $\mathrm{CeO}_{2} \mathrm{NP}$. 
In addition to these inflammatory changes, there is also evidence that the alterations in microvascular function following $\mathrm{CeO}_{2} \mathrm{NP}$ exposure is partially, due to direct nanoparticle interaction. It should be mentioned that the three exposure routes assessed would result in different levels of direct $\mathrm{CeO}_{2} \mathrm{NP}$ interaction at the microvascular level and these differing amounts could have a huge impact on the observed microvascular outcomes. Theoretically, the injection of ENM would result in the highest level of direct endothelial exposure due to the bulk of the particles directly entering the circulation (Stapleton and Nurkiewicz 2014). At this time, it is unknown what the clearance rate from and within the $\mathrm{GI}$ tract is for EMN. Studies have shown that following $\mathrm{CeO}_{2} \mathrm{NP}$ exposure upwards of $95 \%$ of the dose is cleared from the gut in the feces within $24 \mathrm{~h}$ (Hirst et al. 2013). This high clearance rate would have a significant impact on the dose that is capable of interacting with other systemic organs. In addition to overall clearance, the clearance time of ENM between various organs of the GI tract is also important to consider. The time that an ENM spends in the stomach or small intestine could have a significant impact on its chemical properties due to the different $\mathrm{pH}$ in these organs (Hayes et al. 2002). These chemical changes may have a significant impact on $\mathrm{CeO}_{2} \mathrm{NP}$ effects following ingestion. Furthermore, GI tract clearance can also occur due to translocation, which would result in direct exposure to the liver. $\mathrm{TiO}_{2} \mathrm{NP}$ are capable of translocating from the $\mathrm{Gl}$ tract into the circulation and therefore it is reasonable to speculate the $\mathrm{CeO}_{2} \mathrm{NP}$ behave similarly but the level of direct exposure at $24 \mathrm{~h}$ is unknown (Brun et al. 2014). Finally, it has been documented the ENM are capable of translocating from the lungs at a relatively slow rate, which implies that at the time of assessment a small percentage of the $\mathrm{CeO}_{2} \mathrm{NP}$ dose would have directly interacted with the systemic microcirculation following pulmonary exposure (Geraets et al. 2012; Zhu et al. 2009). 
All three exposure routes resulted in endothelium-dependent and -independent microvascular dysfunction, which may be linked to changes in NO bioavailability and impair VSM signaling. NO bioavailability can be altered in multiple ways including decreased NO production, and increased NO scavenging. The injection of $\mathrm{CeO}_{2} \mathrm{NP}$ resulted in a decrease in NO production. This decrease in production could be from NOS uncoupling, decreased intracellular L-arginine, and/or direct contact with $\mathrm{CeO}_{2} \mathrm{NP}$ (Cherng et al. 2011). Furthermore, ENM exposure can result in decrease NO bioavailability due to an increase in MPO activity (Nurkiewicz et al. 2011). This increased activity alters NO bioavailality by increasing the concentration of hypoclorous acid, which scavenges NO and can react with intracellular L-arginine. Additionally, there was also evidence that pulmonary $\mathrm{CeO}_{2} \mathrm{NP}$ exposure may be associated with NOS uncoupling (Chapter 3). Ultimately, these changes in NO bioavailability may impair vascular smooth muscle relaxation, due less NO reaching the VSM cells.

The observed impairments in endothelium-independent dilation may also be due to changes in VSM signaling. Preliminary evidence from Chapter 3 indicates that independent of exposure route the arterioles are unable to respond to NO due potentially to attenuated responses to VSM mediators (e.g. SGC and cGMP) needed for vasodilation. In addition to these mediators, there may also be changes in calcium handling, PKG activity, and/or increased phosphodiesterase activity all of which may also impair the signaling of NO within the VSM (Dora et al. 1997; Perri et al. 2006; Rybalkin et al. 2003). Further studies are needed in order to identify the exact mechanism for the attenuated endotheliumindependent dilation associated with $\mathrm{CeO}_{2} \mathrm{NP}$ exposure in a young health male animal model. 
In addition to VSM signaling, changes in intracellular signaling may also effect endothelial cells. AA metabolism via COX activation can be initiated within the endothelial cells. This activation can promote vasodilation and/or vasoconstriction through a NOindependent pathway. The injection of $\mathrm{CeO}_{2} \mathrm{NP}$ appeared to cause a shift in AA metabolism in $\mathrm{SH}$ rats (Chapter 4). This shift is signaling may have resulted in an increase in $\mathrm{TXA}_{2}$ production, a known vasoconstrictor. This change from prostaglandin production to $\mathrm{TXA}_{2}$ production may be a contributing factor to the inability of $\mathrm{CeO}_{2} \mathrm{NP}$ to restore complete ACh-induced dilation in the hypertensive rats (Chapter 4).

Another contributing factor to the observed microvascular consequences may be ROS alterations. ROS production can be increased by the $\mathrm{CeO}_{2} \mathrm{NP}$ themselves, inflammation, NOS uncoupling, increased NADPH oxidase activity, MPO activity and/or mitochondria dysfunction (Cherng et al. 2011; Dabkowski et al. 2009; Park et al. 2008; Nurkiewicz et al. 2011). An increase in ROS may impair the ability of NO to diffuse to the VSM, which would impair the arterioles ability to dilation. However, in vivo studies (Chapter 4) have also shown that $\mathrm{CeO}_{2} \mathrm{NP}$ are capable of decreasing the level of vascular ROS, which highlights its anti-oxidant activity. The pro- or anti-oxidant potential of $\mathrm{CeO}_{2} \mathrm{NP}$ may be influenced by the initial basal level of ROS. Theoretically, $\mathrm{CeO}_{2} \mathrm{NP}$ may function optimally in the presence of high ROS, which is associated with hypertension. However, if there are low levels of basal $\mathrm{ROS} \mathrm{CeO}_{2} \mathrm{NP}$ may exhibit pro-oxidant activity, but further investigations are needed to confirm this theory.

In addition to ROS, $\mathrm{NO}$ is also capable of being scavenged by the $\mathrm{CeO}_{2} \mathrm{NP}$ directly (Xu and Qu 2014), which may account for some of the observed microvascular alterations. This preference to react with $\mathrm{NO}$ and other ROS is derived from the valance state of the $\mathrm{CeO}_{2} \mathrm{NP}$. These nanoparticles exist in two valence state, $\mathrm{Ce}^{3+}$ and $\mathrm{Ce}^{4+}$ and the ratio of 
these valence states can affect the function of $\mathrm{CeO}_{2} \mathrm{NP}$. Research has shown that $\mathrm{Ce}^{4+}$ reacts more readily with NO, whereas $\mathrm{Ce}^{3+}$ reacts with superoxide (Xu and Qu 2014). This preference could not only influence the anti-oxidant activity of $\mathrm{CeO}_{2} \mathrm{NP}$ but also their impact on microvascular reactivity. It is also important to note, that at this time it is unclear how valence state is altered during in vivo exposures, especially since $\mathrm{pH}$ can influence the overall ratio (Hayes et al. 2002). Future studies need to not only establish the importance of valence state on the anti-oxidant potential of $\mathrm{CeO}_{2} \mathrm{NP}$ but also how in vivo exposure alters the valence state ratio of these nanoparticles.

Additionally, $\mathrm{CeO}_{2} \mathrm{NP}$ exposure may modify thrombosis development, particualy in the $\mathrm{SH}$ rats. The increased leukocyte flux in the $\mathrm{SH}$ rats provided indirect evidence for endothelial cell activation, which results in the production various adhesion proteins and factors essential for impairing fibrinolysis (i.e. PAI-1). PAI-1 is secreted by macrophages, endothelial cells and vascular smooth muscle cells. Furthermore, this factor is controlled by oxidative stress. Studies with nano-copper oxide have shown an increase in PAI-1 secretion following exposure and it is possible that this factor is also elevated in the $\mathrm{SH}$ Sham rats, thus increasing risk of thrombosis (Yu et al. 2010). However, following $\mathrm{CeO}_{2}$ NP exposure there is a decrease in leukocyte flux in the $\mathrm{SH}$ rats, which could indicate a decreased thrombosis risk. Furthremore, addtional studies will be needed to determine if these factors (i.e. leukocyte flux, adhesion proteins, and PAI-1) are also altered in the SD rats and if they are altered overtime in the WKY following $\mathrm{CeO}_{2} \mathrm{NP}$ exposure via multiple exposure routes.

Overall, it is clear that one mechanism cannot account for the observed microvascular dysfunction. Furthermore, the mechanisms of action are likely to change based on exposure route and/or pathology. Regardless these studies have indicated that 
$\mathrm{NO}$ bioavailability and ROS alterations are likely to play a key role in $\mathrm{CeO}_{2} \mathrm{NP}$ in vivo activity and future studies should focus a defining the specific influences of these two mechanisms.

Finally, despite the presence of overt microvascular dysfunction, changes in ROS and NO bioavailability, there were no systemic changes observed in the animals following exposure (e.g. MAP). The control of MAP is dynamic and the body is able to make adjustments for minute-to-minute fluctuations in pressure (via baroreceptors); therefore, there would not initially be observable systemic effects at the timepoint assessed in these studies. Additionally, there is inherit redundancy within the microcirculation, which allows for continued function if one source of reactivity (e.g. NO signaling) is impaired. However, overtime (several weeks to months) the cardiovascular system would not be able to compensate for the impaired microvascular dysfunction and changes in MAP may begin to emerge. Furthermore, the measurements in these experiments were conducted at $24 \mathrm{~h}$ post-exposure. At this time point there would not have been ample time for cardiovascular remodeling (e.g. microvascular rarefraction and cardiac hypertrophy), which can take several weeks (or years in humans) to develop. These structural changes would also contribute to an increase in MAP that would not be able to be compensated for by normal controls (e.g. HR, and vasodilation) and would not have be observed in these experiments. Furthermore, reactive changes in blood pressure and $\mathrm{HRV}$ in response to the $\mathrm{CeO}_{2} \mathrm{NP}$ treatements over a short period of time could be monitored via implantation of telemeters, which would record real-time data on HR, and MAP.

\section{Conclusions and Future Directions}

Clearly, the microvascular effects of $\mathrm{CeO}_{2} \mathrm{NP}$ exposure are vast and the potential mechanisms are extensive. Despite this complexity, the studies in Chapters 2-4 have 
advanced our knowledge of this ENM. There is clear evidence that $\mathrm{CeO}_{2} \mathrm{NP}$ disrupt microvascular reactivity in a young healthy male model; however, in the presence of a disease state $\mathrm{CeO}_{2}$ NP may improve microvascular function. These differing effects highlight the need to investigate $\mathrm{CeO}_{2} \mathrm{NP}$ activity in several animal models (e.g. hypertension, obesity, and diabetes). It also highlights the potential anti-oxidant and antiinflammatory activity of these nanoparticles, which support the development of this ENM as a therapeutic.

Defining the pro- or anti- oxidant activity of $\mathrm{CeO}_{2} \mathrm{NP}$ is critical if this ENM is to be developed for clinical applications. This includes establishing an effective dose as well as investigating the physiological impacts at various time points. Chapter 4 only investigated the influence one dose and one time point. Future studies need to focus on establishing the effective doses in a hypertensive animal model. These studies should also investigate several time points as the anti-oxidant, anti-inflammatory, and microvascular impacts may change if the animals are exposed for shorter or longer time points.

Mechanistically these studies have also begun to investigate the influences of inflammation and direct nanoparticle exposure, however; alterations in autonomic signaling were not studied. Determining the potential changes in autonomic regulations, both within the heart and at the microvascular level are essential if $\mathrm{CeO}_{2} \mathrm{NP}$ are to be development for therapeutic applications, since cardiovascular side effects are one reason that pharmaceuticals are not FDA approved.

$\mathrm{CeO}_{2} \mathrm{NP}$ research and therapeutic development is still in its infancy and many questions about its in vivo activity remain unexplored. The studies presented in this dissertation help to shed light on the microvascular influences of this potential anti-oxidant. They highlight the influences of exposure route and the importance of selecting an 
appropriate animal model, which is essential in understanding the overall impact of these nanoparticles are they continue to be developed for commercial and pharmaceutical applications. 


\section{Reference List:}

1. Brun, E., Barreau, F., Veronesi, G., Fayard, B., Sorieul, S., Chaneac, C., Carapito, C., Rabilloud, T., Mabondzo, A., Herlin-Boime, N., and Carriere, M. (2014). Titanium dioxide nanoparticle impact and translocation through ex vivo, in vivo and in vitro gut epithelia. Part Fibre. Toxicol. 11, 13.

2. Cherng, T. W., Paffett, M. L., Jackson-Weaver, O., Campen, M. J., Walker, B. R., and Kanagy, N. L. (2011). Mechanisms of diesel-induced endothelial nitric oxide synthase dysfunction in coronary arterioles. Environ. Health Perspect. 119(1), 98-103.

3. Colon, J., Hsieh, N., Ferguson, A., Kupelian, P., Seal, S., Jenkins, D. W., and Baker, C. H. (2010). Cerium oxide nanoparticles protect gastrointestinal epithelium from radiation-induced damage by reduction of reactive oxygen species and upregulation of superoxide dismutase 2. Nanomedicine. 6(5), 698-705.

4. Courtois, A., Andujar, P., Ladeiro, Y., Baudrimont, I., Delannoy, E., Leblais, V., Begueret, H., Galland, M. A., Brochard, P., Marano, F., Marthan, R., and Muller, B. (2008). Impairment of NO-dependent relaxation in intralobar pulmonary arteries: comparison of urban particulate matter and manufactured nanoparticles. Environ. Health Perspect. 116(10), 1294-1299.

5. Dabkowski, E. R., Williamson, C. L., Bukowski, V. C., Chapman, R. S., Leonard, S. S., Peer, C. J., Callery, P. S., and Hollander, J. M. (2009). Diabetic cardiomyopathyassociated dysfunction in spatially distinct mitochondrial subpopulations. Am. J. Physiol Heart Circ. Physiol 296(2), H359-H369.

6. Dora, K. A., Doyle, M. P., and Duling, B. R. (1997). Elevation of intracellular calcium in smooth muscle causes endothelial cell generation of $\mathrm{NO}$ in arterioles. Proc. Natl. Acad. Sci. U. S. A 94(12), 6529-6534.

7. Estevez, A. Y., Pritchard, S., Harper, K., Aston, J. W., Lynch, A., Lucky, J. J., Ludington, J. S., Chatani, P., Mosenthal, W. P., Leiter, J. C., Andreescu, S., and Erlichman, J. S. (2011). Neuroprotective mechanisms of cerium oxide nanoparticles in a mouse hippocampal brain slice model of ischemia. Free Radic. Biol. Med. 51(6), $1155-1163$.

8. Feghali, C. A., and Wright, T. M. (1997). Cytokines in acute and chronic inflammation. Front Biosci. 2, d12-d26. 
9. Geraets, L., Oomen, A. G., Schroeter, J. D., Coleman, V. A., and Cassee, F. R. (2012). Tissue distribution of inhaled micro- and nano-sized cerium oxide particles in rats: results from a 28-day exposure study. Toxicol. Sci. 127(2), 463-473.

10. Hayes, S. A., Yu, P., O'Keefe, T. J., O'Keefe, M. J., and Stoffer, J. O. (2002). The Phase Stability of Cerium Species in Aqueous Systems I. E-pH Diagram for the Ce$\mathrm{HClO} 4-\mathrm{H} 2 \mathrm{O}$ System. Journal of The Electrochemical Society 149(12), C623-C630.

11. Hirst, S. M., Karakoti, A., Singh, S., Self, W., Tyler, R., Seal, S., and Reilly, C. M. (2013). Bio-distribution and in vivo antioxidant effects of cerium oxide nanoparticles in mice. Environ. Toxicol. 28(2), 107-118.

12. Hirst, S. M., Karakoti, A. S., Tyler, R. D., Sriranganathan, N., Seal, S., and Reilly, C. M. (2009). Anti-inflammatory properties of cerium oxide nanoparticles. Small 5(24), 2848-2856.

13. Kim, C. K., Kim, T., Choi, I. Y., Soh, M., Kim, D., Kim, Y. J., Jang, H., Yang, H. S., Kim, J. Y., Park, H. K., Park, S. P., Park, S., Yu, T., Yoon, B. W., Lee, S. H., and Hyeon, T. (2012). Ceria nanoparticles that can protect against ischemic stroke. Angew. Chem Int. Ed Engl. 51(44), 11039-11043.

14. LeBlanc, A. J., Moseley, A. M., Chen, B. T., Frazer, D., Castranova, V., and Nurkiewicz, T. R. (2010). Nanoparticle inhalation impairs coronary microvascular reactivity via a local reactive oxygen species-dependent mechanism. Cardiovasc. Toxicol. 10(1), 27-36.

15. Legramante, J. M., Valentini, F., Magrini, A., Palleschi, G., Sacco, S., lavicoli, I., Pallante, M., Moscone, D., Galante, A., Bergamaschi, E., Bergamaschi, A., and Pietroiusti, A. (2009). Cardiac autonomic regulation after lung exposure to carbon nanotubes. Hum. Exp. Toxicol. 28(6-7), 369-375.

16. Ma, J. Y., Zhao, H., Mercer, R. R., Barger, M., Rao, M., Meighan, T., Schwegler-Berry, D., Castranova, V., and Ma, J. K. (2011). Cerium oxide nanoparticle-induced pulmonary inflammation and alveolar macrophage functional change in rats. Nanotoxicology. 5(3), 312-325.

17. Madero-Visbal, R. A., Alvarado, B. E., Colon, J. F., Baker, C. H., Wason, M. S., Isley, B., Seal, S., Lee, C. M., Das, S., and Manon, R. (2012). Harnessing nanoparticles to improve toxicity after head and neck radiation. Nanomedicine. 8(7), 1223-1231. 
18. Mosser, D. M. (2003). The many faces of macrophage activation. J. Leukoc. Biol. 73(2), 209-212.

19. Nalabotu, S. K., Kolli, M. B., Triest, W. E., Ma, J. Y., Manne, N. D., Katta, A., Addagarla, H. S., Rice, K. M., and Blough, E. R. (2011). Intratracheal instillation of cerium oxide nanoparticles induces hepatic toxicity in male Sprague-Dawley rats. Int. J. Nanomedicine. 6, 2327-2335.

20. Nurkiewicz, T. R., Porter, D. W., Barger, M., Castranova, V., and Boegehold, M. A. (2004). Particulate matter exposure impairs systemic microvascular endotheliumdependent dilation. Environ. Health Perspect. 112(13), 1299-1306.

21. Nurkiewicz, T. R., Porter, D. W., Hubbs, A. F., Stone, S., Chen, B. T., Frazer, D. G., Boegehold, M. A., and Castranova, V. (2009). Pulmonary nanoparticle exposure disrupts systemic microvascular nitric oxide signaling. Toxicol. Sci. 110(1), 191-203.

22. Nurkiewicz, T. R., Porter, D. W., Hubbs, A. F., Stone, S., Moseley, A. M., Cumpston, J. L., Goodwill, A. G., Frisbee, S. J., Perrotta, P. L., Brock, R. W., Frisbee, J. C., Boegehold, M. A., Frazer, D. G., Chen, B. T., and Castranova, V. (2011). Pulmonary particulate matter and systemic microvascular dysfunction. Res Rep Health Eff Inst. (164):3-48.

23. Pacurari, M., Qian, Y., Fu, W., Schwegler-Berry, D., Ding, M., Castranova, V., and Guo, N. L. (2012). Cell permeability, migration, and reactive oxygen species induced by multiwalled carbon nanotubes in human microvascular endothelial cells. J. Toxicol. Environ. Health A 75(2), 112-128.

24. Park, E. J., Choi, J., Park, Y. K., and Park, K. (2008). Oxidative stress induced by cerium oxide nanoparticles in cultured BEAS-2B cells. Toxicology 245(1-2), 90-100.

25. Perri, R. E., Langer, D. A., Chatterjee, S., Gibbons, S. J., Gadgil, J., Cao, S., Farrugia, G., and Shah, V. H. (2006). Defects in cGMP-PKG pathway contribute to impaired NO-dependent responses in hepatic stellate cells upon activation. Am. J. Physiol Gastrointest. Liver Physiol 290(3), G535-G542.

26. Porter, D. W., Hubbs, A. F., Mercer, R. R., Wu, N., Wolfarth, M. G., Sriram, K., Leonard, S., Battelli, L., Schwegler-Berry, D., Friend, S., Andrew, M., Chen, B. T., Tsuruoka, S., Endo, M., and Castranova, V. (2010). Mouse pulmonary dose- and time course-responses induced by exposure to multi-walled carbon nanotubes. Toxicology 269(2-3), 136-147. 
27. Prewitt, R. L., Rice, D. C., and Dobrian, A. D. (2002). Adaptation of resistance arteries to increases in pressure. Microcirculation. 9(4), 295-304.

28. Rybalkin, S. D., Yan, C., Bornfeldt, K. E., and Beavo, J. A. (2003). Cyclic GMP phosphodiesterases and regulation of smooth muscle function. Circ. Res. 93(4), 280291.

29. St, L. E., Simonet, L., Pravenec, M., and Kurtz, T. W. (1992). Hypertensive strains and normotensive 'control' strains. How closely are they related? Hypertension 19(5), 419-424.

30. Stapleton, P. A., Minarchick, V. C., Cumpston, A. M., McKinney, W., Chen, B. T., Sager, T. M., Frazer, D. G., Mercer, R. R., Scabilloni, J. F., Andrew, M., Castranova, V., and Nurkiewicz, T. R. (2012). Impairment of Coronary Arteriolar EndotheliumDependent Dilation after Multi-Walled Carbon Nanotube Inhalation: A Time-Course Study. International Journal of Molecular Science 13, 13781-13803.

31. Stapleton, P. A., and Nurkiewicz, T. R. (2014). Vascular distribution of nanomaterials. Wiley. Interdiscip. Rev. Nanomed. Nanobiotechnol. 6(4), 338-348.

32. Wingard, C. J., Walters, D. M., Cathey, B. L., Hilderbrand, S. C., Katwa, P., Lin, S., Ke, P. C., Podila, R., Rao, A., Lust, R. M., and Brown, J. M. (2011). Mast cells contribute to altered vascular reactivity and ischemia-reperfusion injury following cerium oxide nanoparticle instillation. Nanotoxicology. 5(4), 531-545.

33. Xu, C., and Qu, X. (2014). Cerium oxide nanoparticle: a remarkably versatile rare earth nanomaterial for biological applications. NPG Asia Materials 6, 1-16.

34. Yokel, R. A., Au, T. C., Macphail, R., Hardas, S. S., Butterfield, D. A., Sultana, R., Goodman, M., Tseng, M. T., Dan, M., Haghnazar, H., Unrine, J. M., Graham, U. M., Wu, P., and Grulke, E. A. (2012). Distribution, Elimination, and Biopersistence to 90 Days of a Systemically Introduced $30 \mathrm{~nm}$ Ceria-Engineered Nanomaterial in Rats. Toxicol. Sci. 127(1), 256-268.

35. Yu, M., Mo, Y., Wan, R., Chien, S., Zhang, X., and Zhang, Q. (2010). Regulation of plasminogen activator inhibitor-1 expression in endothelial cells with exposure to metal nanoparticles. Toxicol. Lett. 195(1), 82-89.

36. Zhu, M. T., Feng, W. Y., Wang, Y., Wang, B., Wang, M., Ouyang, H., Zhao, Y. L., and Chai, Z. F. (2009). Particokinetics and extrapulmonary translocation of intratracheally 
instilled ferric oxide nanoparticles in rats and the potential health risk assessment. Toxicol. Sci. 107(2), 342-351.

37. Zweifach, B. W., Kovalcheck, S., De Lano, F., and Chen, P. (1981). Micropressureflow relationships in a skeletal muscle of spontaneously hypertensive rats. Hypertension 3(5), 601-614. 


\section{Appendix A}

\section{Appendices}

Methods: Pulmonary Inflammation Assessment: A subset of 12 Wistar and Spontaneously Hypertensive rats were intraveously injection with $\mathrm{CeO}_{2} \mathrm{NP}(0$ or $100 \mu \mathrm{g})$ were anethetized with isofluane ( $5 \%$ induction and $2-3.5 \%$ maintence). The rats were euthanized via exsanguination. The trachea was cannulated and BAL was performed using ice-cold $\mathrm{Ca}^{2+} / \mathrm{Mg}^{2+}$-free phosphate buffered saline (PBS). The first lavage $(6 \mathrm{ml})$ was kept separate from the rest of the lavage sample. Subsequent lavages used $10 \mathrm{ml}$ PBS until $40 \mathrm{ml}$ lavage

fluid was collected. The samples were centrifuged at $650 \times \mathrm{g}, 5 \mathrm{~min}$ at $4^{\circ} \mathrm{C}$. The pooled cells were resuspended in HEPES-buffered medium and cell counts were determined with an electronic cell counter equipped with a cell-sizing attachment. Cytospin Preparation: $1 \times 10^{6}$ BAL cells [both alveolar macrophages (AM) and polymorphonuclear leukocytes (PMN)] in $200 \mu \mathrm{l}$ HEPES-buffered medium were prepared with a cytocentrifuge. The cytospin preparations were stained with modified Wright-Giemsa stain and cell differentials were determined by light microscopy. The differential cell counts were calculated by multiplying the total cell count by the cell differential percentage obtained from the cytospin preparations. 
Figure:

Figure 1:

A

B
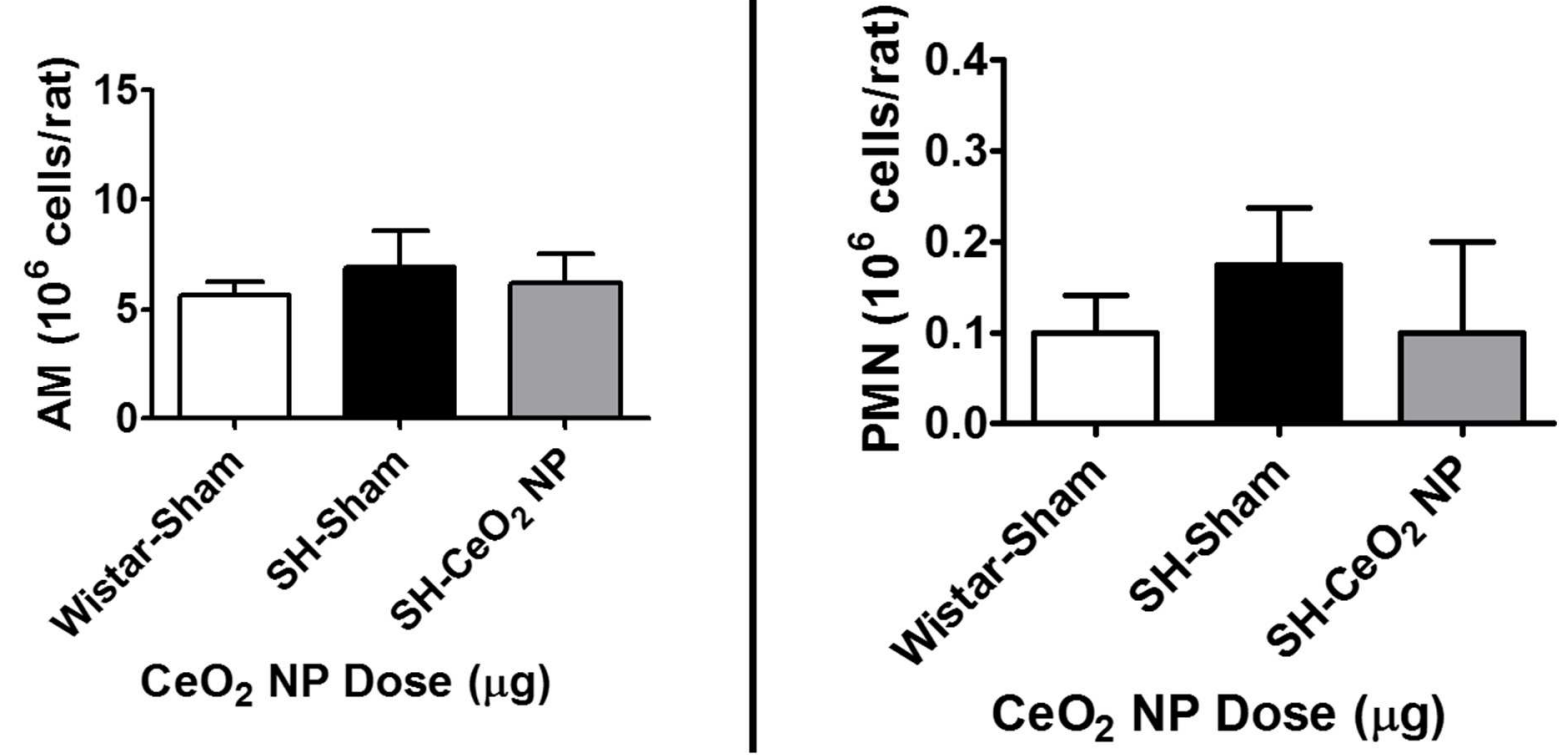

Figure Legend:

Figure 1 Pulmonary inflammation: Pulmonary inflamamtion was not altered after exposure to $\mathrm{CeO}_{2} \mathrm{NP}$ in $\mathrm{SH}$ or WK rats. There was no significant increase in $\mathbf{A}: \mathrm{AM}$ or $\mathbf{B}$ : PMN infiltration 


\section{Appendix B}

Methods: Pro-Inflammatory Cytokine Analysis: Sprague-Dawley rats were exposed to either saline or $\mathrm{CeO}_{2} \mathrm{NP}$ via intravenously injection (0 or $100 \mu \mathrm{g}$ ), gastric gavage (0 or 400 $\mu \mathrm{g}$ ) or intratracheally instilled ( 0 or $65 \mu \mathrm{g}$ ). $24 \mathrm{~h}$ post-exposure the blood was collected via caroid artrey and centrifuged $(1100 \times \mathrm{g})$ to separate the blood components. The plasma was collected, flash frozen in liquid nitrogen, and stored in a $-80^{\circ} \mathrm{C}$ freezer until analysis. A pro-inflammatory cytokine multi-spot assay was completed per manufacturer's directions (MesoScale Diagnostics, Rockville, MD). The pro-inflammatory cytokines assessed were:

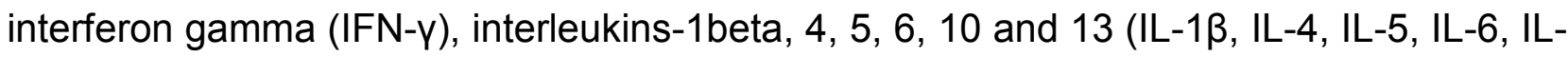
10, and IL-13), tumor necrosis factor alpha (TNF- $\alpha$ ) and keratinocyte chemoattractant/human growth-regulated oncogene (KC/GRO). 
Figure:

Figure 1:

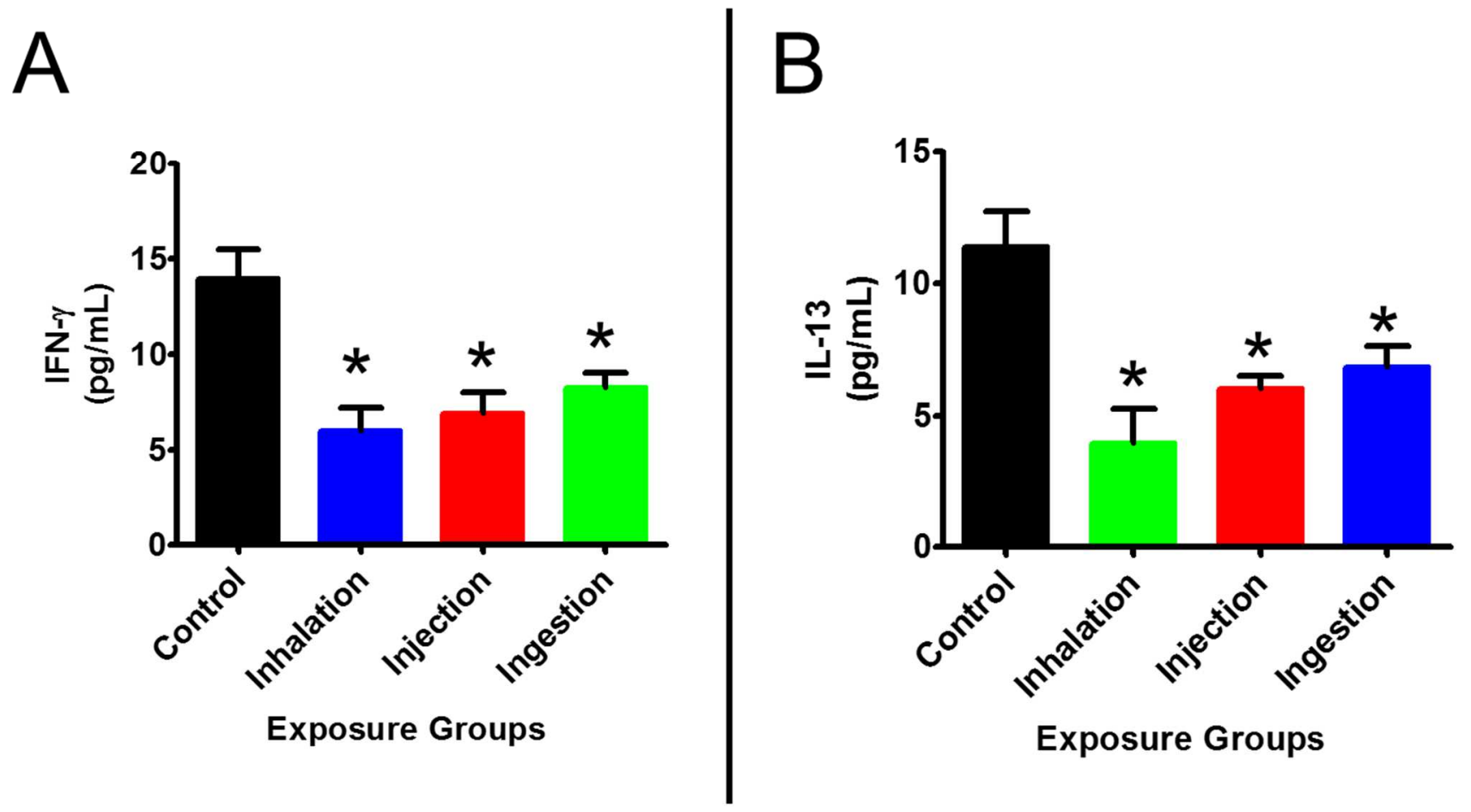

Figure Legend:

Figure 1 Systemic Inflammation: A: Plasma IFN-y levels were significantly decreased in all three exposure groups compared to saline controls $(\mathrm{N}=3)$. B: Plasma IL-13 levels were significantly decreased in all three exposure groups compared to saline controls ( $\mathrm{N}$ = 3). There were no significant differences in plasma IL-1 $\beta$, IL-4, IL-5, IL-6, IL-10, TNF- $\alpha$, or KC/GRO levels (data not shown). ${ }^{*} p \leq 0.05$ vs. Control 


\section{Curriculum Vitae}

\section{Valerie C. Minarchick}

Address: 1 Medical Center Drive

PO Box 9105

Morgantown, WV 26506

Phone: (304) 293-1670

Email:vbukowsk@mix.wvu.edu

Personal Cell: (814) 418-3604

\section{Education:}

Juniata College (2007)

Degree Earned: B.S.

West Virginia University (2009 -

School: Medicine

Anticipated Spring 2015)

Program: Cellular and Integrative

Physiology

Degree Sought Ph.D.

Department: Biology

\section{Professional/Academic Positions:}

$\begin{array}{lll}\begin{array}{l}\text { 2009- } \\ \text { current }\end{array} & \begin{array}{l}\text { West Virginia University } \\ \text { Department: Physiology and } \\ \text { Pharmacology }\end{array} & \begin{array}{l}\text { Graduate Research Assistant } \\ \text { Advisor: Dr. Timothy Nurkiewicz }\end{array} \\ 2007-2009 & \begin{array}{l}\text { National Institute of Occupational } \\ \text { Safety and Health }\end{array} & \begin{array}{l}\text { Regular Research Fellow } \\ \text { Advisor: Dr. Stephen Leonard }\end{array} \\ 2006 & \text { Pfizer Inc. } & \begin{array}{l}\text { Summer Research Intern } \\ \text { Advisor: Dr. Thomas Owen }\end{array} \\ & \text { Juniata College } & \begin{array}{l}\text { Independent Research } \\ \text { Advisors: Dr. Ruth Reed and Dr. } \\ 2006\end{array} \\ & \text { Windber Research } & \text { Michael Boyle } \\ 2005 & & \text { Summer Research Intern } \\ & & \text { Advisor: Dr. Tapan Maity }\end{array}$




\section{Fellowships:}

WVNano Graduate Education Fellowship (2011-2012)

National Science Foundation (Cooperative Agreement 1003907)

NanoSAFE Graduate Education Fellowship (2012-current)

National Science Foundation (Cooperative Agreement 1003907)

IGERT Fellowship (2013-Present)

National Science Foundation (DGE-1144676)

Publications $\left({ }^{*}\right.$, indicates maiden name):

\section{Peer-Reviewed Publications:}

1. *Dabkowski ER, Williamson CL, Bukowski VC, Chapman RS, Leonard SS, Peer CJ, Callery PS and Hollander JM. (2009). Differential Response of Mitochondrial Subpopulations to Diabetic Cardiomyopathy-Associated Dysfunction. Am J Physiol Heart Circ Physiol. 296(2): H359-69. PMID: 19060128

2. *Stefaniak AB, Harvey CJ, Bukowski, VC, and Leonard SS. (2010). Comparison of free radical generation by pre- and post-sintered cemented carbide particles. J Occup Environ Hyg. 7(1): 23-34. PMID: 19904657

3. *Qian Y, Ducatman A, Ward R, Leonard S, Bukowski V, Lan Guo N, Shi X, Vallyathan V, and Castranova V. (2010) Perfluorooctane sulfonate (PFOS) induces reactive oxygen species (ROS) in human microvascular endothelial cells: role in endothelial permeability. J Toxicol Environ Health A. 73(12): 81936. PMID: 20391123

4. Stapleton PA, Minarchick VC, McCawley M, Knuckles TL, Nurkiewicz TR. (2012) Xenobiotic Particle Exposure and Microvascular Endpoints: A Call to Arms. Microcirculation. 19(2): 126-42. PMID: 21951337

5. Peer CJ, Younis IR, Leonard SS, Gannett PM, Minarchick VC, Kenyon AJ, Rojanasakul Y, Callery PS. (2012) Glutathione conjugation of busulfan produces a hydroxyl radical-trapping dehydroalanine metabolite. Xenbiotica. 42(12): 1170-7. PMID: 22725664

6. Stapleton PA, Minarchick VC, Cumpston AM, McKinney W, Chen BT, Sager TM, Frazer DG, Mercer RR, Scabilloni J, Andrew MC, Castranova V, Nurkiewicz TR. (2012) Impairment of Coronary Arteriolar EndotheliumDependent Dilation after Multi-Walled Carbon Nanotube Inhalation: A TimeCourse Study. Int J Mol Sci. 13(11): 13781-803 PMID: 23203034

7. Knuckles TL, Stapleton PA, Minarchick VC, Esch L, McCawley M, Hendryx M, and Nurkiewicz TR. (2013) Air Pollution Particulate Matter Collected from an Appalachian Mountaintop Mining Site Induces Microvascular Dysfunction. Microcirculation. 20(2): 158-69. PMID: 22963349

8. Yi J, Chen BT, Schwegler-Berry D, Frazer D, Castranova V, McBride C, Knuckles TL, Stapleton PA, Minarchick VC, Nurkiewicz TR. (2013) WholeBody Nanoparticle Aerosol Inhalation Exposures. J Vis Exp. 75: e50263. PMID: 23685643 
9. Stapleton PA, Minarchick VC, Yi J, Engels K, McBride CR, Nurkiewicz TR. (2013) Maternal Engineered Nanomaterial Exposure and Fetal Microvascular Function: Does the Barker Hypothesis Apply? Am J Obstet Gynecol. 209(3): 227.e1-11. PMID: 23643573

10. Minarchick VC, Stapleton PA, Porter DW, Wolfarth MC, Ciftyürek E, Barger M, Sabolsky EM, Nurkiewicz TR. (2013) Pulmonary Cerium Dioxide Nanoparticle Exposure Differentially Impairs Coronary and Mesenteric Arteriolar Reactivity. Cardiovasc Toxicol. 13 (4): 323-37. PMID: 23645470

11. Stapleton PA, Nichols CE, Yi J, McBride CR, Minarchick VC, Shepherd DL, Hollander JM, Nurkiewicz TR. (2014) F1 Generation microvascular consequences of gestational nanomaterial exposure. Nanotoxicology. PMID: 25475392

12. Minarchick VC, Stapleton PA, Fix NR, Leonard SS, Sabolsky EM, Nurkiewicz TR. (2015) Intravenous and Gastric Cerium Dioxide Nanoparticle Exposure Disrupts Microvascular Smooth Muscle Signaling. Toxicol Sci. 144 (1): 77-89. PMID: 25481005

13. Armstead AL, Minarchick VC, Porter DW, Nurkiewicz TR and Bingyun L. (2015). Acute inflammatory responses of nanoparticles in an intra-tracheal instillation rat model. PLoS ONE. 10(3): e0118778. PMID: 25738830

14. Madejczyk MS, Baer CE, Dennis WE, Leonard SS, Minarchick V, Jackson DA, Stallings JD, and Lewis JA. (2015) Temporal Changes in Rat Liver Gene Expression after Cadmium and Chromium Exposure. PLoS ONE. (Accepted)

\section{Book Chapter:}

1. Stapleton PA, Knuckles TL, Minarchick VC, Gautam G, Nurkiewicz TR. (2014) Cardiovascular System. In: Wexler, P. (Ed.), Encyclopedia of Toxicology, $3^{\text {rd }}$ edition vol 1. Elsevier Inc., Academic Press, pp. 730-747.

Abstracts $\left({ }^{*}\right.$, indicates maiden name):

1. 'Bukowski VC, Chapman RS, Lewis JA, Jackson DA, Leonard SS. (2008) Comparison of the Acute Effects of Transition Metals on Two Cell Lines. $5^{\text {th }}$ Conference on Metal Toxicity and Carcinogenesis

2. "Bukowski VC, Chapman RS, Leonard SS. (2009) Comparison of the Acute Oxidative Damage of Transition Metals on Two Cell Lines. The Toxicologist. Volume 108 (1) : 66 \#319

3. Minarchick VC, Sabolsky EM, and Nurkiewicz TR.(2011) The effects of ceria nanoparticles on the reactivity of rat mesentery and coronary arterioles. Engineered Nanomaterials Grand Opportunity Consortium Meeting; Van Liere Research Day West Virginia University

4. Minarchick VC, Sabolsky EM, and Nurkiewicz TR. (2011) The effects of ceria nanoparticles on the reactivity of rat mesentery and coronary arterioles. The Toxicologist. Volume 120 (2): 40, \#192.

5. Stapleton PG, Minarchick VC, Cumpston A, McKinney W, Chen BT, Frazer D, Castranova V, Nurkiewicz TR. (2011) Time-Course of Impaired Coronary 
Arteriolar Endothelium-Dependent Dilation After Multi-Walled Carbon Nanotube Inhalation. The Toxicologist. Volume 120 (2): 41 \#194.

6. Minarchick VC; Sabolsky EM and Nurkiewicz TR. (2011) Intratracheal instillation of ceria nanoparticles alters endothelium -dependent and -independent dilation in rat arterioles, Allegheny-Erie Society of Toxicology $25^{\text {th }}$ Annual Spring Meeting

7. Minarchick VC, Stapleton PA, Porter DW, Sabolsky EM, and Nurkiewicz TR. (2012) Pulmonary Nanoceria Exposure Impairs Coronary and Mesenteric Arteriolar Reactivity. The Toxicologist. Volume 126 (1): 198 \#929

8. Knuckles T, Stapleton PA, Minarchick VC, McCawley M, Hendryx M, Esch L, Nurkiewicz TR. (2012) Ambient Mountain Top Mining Particulate Matter Alters Systemic Microvascular Function. The Toxicologist. Volume 126 (1): 324 \#1501

9. Stapleton PA, Minarchick VC, Chen BT, Cumpston A, McKinney W, Frazer D, Castranova V, and Nurkiewicz TR. (2012) Thinking outside the lung: Alternate routes of nanoparticle exposure. The Toxicologist. Volume 126 (1): 197 \#924

10. Minarchick VC, Stapleton PA, Porter DW, Sabolsky EM, and Nurkiewicz TR. (2012) Nano Cerium Dioxide $\left(\mathrm{CeO}_{2}\right)$ Exposure Impairs Mesenteric Arteriolar Reactivity. Van Liere Research Day West Virginia University

11. Minarchick VC, Stapleton PA, Porter DW, Sabolsky EM, and Nurkiewicz TR. (2012) Dose Exposure Route Matter: Assessing the Effects of Nano-Cerium Dioxide Exposure on Arteriolar Reactivity. Allegheny-Erie Regional Chapter of the Society of Toxicology $26^{\text {th }}$ Annual Meeting

12. Stapleton PA, Minarchick VC, Chen BT, Cumpston A, McKinney W, Frazer D, Castranova V, and Nurkiewicz TR. (2012) Thinking Outside the Lung: Biomedical Nanoparticle Exposure. Allegheny-Erie Regional Chapter of the Society of Toxicology $26^{\text {th }}$ Annual Meeting

13. Knuckles T, Stapleton PA, Minarchick VC, McCrawley M, Hendryx M, Esch L, Nurkiewicz TR. (2012) Systemic Microvascular Dysfunction Induced by Ambient Mountain Top Mining Particulate Matter. Allegheny-Erie Regional Chapter of the Society of Toxicology $26^{\text {th }}$ Annual Meeting

14. Spears KS, Stapleton PA, Minarchick VC, Knuckles TL, Nurkiewicz TR. (2012) Comparison of titanium dioxide, zinc oxide, and multi-walled carbon nanotubes on arteriolar system. WVNano Research Experiences for Undergraduate, Summer Undergraduate Research Symposium

15. Minarchick VC, Stapleton PA, Sabolsky EM, Nurkiewicz TR. (2013) Nano-Cerium Dioxide Exposure and Arteriolar Dysfunction: Exposure Route Dependency. The Toxicologist. Volume 132 (1): 18 \#92

16. Minarchick VC, Porter DW, Fix NR, Leonard SS, Sabolsky EM, Nurkiewicz TR. (2013) Inflammatory and Free Radical Generation Characteristics of Nano-Cerium Dioxide. The Toxicologist. Volume 132 (1): 175 \#818

17. Stapleton PA, Minarchick VC, Yi J, McBride CR, Engles K, Nurkiewicz TR. (2013) Uterine and Fetal Outcomes associated with maternal Nanomaterial Exposure. The Toxicologist. Volume 132 (1): 213 \#996

18. Minarchick VC, Porter DW ,Fix NR, Leonard SS, Sabolsky EM, and Nurkiewicz TR. (2013) Nano-Cerium Dioxide Exposure: Free Radical Generation and Arteriolar Dysfunction. Van Liere Research Day West Virginia University 
19. Minarchick VC, Porter DW, Fix NR, Leonard SS, Sabolsky EM, Nurkiewicz TR. (2013) Cerium Dioxide Nanoparticle Exposure: Free Radical Generation, Pulmonary Inflammation and Arteriolar Dysfunction. NanoSAFE Bioelectronics and Biosensing Symposium.

20. Minarchick VC, Porter DW, Fix NR, Leonard SS, Sabolsky EM, Nurkiewicz TR. (2013) Assessing the Toxicity of Cerium Dioxide Nanoparticle Exposure. American Association of Pharmaceutical Scientists Regional Meeting and Research Forum.

21. Stapleton PA, Minarchick VC, Yi J, McBride CR, Engels K, Nurkiewicz TR. (2013) Engineered Nanomaterial Exposure During Gestation: Could the Barker Hypothesis be at Play? Alleghany-Erie Society of Toxicology.

22. Minarchick VC, Stapleton PA, Porter DW, Fix NR, Leonard SS, Sabolsky EM, Nurkiewicz TR. (2013) Free Radical Generation: A Potential Mechanism for Arteriolar Dysfunction Following Cerium Dioxide Nanoparticle Exposure. Allegheny-Erie Regional Chapter of the Society of Toxicology $27^{\text {th }}$ Annual Meeting

23. Minarchick VC, Porter DW, Fix NR, Leonard SS, Sabolsky EM, Nurkiewicz TR (2013) Impact of Cerium Dioxide Nanoparticle Exposure on Microvascular Function. The Cardiovascular Forum Outstanding for Promoting Centers of Excellence and Young Investigators

24. Minarchick VC, Stapleton PA, Fix NR, Leonard SS, Sabolsky EM, Nurkiewicz TR. (2014) Nano-Cerium Dioxide Exposure and Arteriolar Dysfunction: What Is the Mechanism?. The Toxicologist. Volume 138 (1): 127 \#488.

25. Stapleton PG, Minarchick VC, Yi J, Frisbee J, Nurkiewicz TR. (2014) Engineered Nanomaterial Exposure and the Metabolic Syndrome. The Toxicologist. Volume 138 (1): 225 \#872.

26. Madejczyk MS, Baer CE, Dennis WE, Minarchick VC, Leonard SS, Jackson DA. (2014) Temporal Changes in Rat Liver Gene Expression after Cadmium and Chromium Exposure. The Toxicologist. Volume 138 (1): 344 \#1297.

27. Stapleton PG, Nichols CE, Yi J, Minarchick VC, Hollander JM, Nurkiewicz TR. (2014) Gestational Nanomaterial Exposures What Does the Future Hold?. The Toxicologist. Volume 138 (1): 440 \#1689.

28. Minarchick VC, Stapleton PA, Fix NR, Leonard SS, Sabolsky EM, and Nurkiewicz TR. (2014) Cerium Dioxide Nanoparticles: Determining the Source of Microvascular Dysfunction. Van Liere Research Day West Virginia University

29. Minarchick VC, Stapleton PA, Fix NR, Leonard SS, Sabolsky EM, Nurkiewicz TR. (2014) Nanomaterial Exposure Route Differentially Affects Microvascular Function. NanoSAFE Bioelectronics and Biosensing Symposium.

30. Minarchick VC, Stapleton PA, Fix NR, Leonard SS, Sabolsky EM, Nurkiewicz TR. (2014) Determining a Mechanistic Link Between Cerium Dioxide Nanoparticles and Arteriolar Dysfunction. Allegheny-Erie Regional Chapter of the Society of Toxicology $28^{\text {th }}$ Annual Meeting

31. Minarchick VC, Stapleton PA, Fix NR, Leonard SS, Sabolsky EM, Nurkiewicz TR. (2014) Smooth Muscle Signaling: A Mechanism for Cerium Dioxide Nanoparticle Toxicity. West Virginia University School of Pharmacy Regional Research Forum 
32. Minarchick VC, Stapleton PA, Sabolsky EM, Nurkiewicz TR. (2014) Cerium Dioxide Nanoparticles: Pro- or Anti-Oxidant Potential In Vivo?. Society of Toxicology Annual Meeting. March 2015

33. Minarchick VC, Stapleton PA, Sabolsky EM, and Nurkiewicz TR. (2015) Cerium Dioxide Nanoparticles Display Microvascular Anti-oxidant Activity In Vivo. Van Liere Research Day West Virginia University

\section{Invited Oral Presentations:}

1. Size Matters: Understanding Nanomaterials. (March 2012) Science on Tap. West Virginia University Biology Department. Morgantown, WV.

2. Pulmonary Nanoceria Exposure Impairs Coronary and Mesenteric Arteriolar Reactivity. (March 2012) Society of Toxicology National Meeting. San Francisco, CA.

3. Inflammatory and Free Radical Generation Characteristics of Nano-Cerium Dioxide. (March 2013) Society of Toxicology National Meeting. San Antonio, TX.

4. Cerium Dioxide Nanoparticles: Determining the Source of Microvascular Dysfunction. (February 2014). Van Liere Convocation. Morgantown, WV.

5. Nanomaterial Exposure Route Differentially Affects Microvascular Function. (April 2014). NANOSafe 2014 Bioelectronics and Biosensing Symposium. Morgantown, WV.

6. Determining a Mechanistic Link Between Cerium Dioxide Nanoparticles and Arteriolar Dysfunction. (May 2014). Allegheny-Erie Regional Chapter of the Society of Toxicology $28^{\text {th }}$ Annual Meeting. Morgantown, WV.

7. Smooth Muscle Signaling: A Mechanism for Cerium Dioxide Nanoparticle Toxicity. (June 2014). West Virginia University School of Pharmacy Regional Research Forum. Morgantown, WV.

8. Cerium Dioxide Nanoparticles Display Microvascular Anti-oxidant Activity In Vivo. (February 2015). Van Liere Convocation. Morgantown, WV.

9. Determining the Anti-oxidant Potential of Cerium Dioxide Nanoparticles (May 2015). International Symposium on Organic Electronics and Bioelectronics. Clemson, SC.

\section{Department Seminars:}

1. Effects of Pulmonary Ceria Nanoparticles on Arteriolar Reactivity. (March 2011). Department of Physiology and Pharmacology. Morgantown, WV.

2. Pulmonary Nano-Cerium Dioxide Exposure Impairs Coronary and Mesenteric Arteriolar Reactivity (December 2011) Department of Physiology and Pharmacology. Morgantown, WV.

3. Influence of Nanomaterial Exposure Route on Microvascular Function (December 2012). Department of Physiology and Pharmacology. Morgantown. WV.

4. Cerium Dioxide Nanoparticles and Microvascular Dysfunction: The Role of Nitric Oxide (December 2013). Department of Physiology and Pharmacology. Morgantown. WV 
5. Cerium Dioxide Nanoparticle Exposure: Microvascular Dysfunction and Potential Mechanisms (December 2014). Department of Physiology and Pharmacology. Morgantown. WV

\section{Professional Memberships:}

- Society of Toxicology (2011- Present)

- Allegheny-Erie Society of Toxicology Regional Chapter (2011-Present)

- Society of Toxicology Cardiovascular Specialty Section (2011- Present)

- Society of Toxicology Nanotoxicology Specialty Section (2011- Present)

- Women in Toxicology Special Interest Group (2011- Present)

- American Association of Pharmaceutical Scientists (2013- 2014)

- Association for Women in Science (2013- Present)

\section{Meetings Attended:}

- 5th Conference on Metal Toxicity and Carcinogenesis 2008

- Engineered Nanomaterials Grand Opportunity Consortium Meeting 2011

- Society of Toxicology National Meeting 2011-2014

- Allegheny-Erie Regional Chapter of the Society of Toxicology Annual Meeting 2011-2014

- Van Liere Research Day West Virginia University 2011-2014

- NanoSAFE Bioelectronics and Biosensing Symposium 2013-2014

- West Virginia University School of Pharmacy Regional Research Forum 20132014

- The Cardiovascular Forum for Promoting Centers of Excellence and Young Investigators 2013

\section{Honors and Awards:}

- Dr. William J. von Liebig Award for Student Research, May 12007 award for top presentation for undergraduate research at the Juniata College research symposium

- Graduated with Distinction in the Biology POE. May 2007

- Second Place Poster at Van Liere Research Day. West Virginia University. March 2011

- Graduate Student Travel Award- Sponsored by Danish Myo Technology, from the Cardiovascular Toxicology Specialty Section of the Society of Toxicology. March 2012

- Second Place Poster at Van Liere Research Day. West Virginia University. March 2012

- Second Place Poster at Van Liere Research Day. West Virginia University. February 2013 
- First Place Poster Presentation at West Virginia University School of Pharmacy Regional Research Forum. West Virginia University. May 2013

- Outstanding Poster Presentation at The Cardiovascular Forum for Promoting Centers of Excellence and Young Investigators sponsored by the International Academy of Cardiovascular Sciences. University of Louisville. August 2013

- Nominated and Selected for Morgantown Magazine 30 Under 30 Contest. December 2013

- Graduate Student Achievement Award. Women in Toxicology Special Interest Group. Society of Toxicology Annual Meeting. Phoenix, AZ. March 2014.

- Outstanding Graduate Student $1^{\text {st }}$ Place Award. Nanotoxicology Specialty Section. Society of Toxicology Annual Meeting. Phoenix, AZ. March 2014.

- $1^{\text {st }}$ Place Video. YouTox Video Challenge. Society of Toxicology Annual Meeting. Phoenix, AZ. March 2014

- $2^{\text {nd }}$ Place Podia Presentation. West Virginia University School of Pharmacy Regional Research Forum. Morgantown, WV. June 2014

- $2^{\text {nd }}$ Place Oral Presentation. Van Liere Research Day. West Virginia University. February 2015

\section{Professional Service:}

\section{Positions:}

- Society of Toxicology Graduate Student Leadership Council Member (May 20132015)

- Society of Toxicology Student Representative for the Cardiovascular Toxicology Specialty Section (May 2013-2015)

\section{Ad hoc Reviewer:}

\begin{tabular}{|l|l|}
\hline Inhalation Toxicology & Cardiovascular Toxicology \\
\hline $\begin{array}{l}\text { Medicine and Science in Sport and } \\
\text { Exercise }\end{array}$ & Environmental Health Perspectives \\
\hline Nanotoxicology & Life Sciences \\
\hline Particle and Fibre Toxicology & Microcirculation \\
\hline Reproductive Toxicology & PLoS ONE \\
\hline Toxicological Sciences & Toxicology and Applied Pharmacology \\
\hline Biochemical Sciences & $\begin{array}{l}\text { WIREs Nanomedicine } \\
\text { Nanobiotechnology }\end{array}$ \\
\hline Frontiers in Physiology & Chemosphere \\
\hline American Journal of Physiology & \\
\hline
\end{tabular}

\section{Training/Teaching:}


- Evan Vogel (2010): Summer Laboratory Internship; Catholic University of America, Washington, D.C.

- Kenzie Dent (2010): WV-INBRE; West Virginia Wesleyan College, WV.

- Nick Mazzone (2011): Summer Laboratory Internship, WVU Exercise Physiology Program, WV.

- Cody Nichols (2011): Rotation Student, WVU Biomedical Sciences Ph.D. Program, WV.

- Jonathan Boyd (2011): Rotation Student, WWU Biomedical Sciences Ph.D. Program, WV.

- Katie Spears (2012): WVNano National Science Foundation - Research Experience for Undergraduates; Maryville College, TN.

- Shannon Aippersbach (2013): WVU NanoSAFE National Science FoundationResearch Experience for Undergraduates; Penn State, PA

- Gaurav Gautam (2013): Undergraduate Research Experience, West Virginia University, WV

- Ashley Kerr (2014): Rotation Student, WVU Biomedical Sciences Ph.D. Program, WV

- Quincy Hathaway (2014): WVU NanoSAFE National Science Foundation Research Experience for Undergraduates; Wanyesburg University, PA

- Alaeddin Abukabda (2014): Rotation Student, WVU Biomedical Sciences Ph.D. Program, WV

\section{Career Development:}

Nominated for involvement with the Linking Innovation Industry and Commercialization (LIINC) Program through West Virginia University's Office of Research and Economic Development (2013)

\section{Community Service:}

- March 2012 - WVU Nanodays. WVNano. Mountaineer Mall. Volunteer. Morgantown, WV.

- November 2012 - Science Day. NanoSAFE. Mountaineer Mall. Volunteer. Morgantown, WV.

- March 2013 - WVU Nanodays. NanoSAFE. Mountaineer Mall. Volunteer. Morgantown, WV.

- September 2013 - Invited Presenter. "Being a Scientist" Philipsburg-Osceola Elementary School. Philipsburg, PA.

- March 2014 -WVU Nanodays. NanoSAFE. Mountaineer Mall. Volunteer. Morgantown, WV.

- March 2014 - Math and Science Night. Mountainview Elementary School. Volunteer. Morgantown, WV.

- August 2014 -State Fair of West Virginia. Volunteer. Lewisburg, WV.

- November 2014 - Science Day. Mountaineer Mall. Volunteer. Morgantown, WV. 